\title{
Fusarium infection of bread wheat and subsequent mycotoxin contamination of milling products: Impact on quality parameters and composition of flour
}

\author{
Doctoral Dissertation \\ Submitted for the doctoral degree of Agricultural Sciences \\ at the Faculty of Agricultural Sciences \\ of Georg-August-University Göttingen
}

by

Marie Kreuzberger

born in Potsdam, Germany

Göttingen, November 2011 
D 7

Referee: Prof. Dr. E. Pawelzik

Co-referee: Prof. Dr. B. Märländer

Day of disputation: $17^{\text {th }}$ November 2011 


\section{Table of contents}

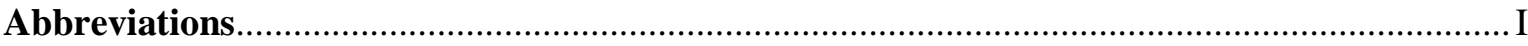

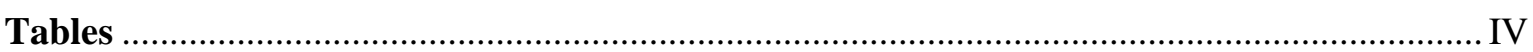

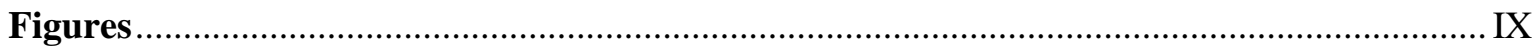

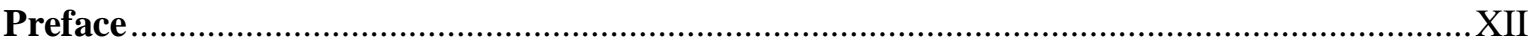

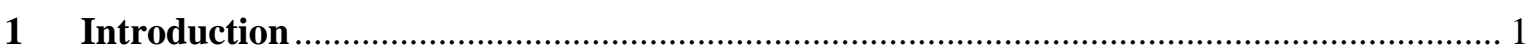

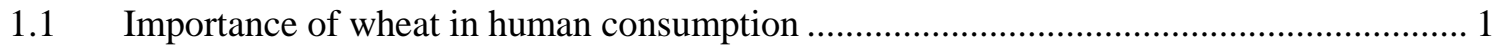

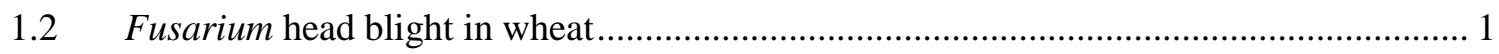

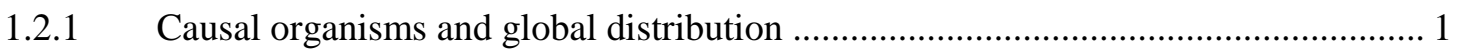

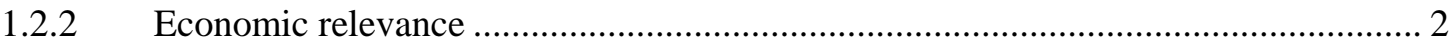

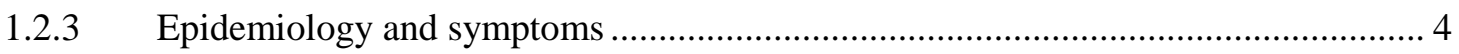

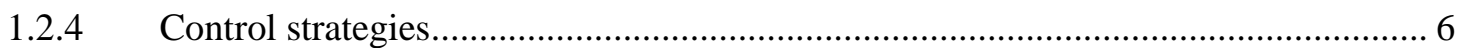

1.3 Significance of gluten proteins for wheat processing ….............................................. 11

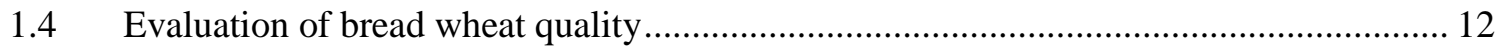

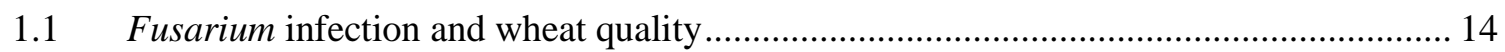

1.1.1 Fate of DON during wheat processing ............................................................... 14

1.1.2 Impact of Fusarium infection on wheat quality and composition.......................... 15

1.1.3 Assessment of Fusarium infection in wheat ......................................................... 18

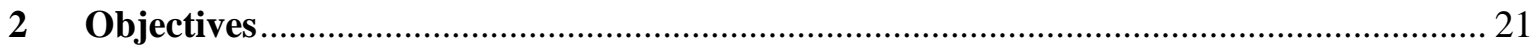

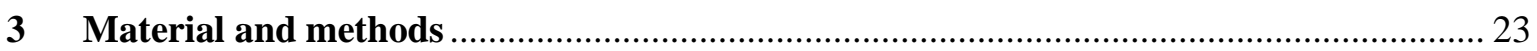

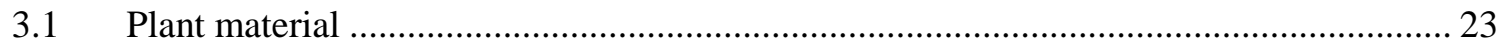

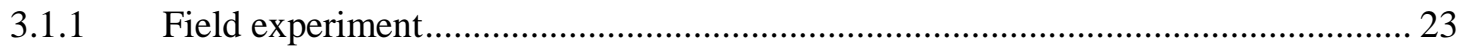

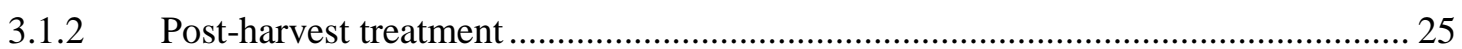

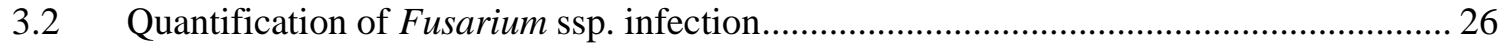

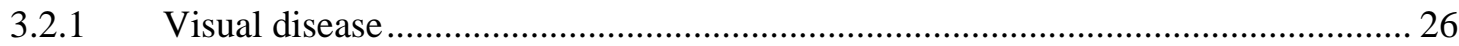

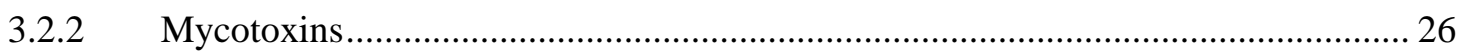

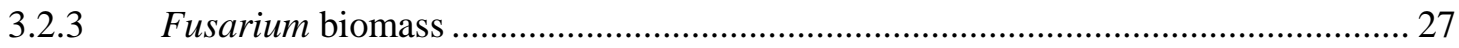

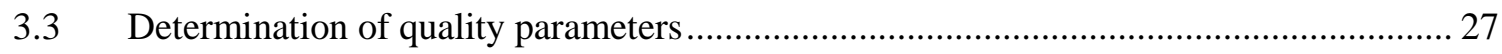

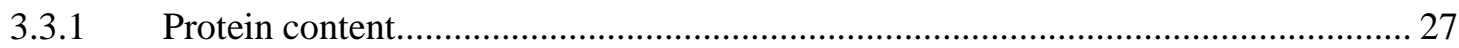


3.3.2 Wet gluten content, sedimentation value, falling number ....................................... 27

3.3.3 Water absorption and mixing properties of dough ................................................ 28

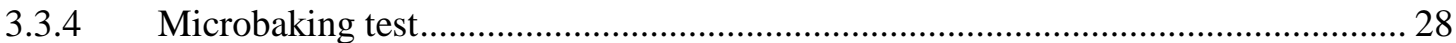

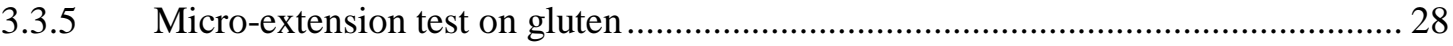

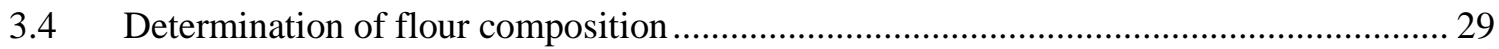

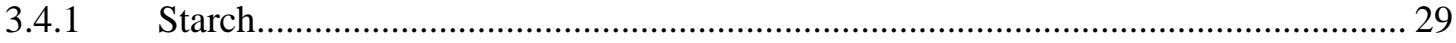

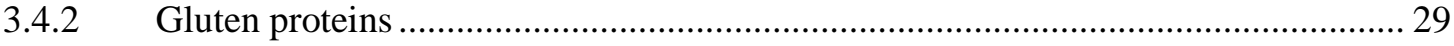

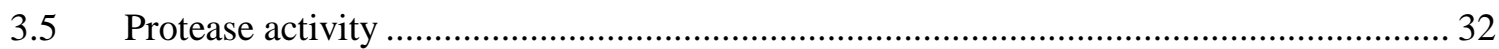

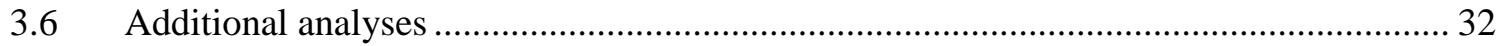

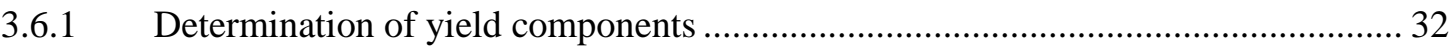

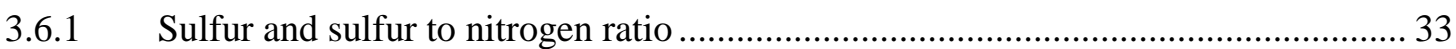

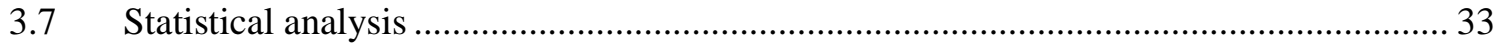

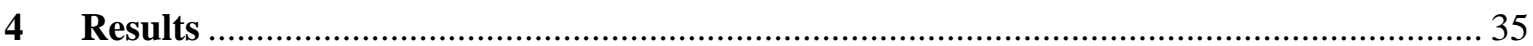

4.1 Fusarium biomass and mycotoxins in milling products ............................................... 35

4.1.1 Occurrence of Fusarium DNA and mycotoxins..................................................... 35

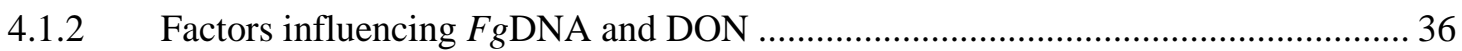

4.1.3 Relationship of visual disease, DON, and FgDNA ................................................ 44

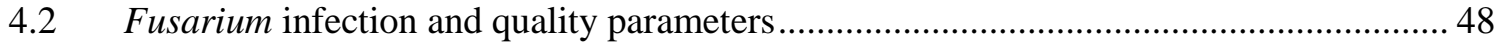

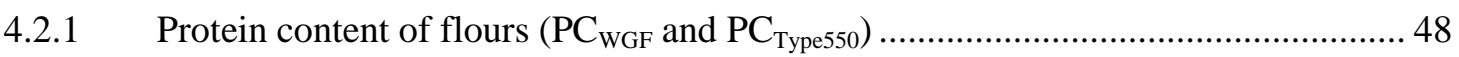

4.2.2 Wet gluten content (WG) and sedimentation value (SV) ..................................... 51

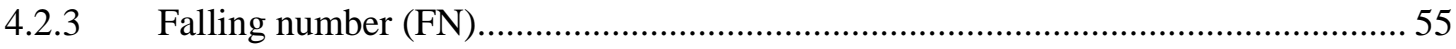

4.2.4 Water absorption (WA) and mixing properties of dough (DDT, DST, DS) ............ 57

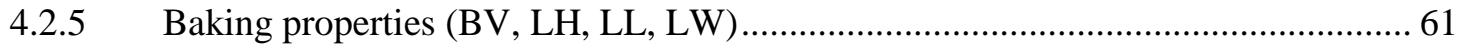

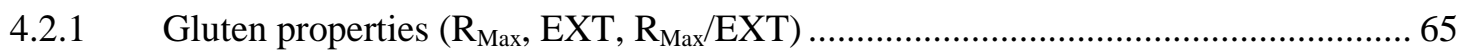

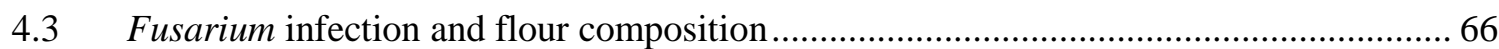

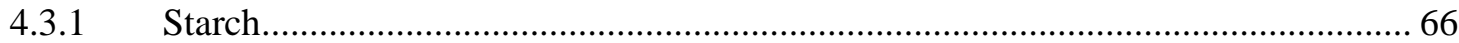

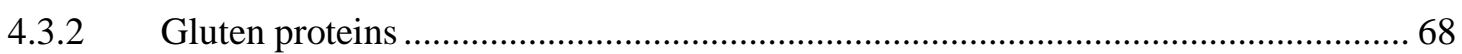

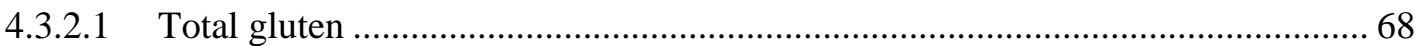

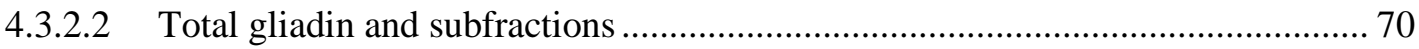

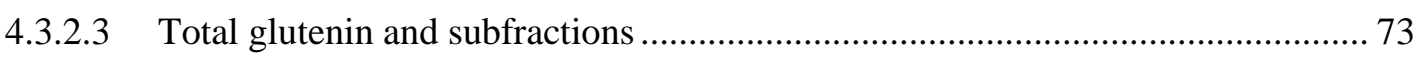




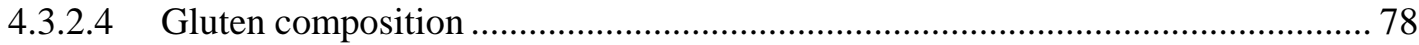

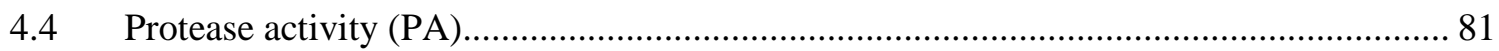

4.5 Relationship among quality parameters and flour components ...................................... 83

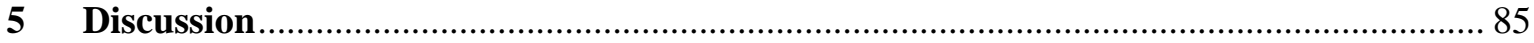

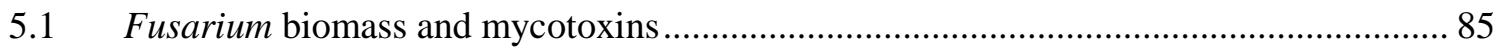

5.1.1 Occurrence of Fusarium DNA and mycotoxins.................................................... 85

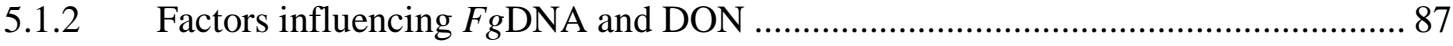

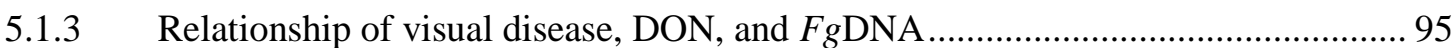

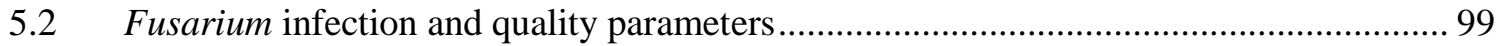

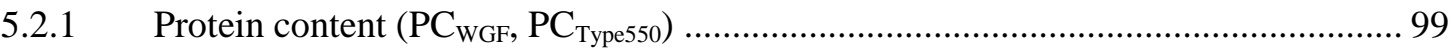

5.2.2 Wet gluten content (WG) and sedimentation value (SV) .................................... 102

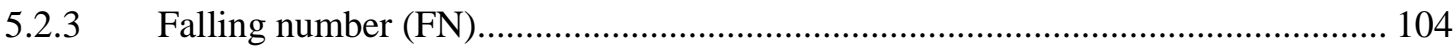

5.2.4 Water absorption (WA) and mixing properties of dough (DDT, DST, DS) .......... 106

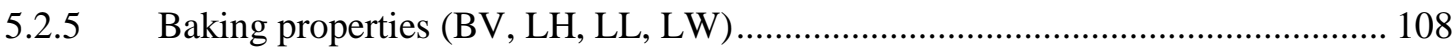

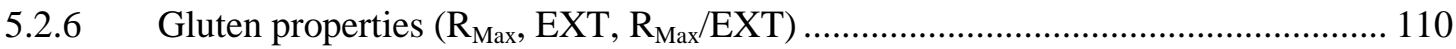

5.3 Fusarium infection and flour composition.................................................................. 111

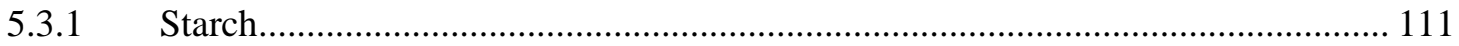

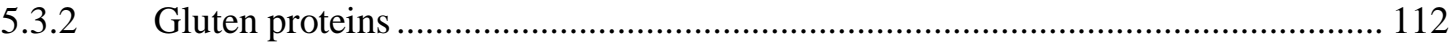

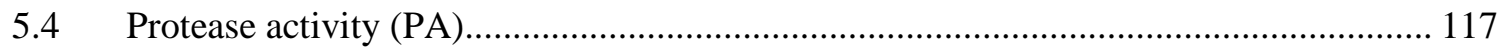

5.5 How does Fusarium infection influence wheat quality?........................................... 119

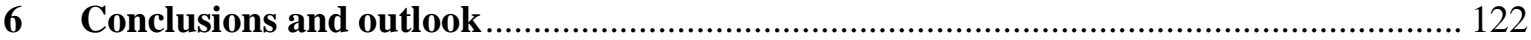

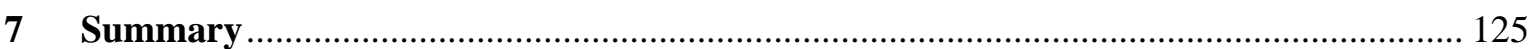

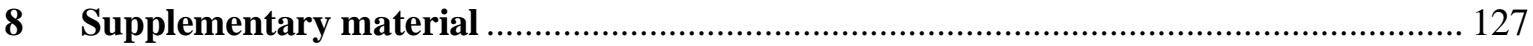

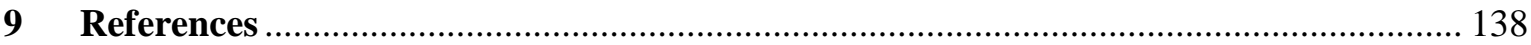

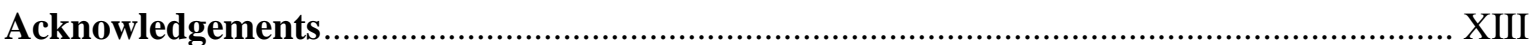

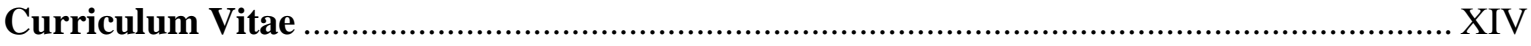




\section{Abbreviations}

15-ADON

3-ADON

$\mathrm{AU}$

BEA

BMEVL

BSA

BV

bw

CIMMYT

cv.

DAS

DDT

DNA

DON

$\mathrm{DON}_{\mathrm{LOG}}$

$\mathrm{DON}_{\mathrm{ORG}}$

DS

DST

DTR

ELISA

EU

$\mathrm{EU}_{\mathrm{Max}}$

$\mathrm{EU}_{\mathrm{MaxCF}}$

$\mathrm{EU}_{\mathrm{MaxUP}}$

EXT

FAEN

FAO

$\mathrm{FB}_{1}$

FDK

FHB

FN

FPU

FUP

FUSX 15-acetyldeoxynivalenol

3-acetyldeoxynivalenol

absorption units

beauvericin

Bundesministerium für Ernährung, Verbraucherschutz, Landwirtschaft

Bundessortenamt (Federal Office of Plant Varieties)

baking volume

bodyweight

International Maize and Wheat Improvement Center

cultivar

diacetoxyscirpenol

dough development time

deoxyribonucleic acid

deoxynivalenol

logarithmically transformed DON content

original DON content

dough softening

dough stability

Drechselera tritici-repentis

Enzyme linked immunosorbent assay

European Union

EU maximum levels

$\mathrm{EU}_{\mathrm{Max}}$ for cereal flour

$\mathrm{EU}_{\mathrm{Max}}$ for unprocessed cereals

extensibility

Forschungsverbund Agrar- und Ernährungswissenschaften Niedersachsen

Food and Agriculture Organization of the United Nations

fumonisin $\mathrm{B}_{1}$

Fusarium damaged kernels

Fusarium head blight

falling number

Fusarium soluble protein units

fusaproliferin

fusarenone $\mathrm{X}$ 
GC

GMF

GY

HMW

HMW-GS

HPLC-MS/MS

ICC

LH

LL

LMW

LMW-GS

LOD

LOQ

LW

MON

MV

MW

$\mathrm{N}$

n

NIV

PA

PAGE

PC

PCR

$\mathrm{PC}_{\text {Type550 }}$

$\mathrm{PC}_{\text {WGF }}$

QTL

RH

$\mathrm{R}_{\mathrm{MAX}}$

RP-HPLC

S

SBA

$\mathrm{SD}$

SDS

SE

SE-HPLC gas chromatograph

Vereinigung Getreide-, Markt-, und Ernährungsforschung

grain yield

high molecular weight

high molecular weight glutenin subunits

high performance liquid chromatography with tandem mass spectrometry

International Association for Cereal Science and Technology

loaf height

loaf length

low molecular weight

low molecular weight glutenin subunits

limit of detection

limit of quantification

loaf width

moniliformin

mean value

molecular weight

nitrogen

number of observations

nivalenol

protease activity

polyacrylamide gel electrophoresis

protein content

polymerase chain reaction

protein content of flour Type 550

protein content of whole grain flour

quantitative trait loci

relative humidity

resistance to extension

reversed-phase high performance liquid chromatography

sulfur

Statistisches Bundesamt

Standard diviation

sodium dodecylsulfate

standard error

size-exclusion high performance liquid chromatography 
SoE

SV

$\mathrm{T} 2$

TA

TDI

TDI

TKW

$\mathrm{T}_{\mathrm{Max}}$

$\mathrm{T}_{\text {Mean }}$

$\mathrm{T}_{\text {Min }}$

WA

WG

WGF

WSG

ZEA severity of effect

sedimentation value

$\mathrm{T}-2$ toxin

Texture Analyzer

tolerable daily intake

tolerable daily intake

thousand-kernel weight

maximum daily temperature

average daily temperature

minimum daily temperature

water absorption

wet gluten

whole grain flour

Wetterstation Göttingen

zearalenone 


\section{Tables}

Tab 1. EU maximum levels ( $E U_{M A X}$ ) for Fusarium toxins in foodstuffs (in $\mu \mathrm{gg}^{-1}$ ) concerning wheat and wheat products according to Commission regulation (EC) No 856/2005

Tab 2. Selected variety descriptions of winter wheat cultivars Centrum and Ritmo (BSA 2007)

Tab 3. Description of fungicides and growth regulator applied in field experiment

Tab 4. Fungicide and growth regulator application in field experiment

Tab 5. Factors and factor levels of field experiment

Tab 6. Gradient program for RP-HPLC for separation of gliadin and glutenin 30

Tab 7. Range of mycotoxin and Fusarium DNA content of wheat milling products (flour Type 550 , whole grain flour, bran)

Tab 8. Proportion of FgDNA and FcDNA from total Fusarium DNA (FgDNA + FcDNA $=100 \%$ ) in milling products (flour Type 550, whole grain flour (WGF), bran) of 2007 36

Tab 9. ANOVA for effects of environment (year, location), pre-crop, wheat cultivar, fungicide, and milling product on DON and FgDNA content.

Tab 10. Specification of maximum and minimum DON levels $\left(D O N_{\operatorname{Max}} / \mathrm{DON}_{\min }\right)\left(\mathrm{mg} \mathrm{kg}^{-1}\right)$ and severity of effect (SoE of single effects of environment (year $x$ location), pre-crop, cultivar, fungicide, milling product, and in selected interactions

Tab 11. Disease incidence (DI), disease severity (DS), and FHB index of winter wheat cv. Centrum and Ritmo in 2007, 2008, and 2009

Tab 12. Coefficient of determination $\left(R^{2}\right)$ of linear regression of DON and FgDNA levels of milling products (flour Type 550, whole grain flour (WGF), bran)

Tab 13. ANCOVA for effects of environment (E) (year, location), pre-crop (P), wheat cultivar (C), and DON ${ }_{L O G}(D O N)$ and ANOVA for effects of $E, P$, and $C$ on protein content of whole grain flour

Tab 14. ANCOVA for effects of environment (E) (year, location), pre-crop (P), wheat cultivar

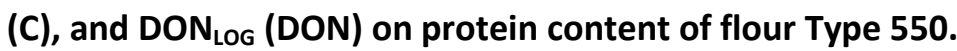

Tab 15. Parameters of linear regression of protein content of Type $550(\%)$ and DON $\mathrm{LOG}_{\mathrm{LOG}}(\mathrm{mg}$ $\mathrm{kg}^{-1}$ ) (DON) in different environments (E) (year, location) and pre-crops (P) across cultivars, and range of original DON values (DON $\left.{ }_{\mathrm{ORG}}\right)$

Tab 17. ANCOVA for effects of environment (E) (year, location), pre-crop (P), wheat cultivar (C), and DON ${ }_{L O G}(D O N)$ and ANOVA for effects of $E, P$, and $C$ on wet gluten content 53

Tab 18. ANCOVA for effects of environment (E) (year, location), pre-crop (P), wheat cultivar (C), and $\mathrm{DON}_{\mathrm{LOG}}$ on sedimentation value 
Tab 19. ANCOVA for effects of environment (E) (year, location), pre-crop (P), wheat cultivar (C), and $\mathrm{DON}_{\mathrm{LOG}}$ on falling number (both measured in whole grain flour) 56

Tab 20. Parameters of linear regression of falling number (s) and $D_{0 N} N_{L O G}\left(\mathrm{mg} \mathrm{kg}^{-1}\right)$ (both measured in whole grain flour) in different environments (E) (years, location) and pre-crops $(P)$ across cultivars, and range of original DON values ( $\left.D O N_{O R G}\right)$ 56

Tab 21. Water absorption (WA) and mixing properties of dough (dough development time: DDT, dough stability: DST, dough softening: DS) of wheat cv. (Centrum, Ritmo) grown after different pre-crops in 2007, 2008, and 2009 (MV \pm SD, $n=6$ )

Tab 22. ANCOVA for effects of environment (E) (year. Location), pre-crop (P), wheat cultivar (C), and DON ${ }_{L O G}(D O N)$ and ANOVA for effects of $E, P$, and $C$ on water absorption 58

Tab 23. ANCOVA for effects of environment (E) (year, location), pre-crop (P), wheat cultivar (C), and DON ${ }_{L O G}(D O N)$ and ANOVA for effects of E, P, and C on dough development time 59 Tab 24. ANCOVA for effects of environment (E) (year, location), pre-crop (P), wheat cultivar (C), and DON $N_{\mathrm{LOG}}(\mathrm{DON})$ and ANOVA for effects of $E, P$, and C on dough stability... 59

Tab 25. ANCOVA for effects of environment (E), pre-crop (P), wheat cultivar (C), and DON ${ }_{\text {LOG }}$ (DON) on dough softening. 60

Tab 26. Parameters of linear regression of dough softening (VU/FU) and DON ${ }_{\mathrm{LOG}}\left(\mathrm{mg} \mathrm{kg}^{-1}\right)$ within different environments (E) (year, location) and pre-crops (P) across cultivars, and range of original DON values (DON ${ }_{\mathrm{ORG}}$ ).

Tab 28. Baking properties(baking volume: BV, loaf length: LL, loaf height: LH, loaf width: LW) wheat cv. (Centrum, Ritmo) grown after pre-crop maize and sugar beet in 2008 and 2009 (pre-crop wheat: not analyzed) (MV $\pm S D, n=6)$

Tab 29. ANCOVA for effects of environment (E) (year, location), pre-crop (P), wheat cultivar (C), and DON ${ }_{\mathrm{LOG}}$ (DON) on baking volume (BV) and loaf height (LH).

Tab 30. ANCOVA for effects of environment (E) (year, location), pre-crop (P), wheat cultivar (C), and DON ${ }_{L O G}(D O N)$ and ANOVA for effects of $E, P$, and $C$ on loaf length

Tab 31. ANCOVA for effects of environment (E), pre-crop (P), wheat cultivar (C), and DON (DON) and ANOVA for effects of $E, P$, and $C$ on loaf width

Tab 32. Parameters of linear regression of baking volume ( $\left.\mathrm{ml} 100 \mathrm{~g}^{-1} \mathrm{flour}\right)$ and $D O N_{\mathrm{LOG}}$ in different environments (E) (year, location), cultivars (C), and pre-crops (P), and range of original DON values (DON $\mathrm{ORG}_{\text {) }}$

Tab 33. Gluten properties (resistance to extension: $R_{\text {MAX, }}$ extensibility: EXT) of wheat cv. (Centrum, Ritmo) grown after pre-crop wheat, maize, and sugar beet in 2007 measured with SMS/Kieffer Dough and Gluten Extensibility Rig with Texture Analyzer (MV $\pm S D, n=6$ ) 
Tab 34. ANCOVA for effects of location (L), pre-crop (P), wheat cultivar (C), and DON $\mathrm{NOG}_{\mathrm{LOG}}$ (DON) and ANOVA for effects of $L, P$, and $C$ on $R_{\text {MAX }} / E X T$ of wet gluten extracted from flour Type 550 in 2007 66

Tab 35. Starch content of flour Type $\mathbf{5 5 0}$ of wheat cultivars (Centrum, Ritmo) grown after different pre-crops in 2007, 2008, and 2009 (MV $\pm S D, n=6)$

Tab 36. ANCOVA for effects of environment (E) (year, location), pre-crop (P), wheat cultivar (C), and DON ${ }_{\mathrm{LOG}}(\mathrm{DON})$ and ANOVA for effects of $E, P$, and $C$ on starch content (\%) of flour Type 550

Tab 38. Total gluten content (\% Protein) of wheat cultivars (Centrum, Ritmo) grown after pre-crops wheat, maize, and sugar beet in 2007, 2008, and 2009 (MV $\pm S D, n=6$ ).

Tab 39. ANCOVA for effects of environment (E) (year, location), pre-crop (P), wheat cultivar (C), and DON ${ }_{\mathrm{LOG}}(\mathrm{DON})$ and $A N O V A$ for effects of $E, P$, and $C$ on total gluten content 69

Tab 40. Parameters of linear regression of total gluten (\% Protein) and $\mathrm{DON}_{\mathrm{LOG}}\left(\mathrm{mg} \mathrm{kg}^{-1}\right)$ within environments (E) (year, location), cultivars (C), and pre-crops (P), and range of original DON values (DON $\mathrm{ORG}$ )

Tab 41. Content of total gliadin and subfractions $(\omega 5, \omega 1,2, \alpha, \gamma)$ (\% Protein) of flour Type 550 from wheat cultivars (Centrum, Ritmo) grown after pre-crop wheat, maize, and sugar beet in 2007, 2008, and 2009 (MV \pm SD, $n=6$ )

Tab 42. ANCOVA for effects of environment (E) (year, location), pre-crop (P), wheat cultivar (C), and DON ${ }_{\mathrm{LOG}}(\mathrm{DON})$ and ANOVA for effects of $E, P$, and $C$ on total gliadin content

Tab 43. ANCOVA for effects of environment (E) (year, location), pre-crop (P), wheat cultivar (C), and DON ${ }_{L O G}(D O N)$ and ANOVA for effects of $E, P$, and C on content of $\alpha$-gliadin

Tab 44. ANCOVA for effects of environment (E) (year, location), pre-crop (P), cultivar (C), and DON $_{\text {LOG }}(D O N)$ on content of $\omega 5$-gliadin, $\omega 1$,2-gliadin, and $\gamma$-gliadin

Tab 45. Content of total glutenin and subfractions ( $\omega b$, HMW-GS, LMW-GS) (\% Protein) of flour Type 550 from wheat cultivars (Centrum, Ritmo) grown after pre-crop wheat, maize, and sugar beet in 2007, 2008, and 2009 (MV $\pm S D, n=6)$

Tab 46. ANCOVA for effects of environment (E) (year, location), pre-crop (P), wheat cultivar (C), and DON ${ }_{\mathrm{LOG}}(\mathrm{DON})$ on content of total glutenin and HMW-GS 75

Tab 47. ANCOVA for effects of environment (E) (year, location), pre-crop (P), cultivar (C), and $D O N_{L O G}(D O N)$ and $A N O V A$ for effects of $E, P$, and $C$ on $\omega b$ content

Tab 48. ANCOVA for effects of environment (E) (year, location), pre-crop (P), cultivar (C), and $D O N_{L O G}(D O N)$ and ANOVA for effects of $E, P$, and C on LMW-GS content.

Tab 49. ANCOVA for effects of environment (E) (year, location), pre-crop (P), wheat cultivar (C), and DON ${ }_{\mathrm{LOG}}$ (DON) on ratio of gliadin/glutenin and LMW/HMW 
Tab 50. Parameters of linear regression of gliadin/glutenin ratio and LMW/HMW ratio and DON $_{\text {LOG }}\left(\mathrm{mg} \mathrm{kg}^{-1}\right)$ of flour Type 550 within environments (E), cultivars (C), and pre-crops (P), and range of original DON values ( $\left.D_{O N} N_{O R G}\right)$

Tab 51. Protease activity (AU $440 \mathrm{~nm}$ ) in flour Type 550 from wheat cultivars (Centrum, Ritmo) grown after pre-crops wheat, maize, and sugar beet in 2007 (MV $\pm S D, n=6)$

Tab 52. ANCOVA for effects of location (L), pre-crop (P), wheat cultivar (C), and DON ${ }_{L O G}$ (DON) on protease activity

Tab 53. Linear relationships among quality parameters and total gluten subfractions where $R^{2} \geq 0.50$ and $p<0.05$

Tab 54. Descriptive statistic, multiple comparison of treatment mean value (MV) for effect of year, location, pre-crop, cultivar, and fungicide as well as severity of effect (SoE) for $\mathrm{PC}_{\text {WGF }}, \mathrm{PC}_{\text {Type550, }}$ WG, SV, and FN

Tab 55. Descriptive statistic, multiple comparison of treatment mean value (MV) for effect of year, location, pre-crop, cultivar, and fungicide as well as severity of effect (SoE) for WA and dough properties (DDT, DST, DS)

Tab 56. Descriptive statistic, multiple comparison of treatment mean value (MV) for effect of year, location, pre-crop, cultivar, and fungicide as well as severity of effect (SoE) for baking properties (BV, LH, LL, LW).

Tab 57. Descriptive statistic, multiple comparison of treatment mean value (MV) for effect of year, location, pre-crop, cultivar, and fungicide as well as severity of effect (SoE) for total gluten, total gliadin, and gliadin subfractions $(\omega 5, \omega 1,2, \alpha, \gamma)$

Tab 58. Descriptive statistic, multiple comparison of treatment mean value (MV) for effect of year, location, pre-crop, cultivar, and fungicide as well as severity of effect (SoE) for total glutenin, glutenin subfractions ( $\omega \mathrm{b}, \mathrm{HMW}-\mathrm{GS}, \mathrm{LMW}-\mathrm{GS}$ ), gliadin/glutenin ratio, and LMW/HMW ratio

Tab 59. Descriptive statistic, multiple comparison of treatment mean value (MV) for effect of year, location, pre-crop, cultivar, and fungicide as well as severity of effect (SOE) for gluten properties ( $R_{\text {MAX }}, E X T, R_{\text {MAX }} / E X T$ ), starch content, PA, yield parameters (TKW, GY), $S$ content, and N/S ratio of flour Type 550

Tab 60. Significance of effects from ANOVA for indirect quality parameters ( $P C_{\text {WGF, }}, \mathrm{PC}_{\text {Type550, }}$ WG, SV, FN, WA), dough properties (DDT, DST, DS), baking properties (BV, LH, LL, LW), gluten properties ( $\left.\mathbf{R}_{\text {MAX }}, E X T, R_{\text {MAX }} / E X T\right)$, and starch content including all analyzed samples .

Tab 61. Significance of effects from ANOVA for total gluten, total gliadin, gliadin subfractions $(\omega 5, \omega 1,2, \alpha, \gamma)$, total glutenin, glutenin subfractions ( $\omega b$, HMW-GS, LMW-GS, 
gliadin/glutenin ratio, LMW/HMW ratio, protease activity, TKW, grain yield, $\mathrm{S}$ content and $\mathrm{N} / \mathrm{S}$ ratio including all analyzed samples

Tab 62. Correlation matrix for yield components and quality parameters of flour $(+/-$ direction of trend, $\mathbf{R}^{2}$, significance) for all analyzed samples

Tab 63. Correlation matrix for yield components, quality parameters of flour, flour components, and PA (+/- direction of trend, $\mathrm{R}^{2}$, significance) for all analyzed samples ....135

Tab 64. Correlation matrix for flour components, and PA (+/- direction of trend, $\mathbf{R}^{2}$, significance) for all analyzed samples.

Tab 65. Mineral $\mathbf{N}\left(\mathrm{N}_{\min }\right)$ content of soil ( $90 \mathrm{~cm}$ depth) after different pre-crops ( $\mathrm{MV}$ of two locations) and fertilization regime with urea-ammonium nitrate (UAN) at different growth stages (GS) according to $\mathrm{BBCH}$

Tab 66. Grain yield (GY), thousand-kernel weight (TKW), sulfur content (S), and ratio of nitrogen:sulfur content (N/S) of flour Type 550 (MV $\pm S D, n=6)$ from cv. Centrum and cv. Ritmo grown after different pre-crops in 2007, 2008, and 2009

Tab 67. Linear relationship between quality parameters and sulfur content (S) of flour Type 550 and grain yield (GY) 


\section{Figures}

Fig 1. Blighted wheat heads (A) and bleaching of upper spike part (B) caused by naturally occurring FHB in 2007, at trial location Torland (51.36 $\left.\mathrm{N}, 9.55^{\circ} \mathrm{E}\right)$, Pictures: BAADER 2007 .. 6

Fig 2. Relative DON content obtained by the use of agronomic methods or fungicides. DON reduction is presented as percentage in relation to the worst case scenario (pre-crop maize, no or minimum tillage, susceptible cultivar, no fungicide application $=100 \%$ DON content), ${ }^{a}$ cv. Dekan, ${ }^{b}$ cv. Ritmo (BEYER ET AL. 2006)

Fig 3. Classification of gluten proteins according to WIESER 2007 and SHEWRY \& HALFORD 2002 (modified)

Fig 4. Scheme of investigated interactions between experimental factors, Fusarium infection, composition of wheat flour/enzyme activity, and wheat quality parameters within objectives of this study

Fig 5. RP-HPLC of gliadin extract (cv. Centrum) with elution ranges for $\omega 5-, \omega 1,2-, \alpha-$, and $\gamma^{-}$ gliadins

Fig 6. RP-HPLC of glutenin extract (cv. Centrum) with elution ranges for $\omega b, \mathrm{HMW}-\mathrm{GS}$, and LMW-GS.

Fig 7. Effect of environment (year, location) on DON and FgDNA content of wheat milling products (flour Type 550, whole grain flour, bran) across all samples. MV $(n=54)$ with same letters are not significantly different at $p<0.05$ according to Tukey test. Error bars indicate SE.

Fig 8. Effect of pre-crop on DON and FgDNA content of wheat milling products (flour Type 550 , whole grain flour, bran) across all samples. $M V(n=108)$ with same letters are not significantly different at $p<0.05$ according to Tukey test. Error bars indicate SE.

Fig 9. Effect of cultivar on DON and FgDNA content of wheat milling products (flour Type 550 , whole grain flour, bran) across all samples. $M V(n=162)$ with same letters are not significantly different at $\mathbf{p}<\mathbf{0 . 0 5}$ according to Tukey test. Error bars indicate SE.

Fig 10. Effect of fungicide treatment on DON and FgDNA content of wheat milling products (flour Type 550, whole grain flour, bran) across all samples. MV $(n=108)$ with same letters are not significantly different at $\mathbf{p}<\mathbf{0 . 0 5}$ according to Tukey test. Error bars indicate SE .. 39

Fig 11. Effect of milling (flour Type 550, whole grain flour, bran) on DON and FgDNA content of milling products. MV $(n=108)$ with same letters are not significantly different at $p<0.05$ according to Tukey test. Error bars indicate SE.

Fig 12. Distribution of DON levels $\left(\mathrm{mg} \mathrm{kg}^{-1}\right)$ of flour Type 550 samples grouped into $\mathrm{EU}_{\mathrm{Max}}$ for cereal and cereal products (unprocessed cereals: 1.25 , Flour: 0.75 , bread: 0.5 , processed cereals/baby food: $\mathbf{0 . 2}$, details: see Tab 1 ). In brackets: number of samples (total: 108, 
below limit of detection (LOD): 32). Box plots with median (solid line), mean (short dash), and whiskers indicating $5^{\text {th }} / 95^{\text {th }}$ percentiles, outliers (dot)

Fig 13. Effect of wheat cultivar (Centrum, Ritmo) and fungicide treatment on DON levels in wheat milling products (flour Type 550, whole grain flour, bran) cultivated after different pre-crops. MV $(n=18)$ with same letters are not significantly different at $p<0.05$ according to Tukey test. Error bars indicate SE.

Fig 14. Relationship between disease incidence (DI) and DON content of flours and bran ( $\mathrm{n}=$ 18 each) milled from two winter wheat cultivars (Centrum, Ritmo) in 2007 and 2009 (Attention: due to otherwise impaired readability of data points, axis of graphs have been set to different scales)

Fig 15. Relationship between disease incidence (DI) and FgDNA content of flours and bran ( $\mathrm{n}$ = 18 each) milled from two winter wheat cultivars (Centrum, Ritmo) in 2007 (Attention: due to otherwise impaired readability of data points, axis of graphs have been set to different scales)

Fig 16. Linear regression of FgDNA and DON content of wheat milling products (flour Type 550, whole grain flour, bran) across all samples (Attention: due to otherwise impaired readability of data points, axis of graphs have been set to different scales)

Fig 17. Protein content (PC) of whole grain flour (WGF) and flour Type 550 milled from two winter wheat cv. (Centrum, Ritmo) grown after pre-crop wheat, maize, and sugar beet in $2007,2008,2009$. Box plots with median (solid line) and whiskers indicating $5^{\text {th }} / 95^{\text {th }}$ percentiles. Box plots $(n=6)$ with same letters are not significantly different at $p<0.05$ according to Tukey test. Outliers are indicated by a dot.

Fig 18. Wet gluten content (WG) and sedimentation value (SV) of flour Type 550 milled from two winter wheat cv. (Centrum, Ritmo) grown after pre-crop wheat, maize, and sugar beet in 2007, 2008, and 2009. Box plots with median (solid line) and whiskers indicating $5^{\text {th }} / 95^{\text {th }}$ percentiles. Box plots $(n=6)$ with same letters are not significantly different at $p<0.05$ according to Tukey test. Outliers are indicated by a dot.

Fig 19. Linear regression of sedimentation value (SV) and DON ${ }_{\mathrm{LOG}}$ of flour Type 550 across cultivars (Centrum, Ritmo) in $\mathbf{2 0 0 9}$ at location Gladebeck after pre-crop maize, $\mathrm{EU}_{\mathrm{MaxCF}}=$ $0.75 \mathrm{mg} \mathrm{kg}^{-1}, \mathrm{EU}_{\text {MaxUP }}=1.25 \mathrm{mg} \mathrm{kg}^{-1}$

Fig 20. Falling number (FN) of wheat cultivars (Centrum, Ritmo) grown after pre-crop wheat, maize, and sugar beet in 2007, 2008, and 2009. Box plots with median (solid line) and whiskers indicating $5^{\text {th }} / 95^{\text {th }}$ percentiles. Box plots $(n=6)$ with same letters are not significantly different at $p<0.05$ according to Tukey test. 
Fig 21. Linear regression between falling number (FN) and DON ${ }_{\mathrm{LOG}}$ (both measured in whole grain flour) from cv. Ritmo in 2007 and 2009 grown after pre-crop maize and wheat across locations (Torland, Gladebeck), $\mathrm{EU}_{\text {MaxcF }}=0.75 \mathrm{mg} \mathrm{kg}^{-1}, \mathrm{EU}_{\mathrm{MaxUP}}=1.25 \mathrm{mg} \mathrm{kg}^{-1}$

Fig 22. Linear regression of dough softening (DS) and $D O N_{L O G}$ in 2007 within locations Torland (TL) and Gladebeck (GB) and within location GB in 2009 across cultivars and pre-crops (for regression parameters see Tab 26), $\mathrm{EU}_{\text {MaxCF }}=0.75 \mathrm{mg} \mathrm{kg}^{-1}, \mathrm{EU}_{\text {MaxUP }}=1.25 \mathrm{mg} \mathrm{kg}^{-1}$ 61

Fig 23. Baking properties (baking volume: BV, loaf heigth: LH, loaf length: LL, loaf width: LW) of two winter wheat cultivars (Centrum, Ritmo) grown after pre-crop wheat, maize, and sugar beet in 2007. Box plots with median (solid line) and whiskers indicating $5^{\text {th }} / 95^{\text {th }}$ percentiles. Box plots $(n=6)$ with same letters are not significantly different at $p<0.05$ according to Tukey test.

Fig 24. Loaves prepared from flour Type $\mathbf{5 5 0}$ from cv. Ritmo grown after pre-crop sugar beet

(A) and pre-crop maize (B) in 2007, Pictures: KREUZBERGER 2008

Fig 25. Average relative proportion (\%) of gliadins $(\omega 5, \omega 1,2, \alpha, \gamma)$, glutenins $(\omega b, H M W-G S$, LMW-GS), and residual (other) protein in total protein of flour Type 550 across all investigated samples $(\mathbf{n}=108)$.

Fig 26. Linear regression of total glutenin content and DON $\mathrm{LOG}_{\mathrm{LO}}$ and $\mathrm{HMW}-\mathrm{GS}$ content and DON $_{\text {LOG }}$ of flour Type 550 within cv. Ritmo in 2007 and across cultivars (Centrum, Ritmo) in 2009 at location Gladebeck (GB), $\mathrm{EU}_{\text {MaxCF }}=0.75 \mathrm{mg} \mathrm{kg}^{-1}, \mathrm{EU}_{\text {MaxUP }}=1.25 \mathrm{mg} \mathrm{kg}^{-1}$

Fig 27. Gliadin/Glutenin ratio and LMW/HMW ratio of wheat cultivars (Centrum, Ritmo) grown after pre-crop wheat, maize, and sugar beet in 2007, 2008, and 2009. Box plots with median (solid line) and whiskers indicating $5^{\text {th }} / 95^{\text {th }}$ percentiles. Box plots $(n=6$, except 2009, Ritmo, pre-crop sugar beet: $n=3$ ) with same letters are not significantly different at $p$ $<0.05$ according to Tukey test. Outliers are indicated by a dot.

Fig 28. Linear regression of gliadin/glutenin ratio and $D O N_{\mathrm{LOG}}\left(\mathrm{mg} \mathrm{kg}^{-1}\right)$ at location Gladebeck (GB) across cultivars and pre-crops in 2007 and 2009 (for other significant linear regressions see Tab 50), $\mathrm{EU}_{\mathrm{MaxCF}}=0.75 \mathrm{mg} \mathrm{kg}^{-1}, \mathrm{EU}_{\mathrm{MaxUP}}=1.25 \mathrm{mg} \mathrm{kg}^{-1}$ 81

Fig 29. Protease activity (PA) and $D \mathrm{~N}_{\mathrm{LOG}}$ of flour Type 550 from wheat (Centrum, Ritmo) grown after pre-crop maize at location Torland in 2007. Each bar represents the MV of the technical measurements of one flour sample

Fig 30. Weather conditions from May $14^{\text {th }}$ to July $16^{\text {th }}$ in 2007, 2008, and 2009: rain incidences with precipitation $(\mathrm{mm})$ and maximum/average/minimum daily temperatures $\left(T_{\max } / T_{\text {mean }} / T_{\min }\right)\left({ }^{\circ} \mathrm{C}\right)$ (WSG 2010) 


\section{Preface}

This study was conducted within the subproject 2 "Influence of fungicide treatment, pre-crop, cultivar susceptibility and Fusarium spp. infection on nutritional and processing quality of bread wheat" of the cooperation project Forschungsverbund Agrar- und Ernährungswissenschaften Niedersachsen (FAEN) and financed by the Ministry of Science and Culture of Lower Saxony, Germany. The influence of the agronomical factors such as cultivar, crop rotation, and fungicide treatment on Fusarium infection level and DON accumulation in wheat grain was mainly investigated by the cooperation partners from the subproject 1 "Agronomic factors influencing the mycotoxin accumulation in Fusarium head blight infected wheat in different crop rotation regimes", Phytopathology and Plant Protection, Department of Crop Sciences, Georg-AugustUniversity Göttingen. The data and results of this project`s work have been published so far as $\mathrm{PhD}$ thesis by GÖDECKE 2010. Since there seems to be some interference between the objectives of this study and from GÖDECKE 2010, it has to be emphasized that even though samples came from the same field trial sampling (composite sample vs. individual sample) and sample preparation (cleaning vs. no cleaning) was different and in accordance with the respective focus of the projects. Additionally, mycotoxin determination was performed with different analytical methods (HPLCMS/MS vs. ELISA). 


\section{Introduction}

\subsection{Importance of wheat in human consumption}

Cereals and cereal products are the most important staple foods worldwide. According to the FAO rice, maize, and wheat are staple foods for 4 bn people and make up about $60 \%$ of the world`s food energy intake. In Germany, cereals contribute 20 to $30 \%$ to the average dietary energy supply (FAO 2011). While total protein content of wheat is comparatively low (only 8-15\%) when compared to other crops, particularly in developing countries it serves as major source of protein intake (SHEWRY 2009). Winter wheat is the most important cereal and crop in Germany. In 2010, $55 \%$ of Germany`s arable land was used for cereal production, $46 \%$ of this area (3.26 $\mathrm{m}$ ha) was utilized for cultivation of winter wheat which made up $53.5 \%$ of the total cereal harvest $(44.3 \mathrm{~m} \mathrm{t})$ (SBA \& BMELV 2010). About $16 \mathrm{~m}$ t of soft wheat were domestically utilized in 2007/8, $54.5 \%$ for feed, $35.0 \%$ for consumption, $7.1 \%$ for industrial use (alcohol, malt, technological starch, energy), and $3.4 \%$ for seed. Mills produced about $6.2 \mathrm{~m} \mathrm{t}$ of bread flour (wheat, rye) in 2008/09 whereas the major proportion $(5.4 \mathrm{~m} \mathrm{t})$ was milled from wheat. $67 \%$ of wheat flour was produced as flour type 550, $11 \%$ as type 405 (BMELV 2009). In 2008/9 consumption of flours from bread cereals accounted for $72.7 \mathrm{~kg}$ per capita per year. Wheat flour made up the major proportion with $63.3 \mathrm{~kg}$ per capita per year (SBA \& BMELV DIV.). $84.6 \mathrm{~kg}$ bread and bakery products per capita were consumed in 2007/08 (BMELV 2009). In Germany, the consumer has the choice out of a worldwide unique diversity of bread and bakery products. The GMF estimated that over 300 kinds of bread and over 1200 types of bakery products are available in Germany (GMF 2004). Due to its great significance in human diet, the production of cereals, including wheat, that is free of contaminants which might pose a threat to human health, is of major interest.

\subsection{Fusarium head blight in wheat}

\subsubsection{Causal organisms and global distribution}

Already in the field as well as immediately post harvesting and during storage several genera of toxigenic fungi-dominating are Aspergillus, Fusarium, and Penicillium- are able to infest wheat (SWEENEY \& DOBSON 1998). In the field, species of the genus Fusarium are of major relevance. In Europe, a complex consisting mainly of Fusarium graminearum ( $F$. graminearum) Schwabe [teleomorph: Giberella zeae (Schwein.) Petch], Fusarium culmorum (F. culmorum) (W.G. Smith) Sacc., Fusarium avenaceum (Fr.) Sacc. (teleomorph: Giberella avenacea R.J. Cook), and Fusarium poae (Peck) Wollenw., and several other less predominant Fusarium spp., is associated with the disease in wheat which is known as Fusarium head blight (FHB) or scab (PARRY ET AL. 1995; BOTTALICO \& PERRONE 2002). FHB and F. graminearum as its predominant etiologic agent have been described as a destructive disease that affects wheat and barley as well as other small-grain 
cereals in the United States, Canada, Europe, Asia and South America (PARRY ET AL. 1995; MCMullen ET AL. 1997; STACK 2000; OsBORNE \& STEIN 2007). The CIMMYT has declared FHB a major factor limiting wheat production worldwide (STACK 2000).

\subsubsection{Economic relevance}

The economic importance of FHB is immense. In the United States, during the 1990s, an estimated loss of 3 bn $\$$ was caused by FHB in wheat and barley and the subsequent yield losses and reduced grain and seed quality. The economic damage partly had a serious social impact on farms and rural communities in FHB stricken regions (MCMULLEN ET AL. 1997; WINDELS 2000). Total economic impacts (direct and secondary) from FHB of 2.7 bn \$ were calculated for wheat and barley in the Northern Great Plains and the Central United States from 1998-2000 (NGANJE ET AL. 2004).

\section{Yield loss}

The threat of FHB epidemics is multifaceted. PARRY ET AL. 1995 revised studies that quantified the loss of yield in wheat in the field under natural occurrence of the disease from 15-70\% in different countries of the world. Controlled inoculation trials with different Fusarium spp. caused losses from 3-60 \%. In China, wheat yield losses ranged from $20-40 \%$ in severe epidemical years, in Canada, losses from 30-70 \% were mentioned for spring wheat (BAI \& SHANER 1994).

SNIJDERS 1990 showed a significant positive relationship between yield reduction and FHB in wheat as well as that yield reduction mainly resulted from the loss of kernel weight and reduction of kernel amount that was caused by FHB. Several studies have demonstrated that FHB damaged grain obtains a lower test weight (e.g. SHOTwELl ET AL. 1985; TUITE ET AL. 1990; JONES \& MIROCHA 1999) and generally shows a reduced thousand-kernel weight compared to healthy grain (e.g. Seitz \& BeChtel 1985; MeYer et AL. 1986; DeXter ET AL. 1996; Jones \& MirOChA 1999). (SCHADE-SCHÜTZE ET AL. 2000) demonstrated that thousand-kernel weight of wheat was reduced in a range from $14-61 \%$ after artificial inoculation with $F$. culmorum.

\section{Seed quality}

FHB also has an impact on seed quality. As the primary inoculum source, infected grain may lead to seedling blight and foot rot (PARRY ET AL. 1995). Seed germination and vigour, if not totally inhibited, can be reduced in such dimensions that it is below commercial standards (BECHTEL ET AL. 1985; ARGYRIS ET AL. 2003).

\section{Grain quality}

\section{Technological quality}

Furthermore, technological traits of grain can be negatively affected because kernel composition is altered by the fungus indicated by the degradation of cell walls, starch granules and storage 
proteins (BeChTEL ET AL. 1985; BOYACIOGLU \& HetTIARACHCHY 1995; JONES \& MiROCHA 1999; SIUDA ET AL. 2010.) Since the influence of Fusarium infection on grain quality is one key aspect of this study, studies regarding this topic will be reviewed in more detail in chapter 1.1.2.

\section{Mycotoxins}

The most crucial aspect of FHB is the association with several mycotoxins that accumulate in the grain already in the field and/or during storage. Mycotoxins in food are secondary metabolites mainly produced by fungi belonging to the three genera Fusarium, Apergillus and Penicllium (MURPHY ET AL. 2006). While the biological role of many mycotoxins is still "elusive" (REVERBERI ET AL. 2010) the threat they pose to humans and animals is more clear. Dose dependent effects on human and animal health range from skin irritations to neurotoxic, immunosuppressiv, and teratogenic to destruction of vital organs (e.g. liver, kidney) carcinogenic, mutagenic, and death (MURPHY ET AL. 2006).

Fusarium mycotoxins usually belong to three main structural groups that are trichothecenes (T-2 toxin (T2), deoxynivalenol (DON), diacetoxyscirpenol (DAS), fusarenone X (FUS), nivalenol (NIV)), zearalenones (zearalenone (ZEA)), and fumonisins (fumonisin $\mathrm{B}_{1}\left(\mathrm{FB}_{1}\right)$ ). Moniliformin (MON), beauvericin (BEA), and fusaproliferin (FUP) are in addition increasingly associated with FHB (BOTTALICO 1998). In Europe, DON and its derivates (3-ADON, 15-ADON) and ZEA are the most frequently detected mycotoxins in association with head blight of wheat and other small grain cereals. DON and derivates are produced by $F$. graminearum and $F$. culmorum. ZEA usually cooccurs with DON and its derivates and is mainly produced by $F$. graminearum, $F$. culmorum, $F$. equiseti, and F. cerealis (BOTTALICO \& PERRONE 2002). Even though, all toxins may represent a hazard to human health, only toxicological aspects of DON and ZEA will be described subsequently in more detail since they are the most prevalent Fusarium toxins and were also investigated in this study.

DON, also known as "vomitoxin" due to its emetic effects in pigs, is associated with gastroenteritis in humans. Toxicological aspects of DON were recently reviewed by PESTKA 2010. Feeding trials, with pigs have shown emesis after acute exposure with DON. Chronic low-dose exposure with DON caused anorexia, growth retardation, immunotoxicity, and impaired reproduction and development deriving from maternal toxicity. Pathophysiologic effects are alteration of neuroendocrine signalling, proinflammatory gene induction, disruption of the growth hormone axis, and gut integrity. In cells, DON elicits ribotoxic stress. Even though undesirable as FHB itself, it can be regarded as a fortunate circumstance that DON is the most prevalent trichothecene detected cereals, since it was demonstrated to be 10 to 20 times less toxic than e.g. T2-toxin and NIV (UENO 1983). 
Toxicological aspects of ZEA were reviewed by ZINEDINE ET AL. 2007. Compared to other toxins, ZEA shows relatively low acute toxicity. Subacute and subchronic toxicity was indicated by interaction of ZEA and metabolites with estrogen receptors, especially sensitive reacted pigs. In rodents, chronic effects were liver lesions with development of hepatocacarcinoma, alterations in several estrogen-related tissues (uterus, mammary glands), myelofibrosis in bone marrow, pituitary adenomas, depression of body weight, inflammation of prostate gland, testicular atrophy, increased nephropathy, retinopathy and cataracts. ZEA also showed haematotoxic effect and is associated with the growth of human breast cancer cells. In cows and pigs, an influence of ZEA on reproduction and development was observed. On the cellular level, ZEA appears to induce DNAadduct formation, DNA fragmentation, targets mitochondria and/or lysosoms, induces lipid peroxidation, cell death and inhibition of protein and DNA syntheses.

So far, it is not possible to eliminate mycotoxins completely from the products meant for consumption during the different processing steps (cleaning, milling, baking/cooking) of wheat (see chapter 1.1.1). With the intention to protect the consumers from mycotoxins in food the European Union (EU) has established maximum levels ( $\left(\mathrm{EU}_{\mathrm{Max}}\right)$ for DON and ZEA in cereals and cereal products with Commission regulation (EC) No. 856/2005 of $6^{\text {th }}$ July. Tab 1 lists those concerning foodstuffs produced from wheat. For DON, the EU recommended maximum tolerable daily intake (TDI) is $1 \mu \mathrm{g} \mathrm{kg}^{-1}$ bodyweight (bw), for ZEA $0.2 \mu \mathrm{g} \mathrm{kg}^{-1}$ bw, respectively. Regarding other Fusarium associated toxins, maximum levels do not yet exist for wheat or wheat products. In the subsequent text $\mathrm{EU}_{\mathrm{Max}}$ for DON in unprocessed cereals and cereal flour are abbreviated as $\mathrm{EU}_{\mathrm{MaxUP}}$ and $\mathrm{EU}_{\mathrm{MaxCF}}$, respectively.

Tab 1. EU maximum levels ( $E U_{\text {MAX }}$ ) for Fusarium toxins in foodstuffs (in $\mu \mathrm{g} \mathrm{kg}^{-1}$ ) concerning wheat and wheat products according to Commission regulation (EC) No $856 / 2005$

\begin{tabular}{lcc}
\hline Product & DON & ZEA \\
\hline $\begin{array}{l}\text { Unprocessed cereals (Durum wheat) } \\
\begin{array}{l}\text { Cereals intended for direct human } \\
\text { consumption, cereal flour }\end{array}\end{array}$ 1250(1750) & 100 \\
$\begin{array}{l}\text { Pasta } \\
\text { Bread (including small bakery wares), pastries, } \\
\text { biscuits, cereal snacks and breakfast cereals }\end{array}$ & 750 & 75 \\
$\begin{array}{l}\text { Processed cereal-based foods and baby foods } \\
\text { for infants and young children }\end{array}$ & 200 & - \\
\hline
\end{tabular}

\subsubsection{Epidemiology and symptoms}

Initial point of the epidemic cycle of FHB is an inoculum source (stubble, crop debris) in the soil where Fusarium spp. either survive as saprophytic mycelium or as chlamydospores. The fungus may from there infect the seedling, causing seedling blight and foot rot (PARRY ET AL. 1994). 
However, FHB is primarily a floral disease even though a few studies have also proposed systemic colonization of the plants as the cause for head blight (STACK 2003). This means that wheat plants were observed to be particularly susceptible to Fusarium infection during flowering and preflowering stages. Airborne and water-splashed (macro-)conidia as well as ascospores released from perithecia infect the wheat florets, resulting in FHB and providing new inoculum (STACK 2003, PARRY ET AL. 1995). Especially, warm and moist weather conditions during wheat anthesis and shortly thereafter promote germination of spores and growth of fungal hyphae into grain tissues (OSBORNE \& STEIN 2007).

By means of light and electron microscopy KANG \& BUCHENAUER 2000 described in detail the process of penetration, infection and invasion of wheat spikes by F. culmorum. Referring to their observations, after spore germination the fungus develops a dense hyphal network on the host surface and penetrates the inner surfaces of lemma, glume, palea, and the upper ovary part by infection hyphae. Palea and lemma can occasionally also be invaded through stomata. By intra- and intercellular growth, fungal hyphae spread in parenchyma and vascular bundles of lemma, glume, ovary and rachis causing severe damage to the host cells. In another study the same authors described a degradation in the cell wall components cellulose, xylan, and pectin in infested tissue and concluded that the infection of wheat spikes is facilitated by cell-wall-degrading enzymes that were secreted by the fungus (KANG \& BUCHENAUER 2000B). Similar observations were made in wheat spikes infected with $F$. graminearum (WANJIRU ET AL. 2002). Further infection within wheat ear occurs vertically through vascular bundles or horizontally through anthers and bracts from primarily infected spikelet to contiguous spikelet (RIBICHICH ET AL. 2000).

Several alterations in the xylem vessels and phloem sieves have been mentioned to cause at least partial interruption of nutrient supply which leads to a premature death of the apical spikelets and results in the typical bleaching ("blight") symptoms of the upper part of the wheat ear (KANG \& BUCHENAUER 2000; RIBICHICH ET AL. 2000; GOSWAMI \& KISTLER 2004). Other typical FHB symptoms in wheat are brown, dark purple to black necrotic spots on spikelets ("scab") as well as distorted and downwards curved ears. Infected kernels appear shriveled and discolored. Grain color reaches from white over light brown to pink and salmon-orange, the later resulting from developed conidia. Reddish colored spore packages can also be visible on the outer surface of spikelets and glumes (BOTTALICO \& PERRONE 2002, GOSWAMI \& KisTLER 2004). 


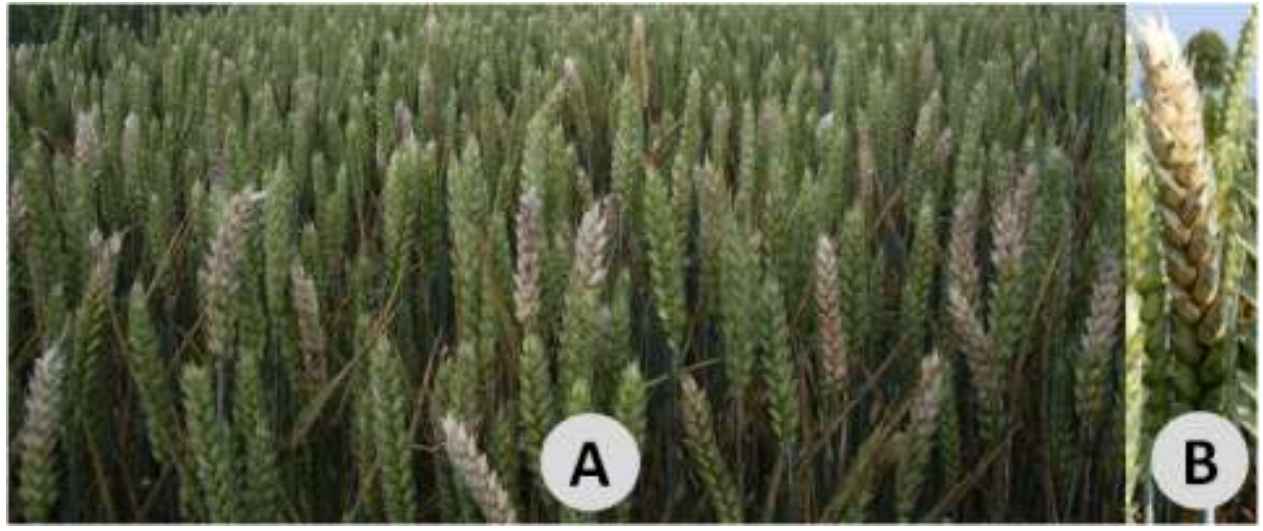

Fig 1. Blighted wheat heads (A) and bleaching of upper spike part (B) caused by naturally occurring FHB in 2007, at trial location Torland (51.36 $\left.\mathrm{N}, 9.55^{\circ} \mathrm{E}\right)$, Pictures: BAADER 2007

\subsubsection{Control strategies}

Due to the disastrous effect of FHB on grain yield and quality, various attempts have aimed to identify factors that support Fusarium infection in the field and develop measures to prevent the frequency and intensity of FHB occurrence. Agronomic practices that control FHB epidemics include choice of (I) pre-crop, (II) tillage system, (III) cultivar, (IV) fungicide application, and (V) fertilizers.

\section{Pre-crop}

The pre-crop can facilitate FHB in wheat in the following year in two ways. Either the pre-crop functions as host plant for Fusarium spp. and therefore, increases inoculum compared to a non host plant or the pre-crop leaves a large amount of crop debris after harvest in which Fusarium spp. survive saprophytically (BEYER ET AL. 2006). Maize has been identified as the pre-crop that promotes FHB and DON contamination in wheat the most. First, maize serves as a host for $F$. graminearum which is the main causal agent of FHB, and second, maize leaves plenty of crop debris where Fusarium spp. can survive (DILL-MACKY \& JONES 2000). Non-cereals such as rapeseed, potato, and sugar beet as well as wheat itself have been demonstrated to cause significantly lower DON levels in subsequent wheat (BECK \& LEPSCHY 2000).

\section{Tillage}

Ascospores and conidia that are forcibly discharged, wind-dispersed or water splashed coming from colonized crop debris present the primary inoculum source for Fusarium infection (XU 2003). Incorporation of Fusarium infested crop residues deep in the soil reduced effectively the $F$. graminearum populations (YI ET AL. 2002). Consequently, the most effective tillage treatment to remove Fusarium spp. colonized crop residues from the soil surface is the application of the moldboard plough. Compared to a chisel plough treatment and a no tillage system the moldboard plough reduced the residuals of corn, wheat, and soybean significantly. Disease incidence and disease severity caused by FHB in wheat in the following year were significantly lower after 
moldboard ploughing (DILL-MACKY \& JONES 2000). A no-ploughing system after pre-crop maize presents the highest risk factor leading to high DON contamination levels in wheat (BECK \& LEPSCHY 2000; BARRIER-GUILLOT ET AL. 2004).

\section{Cultivar}

Since crop management and agrochemical measures are only partly able to control FHB effectively, the cultivation of resistant wheat cultivars is a key aspect in integrated Fusarium control and in prevention mycotoxin accumulation in grains (BUERSTMAYR ET AL. 2009). Researcher worldwide agree that "resistant cultivars will provide the most stable and durable solution to the problem of FHB" and "ensure stable yields and high-quality grain free of mycotoxins" (GILBERT \& TEKAUZ 2000). Resistance mechanisms to FHB are complex and yet not fully understood. It is assumed that a complex of physiological, biochemical and morphological factors leads to a reduced susceptibility which are expressed in active or passive defense reactions by the wheat plant (MIEDANER 1997).

Two types of resistance to FHB are classically distinguished: resistance to initial penetration (type I) and resistance to spreading of the fungus within infected spike (type II) (SCHROEDER \& CHRISTENSEN 1963). Whereas type I resistance is more important in barely, wheat cultivars mainly express type II resistance. So far, the Chinese wheat cultivar Sumai 3 and its derivates have shown the highest degree of type II resistance and at the same time the highest degree of FHB resistance in wheat known so far. Point inoculation in spikelets did not lead to spread of FHB symptoms in the ear. Several infected spikelets within one ear could only be observed under heavy disease pressure in the field (BAI \& SHANER 2004). So far, no genotype with complete resistance to FHB has been found, all genotypes investigated proved to be more or less susceptible (MIEDANER 1997).

Two other types of active resistance mechanisms were proposed by MESTERHAZY 1995. On the on hand, resistance to kernel infection which is measured as percentage of infected kernels. On the other hand tolerance which expresses the ability of the plant to endure the FHB infection and disease, measured in relative yield reduction. Nevertheless, these two types of resistance did not become widely accepted for several reasons (BAI \& SHANER 2004). Another active resistance mechanism is the resistance to DON accumulation in grain (MILLER ET AL. 1985). Usually, in Fusarium infected wheat cultivars DON is detectable in the grain. A study of 116 wheat lines of various origins under greenhouse and field conditions inoculated with a mixture of several $F$. graminearum isolates showed that DON levels varied in a wide range between the cultivars: from trace levels up to $283 \mathrm{mg} \mathrm{kg}^{-1}$ in the greenhouse test and from 2.8 to $52 \mathrm{mg} \mathrm{kg}^{-1}$ in the field (BAI ET $A L$. 2001). Possible explanations for the lower DON content in kernels of some wheat cultivars compared to others grown under identical environmental conditions are: (i) low DON production by the fungus, (ii) enzymatic degradation of DON by the wheat plant during grain development, 
and (iii) high accumulation of DON in other tissues of the spike. The resistance to DON accumulation in grain was termed type III resistance (MILLER \& ARNISON 1986).

Passive resistance mechanisms against FHB have also been investigated. Morphological features of the wheat plant, such as plant height, awndness, spikelet density as well as flowering habit e.g. avoidance of the infection by escape (flowering in boot stage), flowering period, anther morphology, position and density of florets, and time interval that florets are open have been connected with the disease severity (SCHROEDER \& CHRISTENSEN 1963; MESTERHAZY 1995).

Since the phenotypic evaluation of FHB resistance is elaborate and its expression greatly influenced by genotype x environment interactions, breeding efforts for FHB resistance recently concentrate more on the use of molecular markers. FHB resistance is a quantitative trait and to current knowledge quantitative trait loci are present on all of the 21 wheat chromosomes except 7D (KOLB ET AL. 2001; BUERSTMAYR ET AL. 2009).

\section{Fungicide}

The efficacies of various pesticides against FHB has been investigated under controlled conditions (in vitro, greenhouse) as well as in field trials. Results are partly contradictory; therefore, a reduction of mycotoxin content in grain cannot clearly be related to fungicide application (EDWARDS 2004). Triazole fungicides have proven to be the most effective chemical control against FHB so far (BEYER ET AL. 2006). Fungicides with metconazole and tebuconazole as active agents reduced FHB infection and DON content in field samples significantly in comparison to an untreated control (EDWARDS ET AL. 2001). The newer compound prothioconazole applied at growth stages 31,39 , and 65 reduced FHB symptoms by 50, 58 and $83 \%$ and DON levels by 27, 49, $57 \%$, respectively (EDWARDS \& GODLEY 2010).

The application of strobilurin containing fungicides produced contradicting results. Whereas EDWARDS ET AL. 2001 did not find an effect of azoxystrobin on trichothecene-producing Fusarium spp. SIMPSON ET AL. 2001 reported a risk potential coming from azoxystrobin treatment on the contrary. This resulted from an increase in toxigenic Fusarium spp. and increased DON contamination. In a greenhouse trial conducted by PIRGOZLIEV ET AL. 2002 different doses of azoxystrobin reduced FHB and DON levels, even though not as efficiently as metconazole.

Besides the choice of the active ingredient the right timing for fungicide application plays a key role in the chemical control of FHB. BEYER ET AL. 2006 revised several studies that observed the best efficacies of fungicides when applied during wheat anthesis. Application pre-anthesis or postanthesis led to a drastically reduced impact of the fungicides. 


\section{Fertilizer}

The use of different fertilizer regimes are assumed to affect FHB either by (i) influencing the decomposition rate of crop debris, (ii) creation of physiological stress on host plant or (iii) changing construction of cereal canopy (EDWARDS 2004). Nevertheless, the role of fertilization measures, especially nitrogen fertilization, in FHB development is still discussed controversially. A standard management that included a single application of $70 \mathrm{~kg} \mathrm{ha}^{-1}$ of ammonium nitrate at seeding was compared with the standard management and two supplementary nitrogen applications, $50 \mathrm{~kg} \mathrm{ha}^{-1}$ each. Supplementary nitrogen fertilization resulted in significantly higher incidence of Fusarium spp. in wheat and triticale. The same effect was observed in two-row and six-row barely, even though supplementary nitrogen of $50 \mathrm{~kg} \mathrm{ha}^{-1}$ was only applied once (MARTIN ET AL. 1991). An earlier study compared forms of nitrogen fertilizers and showed lower FHB incidence in wheat where urea was applied compared to the use of ammonium nitrate (TEICH 1987). LEMMENS ET AL. 2004 compared different types of mineral and organic nitrogen fertilizers and could not find an effect on FHB. But they observed an increase of FHB intensity with increasing nitrogen input over a range from 0 to $160 \mathrm{~kg} \mathrm{ha}^{-1}$. In another experiment, published within the same study, they showed a significant increase of FHB intensity and DON contamination in grain with increasing nitrogen input, but only in wheat with nitrogen deficit $(<80$ $\left.\mathrm{kg} \mathrm{ha}^{-1}\right)$. At higher input rates, common in agricultural practice, FHB intensity and DON levels remained on a constant level. They concluded that nitrogen fertilization is not a practical control strategy in managing FHB in the field. AUFHAMMER ET AL. 2000 and OLDENBURG ET AL. 2007A came to the same conclusion after investigating the effect of different types of nitrogen fertilizers, compositions, doses, and applications times on FHB in the field.

\section{Other measures}

For the sake of completeness, it should be mentioned that other methods to control FHB and DON contamination are also discussed, such as avoidance of growth regulators, biological measures, weed management, insect control, and transgenic approaches. But so far, there is not enough reliable data to evaluate the possible contribution these measures might have against FHB (EDWARDS 2004; SNIJDERS 2004).

\section{Quantifying the effects of different control strategies affecting FHB and DON}

On the data basis of only field trials which were reviewed by BEYER ET AL. 2006, the authors made the attempt to evaluate the efficacy of different methods to control FHB and therefore DON contamination in the grain. The model to quantify the effect on DON included previous crop, tillage, choice of cultivar, and fungicide treatment as influencing factors. The outcome is presented in Fig 2. 


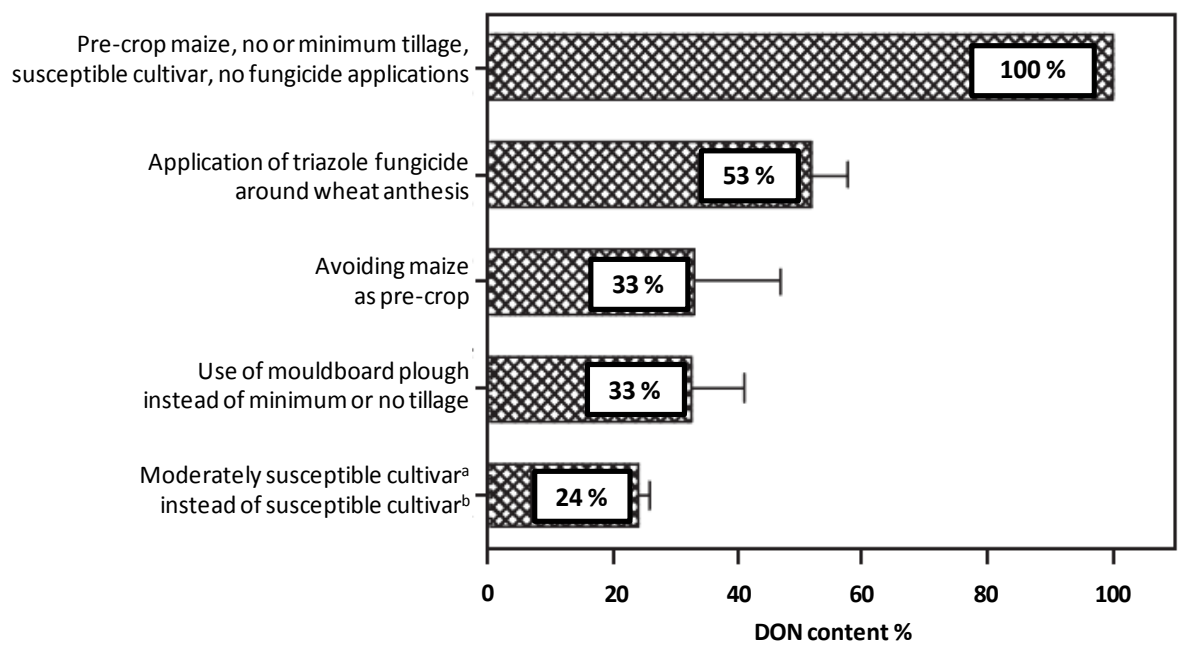

Fig 2. Relative DON content obtained by the use of agronomic methods or fungicides. DON reduction is presented as percentage in relation to the worst case scenario (pre-crop maize, no or minimum tillage, susceptible cultivar, no fungicide application = $100 \%$ DON content), ${ }^{\mathrm{a}} \mathrm{cv}$. Dekan, ${ }^{\mathrm{b}} \mathrm{cv}$. Ritmo (BEYER ET AL. 2006)

It becomes clear, that to the current state of knowledge the choice of a moderately susceptible cultivar compared to a more susceptible one is the most effective strategy to minimize DON contamination in wheat grain. DON contamination in comparison to the worst case situation was decreased to $24 \pm 7 \%$ by that measure, followed by ploughing which reduced DON to $33 \pm 7 \%$, avoiding maize as previous crop which lowered DON content to $33 \pm 11 \%$, and triazole treatment during anthesis which could only decrease DON levels to $53 \pm 4 \%$ (Fig 2).

The authors of that study assumed that factors such as $\mathrm{N}$ fertilization and growth regulators might have indirect effects on DON contamination but due to the limited data available concerning these factors they did not account for them. The results are in accordance with the findings of OBST ET AL. 2000 who identified five DON risk factors based on long-term Fusarium monitoring of Bavarian wheat: (i) pre-crop maize, (ii) minimum tillage after maize, (iii) cultivation of moderately to highly susceptible wheat varieties, (iv) use of strobilurin fungicides, and (iv) warm and wet weather conditions during wheat anthesis. The accumulation of the factors increased the risk of high DON levels not in an additive, but in a multiplicative way. Therefore, it is assumed that the avoidance of one or more risk factors which can be managed by the farmer may also decrease DON content in a synergistic manner (BEYER ET AL. 2006). 


\subsection{Significance of gluten proteins for wheat processing}

The worldwide success of wheat as crop plant does not only derive from its high adaptation capabilities to various climatic conditions and high yield potential but is largely also a result of the unique characteristics of dough produced from wheat flours (SHEWRY 2009). The viscoelastic properties of wheat dough make it suitable for various end-uses (bread, cakes, biscuits, pasta, noodles) of which the processing of leavened bread is particularly important (WEEGELS ET AL. 1996; SHEWRY 2009). These properties derive from the wheat storage proteins which are also termed 'gluten' proteins due to their ability to form a network in dough that is able to trap carbon dioxide (SHEWRY 2009). Due to their insolubility in water or dilute saline but their extractability in alcohol-water solutions OSBORNE 1924 classified wheat gluten proteins as 'prolamins'. These can be further separated into gliadins, which are soluble in e.g. $60 \%$ ethanol-water solution, and glutenins which need additional reducing agents to become soluble owed to their higher degree of polymerization and connection by interchain disulphide bonds (WIESER ET AL. 1998; SHEWRY ET $A L$. 2002). Gluten proteins (gliadin + glutenins) make up for $80-85 \%$ of total protein in mature wheat grain, while albumins (water-soluble) and globulins (soluble in salt-water solution) play a minor role and mainly function as metabolic and structural proteins (SHEWRY \& HALFORD 2002; GOESAERT ET AL. 2005). Prolamins of wheat are exclusively located in the endosperm while e.g. globulins are also present in the outer part of the aleurone layer and in the embryo (SHEWRY \& HALFORD 2002).

According to WIESER 2007 and SHEWRY \& HALFORD 2002, gliadins and glutenins can be classified into several subgroups (Fig 3) that differ in their proportion of total gluten, molecular weight, amino acid composition (not shown), and their ability to form interchain disulfide bonds due to different levels of cysteine. Gliadins, generally monomers with molecular weight (MW) from 28$55 \mathrm{kDa}$, can be divided into $\omega$-gliadins that lack cysteine and are therefore not able to form disulphide crosslinks between proteins, while a-//-gliadins and $\gamma$-gliadins contain relatively high contents of cysteine and are able to form intrachain bonds. Glutenins are highly polymerized proteins that can be roughtly divided into low-molecular-weight glutenin subunits (LMW-GS) with MWs from 32-35 kDa and high-molecular-weight glutenin subunits (HMW-GS) with MWs from 67-88 kDa. LMW-GS form interchain bonds, HMW-GS are linked by intra- as well as interchain disulfide bonds. SHEWRY \& HALFORD 2002 assign prolamins into a sulfur-rich group (e.g. $\alpha-, \gamma$ gliadins, subunits of LMW-GS), a sulfur-poor group ( $\omega$-gliadins, subunits of LMW-GS), and HMW-GS that contain also subgroups that are rich in sulfur.

Both, gliadins and glutenins, contribute to the rheological dough characteristics, however in a different manor. Gliadins are less elastic and cohesive than glutenins and rather contribute to viscosity and extensibility of dough while glutenins contribute, on the contrary, to its strength and elastic properties (WIESER \& KIEFFER 2001; WIESER 2007). Especially the HMW-GS subgroup has 
been demonstrated to be important for rheological gluten and dough properties as well as for baking volume (WIESER \& ZIMMERMANN 2000; WIESER \& KIEFFER 2001).

Even though wheat protein content is comparatively low with regard to other crops, the remarkable functions of the storage protein fraction make wheat one of the most consumed diets of the world (SHEWRY 2009). Therefore, the influence of Fusarium infection on protein content of grain, flour, as well as on content and composition of gluten proteins and subfractions is a key aspect in this study.

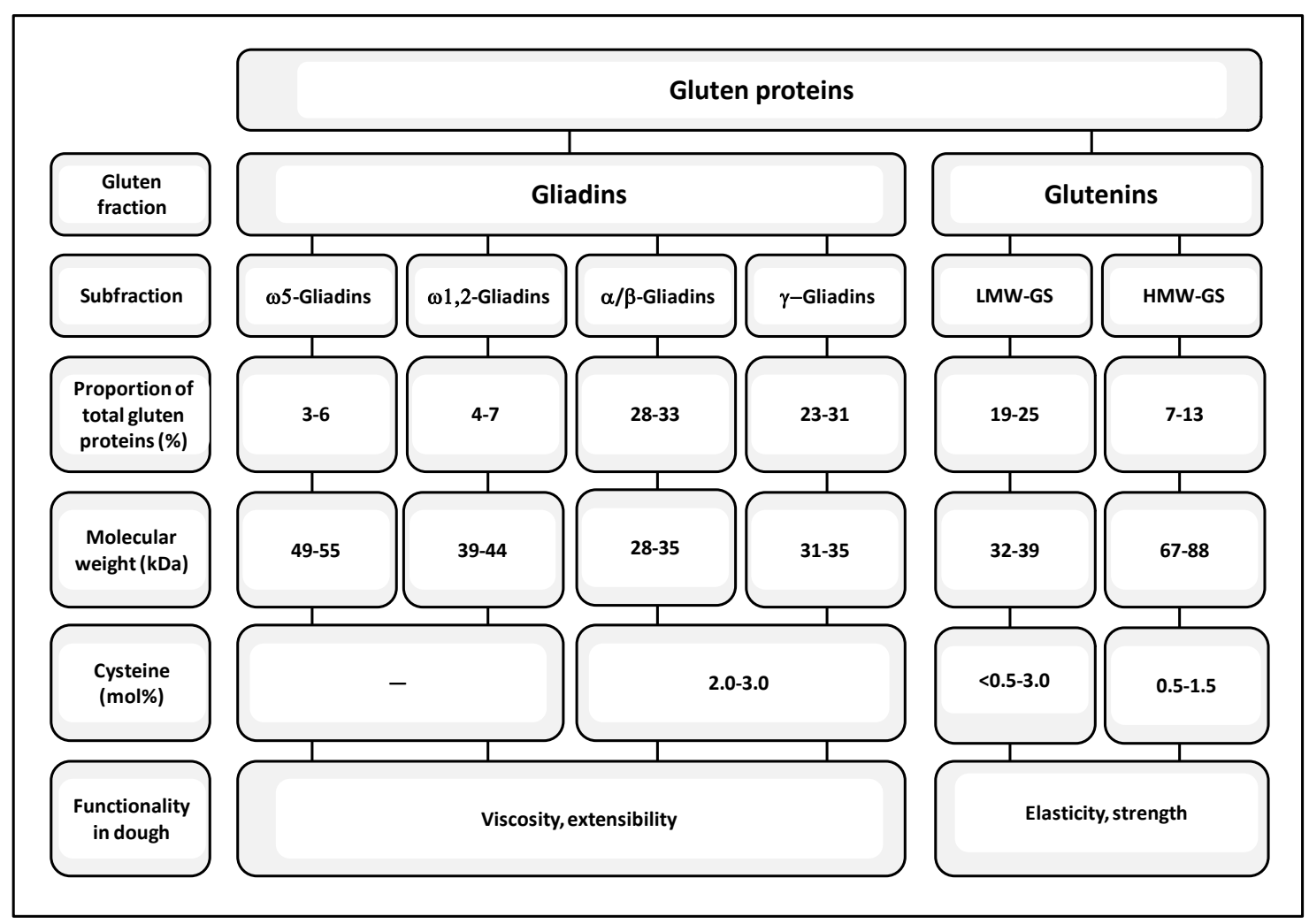

Fig 3. Classification of gluten proteins according to WIESER 2007 and SHEWRY \& HALFORD 2002 (modified)

\subsection{Evaluation of bread wheat quality}

In general, the technological value of wheat is strongly influenced by the functional properties of starch, and protein, particularly gluten protein, as well as by quantity of these components. Both quality and quantity of grain components are strongly linked to each other and primarily depend on genetic background (cultivar) as well as on environmental conditions (climate, soil, fertilization, pathogens). All of these factors influence the final baking quality which is defined by e.g. water absorption of flour, tolerance to mixing (dough), and baking volume (SEIBEL 2005; SELING 2010).

International standards that define terms and methods for wheat grading do not yet exist, even though processing tools are similar and quality of the end product is usually described with the same expressions in different countries (POSNER \& HIBBS 2005). Council Regulation (EC) No $1784 / 2003$ of $29^{\text {th }}$ September 2003 is the basis for the common organization of the market in 
cereals in the European Union. It describes the intervention system for the internal market and support measures for European cereal products when traded on the world market. Related to this act is Commission Regulation (EC) No $824 / 2000$ of $20^{\text {th }}$ April 2000 which lays down the procedures for the assumption of cereals by intervention agencies and describes methods of analysis for certifying that cereals are "sound, fair and of marketable quality". For durum wheat, common wheat (includes bread wheat), barley, maize, and sorghum the regulation establishes parameters e.g. maximum moisture content, the maximum percentage of impurities and the minimum specific weight. Evaluation of grain by e.g. by determination of besatz, falling number, moisture content, zeleny sedimentation, and protein content base upon the standard methods established by the International Association of Cereal Chemistry (ICC). The requirement for "marketable quality" includes the compliance with legal regulations that rule e.g. the maximum content of mycotoxins in cereals (see chapter 1.2.2, Tab 1).

In Germany, wheat is mainly traded as cultivars or quality groups; in some years a minimum falling number and a minimum protein content is required (SEIBEL 2005). The Federal Office of Plant Varieties (BSA) annually publishes Descriptive Variety Lists that describe the listed and marketed varieties of the most important agricultural and vegetable species regarding cultivation, resistance, quality, and yield. Technological quality of bread wheat is thereby estimated by indirect quality characteristics (protein content, falling number, sedimentation value, pearling index, water absorption of flour), milling properties (ash number, flour yield) and baking properties (baking volume, dough elasticity and surface consistency) (BSA 2007). The assignment of soft wheat cultivars to quality groups $(\mathrm{E}, \mathrm{A} ; \mathrm{B}, \mathrm{C})$ is based on defined minimum requirements for the most important quality characteristics whereas baking properties and baking volume in particular play the major role. Together with protein quality and starch properties, protein content particularly determines the quality of wheat for end-use (SELING 2010). While the determination of e.g. protein content, falling number (as a measure of $\alpha$-amylase activity in grain, indicating sprout damage), and sedimentation value (as a measure of protein swelling in acidy or SDS solution indicating protein quality) are taken as fast inexpensive measures to indicate baking performance, the investigation of e.g. dough mixing properties and the actual baking test (as ultimate method to evaluate quality of end-product) are time consuming and costly for which they are only applied in mills and large bakeries that own the specific equipment (SEIBEL 2005). In this work, both fast standard procedures as well as more elaborate methods for the evaluation of bread wheat quality were used with the objective to gain a better overall picture how Fusarium infection influences wheat quality. 


\subsection{Fusarium infection and wheat quality}

\subsection{1 \\ Fate of DON during wheat processing}

Various studies have so far focused on the possible retention of DON, the Fusarium mycotoxin with the highest occurrence in wheat, during primary processing (cleaning, milling) and secondary processing (baking, cooking) of wheat. The efficiency to remove DON contaminated kernels from the mixture of healthy and unhealthy kernel of several processes prior to milling -sorting, sieving, and scouring- with varying equipment has been tested. Cleaning was demonstrated to be capable to remove DON partly with varying success. SCOTT ET AL. 1983 found the highest DON concentration in dockage and therefore expected at least a slight reduction of DON content in cleaned wheat. Removal of dust and screenings reduced DON content about 7\% to 23\% (Young ET AL. 1984). In cleaned wheat, DON content decreased in a range from 6 to 19\%. In other studies, obtained cleaning efficiencies from 48 to $86 \%$ depending on the original DON concentration in the grain lot (ABbas ET AL. 1985; SeITZ et AL. 1985; SeItZ ET AL. 1986). TKaChUK ET AL. 1991 removed shriveled and light severely infected wheat kernels ("tombstone kernels") and therefore kernels with the highest DON concentrations effectively by gravity table. Separation by gravity table is based on the principle that Fusarium damaged kernels are of lower density, a principle that has also been used by HUFF \& HAGLER 1985 in a less practical treatment which involved the removal of buoyant kernels in water and sucrose solution. DON content in wheat decreased by $68 \%$ to $96 \%$. Scouring of wheat reduced DON level by $22 \%$ in one wheat cultivar (NOWICKI ET AL. 1988).

Most of the wheat meant for human consumption is converted into wheat flour by milling. Since the early 1980s a large amount of studies worldwide have reported on the distribution of DON in milling fractions gained from test mills. Independent of wheat cultivar, DON was distributed in all milling fractions, with the highest amounts usually concentrated in milling fractions containing more of the outer layers (germ and bran) of the kernels (SCOTT ET AL. 1983; YOUNG ET AL. 1984; ABbas ET AL. 1985; SEITZ ET AL. 1985; SEITZ ET AL. 1986; TRIGO-STOCKLI ET AL. 1996; GARTNER ET AL. 2008; LANCOVA ET AL. 2008). In flours produced from the inner proportion of the endosperm, DON levels could be reduced by fractionation to some extent (SCOTT ET AL. 1983; GARTNER ET AL. 2008; LANCOVA ET AL. 2008). DEXTER ET AL. 1996 reported an average DON reduction of $50 \%$ in white flour produced from four wheat cultivars.

Wheat flour is used for the processing of diverse foods e.g. bread, cakes, pasta, and noodles. Therefore, numerous studies have also focused on the retention of DON during cooking processes, investigating the behavior of DON during heating. A few studies showed that DON was neither destroyed nor reduced during baking at temperature between 170 to $350{ }^{\circ} \mathrm{C}$ with varying baking times (ElbanNa ET AL. 1983; SCOTT ET AL. 1983; TANAKA ET AL. 1986; SUGITA-Konishi ET AL. 2006; LANCOVA ET AL. 2008) which underlines the heat-stability of DON. Other studies report a reduction of DON in bread in a range from 19 to 69\% (YouNG ET AL. 1984; ABBAS ET AL. 1985). 
SAMAR ET AL. 2001 observed a reduction of DON by $41 \%$ and 56\% in French bread and Vienna bread, respectively, during fermentation at $50^{\circ} \mathrm{C}$. Two additives, sodium bisulfite and L-cysteine, reduced DON level in bread by 38.0 to $46.0 \%$ (BOYACIOGLU ET AL. 1993). SEITZ ET AL. 1986 showed a decrease of DON level in wheat with lower DON contamination, whereas DON content in bread made from wheat with more than $1.6 \mathrm{mg} \mathrm{kg}^{-1} \mathrm{DON}$ increased. Studies that investigated the effect of other cooking processes such as frying, spaghetti and noodle cooking, extrusion, and superheated steam treatment have been thoroughly reviewed by KUSHIRO 2008 and will not be mentioned here. It should just be mentioned that DON is highly water-soluble and can therefore be reduced by a large extent from spaghetti and noodles when boiling in water and discarding of cooking water.

In summary, DON can be reduced to some degree and step by step during the different wheat processing steps, but cannot be totally eliminated from the end-products. One crucial problem is that separation of Fusarium infected kernels is not easy to solve, since FHB level does not always correlate with DON content in the kernels and FHB/DON ratio varies among cultivars. Also, the observed reduction of DON levels during secondary processing might partly result from the degradation and conjugation of DON. The toxicological effect of such degradation products and conjugated DON is unknown (KUSHIRO 2008).

\subsubsection{Impact of Fusarium infection on wheat quality and composition}

While studies on the pathogenicity and epidemiology of FHB, resistance mechanisms, associated mycotoxins as well as control measures in the field is abundant, literature on the impact of Fusarium infection on wheat quality seems comparatively scarce. Although it is understandable, that the management of FHB has in the past primarily focused on food safety and therefore on the avoidance of mycotoxin contamination in grain, the effects of FHB on grain quality are not to be underestimated. Researchers have just recently become aware that quality assurance in FHB affected wheat is essential for wheat marketing. Because the wheat price is directly determined by its processing attributes, influence of FHB on wheat milling performance, flour properties and endproduct quality have just recently confirmed its partially adverse effects (DEXTER \& NOWICKI 2003).

Early works on the influence of Fusarium infection on processing quality of wheat date back to the 1950s. FINNEY 1954 (cited in SEITZ ET AL. 1986) already reported a reduced baking performance for scab infected wheat in the U.S.; in Germany, BOCKMANN 1964 first investigated the influence of Fusarium infection on baking performance in detail, later other European researchers such as JOVICEVIC 1972; Berova \& MLADENOV 1974; ZWATZ 1975; SARIC ET AL. 1980 (cited in MEYER ET AL. 1986) also reported a loss in wheat quality due to Fusarium infection of grain. Since the 
1980s scientists worldwide have continuously published results on the influence of Fusarium infection on quality parameters of wheat and the effect of the fungus on the composition of flour.

Authors have first of all focused on milling value of wheat (measured as flour yield, ash content, flour color) (HAmilton \& TRENHOLM 1984; Bechtel ET AL. 1985; MEYER ET AL. 1986; SEITZ ET AL. 1986; TKACHUK ET AL. 1991; DeXTER ET AL. 1996; MATTHAUS ET AL. 2004; GARTNER ET AL. 2008). However, even more studies investigated the impact of Fusarium infection on quality parameters that give a fast indication of flour properties (protein content, sedimentation value, falling number, wet gluten, water absorption) and are easy to assess (BOCKMANN 1964; HAMILTON \& Trenholm 1984; Bechtel et AL. 1985; SeItZ \& Bechtel 1985; MeYer ET AL. 1986; SeitZ ET AL. 1986; Boyacioglu \& Hettiarachchy 1995; DeXter ET AL. 1996; PAWElzIK et aL. 1998; HERMANN ET AL. 1999; Nightingale ET AL. 1999; MATthaus ET AL. 2004; PRANGE ET AL. 2005; WANG ET AL. 2005A; WANG ET AL. 2005B; TERZI ET AL. 2007; GARTNER ET AL. 2008; WANG ET AL. 2008; SIUDA ET AL. 2010). Fewer studies have reported on the impact of Fusarium infection on mixing properties of dough (measured as dough development time, dough stability, dough softening) (BocKMANN 1964; MEYer ET AL. 1986; DeXTER ET AL. 1996; PAWELZIK ET AL. 1998; Nightingale ET AL. 1999; WANG ET AL. 2005B; GARTNER ET AL. 2008), rheological dough properties (resistance to extension, extensibility, elasticity) (MEYER ET AL. 1986; PAWELZIK ET AL. 1998; Nightingale et AL. 1999; ANTES ET AL. 2001; PRANGE ET AL. 2005; WANG ET AL. 2005B; LANCOVA ET AL. 2008) as well as other dough properties (measured as dough volume, fermentation time, proofing time, proofing stability) (LANCOVA ET AL. 2008). In contrast, more studies investigated baking volume (MEYer ET AL. 1986; SEITZ ET AL. 1986; DeXTER ET AL. 1996; Nightingale ET AL. 1999; ANTES ET AL. 2001; PRANGE ET AL. 2005; WANG ET AL. 2005B; TeRZI ET AL. 2007; GARTNER ET AL. 2008; LANCOVA ET AL. 2008), which can be regarded as the ultimate parameter to evaluate baking performance of a flour and end-use quality. A few authors also reported on the influence on further baking properties (crumb and crust color, crumb structure, shape) (BOCKMANN 1964; DEXTER ET AL. 1996; WANG ET AL. 2005B; TERZI ET AL. 2007)

While parameters indicating the processing quality of wheat have been investigated by a bigger number of researchers, only a few of them focused on the impact of Fusarium infection on single grain or flour components other than total protein. Most studies have focused on the content and properties of starch e.g. starch damage, pasting properties, amylose content (MEYER ET AL. 1986;

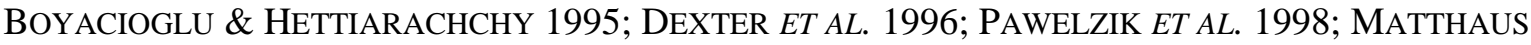
ET AL. 2004; WANG ET AL. 2005A; SIUDA ET AL. 2010) which presents the major component of wheat grain. Others investigated carbohydrates other than starch were sugars ((non-)reducing sugars, maltose, sucrose) (MEYER ET AL. 1986; BOYACIOGLU \& HETTIARACHCHY 1995; PAWELZIK ET AL. 1998; WANG ET AL. 2005A), and major cell wall components (cellulose, hemicelluloses) (HAMilton \& TRENHOLM 1984; BoyaCiOGLU \& HetTiARACHCHY 1995; MATthaUS ET AL. 2004; 
WANG ET AL. 2005A). A few studies also investigated quantitative and qualitative changes in protein composition whereas the focus mainly lay on gluten composition (BECHTEL ET AL. 1985; MeYer ET AL. 1986; BOyACIOGLU \& HetTiARACHCHY 1995; DeXTER ET AL. 1996; Nightingale ET AL. 1999; ANTES ET AL. 2001; PRANGe ET AL. 2005; WANG ET AL. 2005B; EgGert ET AL. 2010). Only four studies reported on changes in lipid content and lipid composition, including single fatty acids (HAMilton \& TRENHOlm 1984; Meyer ET AL. 1986; Boyacioglu \& HeTtiarachChy 1995; WANG 2004) which is most likely a result of the minor role of lipids in grain (1.5-2.5\% of dry matter) however not necessarily insignificant role in gas-holding capacity of dough (BROOKER 1996; BELITZ ET AL. 2009).

Since the results of the respective studies are used in the discussion (chapter 5.2 and 5.3) for comparison with our own results and are then for that purpose described in more detail, at this point only a short summary of the most important findings of the above mentioned studies is given.

Several studies observed a reduced milling value of FHB damaged wheat. While flour yield decreases, most researchers found higher ash contents in flours milled from Fusarium damaged wheat which resulted in a darker flour color equal to a loss of brightness. MEYER ET AL. 1986 even reported an adverse affect on flour odor. Regarding flour properties, results were contradictory. Researcher found an increase, a decrease, as well as no effect of Fusarium infection on protein content, sedimentation value, wet gluten, falling number, and water absorption. Mixing properties of dough were generally found to be weaker. In addition, dough was reduced in strength, stickier and therefore more difficult to handle. LANCOVA ET AL. 2008 recently recorded higher dough volume and a longer fermentation time in wheat flour with higher DON levels measured with fermentograph. Dough resistance and proofing time recorded with maturograph increased whereas proofing stability, also measured with maturograph, decreased.

As for baking properties, after comparison of results from different studies, it was apparent that impact of Fusarium infection is not clear yet, since either an increase or a decrease of baking volume was observed as well as no effect. FinNEY 1954 (cited in SEITZ ET AL. 1986) and SEITZ ET AL. 1986 described the crumb color of Fusarium contaminated bread as unsatisfactory. Crumb and crust color became darker in bread made from heavily Fusarium infected wheat compared to less infected samples (BOCKMANN 1964; WANG ET AL. 2005B). BOCKMANN 1964 noticed bigger pores in loaves baked from Fusarium contaminated wheat whereas DEXTER ET AL. 1996 could not observe an effect of Fusarium damage on crumb structure. Loaf shape also changed in an undesired manor (WANG ET AL. 2005B).

Changes of quality parameters have been tried to explain by changes in the composition of grain and flours after Fusarium infection whereas results were not as contradictory as for processing quality, which is probably due to the smaller number of studies published investigating single grain components. Starch content of grain (PAWELZIK ET AL. 1998; MATTHAUS ET AL. 2004; SiUdA ET AL. 
2010) and pasting properties of starch were reduced (WANG ET AL. 2005A) while content of reducing sugars increased (MEYER ET AL. 1986; BOYACIOGLU \& HETTIARACHCHY 1995; PAWELZIK ET AL. 1998). Regarding protein composition, all investigators observed a quantitative change after Fusarium infection, however by means of different separation methods including, SDS-PAGE, Kjedahl principle, RP-HPLC, SE-HPLC, and turbidimetry which makes a direct comparison of investigated protein fractions difficult. None of these studies (except EGGERT ET AL. 2010) have investigated gluten fractions and subfractions separated according to the detailed classification of WIESER 2007 (Fig 3) and which have been demonstrated to correspond well to dough, gluten, and baking properties.

Observed changes in wheat quality and biochemical composition of flour have been assumed to have resulted to a large extend from changes in enzyme activity after Fusarium infection. Some authors measured the activity of amylase, protease, and cell wall degrading enzymes (cellulase xylanase, 1,3-ß-glucanase) and found it increased in Fusarium infected grain (MEYER ET AL. 1986; DeXTer ET AL. 1996; PAWElZiK eT AL. 1998; Nightingale ET AL. 1999; Matthaus ET AL. 2004; WANG ET AL. 2005A; WANG ET AL. 2005B). Biochemical changes observed in wheat kernels after Fusarium infection were also examined by means of microscopic studies. Fusarium infected wheat kernels investigated by electron microscopy showed already in lightly infected kernels the presence of fungal hyphae in pericarp, aleuron layer, endosperm, and the penetration of cell walls. Heavily infected kernels consisted mainly out of the outer kernel layers and showed nearly a complete loss of storage protein and starch granules in endosperm (BECHTEL ET AL. 1985; MEYER ET AL. 1986; NigHTINGALE ET AL. 1999). A decrease in staining storage proteins and a change in starch granule surface examined with means of light microscopy supported the hypothesis of enzymatic degradation of protein, starch, and other kernel components during Fusarium infection (BECHTEL ET AL. 1985; SEITZ \& BECHTEL 1985; WANG ET AL. 2005A).

\subsubsection{Assessment of Fusarium infection in wheat}

One crucial aspect about the investigation of the impact of Fusarium infection on wheat quality is how intensity of Fusarium infection is defined. Studies that reported on the respective topic have assessed Fusarium damage and their investigated material in several ways. This may lead to a limited comparability of the results and may partly explain contradictory results gained for several quality parameters (chapter 1.1.2).

The major proportion of authors cited in chapter 1.1.2 used wheat samples that had been separated into several kernel fractions, according to the occurrence and severity of Fusarium symptoms and the resulting change of morphological kernel features such as shape, color, and weight (BECHTEL ET AL. 1985; SeITZ \& BeChTEl 1985; SeITZ ET AL. 1986; BOYACIOGLU \& HeTtIARACHCHY 1995; DeXTER ET AL. 1996; JONES \& MiRocha 1999; Nightingale ET AL. 1999; SiUda ET AL. 2010). 
Sample separation into lightly, moderately, and severely infected kernels basically followed individual classification procedures. E.g. BECHTEL ET AL. 1985 and BOYACIOGLU \& HETTIARACHCHY 1995 each hand-picked three kernel categories while SIUDA ET AL. 2010 subdivided four kernel categories by self-defined degree of kernel infestation. Others used composite samples with varying degrees of Fusarium damaged kernels (FDK) (SEITZ ET AL. 1986; DEXTER ET AL. 1996; JONES \& MiROCHA 1999). DON levels of the respective samples were determined in most cases additionally. According to these, DON levels of lightly infected samples (kernels) ranged from $0.0-2.5 \mathrm{mg} \mathrm{kg}^{-1}$, in moderately infected samples (kernels) from 0.4-22.7 mg $\mathrm{kg}^{-1}$, and in severely infected samples (kernels) from $22.7-113.0 \mathrm{mg} \mathrm{kg}^{-1}$, indicating that equal sample classification by morphological kernel features resulted in a wide range of DON concentrations in the investigated material between studies. During wheat processing, the removal of severely and moderately infected kernels by cleaning procedures is possible to a certain degree (see chapter 1.1.1.). Therefore, the separate analysis of processing quality and biochemical composition of single moderately to severely infected wheat kernels in comparison to a control or composite samples with high percentage of FDK allows for the exemplified demonstration of Fusarium damage on grain but rather lacks practical relevance. First, a grain lot contains a mixture of all kernel classes. Second, marketability of wheat in Northern America and the EU is limited by the percentage of FDK (DEXTER \& NOWICKI 2003; COMMISSION REGULATION (EC) NO 824/2000). In addition, in the EU unprocessed wheat must not contain more than $1.25 \mathrm{mg} \mathrm{kg}^{-1} \mathrm{DON}$ (COMMISSION REGULATION (EC) No 856/2005). Most of the studies investigated wheat samples and kernels that exceeded these values manifolds. e.g. NightingALE ET AL. 1999 compared clean wheat that contained $0.5 \mathrm{mg} \mathrm{kg}^{-1}$ DON with Fusarium damaged wheat that comprised 88.0-113.0 $m g \mathrm{~kg}^{-1}$ DON.

A large number of studies described the Fusarium infection exclusively by the DON concentration of grain partly using wheat samples exceeding $\mathrm{EU}_{\mathrm{MAX}}$ up to 24-fold (HAMILTON \& TRENHOLM 1984; ANTeS et AL. 2001; Matthaus eT AL. 2004; PRANGe eT AL. 2005; Terzi ET AL. 2007; LANCOVA ET AL. 2008). A smaller number of authors described Fusarium intensity by visual disease assessment in the field by means of different rating scales measuring either disease incidence (MEYER ET AL. 1986; PAWELZIK ET AL. 1998; HERMANN ET AL. 1999) or disease severity (GARTNER ET AL. 2008). Corresponding DON levels were only determined by HERMANN ET AL. 1999 and GARTNER ET AL. 2008. Since DON levels in harvested grain and visual disease are not always closely correlated (DEXTER \& NOWICKI 2003) it is difficult to compare the results of these studies with the studies that only detected DON. One working group even used an enzyme-linked immunosorbent assay (ELISA) to determine the degree of Fusarium infection by soluble Fusarium protein and subdivides sample material by means of this method (WANG 2004; WANG ET AL. 2005A; WANG ET AL. 2005B; WANG ET AL. 2008). However, they neither assessed visual disease nor mycotoxin content of grain which makes comparison with other studies difficult. Yet, since 
Fusarium infection of wheat in this study was provoked by artificial inoculation with a high concentration of macroconidia from F. culmorum, it can be assumed that DON concentration in grain was also high.

Aside from the aspect of assessment of Fusarium infection and preparation of sample material of wheat used for quality determination, two other aspects have to be considered. Most studies used artificial inoculation in order to gain Fusarium infected wheat, which is also probably the explanation for partly very high DON levels in these studies. Therefore, generally $F$. culmorum (MeYer ET AL. 1986; PAWElziK ET AL. 1998; MAtThaus et AL. 2004; WANG 2004; WANG ET AL. 2005A; WANG ET AL. 2005B; GARTNER ET AL. 2008; WANG ET AL. 2008; SiUdA ET AL. 2010), a spore mixture (ANTES ET AL. 2001; PRANGE ET AL. 2005; LANCOVA ET AL. 2008) or F. graminearum (BOYACIOGLU \& HeTtiARACHCHY 1995; HERMANN ET AL. 1999; ANTES ET AL. 2001) was used. Since it`s known that different Fusarium spp. prefer different growing conditions and also interact with each other (XU ET AL. 2007), it can be assumed that fungal biomass differed widely between the respective studies. Furthermore, the major proportion of the studies used wheat samples conducted in field trials with low amount of factor levels for experimental factors involved. In a number of studies just one growing season (and more than one cultivar) (DEXTER ET AL. 1996; NightingaLE ET AL. 1999; TERZI ET AL. 2007; GARTNER ET AL. 2008; LANCOVA ET AL. 2008) or just one cultivar were investigated (PAWELZIK ET AL. 1998; MATTHAUS ET AL. 2004; WANG 2004; WANG ET AL. 2005A; WANG ET AL. 2005B). Other studies used composite samples partly coming from harvest surveys where precise growing conditions are therefore not known (HAMILTON \& Trenholm 1984; Bechtel et AL. 1985; SeitZ et AL. 1985; SeitZ et al. 1986; JONES \& MirochA 1999). BOYACIOGLU \& HETTIARACHCHY 1995 cultivated one spring wheat cultivar under greenhouse conditions. These studies could consequently not consider the abundant number of possible interactions between environmental conditions, cultivars, and agricultural practices such as crop rotation, fungicide treatment, fertilization, and tillage which might have an impact on the occurrence of FHB and on wheat quality and grain composition as well.

All together, this underlines the need for a multifactorial field trial over several growing seasons where natural Fusarium infection occurs as a result of different environmental conditions and agricultural practices and where the impact of Fusarium infection on quality parameters of wheat and important flour components can be evaluated within the context of these. Fusarium infection of wheat should be than be quantified by visual disease in the field, as well as by subsequent mycotoxin concentrations and content of fungal biomass in milling products that were gained from cleaned wheat samples that represent, as common practice, a composite of healthy kernels as well as FDK. 


\section{Objectives}

Research on the influence of Fusarium infection on processing quality of wheat and single grain constituents with functional properties seems relatively scarce compared to literature dealing with Fusarium mycotoxins, prevention strategies and epidemiology of FHB. The impact of FHB on processing quality and kernel composition was shown to be contradictory and of varying severity when comparing the results of a number of studies (see chapter and 1.1.2 and 1.1.3) which can partly be attributed to the way how Fusarium infection was quantified in the different studies and how investigated material was gained. Hardly any study presented data on more than growing season under otherwise identical growing conditions.

Therefore, in the first part of this study the objective was to make a contribution to answering the following questions:

- Which of the experimental factors (environment, cultivar, pre-crop, fungicide) of a field experiment conducted over a time period of three years influence the mycotoxin contamination in milling products (flour Type 550, whole grain flour, bran) gained from cleaned wheat?

- Which Fusarium toxins and Fusarium spp. are detectable in wheat milling products?

- Can a subsequent mycotoxin contamination of milling products already be estimated from visual rating parameters (disease intensity, disease severity, Fusarium head blight index) obtained in the field?

- How are Fusarium biomass and produced mycotoxins related in wheat milling products?

In the second part of the study the focus of the investigations lies on the impact of Fusarium infection on wheat quality traits -with focus on parameters that are commonly assessed in agricultural trade, mills, and bakeries- and flour composition - with focus on gluten proteins- while taking the following questions into account:

- Which of the experimental factors (environment, cultivar, pre-crop) influence Fusarium infection (quantified than as DON concentration), wheat quality, and composition of wheat flour Type 550?

- In what way does Fusarium spp. infection have an impact on wheat quality and flour composition (starch, protein, gluten, enzyme activity)?

- Is there a correlation between the investigated wheat quality parameters and flours components e.g. gluten proteins?

- If there is an effect of Fusarium spp. infection on wheat quality and flour composition, how high are DON levels in the respective flours? Are these samples, with regard to $\mathrm{EU}_{\mathrm{MAX}}$, still suitable for wheat processing and human consumption, respectively? 
- If there is an effect of Fusarium spp. infection on wheat quality and flour composition, is this impact relevant for practical wheat processing, particularly for bread and roll production?

Fig 4 gives an overview of possible interactions between experimental factors, Fusarium infection, chemical flour composition, and wheat quality traits that were investigated within this work. Additional information on grain yield, thousand-kernel weight, and sulfur content of flours are not shown in particular in the results sections but can be looked up in the supplementary material and are partly mentioned in the discussion.

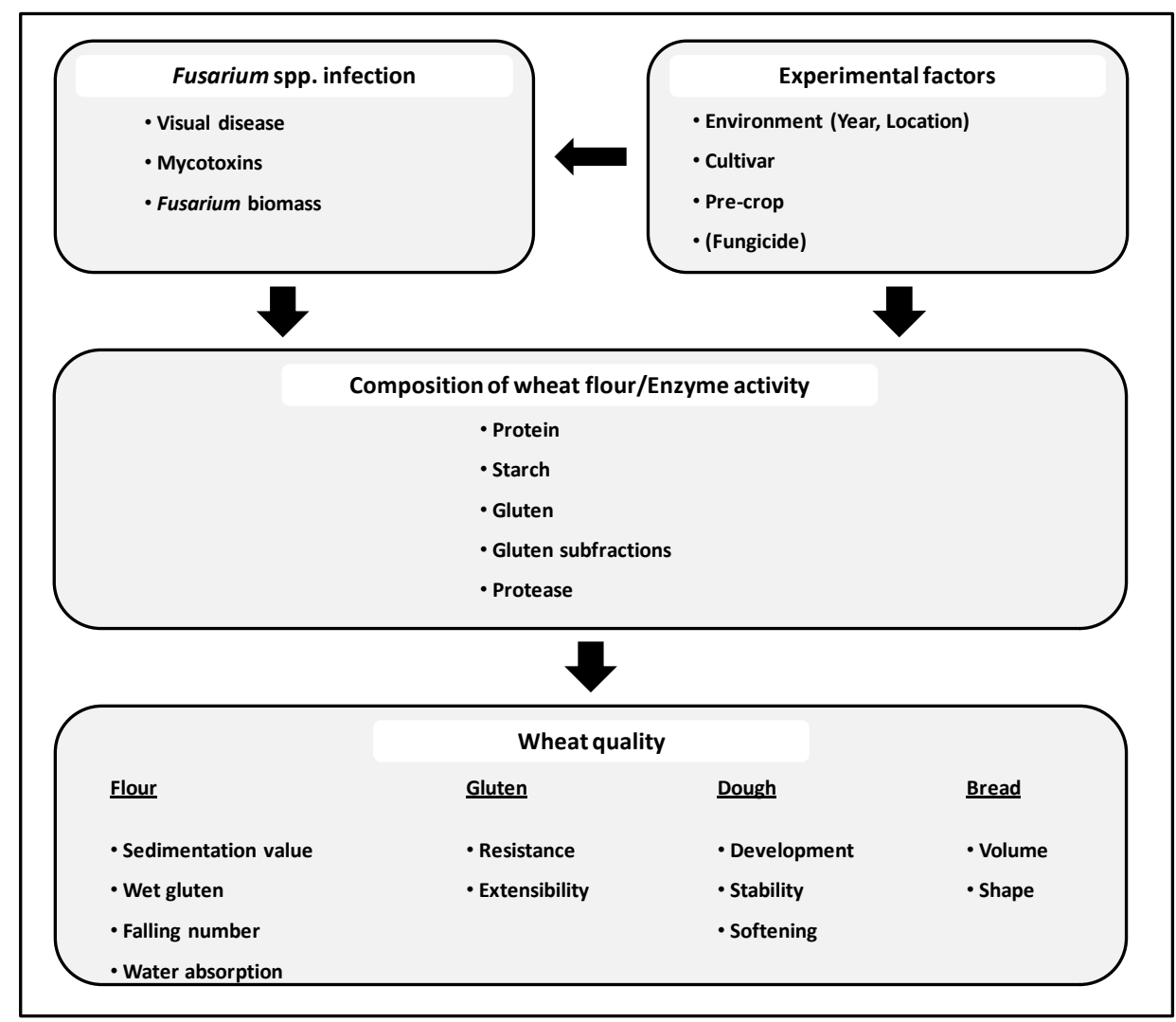

Fig 4. Scheme of investigated interactions between experimental factors, Fusarium infection, composition of wheat flour/enzyme activity, and wheat quality parameters within objectives of this study 


\section{Material and methods}

\subsection{Plant material}

\subsubsection{Field experiment}

To investigate the above mentioned a field experiment over the time period of three years (20072009) was conducted. Trial locations were situated 15 to $20 \mathrm{~km}$ north of Göttingen, in the south of Lower Saxony, Germany, and termed Torland $\left(51.36^{\circ} \mathrm{N}, 9.55^{\circ} \mathrm{E}\right)$ and Gladebeck $\left(51.37^{\circ} \mathrm{N}, 9.52^{\circ}\right.$ E) in the subsequent text. The dominant soil type on these locations is braunerde, either braunerde mixed with lime stone (Torland) or para-braunerde (Gladebeck). Torland lies $140 \mathrm{~m}$ above sea level, Gladebeck above $165 \mathrm{~m}$, respectively. The average annual precipitation in this region is 645 mm (WSG 2003). The trial design was conducted as split-split-split plot including pre-crop, cultivar, and fungicide treatment as experimental factors. A detailed description of the trail was already given by GÖDECKE 2010. Detailed information about weather conditions around wheat anthesis (May-July) in the respective years can be viewed in the supplementary material (Fig 30) and was gained from the Weather Station Göttingen (WSG 2010, 51.63 $\mathrm{N}, 9.86^{\circ} \mathrm{E}, 171 \mathrm{~m}$ above sea level). Pre-crops were winter wheat, (forage) maize, and sugar beet which are commonly grown crops in Lower Saxony and Germany. To enhance natural Fusarium spp. infection, reduced tillage was applied. Subsequently grown winter wheat cultivars (cv.) were cv. Centrum and cv. Ritmo. Both were classified as bread wheat cultivars (quality class B) and where chosen because they differed strongly in their susceptibility against Fusarium infection according to BSA 2007. Cv. Centrum generally showed a low to very low susceptibility against FHB, cv. Ritmo was highly susceptible. Both cultivars differed only slightly in their quality traits (Tab 2).

Tab 2. Selected variety descriptions of winter wheat cultivars Centrum and Ritmo (BSA 2007)

\begin{tabular}{|c|c|c|}
\hline Characteristic trait & Centrum & Ritmo \\
\hline Susceptibility against FHB & 2 & 7 \\
\hline Falling number & 6 & 7 \\
\hline Crude protein & 3 & 3 \\
\hline Sedimentation value & 6 & 5 \\
\hline Pearling value & 6 & 5 \\
\hline Ash & 5 & 5 \\
\hline Water absorption ability & 5 & 6 \\
\hline Flour yield T 550 & 7 & 6 \\
\hline Baking volume & 5 & 5 \\
\hline dominating property & 3 & 3 \\
\hline Surface properties of dough & 3 & 3 \\
\hline
\end{tabular}


Fungicide treatments were applied as described in Tab 3 and Tab 4. Fungicides were applied against fungal leaf pathogens in the conventional way at start $(\mathrm{BBCH} 31)$ and end of shooting (BBCH 39). Fungicide treatments were applied according to the project objectives of FAEN project 1 and were explained in more detail by GÖDECKE 2010. However, it should be emphasized at this point that fungicides were not applied against FHB or prevention of the disease but rather used to study the physiological effects of fungicides on the plant (in interaction with a Fusarium spp. infection).

Tab 3. Description of fungicides and growth regulator applied in field experiment

\begin{tabular}{|c|c|c|c|}
\hline Commercial name & Active ingredient & Class & Indication in wheat \\
\hline Amistar & Azoxystrobin & Strobilurine & $\begin{array}{c}\text { DTR, rusts, Septoria } \\
\text { Powdery Mildew }\end{array}$ \\
\hline Bravo & Chlorthalonil & & $\begin{array}{l}\text { Rusts, Septoria, } \\
\text { Powdery Mildew }\end{array}$ \\
\hline CCC & Chlorocholine chloride & & Growth regulator \\
\hline Corbel & Fenpropimorph & Morpholine & $\begin{array}{l}\text { Rusts, Powdery } \\
\text { Mildew }\end{array}$ \\
\hline Flexity & Metrafenone & & $\begin{array}{c}\text { Pseudocercosporella, } \\
\text { Powdery Mildew }\end{array}$ \\
\hline Opus & Epoxiconazol & Azole & $\begin{array}{l}\text { Rusts, Septoria, } \\
\text { Powdery Mildew }\end{array}$ \\
\hline Proline & Prothioconazol & Azole & $\begin{array}{c}\text { DTR, rusts, Septoria, } \\
\text { Powdery Mildew, } \\
\text { Fusarium, } \\
\text { Pseudocercosporella }\end{array}$ \\
\hline
\end{tabular}

Tab 4. Fungicide and growth regulator application in field experiment

\begin{tabular}{ccccccc}
\hline BBCH* & \multicolumn{2}{c}{ Triazole } & \multicolumn{2}{c}{ Strobilurine } & \multicolumn{2}{c}{ Chlorthalonil } \\
\hline \multirow{3}{*}{31} & splitted & CCC & splitted & CCC & splitted & CCC \\
& 0.8 & Proline & 1.0 & Amistar & 1.0 & Bravo \\
& 1.0 & Bravo & 1.0 & Bravo & 1.0 & Corbel \\
\hline \multirow{2}{*}{39} & 1.0 & Opus & 1.0 & Amistar & 1.0 & Bravo \\
& 1.0 & Bravo & 1.0 & Bravo & 1.0 & Corbel \\
* Development stage of wheat according to Federal Biological Research Centre for \\
Agriculture and Forestry, Federal Office of Plant Varieties and the Chemical Industry, values \\
show the dosage of fungicide and growth regulator in I ha ${ }^{-1}$
\end{tabular}

Further details of agricultural measures (seed density, soil preparation, etc.) can be viewed in the thesis of GÖDECKE 2010. Nitrogen fertilization regime can be viewed in the supplementary material of this thesis (Tab 65). Tab 5 gives an overview of all experimental factors and factor levels. 
Tab 5. Factors and factor levels of field experiment

\begin{tabular}{cccccc}
\hline & \multicolumn{5}{c}{ Factor } \\
\cline { 2 - 6 } & Year & Location & Cultivar & Pre-crop & Fungicide \\
\hline \multirow{3}{*}{ Factor level } & 2007 & Torland & Centrum & Winter wheat & Strobilurin \\
& 2008 & Gladebeck & Ritmo & Maize & Triazole \\
2009 & & & Sugar beet & Chlorthalonil \\
\hline
\end{tabular}

Wheat was harvested during end of July beginning of August at moisture content of 14.5-16.0\%. Each sub-subplot was harvested completely by combine harvester (Farmliner, Deutz-Fahr, Cologne, Germany) and yield was documented. Grain was harvested from 196 plots $\left(25 \mathrm{~m}^{2}\right)$ since each factor combination (cultivar $\mathrm{x}$ pre-crop $\mathrm{x}$ fungicide) was replicated 4 times. $2.5 \mathrm{~kg}$ were taken from each plot as a subsample, representing $15-20 \%$ of the yield coming from one plot.

\subsubsection{Post-harvest treatment}

\section{Cleaning and sampling}

Samples were left to air drying until grain moisture was $<14 \%$. Grain was than cleaned with standard settings of A/S Rationel Kornservice, Esbjerk, Denmark. $1.5 \mathrm{~kg}$ of each of the four plots coming from the same treatment (location $\mathrm{x}$ pre-crop $\mathrm{x}$ cultivar $\mathrm{x}$ fungicide) were combined. This created a representative harvest sample for each factor combination and randomized effects of the field trial. Therefore, fungicide application only added to variability of samples within the combination of location x pre-crop x cultivar ( 2 locations $\mathrm{x} 3$ pre-crops $\mathrm{x} 2$ cultivars $\mathrm{x} 3$ fungicides $=36$ samples) and could not be considered in the complete interaction of environment (year $\mathrm{x}$ location) $\mathrm{x}$ pre-crop $\mathrm{x}$ cultivar $\mathrm{x}$ fungicide since there existed just one observation (n) of this combination. Grain samples were stored at room temperature in burlap bags until milling.

\section{Milling and preparation of flours and bran (milling products)}

After one month of storage $100 \mathrm{~g}$ of grain of each sample were milled to whole grain flour (WGF) (ZM 100, Retsch GmbH, Haan, Germany) with a mesh of $0.5 \mathrm{~mm}$. Flour Type 550 was gained by milling $2 \mathrm{~kg}$ of grain into several milling fractions (2007: Buhler laboratory mill type MLU 202, Uzwil, Switzerland; 2008/9: Quadrumat Senior 220/380, Brabender, Duisburg, Germany) after tempering grain at room temperature for $12 \mathrm{~h}$ to moisture content of $15.5 \%$. For the determination of mineral (ash) content of milling streams, ICC STANDARD NO 104/1 was slightly modified. $5 \mathrm{~g}$ of flour was dried in drying oven (Ecocell 55, MMM Medcenter Einrichtungen GmbH, Munich, Germany) until constant weight and after that incinerated in a muffle furnance (MR 260, Heraeus Holding $\mathrm{GmbH}$; Hanau, Germany) for $4 \mathrm{~h}$ at $900^{\circ} \mathrm{C}$. Determination was replicated at least two times. Ash content was calculated on the basis of dry matter (DM). Than milling streams were mixed to gain an average ash content of $0.55 \%$. Flours that contain an ash content from $0.51-0.63 \%$ are termed flour Type 550 according to DIN 10355. All of the bran (30-35\% of grain) obtained from milling flour Type 550 was collected and milled to smaller particle size (ZM 100, Retsch 
GmbH, Haan, Germany) with the mesh of $0.5 \mathrm{~mm}$. Over three years, a total $\mathrm{n}$ of $108 \mathrm{WGF}$, Type 550 , and bran were gained each.

\section{Storage}

Flours and bran were kept in air-tight bottles (PE) at $4-8{ }^{\circ} \mathrm{C}$ in the dark until analysis.

\subsection{Quantification of Fusarium ssp. infection}

\subsubsection{Visual disease}

Occurrence of Fusarium head blight was evaluated approximately 15-20 days after anthesis at BBCH 75 (medium milk). Fusarium head blight index (FHB index in \%) was calculated as the product of disease incidence (DI), presenting the percentage of spikes infected, and disease severity (DS), presenting the proportion of infected spikelets per infected spike, and was determined as described by WILCOXSON ET AL. 1992. FHB index can be interpreted as the average proportion of diseased spikelet per spike (FHB index $=$ DI $*$ DS). DI was determined in all three years for a total of 432 plots. Due to very few symptoms visible, DS was not determined in 2009. Therefore, FHB index could only be calculated in 2007 and 2008 for a total of 288 plots.

\subsubsection{Mycotoxins}

Mycotoxin determination was performed by means of HPLC-MS-MS by S. Limsuwan and P. Kössler in the laboratory of Molecular Phytopathology and Mycotoxin research, Department of Crop Sciences, University of Göttingen, Germany. 5 g of flours (WGF: $n=108$, Type 550: $n=$ $108)$ and bran $(n=108)$ were extracted with acetonitrile-water $(84: 16)$ in 2007 , and methanolisopropanol-water (80:5:15) in 2008 and 2009 and the extracts were cleared, defatted, concentrated and filtered as described previously by ADEJUMO ET AL. 2007. The analytes were eluted and separated by HPLC on polar modified $\mathrm{C}_{18}$ phase using a methanol-water gradient containing $5 \mathrm{mM}$ acetic acid. DON, 3-ADON, 15-ADON; NIV, FUSX, and ZEA were detected by tandem mass spectrometry using transitions described by KLOTZEL ET AL. 2006 and ADEJUMO ET AL. 2007. Calibration curves were prepared in matrix extracts using certified analytical standards and processed in the same way as the samples. For DON, limit of detection (LOD) was $0.015 \mathrm{mg} \mathrm{kg}^{-1}$; limit of quantification (LOQ) was 0.100 (2007), 0.010 (2008), and 0.050 (2009) $\mathrm{mg} \mathrm{kg}^{-1}$. For 3ADON, LOD was $0.015 \mathrm{mg} \mathrm{kg}^{-1}$, LOQ was $0.05 \mathrm{mg} \mathrm{kg}^{-1}$. For ZEA, LOD was $0.002 \mathrm{mg} \mathrm{kg}^{-1}$, LOQ was 0.025 (2007/2008) and $0.005 \mathrm{mg} \mathrm{kg}^{-1}$ (2009). LOD and LOQ applied to all milling products including flour Type 550, whole grain flour, and bran. 15-ADON, NIV, and FUSX were not detected in any of the samples. Mycotoxin content of flours and bran is usually presented in $\mathrm{mg} \mathrm{kg}^{-}$ ${ }^{1}$, except for Tab 7 where $\mu \mathrm{g} \mathrm{kg}^{-1}$ is used in the context of the other toxins. All values are based on DM. 


\subsubsection{Fusarium biomass}

Fusarium biomass was assessed as $F$. graminearum and F. culmorum DNA (Fusarium DNA) by real-time PCR and was performed in the laboratory of Molecular Phytopathology and Mycotoxin research, Department of Crop Sciences, University of Göttingen, Germany. DNA from $F$. graminearum and F. culmorum was extracted from $100 \mathrm{mg}$ of flour (WGF: $\mathrm{n}=108$, Type 550: $\mathrm{n}=$ $108)$ and bran $(\mathrm{n}=108)$ material using the modified CTAB protocol and purified by polyethylene glycol precipitation as described by BRANDFASS \& KARLOVSKY 2008. Real-time PCR for $F$. culmorum was performed as described previously by BRANDFASS \& KARLOVSKY 2006. The realtime PCR for $F$. graminearum was performed under identical conditions except that the $\mathrm{MgCl}_{2}$ concentration was set to $2.5 \mathrm{mM}$. Standards of fungal DNA were combined with plant DNA extracted from flour samples free of Fusarium spp. in order to simulate the effects of the plant matrix on the PCR. The limit of quantification for F. culmorum was $500 \mathrm{pg}$ fungal DNA g ${ }^{-1}$ flour. For $F$. graminearum, the LOQ was the same in 2007 and 2008. In 2009, the LOQ was $300 \mathrm{pg} \mathrm{g}^{-1}$ flour. The limit of detection has not been determined. DNA content of $F$. graminearum ( $F g$ DNA) and $F$. culmorum ( $F c$ DNA) in flours and bran is presented in $\mu \mathrm{g} \mathrm{kg}^{-1}$. All values are based on DM.

\subsection{Determination of quality parameters}

\subsubsection{Protein content}

Nitrogen (N) content of WGF and flour Type 550 (2009) was determined according to Dumas principle from $100 \mathrm{mg}$ dried flour by C/N analyzer (Vario MAX CN Elementar Analysensysteme GmbH, Hanau, Germany). N of 100 mg dried of flour Type 550 from 2007 and 2008 was analyzed with elemental analyzer (Elementar Vario EL, Elementar Analysensysteme GmbH, Hanau, Germany). Quantitative $\mathrm{N}$ determination was performed in the laboratory of the Institute of Soil Science, Department of Crop Sciences, University of Goettingen, Germany and at the Institute of Soil Science, Leibniz University of Hannover, Germany. Protein content (PC) was calculated according to ICC No. 105/2 ( $\mathrm{N} \times 5.7)$. PC of WHG and flour Type 550 is referred to as $\mathrm{PC}_{\mathrm{WGF}}(\mathrm{n}=$ 108) and $\mathrm{PC}_{\text {Type } 550}(\mathrm{n}=108)$.

\subsubsection{Wet gluten content, sedimentation value, falling number}

Wet gluten content $(\mathrm{WG})$ of flour Type $550(\mathrm{n}=108)$ was determined by following standard procedures described by ICC STANDARD NO. 106/2. Sedimentation value (SV) of flour Type 550 ( $n=108$ ) was determined with Sodium Dodecyl Sulfat (SDS) test according to ICC STANDARD No. 151. Hagberg falling number $(\mathrm{FN})$ of WGFs $(\mathrm{n}=108)$ was measured according to ICC STANDARD NO. 107/1 with Falling Number System FN1200 (Perten Instruments, Huddinge, Sweden). 


\subsubsection{Water absorption and mixing properties of dough}

In 2007, water absorption (WA) and dough properties of flour Type 550 (2007: $\mathrm{n}=36,2008 / 9: \mathrm{n}=$ 24 each) were obtained by using a valorigraph (Type FQA-205, Metefem, Budapest, Hungary) similar to the Brabender farinograph using modified ICC STANDARD NO. 115/1. Obtained valorigrams were analyzed manually. In 2008 and 2009 dough properties were gained by use of Farinograph (Brabender®, No. 901368, type 810105 001, Duisburg, Germany). Farinograms were analyzed with Brabender® Farinograph Version 4.0.3. Each measurement was repeated three times. WA of flour is the volume of water required to produce dough with a maximum consistency of $500 \mathrm{VU}$ or $500 \mathrm{FU}$, respectively. WA is expressed as a percentage (\%), meaning ml per $100 \mathrm{~g}$ of flour at $14 \%$ moisture content. Mixing behavior of dough prepared from these flours is characterized by dough development time (DDT), dough stability (DST), and degree of softening (DS). DDT ( $\mathrm{min}$ ) indicates the time from the moment where water is added until dough reaches its maximum consistency. The time where the dough maintains its maximum consistency is indicated by DST ( $\mathrm{min}$ ). DS (VU/FU) expresses the difference in dough consistency between maximum consistency and consistency 12 min after maximum.

\subsubsection{Microbaking test}

Dough production for microbaking test was done according to the following recipe: $50 \mathrm{~g}$ flour Type 550 (corrected to $14 \%$ moisture content) were mixed with $1 \%$ sucrose, $1 \%$ fat, $1.5 \%$ salt, $5 \%$ fresh yeast, and $0.002 \% \mathrm{~L}$-ascorbic acid based on flour weight. Than the water amount was added that was obtained with Valorigraph or Farinograph (see chapter 3.3.3) before. Dough preparation followed procedures of Rapid-Mix-Test (RMT). Dough was mixed for 2 min at $30{ }^{\circ} \mathrm{C}$ and proofed for $20 \mathrm{~min}$ at $30^{\circ} \mathrm{C}$ in a water saturated atmosphere (Ecocell 55, MMM Medcenter Einrichtungen $\mathrm{GmbH}$, Munich, Germany). Dough was divided into five pieces of equal weight and relaxed for further three minutes. In order to remove air bubbles, dough balls were formed with a noodle machine (model Atlas 150, Marcato, Italy) and rolled into a log shape. Thereafter, pieces were proofed again for $45 \mathrm{~min}$. Baking was performed for $12 \mathrm{~min}$ at $240{ }^{\circ} \mathrm{C}$ (electric furnance, AEG Haustechnik, Nuernberg, Germany) as described by KIEFFER ET AL. 1993. Baking volume (BV) was measured after loaves had cooled by rapeseed displacement (SEIBEL 1985); loaf dimensions, length (LL), height (LH), width (LW) by digital slide gauge (Digital caliper 0-150 mm, WK 1020 $\mathrm{SK})$. BV is expressed in $\mathrm{ml} 100 \mathrm{~g}^{-1}$ flour, loaf dimensions in mm. $\mathrm{n}$ was 36 in 2007 and 24 in 2008 and 2009, respectively.

\subsubsection{Micro-extension test on gluten}

Determination of gluten properties of Fusarium infected wheat flour was acquired in the context of the Bachelor thesis of J. Schelle (SCHELLE 2010). For flour Type 550 from 2007, wet gluten was determined according to ICC STANDARD NO. 106/2. Afterwards, wet gluten was centrifuged for 5 
min at $5000 \mathrm{rpm}$, placed in a teflon form base and relaxed for $40 \mathrm{~min}$ at $30^{\circ} \mathrm{C}$ in water saturated atmosphere (Ecocell 55, MMM Medcenter Einrichtungen GmbH, Munich, Germany) as described by KIEFFER ET AL. 1998. Measurement of gluten extensibility was performed with the SMS/Kieffer Doug and Gluten Extensibility Rig and the Texture Analyser (TA) (TA-XT2, Stable Micro Systems, Surrey, England). The test procedure of micro-extension followed basically the description of KIEFFER ET AL. 1981 using a $25 \mathrm{~kg}$ load cell. The precise settings were: test speed 3.3 $\mathrm{mm} \mathrm{s}^{-1}$, distance $140 \mathrm{~mm}$, trigger force $5 \mathrm{~g}$, data acquisition rate: $200 \mathrm{pps}$.

For each sample wet gluten was extracted twice, and from each wet gluten sample three to four gluten strips were stretched until rupture according to the description of the instruction manual (SMEWING 1995). Obtained graphs of gluten extension were analyzed with Texture Expert Version 1.22. Peak force, which corresponds to resistance to extension $\left(\mathrm{R}_{\mathrm{MAX}}\right)$, and the distance at which the peak force occurs were measured. $\mathrm{R}_{\mathrm{MAX}}$ is presented in N, extensibility (EXT) in mm. Since gluten partly did not rupture even though stretched to maximum of $140 \mathrm{~mm}$, the ratio of $\mathrm{R}_{\mathrm{MAX}}$ to EXT $(\mathrm{N} / \mathrm{m})$ was calculated to compare and gluten properties anyhow. Stability of measurement was determined by measuring the gluten properties of a commercial wheat flour of type 550. Wet gluten was prepared three times as described before and a total of 12 gluten stripes were stretched. The average relative difference of a single measurement from the mean value of all measurements was $10.0 \%$ for $\mathrm{R}_{\mathrm{MAX}}, 10.5 \%$ for $\mathrm{EXT}$, and 13.5 for $\mathrm{R}_{\mathrm{MAX}} / \mathrm{EXT}$.

\subsection{Determination of flour composition}

\subsubsection{Starch}

For determination of starch content, flour Type $550(\mathrm{n}=108)$ were dissolved in hydrochloric acid according to ICC STANDARD NO. 123/1 and measured by polarimetric method (Polarimeter type V DrNa, Zeiss AG, Jena, Germany). Protein was precipitated with wolframatophosphoric acid. Starch content was calculated with the rotation angle of the filtrate at $589 \mathrm{~nm}$. Each measurement was repeated twice.

\subsubsection{Gluten proteins}

\section{Extraction}

Extraction of gliadins and glutenins from $100 \mathrm{mg}$ of flour Type $550(\mathrm{n}=108)$ was conducted with the solvents and procedure according to WIESER 2000. Before each extraction step, solvent and flour or sediment, respectively, were vortexed for two minutes. Albumins/globulins and gliadins were extracted at room temperature with magnet stirring (Variomag Multipoint 15, $\mathrm{H}+\mathrm{P}$ Labortechnik AG, Oberschleissheim, Germany). Extraction of glutenins was performed for $20 \mathrm{~min}$ at $60{ }^{\circ} \mathrm{C}$ in a thermomixer (Thermomixer comfort, Eppendorf AG, Hamburg, Germany) at 750 rpm. Suspensions were centrifuged (Centrifuge 5804R, Eppendorf, Hamburg, Germany) at $20{ }^{\circ} \mathrm{C}$ 
for $15 \mathrm{~min}$ at $7500 \mathrm{rpm}$. Each sample was extracted twice. Protein extracts were stored at $-20^{\circ} \mathrm{C}$ until measurement.

\section{Protein standards}

For quantification of protein fractions, gliadin and glutenin standards were prepared from commercially available gluten from wheat (Sigma-Aldrich Chemie GmbH, Steinheim, Germany) as described by EGGERT ET AL. 2011. PC of isolated gliadin and glutenin was determined by $\mathrm{C} / \mathrm{N}$ analyser as described in chapter 1.4.2. PC of gliadin and glutenin standard were 93.41 and $100 \%$ of DM, respectively. Gliadin and glutenin standards were solved and determined as described by WIESER 2000.

\section{Detection with RP-HPLC}

Quantification of gliadin and glutenin fractions followed with slight modification the description of WiEser ET AL. 1998 and EgGert ET AL. 2010. For the RP-HPLC, a PerfectSil $300 \mathrm{C}_{8} 300$ x 4.6 column (Machery-Nagel, Dueren, Germany) was used. Mobile phases were $A=0,1 \%$ trifluoroacetic acid (TFA) (Merck, Darmstadt, Germany) in $\mathrm{H}_{2} \mathrm{O}$ (v/v) (Chromanorm, VWR, Fontenay-Sous-Bois, France) and B = 0,1 \% TFA in acetonitrile (v/v) (HiPerSolv, Chromanorm, VWR; Leuven, Belgium). All solvents were of HPLC grade. $100 \mu 1$ of the aliquots of gliadin and glutenin were injected. For separation of protein fractions the gradient program shown in Tab 6 was applied.

Tab 6. Gradient program for RP-HPLC for separation of gliadin and glutenin

\begin{tabular}{ccc}
\hline Time (Min) & \% A & \% B \\
\hline 0 & 100 & 0 \\
5 & 76 & 24 \\
50 & 50 & 50 \\
54 & 10 & 90 \\
$59-70$ & 100 & 0 \\
\hline
\end{tabular}

Flow rate was $1 \mathrm{ml} \mathrm{min}{ }^{-1}$; the column temperature was set at $50{ }^{\circ} \mathrm{C}$. Chromatograms for gliadins (Fig 5) and glutenins (Fig 6) show exemplified the retention times of single subfractions. Gliadin subfractions were separated into $\omega 5-, \omega 1,2-, \alpha-, \gamma$-gliadins, whereas glutenins were separated into $\omega b$, HMW-GS, and LMW-GS. $\omega \mathrm{b}$ gliadin represents a small proportion of gliadins that are linked to the glutenins (WIESER \& SEILMEIER 1998). 


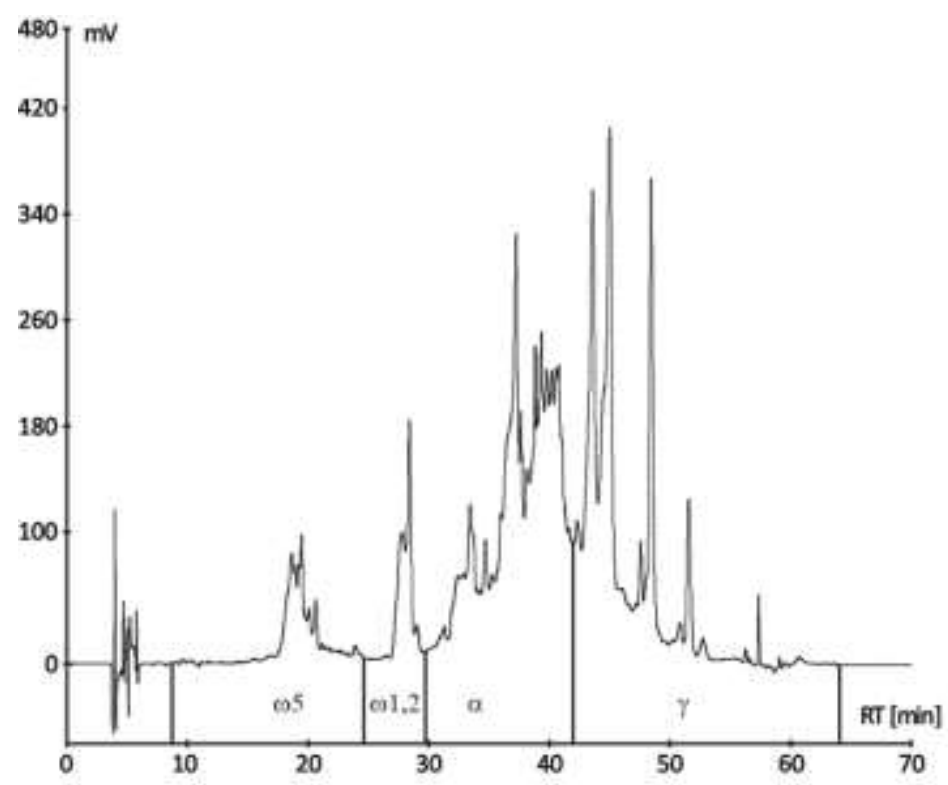

Fig 5. RP-HPLC of gliadin extract (cv. Centrum) with elution ranges for $\omega 5-, \omega 1,2-, \alpha-$, and $\gamma$-gliadins

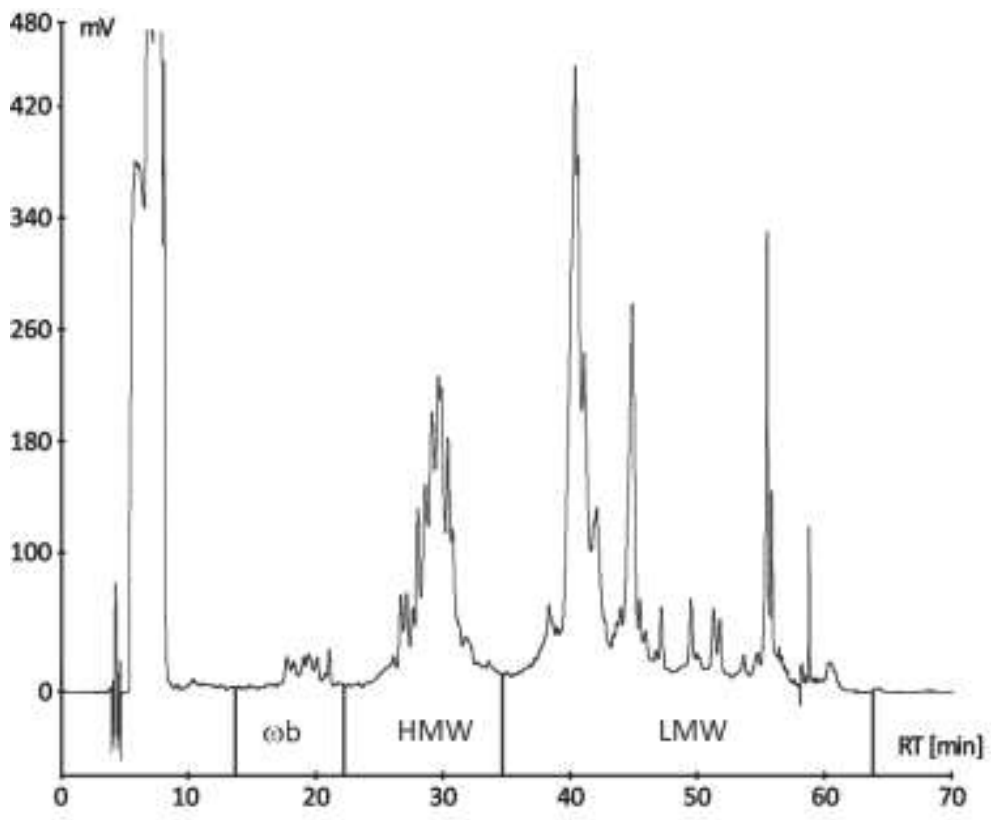

Fig 6. RP-HPLC of glutenin extract (cv. Centrum) with elution ranges for $\omega b$, HMW-GS, and LMW-GS

For the quantification of the protein fractions gliadin and glutenin standards were used. In order to eliminate the effect of starch accumulation and the adverse relationship with PC in grain, quantity of gliadin, glutenin as well as subfractions was calculated as percentage of total protein in flour Type 550 (\% Protein).

HPLC system (MZ Analysentechnik, Mainz, Germany) consisted of autosampler (Jasco AS-2051 Plus Intelligent Sampler), oven (Jasco CO-2060 Plus Intelligent Column Thermostat), degaser (Jasco DG-2080-54 4-Line-Degaser), pump (Jasco PU-2080 Plus Intelligent HPLC Pump), gradient mixer (Jasco LG-2080-04 S), and detector (Jasco MD-2015 Plus Multiwavelength Detector). 
Obtained chromatograms were analyzed by Jasco ChromPass Chromatography Data Systems Version 1.8.6.1.

\subsection{Protease activity}

Protease activity (PA) was determined for flours Type 550 from $2007(n=36)$.

\section{Extraction}

$400 \mathrm{mg}$ of flour Type 550 was extracted with $1.5 \mathrm{ml}$ sodium acetate buffer $\left(50 \mathrm{mM}\right.$, pH 5.5) at $4^{\circ} \mathrm{C}$ for $12 \mathrm{~h}$ by shaking overhead. After centrifugation (10 $000 \mathrm{rpm}, 15 \mathrm{Min}$ ), aliquots were stored at $20^{\circ} \mathrm{C}$. Each sample was extracted at least twice.

\section{Synthesis of azogelatin}

Synthesis of azogelatin followed the procedure decribed by JONES ET AL. 1998, except that gelatin from porcine skin (high gel strength, Fluka, St. Louis, USA) bloom $250 \mathrm{~g}$ was used.

\section{In-solution assay with azogelatin}

In-solution assay with azogelatin followed basically the descriptions from JONES ET AL. 1998. 0.17 $\mathrm{ml}$ of enzyme extract was mixed with $0.17 \mathrm{ml}$ ammonium acetate $(0.1 \mathrm{M}, \mathrm{pH} 5.5), 0.017 \mathrm{ml}$ Cysteine $(0.1 \mathrm{M})$. To start the reaction, $0.5 \mathrm{ml}$ of azogelatin $(1 \%(\mathrm{w} / \mathrm{v}))$ was added. In order to simulate similar temperature conditions as present during dough mixing in Valorigraph/Farinograph, samples were incubated at $30^{\circ} \mathrm{C}$ with $300 \mathrm{rpm}$ for $1 \mathrm{~h}$ (Thermomixer comfort, Eppendorf AG, Hamburg, Germany). At the end of incubation, reaction was stopped by adding $0.857 \mathrm{ml}$ tricloric acid (25\% (v/v) TCA) and incubating samples on ice for $15 \mathrm{~min}$. After centrifugation for $10 \mathrm{~min}$ at $14000 \mathrm{rpm}$ and $4^{\circ} \mathrm{C}$ (Centrifuge 5804R, Eppendorf, Hamburg, Germany) the supernatant was measured photometrically in a microcuvette at $440 \mathrm{~nm}$ (Spectrophotometer, Hewlett Packard 8453, Palo Alto, USA). For blank, solutions were incubated without enzyme extract; enzyme extract was added after TCA had been added. For each extract, one blank was prepared; in-solution assay with enzyme extract was repeated three times.

\subsection{Additional analyses}

\subsubsection{Determination of yield components}

Grain yield (GY) (dt ha ${ }^{-1}$ ) was calculated by considering the harvest of a total plot $\left(25 \mathrm{~m}^{2}\right)$. Thousand-kernel weight (TKW) was conducted by measuring the weight of 100 randomly picked intact kernels. Measurement was repeated four times. TKW (g) was calculated on moisture content of $14 \%$. Both measures were determined as additional information and not presented in the results but in the supplementary material (Tab 66). 


\subsubsection{Sulfur and sulfur to nitrogen ratio}

Sulfur (S) content of flour Type 550 from $2007(\mathrm{n}=36)$ and $2008(\mathrm{n}=36)$ was analyzed with elemental analyzer (Elementar Vario EL, Elementar Analysensysteme GmbH, Hanau, Germany). Quantitative S determination was performed in the laboratory of the Institute of Soil Science, Leibniz University of Hannover, Germany. S content of flours was determined as additional information and not presented in the results but in the supplementary material (Tab 66). The same applies to the calculated ratio of N/S. The purpose of the investigation was to rule out sulfur deficiency in grain.

\subsection{Statistical analysis}

Data analyses were performed by SAS version 9.2, SAS Institute, Cary, NC, USA and STATISTICA version 8.0, StatSoft, Inc., Tulsa, OK, USA. Graphs were conducted by means of SigmaPlot version 10.0, Systat Software GmbH, Erkrath, Germany.

To investigate the factors influencing DON and $F g$ DNA, the experimental design was considered to be completely randomized since samples of four plots from each treatment were combined (as described in 3.1.2). Analysis of variance (ANOVA SAS: proc mixed) was conducted with untransformed data restricting higher-order interaction effects to the number of factors minus 1 since no replication for each treatment was available. Assumptions were normal distribution and homogenicity of variance checking residuals graphically (histogram, q-q-plot, residual plot). Main factors that were considered in ANOVA were environment (as a combination of year and location), cultivar, pre-crop, fungicide and milling fraction. Data of flour Type 550, WGF, and bran of each treatment were taken into account as repeated measurement of the same experimental unit. Depending on the outcome of the global $F$ test statistic, multiple comparisons of means were applied according to Tukey and Kramer. Unless not stated otherwise the significance level was $\alpha=$ 0.05 . With the objective to elucidate effects at the level $\mathrm{p}<\alpha<0.05$ effects were sliced into single factors. Data is presented graphically as bar chart with mean values (MV) and standard error (SE) of the respective treatments. For DON, for each experimental factor the severity of effect (SoE) was calculated according to KOCH ET AL. 2006, dividing the maximal MV with the minimum MV of each treatment (treatment included data of all other factors) in order to evaluate the relative importance of each factor for occurrence of DON in milling products.

To investigate the influence of environment (year $\mathrm{x}$ location), cultivar, and pre-crop on wheat quality and flour composition, ANOVA considered the data of three years. Interactions were calculated to the level of 2. Data in chapter 4.2 and 4.3 is either presented graphically as box plots where one box plots comprises six biological samples (from two locations and three fungicide treatments) or in tables where mean values (MV) and standard deviation (SD) of the respective treatments are given. Multiple comparisons of MVs were generally performed according to Tukey 
and Kramer by slicing years. For additional information, ANOVA was also performed for the separate effects of year, location, cultivar, pre-crop, and fungicide up to 3-fold interactions. SoE for the single experimental factors was calculated, as described before, in addition. Both can be looked up in the supplementary material (Tab 54-Tab 66).

In order to investigate how Fusarium infection affected wheat quality and flour composition, effect of environment, pre-crop, cultivar, and DON was tested by performing analysis of covariance (ANCOVA) whereas DON, taken as a measure for intensity of Fusarium infection, was introduced into the model as covariate and a ANCOVA strategy was performed according to LITTEL ET AL. 2006. ANCOVA included the categorical effects of environment (year x location), pre-crop, and cultivar restricting higher-order interaction effects to the number of factors minus 1.

Since in 2008, DON concentrations were very low or below LOD, it was impossible to evaluate the impact of Fusarium infection on quality parameters in the respective year. Thus, only data of 2007 and 2009 were included into ANCOVA. Since DON data of 2007 and 2009 did not exhibit normal distribution, DON data was logarithmically transformed ( $\left.\mathrm{DON}_{\mathrm{LOG}}\right)$. Zero DON values were taken into account by adding a small value (0.01) to the logarithmic function. Normal distribution of quality parameters was checked graphically (see above). If ANCOVA revealed a significant effect $(\mathrm{p}<0.05)$ of $\mathrm{DON}_{\mathrm{LOG}}$ alone or in combination with other factors this effect was further investigated by performing simple linear regressions (proc reg) with $\mathrm{DON}_{\mathrm{LOG}}$ and the respective parameter separated by the interacting factor or factor combination. Linear regressions are presented if $\mathrm{DON}_{\mathrm{LOG}}$ explained at least $50 \%$ of variability in quality parameters (coefficient of determination $\left.R^{2} \geq 0.50, p<0.05\right)$ and contained at least six observations. $R^{2}=0.50$ corresponds to correlation coefficient $\mathrm{r}$ of $\sim 0.71$ and describes a moderate relationship among target and in depended variable. Original DON data $\left(\mathrm{DON}_{\mathrm{ORG}}\right)$ of respective samples was either displayed in the tables or in the text. If there was no significant influence of DON, the covariate DON could be omitted from the model resulting in a simple ANOVA.

Relationships among quality parameters and flour components were investigated by linear regression. If $R^{2}$ was $\geq 0.50$ at a significance level $p<0.05$, correlations were presented with trend $(+/-)$ in chapter 4.5. Additionally, complete correlation matrices can be looked up in the supplementary material (Tab 62-Tab 64) 


\section{Results}

\subsection{Fusarium biomass and mycotoxins in milling products}

\subsubsection{Occurrence of Fusarium DNA and mycotoxins}

Depending on year, Fusarium ssp. and type of toxin differing levels of Fusarium DNA and mycotoxins were detected in flours and bran (Tab 7). Both Fusarium DNA and mycotoxin could be detected in all milling products. Highest Fusarium DNA and toxin concentrations were detected in 2007.

Tab 7. Range of mycotoxin and Fusarium DNA content of wheat milling products (flour Type 550, whole grain flour, bran)

\begin{tabular}{|c|c|c|c|c|c|c|c|c|c|c|}
\hline \multirow[b]{3}{*}{ Fungal DNA ( $\left.\mu \mathrm{g} \mathrm{kg}^{-1}\right)$} & \multirow[b]{3}{*}{ Year } & \multicolumn{9}{|c|}{ Milling product } \\
\hline & & \multicolumn{3}{|c|}{ Flour Type 550} & \multicolumn{3}{|c|}{ Whole grain flour } & \multicolumn{3}{|c|}{ Bran } \\
\hline & & Min & Median & Max & Min & Median & Max & Min & Median & Max \\
\hline & 2007 & 4 & 42 & 317 & 8 & 119 & 765 & $<L O Q$ & 319 & 2771 \\
\hline \multirow[t]{3}{*}{ F. graminearum } & 2008 & $<\mathrm{LOQ}$ & $<\mathrm{LOQ}$ & 10 & $<\mathrm{LOQ}$ & $<\mathrm{LOQ}$ & 18 & $<\mathrm{LOQ}$ & $<\mathrm{LOQ}$ & $<\mathrm{LOQ}$ \\
\hline & 2009 & $<\mathrm{LOQ}$ & $<\mathrm{LOQ}$ & 39 & $<\mathrm{LOQ}$ & $<\mathrm{LOQ}$ & 200 & $<\mathrm{LOQ}$ & $<\mathrm{LOQ}$ & 63 \\
\hline & 2007 & $<L O Q$ & 3 & 19 & $<\mathrm{LOQ}$ & 6 & 65 & $<\mathrm{LOQ}$ & $<\mathrm{LOQ}$ & 134 \\
\hline \multirow[t]{2}{*}{ F. culmorum } & 2008 & & - & & & - & & & - & \\
\hline & 2009 & $<\mathrm{LOQ}$ & $<\mathrm{LOQ}$ & $<\mathrm{LOQ}$ & $<\mathrm{LOQ}$ & $<\mathrm{LOQ}$ & $<\mathrm{LOQ}$ & $<\mathrm{LOQ}$ & $<\mathrm{LOQ}$ & $<\mathrm{LOQ}$ \\
\hline \multicolumn{11}{|l|}{ Mycotoxin $\left(\mu \mathrm{g} \mathrm{kg}^{-1}\right)$} \\
\hline \multirow{3}{*}{ DON } & 2007 & 312 & 1,588 & 11,843 & 197 & 1,260 & 10,237 & 506 & 2,332 & 16,437 \\
\hline & 2008 & $<L O D$ & $<L O D$ & 109 & $<L O D$ & $<L O D$ & 283 & $<L O D$ & $<L O D$ & 227 \\
\hline & 2009 & $<L O D$ & 406 & 8,416 & $<\mathrm{LOD}$ & 171 & 4,624 & $<L O D$ & 309 & 6,865 \\
\hline \multirow{3}{*}{ 3-ADON } & 2007 & $\angle L O D$ & $\angle L O D$ & 524 & $<L O D$ & $<L O D$ & 102 & $<L O D$ & $\angle L O D$ & 425 \\
\hline & 2008 & $<L O D$ & $<L O D$ & $<L O D$ & $<L O D$ & $<L O D$ & $<L O D$ & $<L O D$ & $<L O D$ & $<L O D$ \\
\hline & 2009 & & - & & $<\mathrm{LOD}$ & $<\mathrm{LOD}$ & 295 & & - & \\
\hline \multirow{3}{*}{ ZEA } & 2007 & $<L O D$ & $<L O D$ & 86 & $<L O D$ & $<L O D$ & 175 & $<L O D$ & $<L O D$ & $<L O D$ \\
\hline & 2008 & $<L O D$ & $<L O D$ & $<L O D$ & $<L O D$ & $<L O D$ & $<L O D$ & $<L O D$ & $<L O D$ & $<L O D$ \\
\hline & 2009 & & - & & $<\mathrm{LOD}$ & $<\mathrm{LOD}$ & 73 & & - & \\
\hline
\end{tabular}

Min: minimum content, Max: maximum content, DON: deoxynivalenol, 3-ADON: 3-acetyldeoxynivalenol, ZEA: zearalenone, LOD: limit of detection, LOQ: limit of quantification, "-" not analyzed, flours and bran per year: $n=36$

Total Fusarium DNA predominantly consisted of FgDNA (Tab 8). Only in 2007, both Fusarium species, $F$. graminearum and $F$. culmorum, could be detected by qPCR. The $F c$ DNA content was significantly lower than $F g$ DNA content of all milling products. In flours and bran, $F c$ DNA just made up an average proportion of approx. 8\% of total Fusarium DNA. The relationship between the two species was positive, but very weak $\left(\mathrm{R}^{2}=0.03-0.12\right)$ Therefore, for further analysis FcDNA levels will not be considered. 
Tab 8. Proportion of FgDNA and $F c$ DNA from total Fusarium DNA (FgDNA + FcDNA $=100 \%$ ) in milling products (flour Type 550, whole grain flour (WGF), bran) of 2007

\begin{tabular}{|c|c|c|c|c|c|c|}
\hline & \multicolumn{2}{|c|}{ Flour Type 550} & \multicolumn{2}{|c|}{ WGF } & \multicolumn{2}{|c|}{ Bran } \\
\hline & Fg DNA (\%) & Fc DNA (\%) & Fg DNA (\%) & Fc DNA (\%) & Fg DNA (\%) & Fc DNA (\%) \\
\hline Median & 93 & 7 & 93 & 7 & 100 & 0 \\
\hline MV & 90 & 10 & 91 & 9 & 92 & 5 \\
\hline SD & 12 & 12 & 11 & 11 & 18 & 9 \\
\hline$p$ & \multicolumn{2}{|c|}{$* * *$} & \multicolumn{2}{|c|}{$* * *$} & \multicolumn{2}{|c|}{$* * *$} \\
\hline $\mathbf{R}^{2}$ & \multicolumn{2}{|c|}{0.05} & \multicolumn{2}{|c|}{0.12} & \multicolumn{2}{|c|}{0.03} \\
\hline
\end{tabular}

MV mean value SD standard diviation, WGF whole grain flour, flours and bran: $\mathbf{n}=\mathbf{3 6}$ each, $\mathrm{p}$ significance level: $* * * p<0.001$ according to student`s pairwise t-test, $\mathbf{R}^{2}$ coefficient of determination

In all milling products, DON was the most frequently occurring and also quantitatively the most important Fusarium toxin of all toxins analyzed. Especially in 2007, up to 50\% of all Type 550 flours and bran samples surpassed the $\operatorname{EU}_{\mathrm{MaxCF}}\left(750 \mu \mathrm{g} \mathrm{kg}{ }^{-1}\right)$ at least twice. In 2007, also 3-ADON could be detected in 14, 2, and 8 samples of flour Type 550, WGF, and bran, respectively. Additionally, ZEA was found in one sample of flour Type 550 and 12 WGFs in levels exceeding the $\mathrm{EU}_{\mathrm{MaxCF}}\left(75 \mu \mathrm{g} \mathrm{kg}^{-1}\right)$. In 2008, only DON could be detected in 7, 17, and 15 samples of flour Type 550, WGF, and bran, respectively. In 2009, 13 WGFs contained 3-ADON, three contained ZEA. In none of the years of investigation, 15-ADON, FUSX or NIV could be detected in any of the milling products. Further data analysis will therefore take only DON content of milling products into account.

\subsubsection{Factors influencing FgDNA and DON}

The results for ANOVA for DON and $F$. graminearum biomass are presented in Tab 9. Most effects that showed a significant influence on DON also affected $F g$ DNA content in milling products. For both, significant effects of environment (as a combination of year and location), precrop, cultivar, fungicide, milling fraction, as well as the interactions of environment-pre-crop, environment-cultivar, environment-milling fraction, environment-pre-crop-cultivar, environmentpre-crop-milling fraction, environment-cultivar-milling fraction, environment-pre-crop-cultivarmilling fraction, pre-crop-cultivar, pre-crop-milling fraction, pre-crop-cultivar-fungicide, cultivarfungicide, and cultivar-milling fraction were observed. Additionally, for DON, the interaction of environment-fungicide, environment-pre-crop-fungicide, environment-cultivar-fungicide, environment-pre-crop-cultivar-fungicide, and pre-crop-fungicide was significant. For $F g D N A$, also a significant effect of pre-crop-cultivar-milling fraction was detected. Interestingly, interactions with fungicides did not have a significant effect on $\mathrm{FgDNA}$ in milling products, except the interaction of cultivar-fungicide, which was usually the case for DON. 
Tab 9. ANOVA for effects of environment (year, location), pre-crop, wheat cultivar, fungicide, and milling product on DON and $F g$ DNA content

\begin{tabular}{|c|c|c|c|c|c|}
\hline \multirow[b]{2}{*}{ Effect } & \multirow[b]{2}{*}{ DF } & \multicolumn{2}{|c|}{ DON } & \multicolumn{2}{|c|}{ Fg DNA } \\
\hline & & $\mathbf{F}$ & $p$ & $\mathbf{F}$ & $p$ \\
\hline Environment (E) & 5 & 261.54 & $* * *$ & 178.52 & $* * *$ \\
\hline Pre-crop (P) & 2 & 392.47 & $* * *$ & 148.36 & $* * *$ \\
\hline Cultivar (C) & 1 & 587.01 & $* * *$ & 198.93 & $* * *$ \\
\hline Fungicide (F) & 2 & 36.52 & $* * *$ & 3.60 & $* * *$ \\
\hline Milling product (MP) & 2 & 34.14 & $* * *$ & 127.85 & $* * *$ \\
\hline$E \times P$ & 10 & 56.75 & $* * *$ & 56.40 & $* * *$ \\
\hline $\mathrm{E} \times \mathrm{C}$ & 5 & 95.74 & $* * *$ & 68.89 & $* * *$ \\
\hline$E \times F$ & 10 & 7.88 & $* * *$ & 1.34 & n.s. \\
\hline $\mathrm{E} \times \mathrm{MP}$ & 10 & 14.36 & $* * *$ & 57.15 & $* * *$ \\
\hline$E \times P \times C$ & 10 & 21.94 & $* * *$ & 19.94 & $* * *$ \\
\hline$E \times P \times F$ & 20 & 3.03 & $* *$ & 0.64 & n.s. \\
\hline$E \times P \times M P$ & 20 & 5.75 & $* * *$ & 21.82 & $* * *$ \\
\hline $\mathrm{E} \times \mathrm{C} \times \mathrm{F}$ & 10 & 6.23 & $* * *$ & 2.05 & $(*)$ \\
\hline $\mathrm{E} \times \mathrm{C} \times \mathrm{MP}$ & 10 & 8.09 & $* * *$ & 25.58 & $* * *$ \\
\hline$E \times F \times M P$ & 20 & 1.81 & $(*)$ & 0.51 & n.s. \\
\hline $\mathrm{ExP} \times \mathrm{C} \times \mathrm{F}$ & 20 & 2.10 & $*$ & 1.66 & $(*)$ \\
\hline$E \times P \times C \times M P$ & 20 & 3.70 & $* * *$ & 8.73 & $* * *$ \\
\hline$E \times P \times F \times M P$ & 40 & 1.51 & $(*)$ & 0.35 & n.s. \\
\hline$E \times C \times F \times M P$ & 20 & 1.56 & n.s. & 1.21 & n.s. \\
\hline$P \times C$ & 2 & 141.37 & $* * *$ & 57.09 & $* * *$ \\
\hline$P \times F$ & 4 & 10.60 & $* * *$ & 1.59 & n.s. \\
\hline $\mathrm{P} \times \mathrm{MP}$ & 4 & 7.29 & $* * *$ & 46.26 & $* * *$ \\
\hline$P \times C \times F$ & 4 & 7.98 & $* * *$ & 4.14 & $* *$ \\
\hline$P \times C \times M P$ & 4 & 2.47 & $(*)$ & 18.98 & $* * *$ \\
\hline$P \times F \times M P$ & 8 & 1.19 & n.s. & 0.55 & n.s. \\
\hline$P \times C \times F \times M P$ & 8 & 0.60 & n.s. & 2.01 & $(*)$ \\
\hline $\mathrm{CxF}$ & 2 & 20.00 & $* * *$ & 6.14 & $* *$ \\
\hline $\mathrm{C} \times \mathrm{MP}$ & 2 & 10.40 & $* * *$ & 56.98 & $* * *$ \\
\hline$C \times F \times M P$ & 4 & 0.94 & n.s. & 2.71 & n.s. \\
\hline $\mathrm{F} \times \mathrm{MP}$ & 4 & 1.40 & n.s. & 0.97 & n.s. \\
\hline
\end{tabular}

In the following, the fixed effects of environment, pre-crop, cultivar, fungicide, and milling fraction on DON and $F g$ DNA levels will be described in detail.

\section{Single effects}

\section{Environment}

Both, DON and $F g$ DNA, were significantly influenced by the environment as a combination of location and year (Fig 7). The highest DON and $F g$ DNA levels in milling products were detected in 2007. Interestingly, while the DON content did not differ significantly between the two locations in this year, samples from Torland showed a significantly higher $\mathrm{FgDNA}$ content than those from Gladebeck. In the two following years, milling products showed significantly lower DON and FgDNA levels compared to 2007. As already described by Tab 7, in 2008, in most samples DON levels were below LOD or LOQ for $F g$ DNA, respectively. No difference between the two locations 
was observed. In 2009, an effect of location was determined, since samples from Torland contained approx. twice as much DON as those from Gladebeck, while there was no difference in $F g D N A$ content.

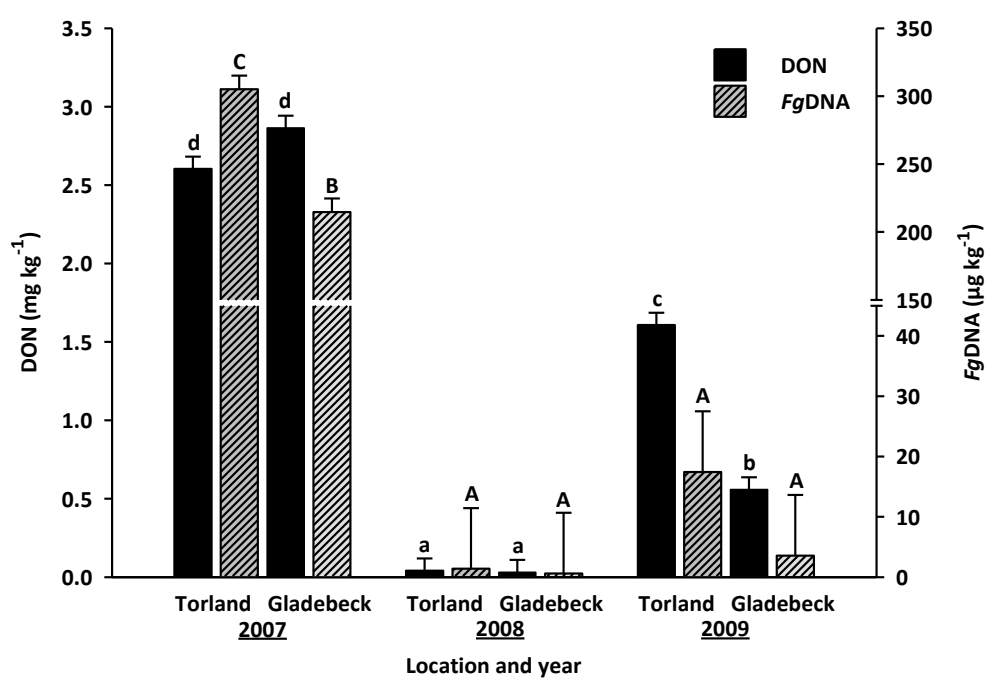

Fig 7. Effect of environment (year, location) on DON and FgDNA content of wheat milling products (flour Type 550, whole grain flour, bran) across all samples. MV $(n=54)$ with same letters are not significantly different at $p<0.05$ according to Tukey test. Error bars indicate SE.

\section{Pre-crop}

Looking at DON and $F g$ DNA levels in milling products after three different pre-crops, for both a clear descending order of maize > wheat $>$ sugar beet could be set up (Fig 8). Cereal products milled from wheat grown after maize comprised 3- to 5-fold higher DON levels than from wheat harvested after pre-crop wheat and sugar beet.

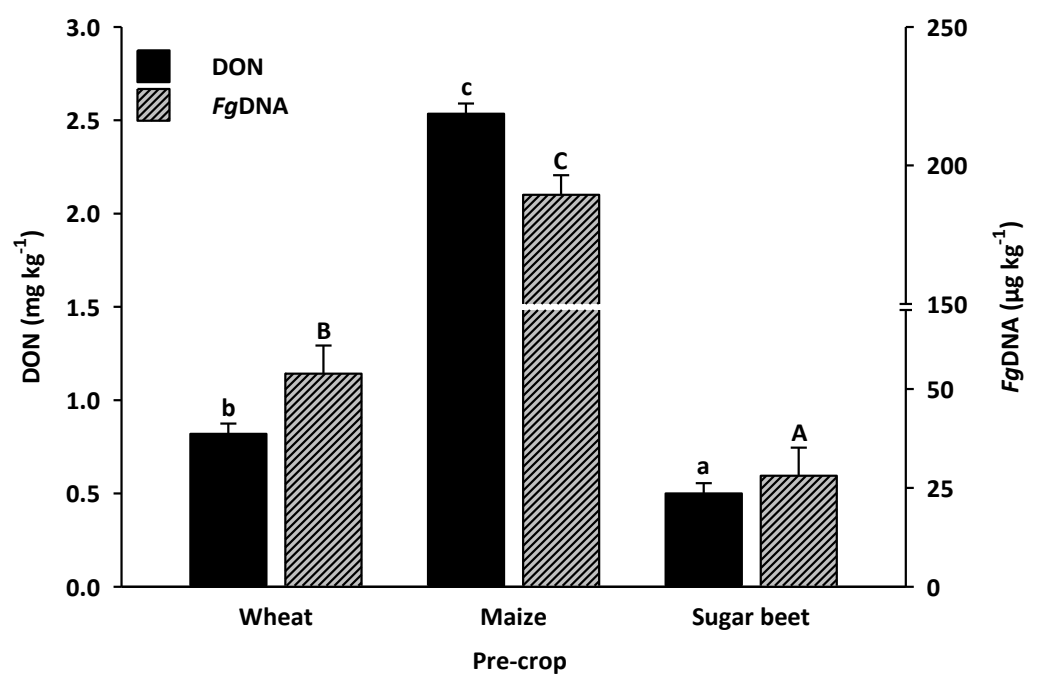

Fig 8. Effect of pre-crop on DON and FgDNA content of wheat milling products (flour Type 550, whole grain flour, bran) across all samples. $\mathrm{MV}(n=108)$ with same letters are not significantly different at $p<$ 0.05 according to Tukey test. Error bars indicate SE. 


\section{Cultivar}

Susceptibility of cultivars against FHB was reflected by their DON and $F g$ DNA levels (Fig 9). Milling products from cv. Centrum (low susceptibility) contained in average only $25 \%$ of the DON and $F g$ DNA levels detected in milling products from cv. Ritmo (high susceptibility).

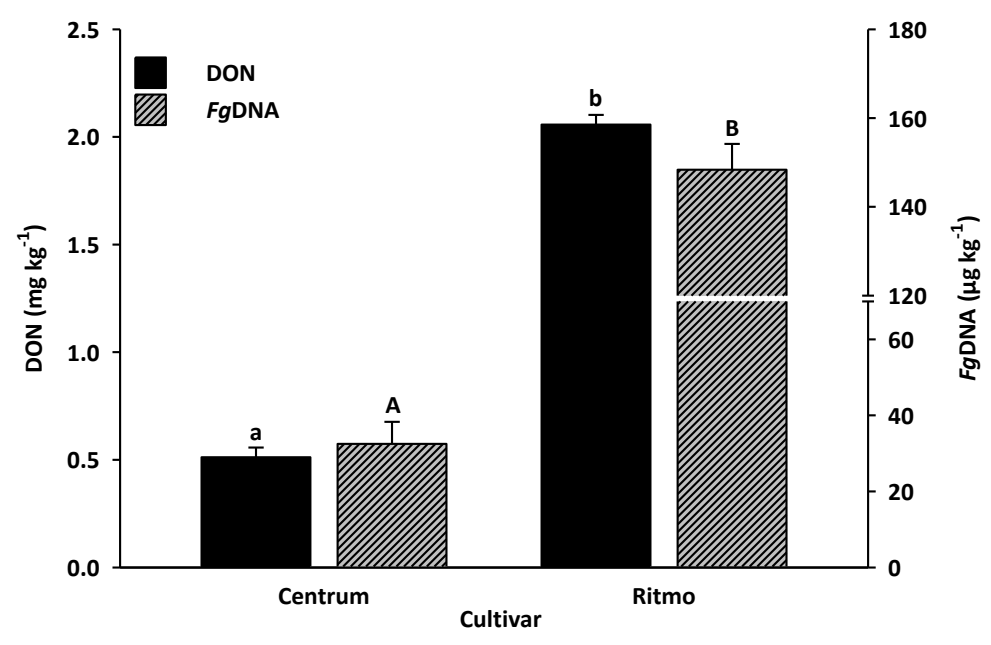

Fig 9. Effect of cultivar on DON and FgDNA content of wheat milling products (flour Type 550, whole grain flour, bran) across all samples. MV ( $n=162)$ with same letters are not significantly different at $p<$ 0.05 according to Tukey test. Error bars indicate SE.

\section{Fungicide}

Fungicide application during shooting had an effect on DON and $F g$ DNA levels in the harvested grain and milling products as well (Fig 10). While triazole application clearly resulted in significantly lower DON contents, and when compared to strobilurin treatment, also in significantly less $F g$ DNA, milling products gained from chlorthalonil and strobilurin treatment showed similar amounts of DON and $F g$ DNA.

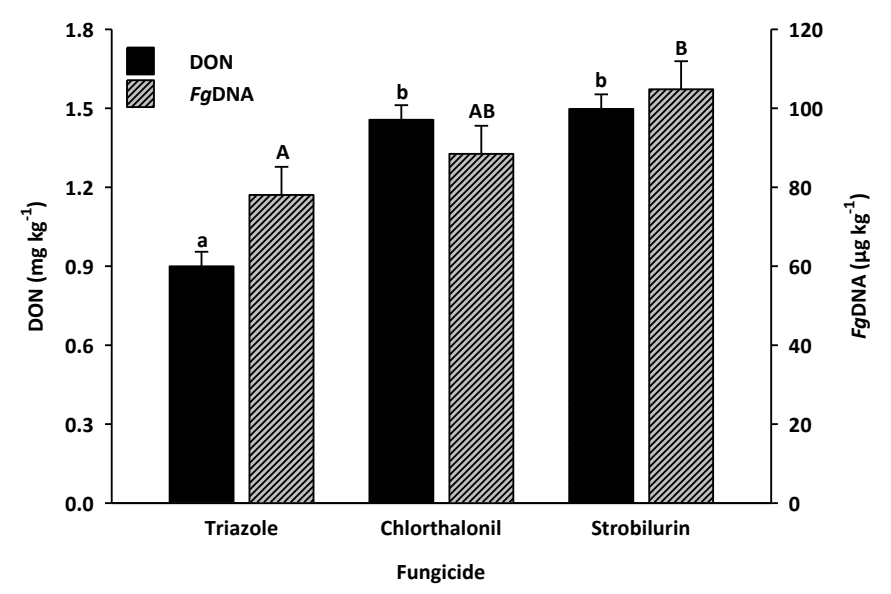

Fig 10. Effect of fungicide treatment on DON and FgDNA content of wheat milling products (flour Type 550 , whole grain flour, bran) across all samples. $M V(n=108)$ with same letters are not significantly different at $p<0.05$ according to Tukey test. Error bars indicate SE 
DON and FgDNA levels also strongly depended on the milling product (Fig 11). For $F g D N A$ amounts, a clear descending order of bran > WGF > flour Type 550 was determined. For DON levels, rather unexpected, the order was bran = flour Type $550>$ WGF. While obviously in bran (0.009) and WGF (0.013), the ratio of DON:DNA (mg DON per $\mu \mathrm{g} F g \mathrm{DNA}$ ) was equally high, the comparatively high amount of DON in flour Type $550(0.061)$ led to a higher DON:DNA ratio in this flour.

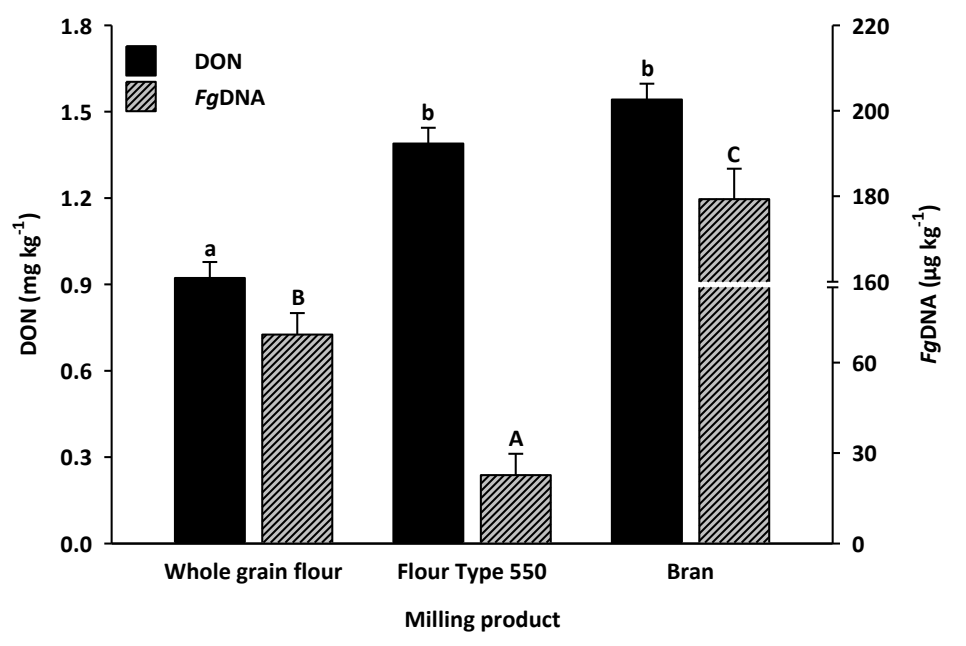

Fig 11. Effect of milling (flour Type 550, whole grain flour, bran) on DON and FgDNA content of milling products. MV $(n=108)$ with same letters are not significantly different at $p<0.05$ according to Tukey test. Error bars indicate SE.

Since flour Type 550 was used for the determination of most quality parameters and gluten proteins, the distribution of DON content in this milling fraction is shown in particular (Fig 12). Approximately $40 \%$ of all flours contained DON levels below the $\mathrm{EU}_{\mathrm{Max}}$ for DON in baby food $\left(0.2 \mathrm{mg} \mathrm{kg}^{-1} \sim 10 \%\right)$ including samples with DON levels lower than the LOD $(\sim 30 \%)$. In $29 \%$ of the samples, DON contents ranged from 0.20 to less than $1.25 \mathrm{mg} \mathrm{kg}^{-1} \cdot \mathrm{EU}_{\mathrm{Max}}$ for unprocessed cereals $\left(\mathrm{EU}_{\mathrm{MaxUP}}\right)\left(1.25 \mathrm{mg} \mathrm{kg}^{-1}\right)$ was exceeded in $31 \%$ of the flours. $50 \%$ of these contained up to $2.8 \mathrm{mg} \mathrm{kg}^{-1}$ DON (median), $75 \%$ of all samples comprised DON levels up to approx. $4 \mathrm{mg} \mathrm{kg}^{-1}$, the remaining of the samples contained more than $4 \mathrm{mg} \mathrm{kg}^{-1}$ up to extreme values of $11.8 \mathrm{mg} \mathrm{kg}^{-1}$ DON. 


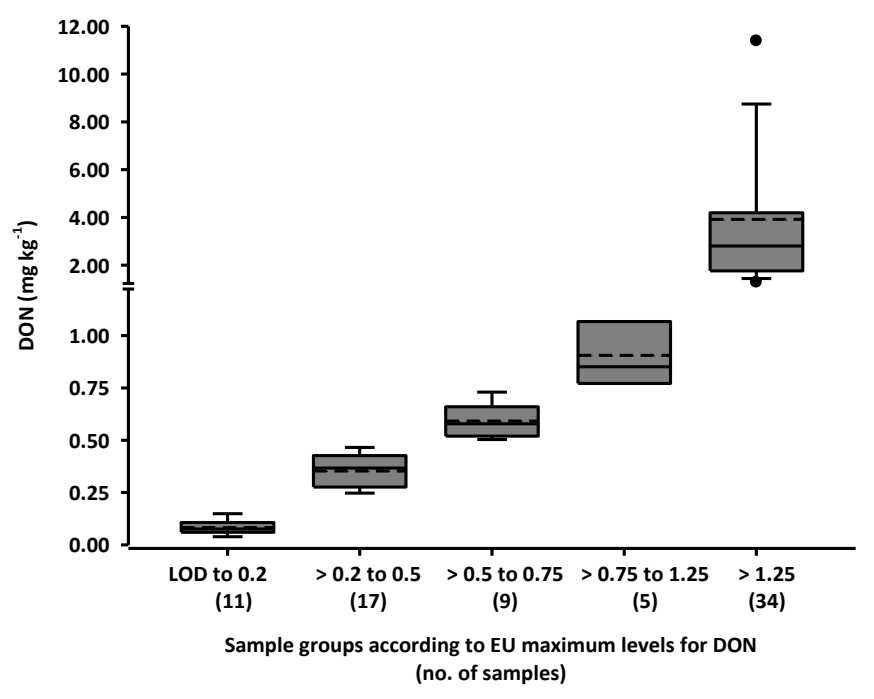

Fig 12. Distribution of DON levels $\left(\mathrm{mg} \mathrm{kg}^{-1}\right)$ of flour Type 550 samples grouped into $\mathrm{EU}_{\mathrm{Max}}$ for cereal and cereal products (unprocessed cereals: 1.25 , Flour: 0.75 , bread: 0.5 , processed cereals/baby food: 0.2 , details: see Tab 1). In brackets: number of samples (total: 108, below limit of detection (LOD): 32). Box plots with median (solid line), mean (short dash), and whiskers indicating $5^{\text {th }} / 95^{\text {th }}$ percentiles, outliers (dot).

All single factors considered in the ANOVA -year, location (environment), pre-crop, cultivar, fungicide treatment, and milling product- had a significant effect on FgDNA and DON levels in wheat milling products (Tab 9). The previous figures (Fig 7, Fig 8, Fig 9, Fig 10, Fig 11) showed a high positive correspondence between DON and FgDNA regardless of the factors looked upon (except for flour Type 550 in Fig 11).

\section{Interactions}

In addition, a large number of significant interactions between the experimental factors were calculated (Tab 9). A short summary on these interactions is given below. Out of all, the interaction of pre-crop - cultivar - fungicide is described in more detail.

Since the environment, especially the year of harvest, played a key role in the occurrence of FHB and associated DON (shown in Fig 7), significant simple, dual, and triple interactions of the environment with all other experimental factors occurred. In 2008, a year with hardly any detectable Fusarium infection (measured as $F g$ DNA and DON), a significant difference in $F g$ DNA and DON levels between locations, cultivars, pre-crops, fungicides, and milling products could not be observed, while in 2007 the effect of these factors was distinct. At the same time, the effect of cultivar susceptibility, fungicide treatment, and milling fraction on DON became extraordinarily pronounced after previous crop maize and was less or not at all prevalent after pre-crop sugar beet reflected in significant interactions of these factors with the pre-crop. The same applied to significant interactions with the cultivar. Only the highly susceptible cv. Ritmo showed significant differences in fungicide treatments and milling fractions regarding FgDNA and DON levels (data not shown). 
Fig 13 shows the details of the interaction pre-crop - cultivar - fungicide subdivided for the effect of pre-crop. This interaction is especially interesting because it includes only factors a farmer can manage. Five things can be affiliated: 1) both cultivars contained highest DON levels after maize pre-crop 2) after pre-crop maize and wheat, susceptible cv. Ritmo comprised significantly more DON than less susceptible cv. Centrum (except for triazole application in pre-crop wheat) 3) strobilurin and chlorthalonil application resulted in higher DON contamination in cv. Ritmo after maize pre-crop compared to triazole treatment; after pre-crop wheat, only strobilurin treatment contained significantly higher DON levels in comparison to triazole 4) in cv. Centrum, fungicides did not show a significant effect on DON 5) after pre-crop sugar beet, neither effect of cultivar nor fungicide was distinct. 

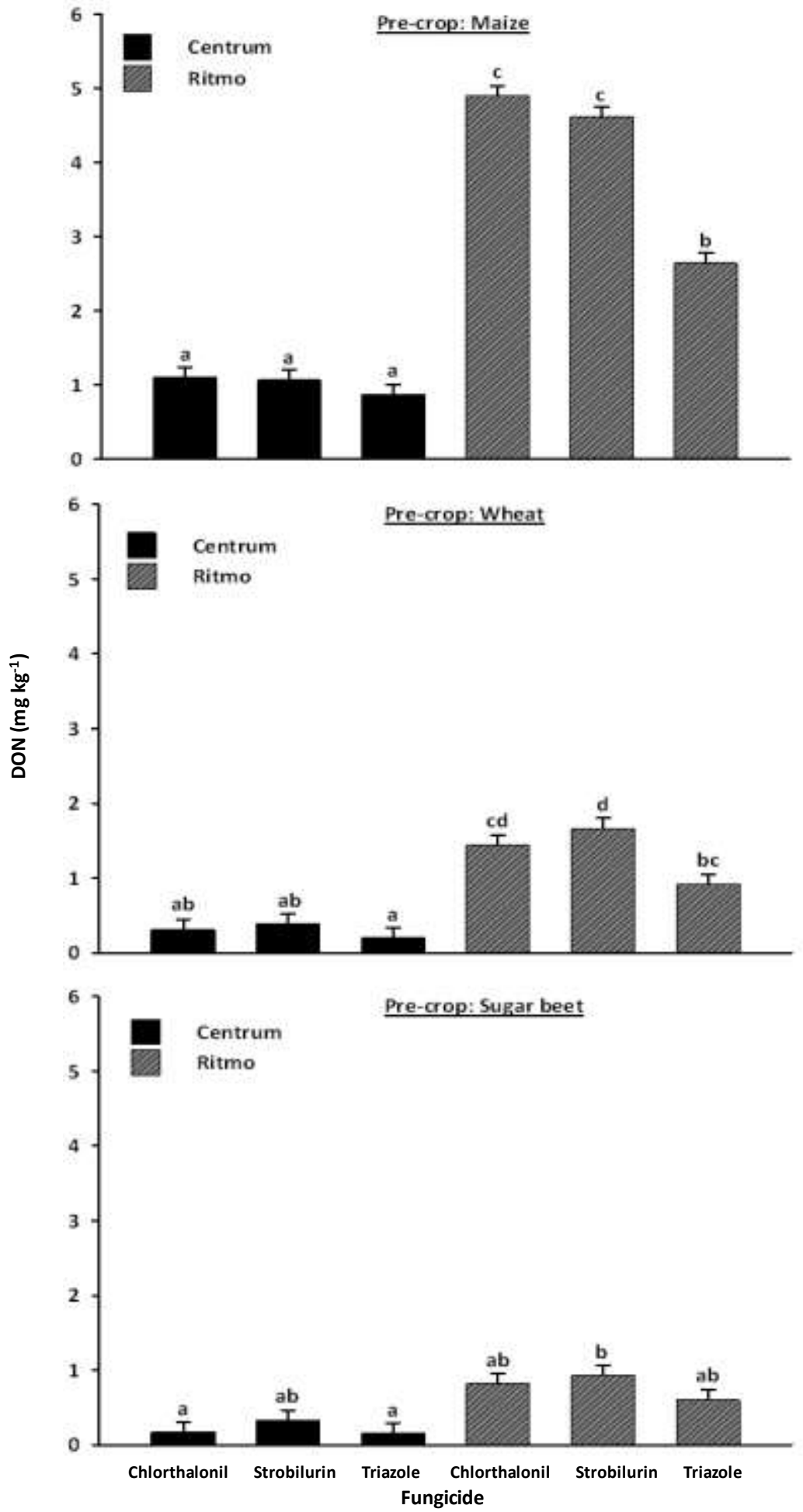

Fig 13. Effect of wheat cultivar (Centrum, Ritmo) and fungicide treatment on DON levels in wheat milling products (flour Type 550, whole grain flour, bran) cultivated after different pre-crops. MV $(n=18)$ with same letters are not significantly different at $p<0.05$ according to Tukey test. Error bars indicate SE.

In the present field trial, maximum DON levels $\left(\mathrm{DON}_{\mathrm{Max}}\right)$ were obtained in 2007 at location Gladebeck, after previous crop maize, susceptible cv. Ritmo, the application of strobilurin (or chlorthalonil in interaction with pre-crop and cultivar), and in bran (Tab 10). Minimum DON levels $\left(\mathrm{DON}_{\mathrm{Min}}\right)$ were present at the same location in 2008 , after pre-crop sugar beet, in less susceptible cv. Centrum, triazole treatment, and in WGF. 
Evaluation of the single experimental factors regarding their contribution to DON levels in wheat by SoE, it became obvious that environment (year $\mathrm{x}$ location) was the most important factor, followed by pre-crop and cultivar. Fungicide treatment and milling product played a comparatively minor role. Out of all interactions, including just agricultural measures, SoE was highest (30.6) within the interaction of pre-crop-cultivar-fungicide.

Tab 10. Specification of maximum and minimum DON levels $\left(\mathrm{DON}_{\mathrm{Max}} / \mathrm{DON}_{\min }\right)(\mathrm{mg}$ $\mathrm{kg}^{-1}$ ) and severity of effect (SoE of single effects of environment (year x location), precrop, cultivar, fungicide, milling product, and in selected interactions

\begin{tabular}{|c|c|c|c|c|c|c|}
\hline Effect & $\mathbf{n}$ & Specification & $\mathrm{DON}_{\text {Max }}\left(\mathrm{mg} \mathrm{kg}^{-1}\right)$ & Specification & $\mathrm{DON}_{\mathrm{Min}}\left(\mathrm{mg} \mathrm{kg}^{-1}\right)$ & SoE \\
\hline Environment (E) & 54 & Gladebeck 2007 (GL 07) & 2.86 & Gladebeck 2008 (GL 08) & 0.03 & 90.7 \\
\hline Pre-crop (P) & 108 & Maize (M) & 2.53 & Sugar beet (SB) & 0.50 & 5.1 \\
\hline Fungicide (F) & 108 & Strobilurin (S) & 1.50 & Triazole $(\mathrm{T})$ & 0.90 & 1.7 \\
\hline Milling fraction (MF) & 108 & Bran (B) & 1.54 & Whole grain flour (WGF) & 0.92 & 1.7 \\
\hline$P \times C \times F$ & 18 & $\mathrm{M} \times \mathrm{R} \times \mathrm{Chl}$ & 4.90 & $\mathrm{SB} \times \mathrm{C} \times \mathrm{T}$ & 0.16 & 30.6 \\
\hline $\mathrm{CxF}$ & 54 & $\mathrm{R} \times \mathrm{S}$ & 2.40 & $\mathrm{C} \times \mathrm{T}$ & 0.41 & 5.8 \\
\hline
\end{tabular}

$\mathrm{n}$ number of observations, SoE severity of effect $=\mathrm{DON}_{\mathrm{Max}} / \mathrm{DON}_{\mathrm{Min}}$, WGF whole grain flour

\subsubsection{Relationship of visual disease, DON, and $\mathrm{FgDNA}$}

\section{Visual disease}

Visual disease in the field was measured as DI, DS, and FHB index (Tab 11). All three parameters were influenced by year and cultivar (neglecting other experimental factors, e.g. pre-crop, fungicide). DI was significantly higher in highly susceptible cv. Ritmo than in cv. Centrum in all three years. DS and FHB index of cv. Ritmo were significantly higher than that of cv. Centrum in 2007, but not in 2008. Highest DI, DS, and FHB index were determined in both cultivars in 2007. Coefficients of correlation for linear regression of DI:DS, DI:FHB, and DS:FHB across 2007, 2008 and cultivars were $0.50(\mathrm{p}<0.001), 0.98(\mathrm{p}<0.001)$, and $0.50(\mathrm{p}<0.001)$, respectively.

Tab 11. Disease incidence (DI), disease severity (DS), and FHB index of winter wheat cv. Centrum and Ritmo in 2007, 2008, and 2009

\begin{tabular}{|c|c|c|c|c|c|c|c|c|c|c|c|c|c|}
\hline Year & & \multicolumn{4}{|c|}{ DI (\%) } & \multicolumn{4}{|c|}{ DS (\%) } & \multicolumn{4}{|c|}{ FHB index (\%) } \\
\hline \multirow[t]{2}{*}{2007} & Mean & 4.571 & \multirow{2}{*}{$a$} & 12.440 & \multirow{2}{*}{ b } & 29.876 & \multirow{2}{*}{ a } & 48.819 & \multirow{2}{*}{ b } & 1.448 & 0 & 6.766 & $h$ \\
\hline & Median & 1.016 & & 3.667 & & 29.125 & & 49.125 & & 0.301 & a & 1.762 & N \\
\hline 2008 & Mean & 0.002 & a & 0.005 & b & 8.611 & a & 8.646 & $a$ & 0.001 & a & 0.001 & a \\
\hline \multirow[t]{2}{*}{2009} & Mean & 0.045 & \multirow{2}{*}{$a$} & 0.705 & \multirow{2}{*}{ b } & - & & - & & - & & - & \\
\hline & Median & 0.030 & & 0.400 & & - & & - & & - & & - & \\
\hline
\end{tabular}

${ }^{a}$ Means and medians for cultivars based on $n=18$ per year, "-" not determined, different letters indicate significant differences between cultivars within years with $p<0.05$ according to Mann-Whitney-U test 


\section{Visual disease and DON}

Since DI correlated very well with FHB index and DI was determined in all three years, the relationship of DI and DON levels in milling products was investigated (Fig 14). In 2007, the DON content of milling products was best described with a logarithmic function of DI. 80 to $89 \%$ of the variability in DON levels could be explained in this way, except for bran and WGF of cv. Ritmo. In 2009, DON levels were best described as a linear function of DI, $\mathrm{R}^{2}$ was 0.71 to 0.91 . In 2008, in most plots DI was zero and only in a few samples, DON could be detected. Therefore, no function for DON was calculated since relationship of DON:DI can only be defined when FHB occurs. Logarithmic functions of FHB for the prediction of DON (calculation only meaningful in 2007) resulted in similar $\mathrm{R}^{2}$ as the functions of DI (data not shown).
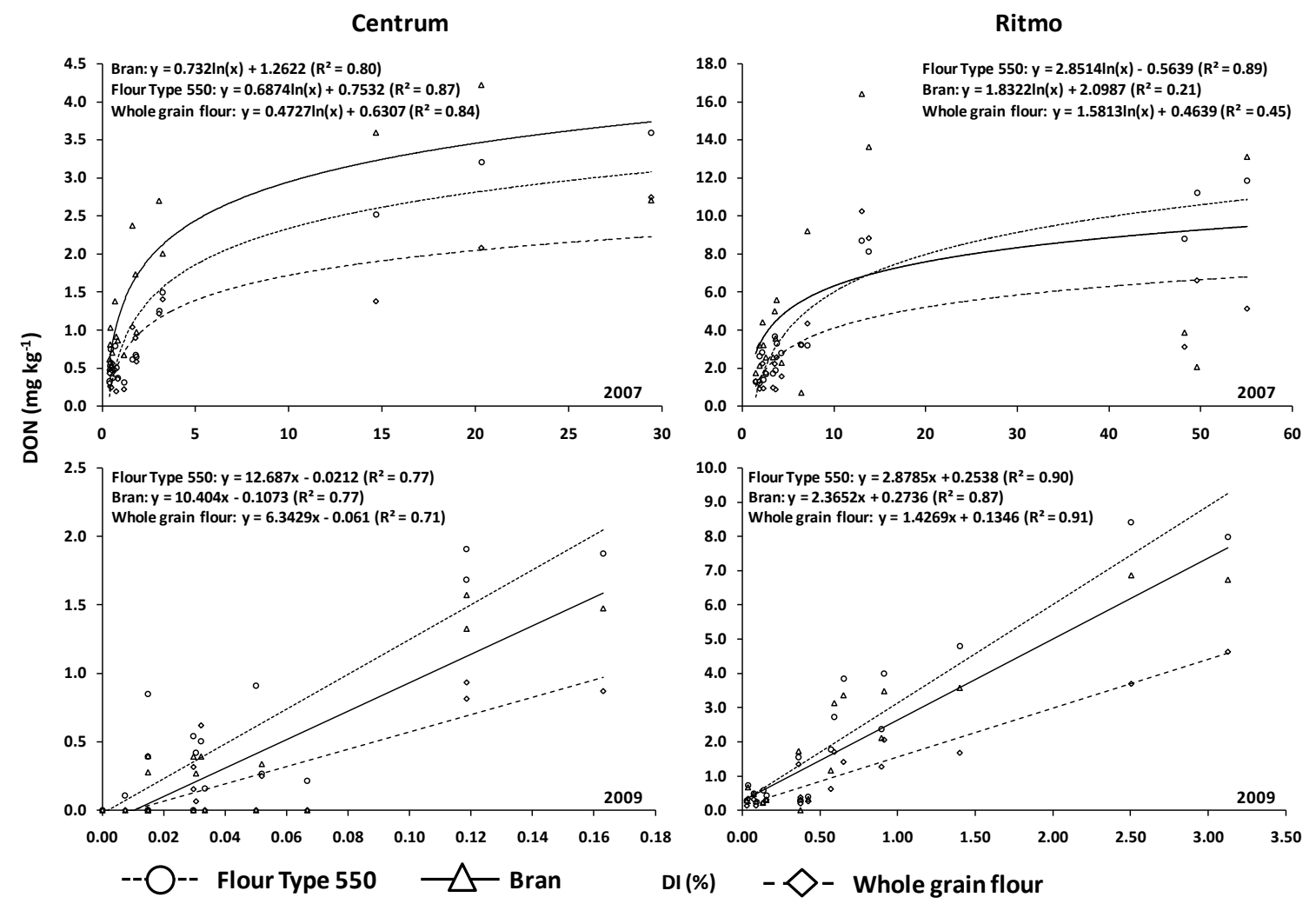

Fig 14. Relationship between disease incidence (DI) and DON content of flours and bran ( $\mathrm{n}=18$ each) milled from two winter wheat cultivars (Centrum, Ritmo) in 2007 and 2009 (Attention: due to otherwise impaired readability of data points, axis of graphs have been set to different scales)

\section{Visual disease and $\mathrm{FgDNA}$}

In 2007, relationship of visual disease and $F g$ DNA levels in milling products could be well described with logarithmic functions of DI for both cultivars (Fig 15). DI described 62 to $88 \%$ of variability in $F g$ DNA concentrations in flours and bran. In 2008 and 2009, most samples did not contain quantifiable amounts of $\mathrm{FgDNA}$ ( $\mathrm{Tab} 7$ ) so that the relationship between both parameters could not be investigated even though DI was not necessarily zero. Since DI correlated highly with FHB, it was not unexpected that $F g$ DNA also related highly to FHB; logarithmic functions of FHB 
to estimate $F g \mathrm{DNA}$ levels in milling products possessed $\mathrm{R}^{2} \mathrm{~s}$ from 0.66 to 0.87 for both cultivars; the $\mathrm{R}^{2}$ for logarithmic functions of DS obtained lower $\mathrm{R}^{2}(0.05-0.57)$ indicating none to moderate positive correlation with $\mathrm{FgDNA}$ in cv. Centrum $\left(\mathrm{R}^{2}=0.05-0.26\right)$ and none to weak correlation in cv. Ritmo ( $\left.\mathrm{R}^{2}=0.39-0.57\right)$ (data not shown).
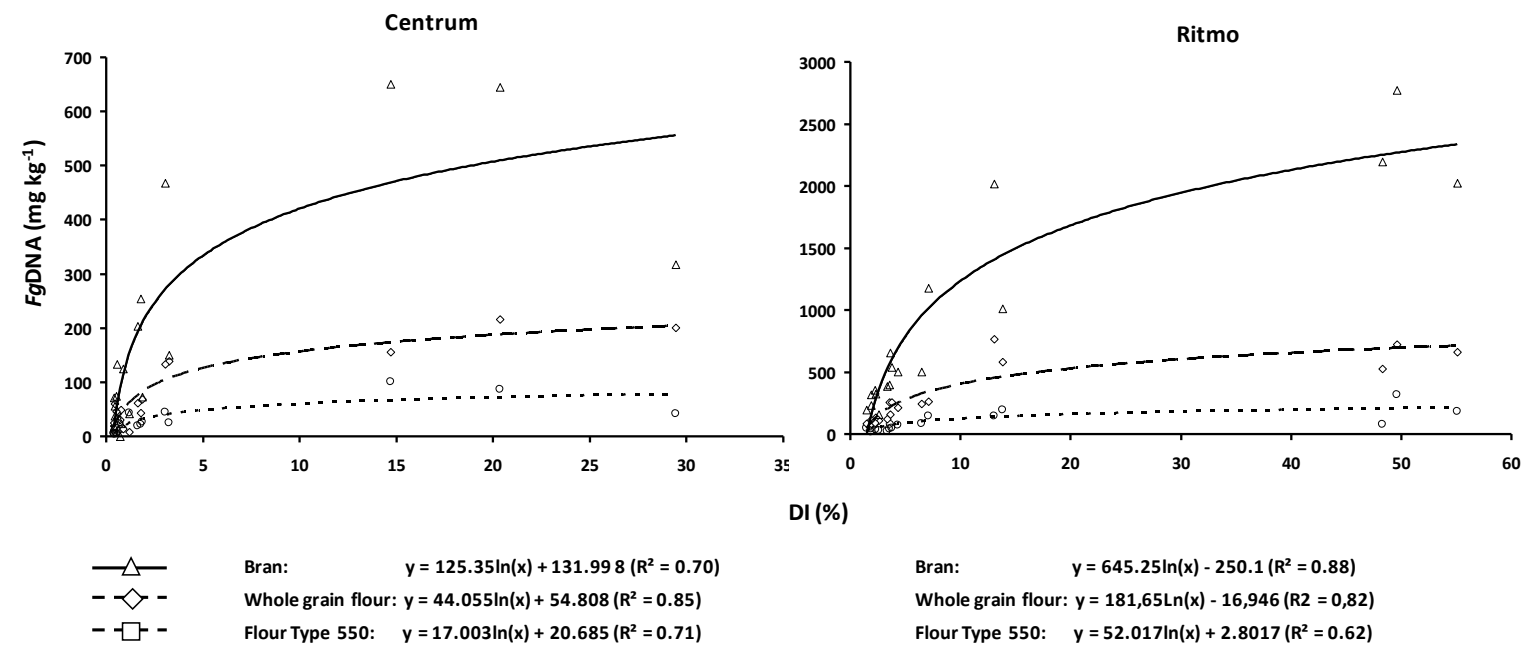

Fig 15. Relationship between disease incidence (DI) and FgDNA content of flours and bran ( $\mathrm{n}=18$ each) milled from two winter wheat cultivars (Centrum, Ritmo) in 2007 (Attention: due to otherwise impaired readability of data points, axis of graphs have been set to different scales)

\section{DON and FgDNA}

In a linear model, DON and $F g$ DNA measured in flours and bran across all samples were positively correlated (Fig 16). $65 \%$ to $85 \%$ of variance of DON content in milling products was explained by the presence of $F g D N A$. The highest $\mathrm{R}^{2}$ was gained from the prediction model of WGF. Remarkably, the slope of the regression curve of flour Type 550 was four times as steep $(\mathrm{a}=$ $0.04)$ as the slopes of the curves estimated from WGF and bran $(a=0.01$ and 0.007$)$. The DON concentration per $\mu \mathrm{g} F g$ DNA which can be predicted from the slope of the models was similar to DON:DNA ratio calculated from data shown already in Fig 11. A detailed description of differences between cultivars in DON:DNA ratio can be viewed in GöDECKE 2010. 

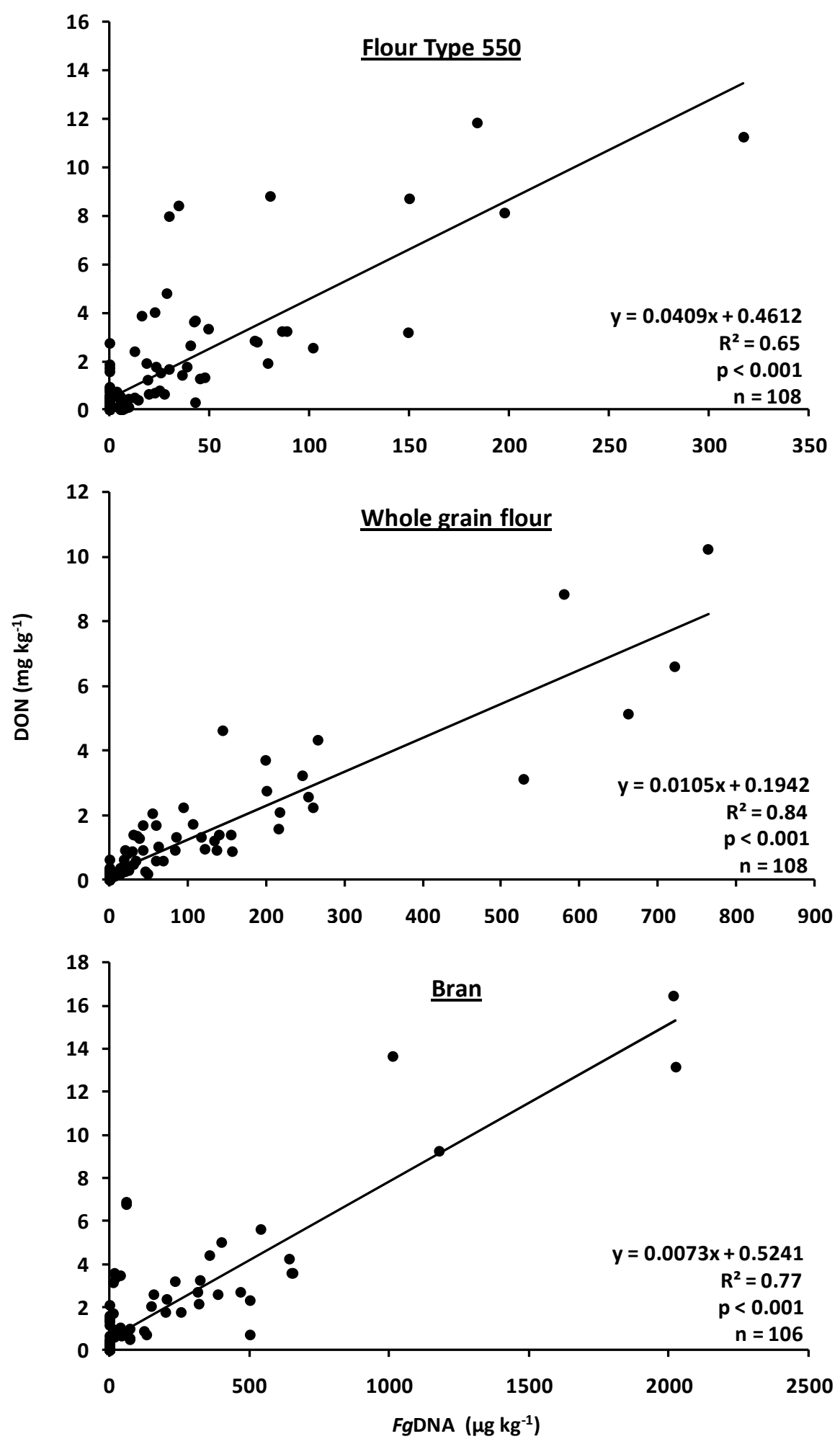

Fig 16. Linear regression of FgDNA and DON content of wheat milling products (flour Type 550, whole grain flour, bran) across all samples (Attention: due to otherwise impaired readability of data points, axis of graphs have been set to different scales)

There also existed a close positive relationship between the DON levels of all milling products $\left(\mathrm{R}^{2}=0.67-0.83\right)$ as well as between their $F g \mathrm{DNA}\left(\mathrm{R}^{2}=0.81-0.88\right)$ contents (Tab 12). 
Tab 12. Coefficient of determination $\left(\mathrm{R}^{2}\right)$ of linear regression of DON and $\mathrm{FgDNA}$ levels of milling products (flour Type 550, whole grain flour (WGF), bran)

\begin{tabular}{|c|c|c|c|c|}
\hline & \multicolumn{2}{|c|}{ Flour Type 550} & \multicolumn{2}{|c|}{ WGF } \\
\hline & DON & $F g$ DNA & DON & $\mathrm{Fg}$ DNA \\
\hline WGF & 0.79 & 0.83 & - & - \\
\hline Bran & 0.67 & 0.81 & 0.83 & 0.88 \\
\hline
\end{tabular}

\subsection{Fusarium infection and quality parameters}

\subsubsection{Protein content of flours $\left(\mathrm{PC}_{\mathrm{WGF}}\right.$ and $\left.\mathrm{PC}_{\mathrm{Type} 550}\right)$}

$\mathrm{PC}_{\mathrm{WGF}}$ was mainly influenced by year and pre-crop (Tab 54). In 2007, grain contained significantly more protein $(\varnothing 14.0 \%)$ than in 2008 and 2009 where PC averaged only $11.3 \%$ and $12.3 \%$, respectively. Across years and cultivars, wheat grown after wheat contained significantly more grain protein (about 4.7 and $4.2 \%$ ) than grown after maize and sugar beet, respectively. Across all samples, cv. Ritmo (Ø 12.7\%) contained significantly more protein than cv. Centrum (Ø 12.4\%) which was mainly due to 2007, the only year where a significant difference in PC between the two cultivars was apparent (cv. Centrum: Ø 13.7\%, cv. Ritmo: Ø 14.3\%).

Within 2007, $\mathrm{PC}_{\mathrm{WGF}}$ of cv. Centrum was highest after pre-crop sugar beet (Ø 14.1\%), cv. Ritmo contained highest $\mathrm{PC}_{\mathrm{WGF}}$ after pre-crop wheat (14.7\%) (Fig 17). Within years 2008 and 2009, both cultivars exhibited higher $\mathrm{PC}_{\mathrm{WGF}}$ after pre-crop winter wheat (2008: 11.8\%, 2009: 12.8\%) than after maize (2008: 11.3\%, 2009: 12.0\%) and sugar beet (2008: 11.0\%, 2009: 12.0\%), while the difference between the later two pre-crops was not significant.

Milling of flour Type 550 reduced PC in dry matter compared to WGF (Fig 17). Flour Type 550 contained averagely $11.7,10.2$, and $10.4 \%$ protein in 2007, 2008, and 2009 which resembled a reduction of 1-2\% protein when compared to WGF (Tab 54). Milling smoothed $\mathrm{PC}_{\text {Type550 }}$ which is indicated by narrower percentiles of box plots (Fig 17), nevertheless, the effect of year and precrop which was present in WGF mainly remained visible. Both, $\mathrm{PC}_{\mathrm{WGF}}(\mathrm{x})$ and $\mathrm{PC}_{\mathrm{Type5} 50}(\mathrm{y})$ were significantly positively correlated $\left(\mathrm{y}=0.5933 \mathrm{x}+3.342, \mathrm{R}^{2}=0.892, \mathrm{p}<0.001, \mathrm{n}=108\right)$. 

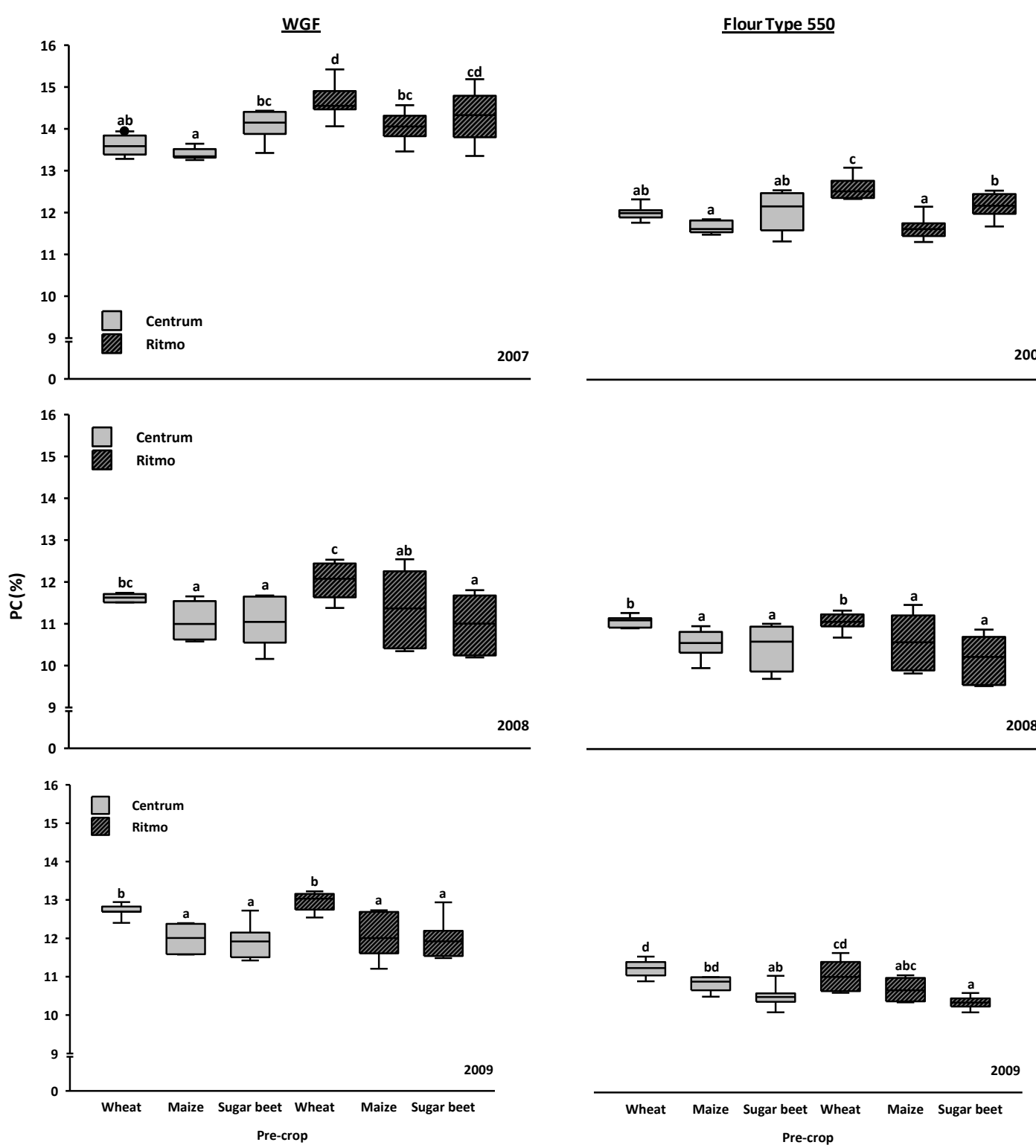

Fig 17. Protein content (PC) of whole grain flour (WGF) and flour Type $\mathbf{5 5 0}$ milled from two winter wheat cv. (Centrum, Ritmo) grown after pre-crop wheat, maize, and sugar beet in 2007, 2008, 2009. Box plots with median (solid line) and whiskers indicating $5^{\text {th }} / 95^{\text {th }}$ percentiles. Box plots $(n=6)$ with same letters are not significantly different at $p<0.05$ according to Tukey test. Outliers are indicated by a dot.

Obviously, none of the variability in protein data could be sufficiently explained by the concentration of DON in grain (and therefore Fusarium infection) (Tab 13). This leads to the conclusion that in WGFs (and grain respectively), PC was not affected by Fusarium infection. Subsequently, the model could be reduced (by performing ANOVA) to the main effects environment (year x location), pre-crop, and cultivar which all affected PC $_{\mathrm{WGF}}$ significantly (Tab 13, Fig 17). 
Tab 13. ANCOVA for effects of environment (E) (year, location), pre-crop (P), wheat

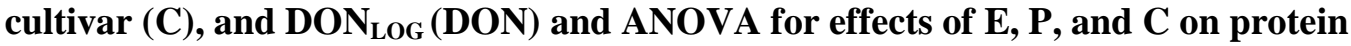
content of whole grain flour

\begin{tabular}{|c|c|c|c|c|c|}
\hline \multirow[b]{2}{*}{ Effect } & \multicolumn{3}{|c|}{ ANCOVA } & \multicolumn{2}{|c|}{ ANOVA } \\
\hline & DF & $\mathbf{F}$ & $p$ & $\mathbf{F}$ & $p$ \\
\hline Environment (E) & 3 & 19.79 & $* * *$ & 273.9 & $* * *$ \\
\hline Pre-crop (P) & 2 & 10.31 & $* * *$ & 32.65 & $* * *$ \\
\hline$E \times P$ & 6 & 3.11 & $*$ & 14.02 & $* * *$ \\
\hline Cultivar (C) & 1 & 0.32 & n.s. & 36.47 & $* * *$ \\
\hline $\mathrm{E} \times \mathrm{C}$ & 3 & 1.11 & n.s. & 6.03 & $* *$ \\
\hline $\mathrm{P} \times \mathrm{C}$ & 2 & 2.96 & $(*)$ & 5.55 & $* *$ \\
\hline$E \times P \times C$ & 4 & 0.78 & n.s. & 1.87 & n.s. \\
\hline DON & 1 & 1.04 & n.s. & & \\
\hline DON x E & 3 & 0.43 & n.s. & & \\
\hline DON x P & 2 & 0.57 & n.s. & & \\
\hline DON $x$ ExP & 6 & 0.94 & n.s. & & \\
\hline DON x C & 1 & 0.12 & n.s. & & \\
\hline DON x ExC & 3 & 0.6 & n.s. & & \\
\hline DON $x \mathrm{P} \times \mathrm{C}$ & 2 & 0.8 & n.s. & & \\
\hline DON $x E \times P \times C$ & 4 & 0.24 & n.s. & & \\
\hline
\end{tabular}

In contrast to WGF, for flour Type 550 a significant effect of $\mathrm{DON}_{\mathrm{LOG}}$ on PC was calculated aside from significant effects of environment and pre-crop (Tab 14).

Tab 14. ANCOVA for effects of environment (E) (year, location), pre-crop (P), wheat

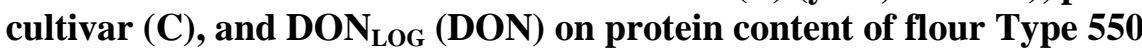

\begin{tabular}{|c|c|c|c|}
\hline Effect & DF & $\mathbf{F}$ & $p$ \\
\hline Environment (E) & 3 & 18.41 & $* * *$ \\
\hline Pre-crop (P) & 2 & 8.42 & $* *$ \\
\hline$E \times P$ & 6 & 2.25 & $(*)$ \\
\hline Cultivar (C) & 1 & 0.71 & n.s. \\
\hline$E \times C$ & 3 & 1.92 & n.s. \\
\hline$P \times C$ & 2 & 1.15 & n.s. \\
\hline$E \times P \times C$ & 5 & 0.63 & n.s. \\
\hline DON & 1 & 6.78 & $*$ \\
\hline DON x E & 3 & 3.66 & $*$ \\
\hline DON x P & 2 & 2.59 & $(*)$ \\
\hline DON XExP & 6 & 3.21 & $*$ \\
\hline DON x C & 1 & 5.89 & $*$ \\
\hline DON xExC & 3 & 0.53 & n.s. \\
\hline DON $\times \mathrm{P} \times \mathrm{C}$ & 2 & 0.78 & n.s. \\
\hline DON $x E \times P \times C$ & 5 & 1.38 & n.s. \\
\hline
\end{tabular}

Further analysis by linear regression showed that $\mathrm{PC}_{\text {Type550 }}$ increased significantly across cultivars with higher DON contents after previous crop wheat in 2007, but decreased in 2009 at location Torland when grown after wheat and sugar beet (Tab 15). In 2007, within the range of 0.31 to 3.65 mg DON kg-1 $\mathrm{PC}_{\text {Type550 }}$ increased by 0.58 to $1.09 \%$ if $\mathrm{DON}_{\mathrm{LOG}}$ increased by $1 \mathrm{mg} \mathrm{kg}^{-1}$. 
In $2009, \mathrm{PC}_{\text {Type550 }}$ was reduced about 0.46 and $0.75 \%$ per $1 \mathrm{mg} \mathrm{DON}_{\mathrm{LOG}} \mathrm{kg}^{-1}$ within a range of DON $_{\text {ORG }}$ similar to 2007.

Tab 15. Parameters of linear regression of protein content of Type $550(\%)$ and $\mathrm{DON}_{\mathrm{LOG}}\left(\mathrm{mg} \mathrm{kg}^{-1}\right)(\mathrm{DON})$ in different environments (E) (year, location) and pre-crops (P) across cultivars, and range of original DON values (DON $\left.{ }_{\text {ORG }}\right)$

\begin{tabular}{|c|c|c|c|c|c|c|c|c|c|c|}
\hline \multirow[t]{2}{*}{ Effect } & \multicolumn{4}{|c|}{ Effect level } & \multirow[b]{2}{*}{$\mathbf{n}$} & \multirow[b]{2}{*}{$\mathbf{R}^{2}$} & \multirow[b]{2}{*}{$p$} & \multirow[b]{2}{*}{$\mathbf{0}$} & \multicolumn{2}{|c|}{$\mathrm{DON}_{\mathrm{ORG}}\left(\mathrm{mg} \mathrm{kg}^{-1}\right)$} \\
\hline & Year & Location & Cultivar & Pre-crop & & & & & a & Min-Max \\
\hline \multirow{5}{*}{$E \times P$} & \multirow{3}{*}{2007} & $\mathrm{TL} \& \mathrm{~GB}$ & \multirow{3}{*}{$\begin{array}{l}\text { Centrum } \\
\text { \& Ritmo }\end{array}$} & \multirow{3}{*}{ Wheat } & 12 & 0.75 & $* * *$ & 11.98 & 0.85 & $0.31-3.65$ \\
\hline & & $\mathrm{TL}$ & & & 6 & 0.78 & $*$ & 11.91 & 0.58 & $0.31-2.75$ \\
\hline & & GB & & & 6 & 0.88 & $* *$ & 12.06 & 1.09 & $0.37-3.30$ \\
\hline & \multirow{2}{*}{2009} & \multirow{2}{*}{ TL } & Centrum & Wheat & 6 & 0.68 & $*$ & 10.51 & -0.46 & $0.42-3.99$ \\
\hline & & & \& Ritmo & Sugar beet & 6 & 0.88 & $* *$ & 9.60 & -0.75 & $0.16-0.91$ \\
\hline
\end{tabular}

$\mathrm{n}$ number of observations, $\mathrm{p}$ significance: ${ }^{* * *},{ }^{* *}$, and ${ }^{*}=\mathrm{p}<0.001,0.01,0.05, \mathrm{~b}$ constant, a slope, TL Torland, GB Gladebeck

\subsubsection{Wet gluten content (WG) and sedimentation value (SV)}

WG was significantly influenced by year, pre-crop, and cultivar (Tab 54, Fig 18). Flour Type 550 contained 38.0\%, 29.1\%, and 26.4\% WG across all samples in 2007, 2008, and 2009, respectively. Regarding cultivar, from cv. Ritmo significantly more WG could be gained than from cv. Centrum. The difference in WG between both cultivars was about 21\%, 13\%, and 10\% in 2007, 2008, and 2009 , respectively. While WG was hardly influenced by pre-crop in cv. Centrum (except 2009), in cv. Ritmo WG was significantly lower after previous crop maize < sugar beet < wheat in 2007 and in 2009 maize=sugar beet < wheat. The wider range of the box plots in Fig $18 \mathrm{of} \mathrm{cv}$. Ritmo compared to cv. Centrum indicated a stronger variation of WG in this cultivar which may have been caused by other factors, e.g. location or Fusarium infection. However, ANCOVA did not reveal a significant effect of $\mathrm{DON}_{\mathrm{LOG}}$ on WG (Tab 17). 

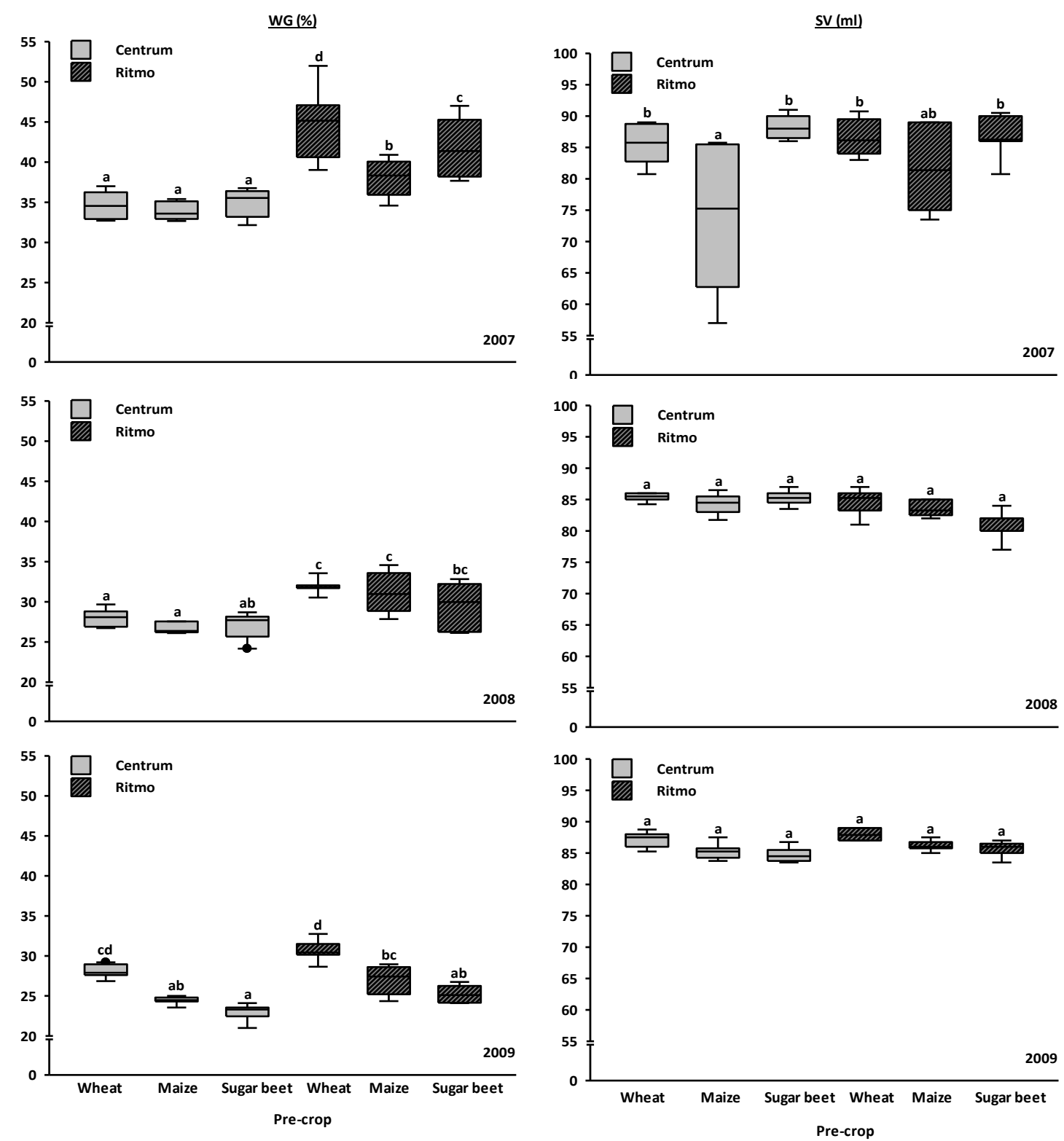

Fig 18. Wet gluten content (WG) and sedimentation value (SV) of flour Type 550 milled from two winter wheat cv. (Centrum, Ritmo) grown after pre-crop wheat, maize, and sugar beet in 2007, 2008, and 2009. Box plots with median (solid line) and whiskers indicating $5^{\text {th }} / 95^{\text {th }}$ percentiles. Box plots $(n=6)$ with same letters are not significantly different at $p<0.05$ according to Tukey test. Outliers are indicated by a dot. 
Tab 17. ANCOVA for effects of environment (E) (year, location), pre-crop (P), wheat cultivar (C), and DON ${ }_{\mathrm{LOG}}(\mathrm{DON})$ and ANOVA for effects of $E$, $P$, and $C$ on wet gluten content

\begin{tabular}{|c|c|c|c|c|c|}
\hline \multirow[b]{2}{*}{ Effect } & \multicolumn{3}{|c|}{ ANCOVA } & \multicolumn{2}{|c|}{ ANOVA } \\
\hline & DF & $\mathbf{F}$ & $p$ & $F$ & $\mathbf{p}$ \\
\hline Environment (E) & 3 & 23.47 & $* * *$ & 420.84 & $* * *$ \\
\hline Pre-crop (P) & 2 & 1.94 & n.s. & 51.64 & $* * *$ \\
\hline$E \times P$ & 6 & 1.57 & n.s. & 19.72 & $* * *$ \\
\hline Cultivar (C) & 1 & 2.11 & n.s. & 211.48 & $* * *$ \\
\hline $\mathrm{E} \times \mathrm{C}$ & 3 & 0.56 & n.s. & 17.39 & $* * *$ \\
\hline$P \times C$ & 2 & 0.65 & n.s. & 7.19 & $* *$ \\
\hline$E \times P \times C$ & 6 & 0.65 & n.s. & 4.77 & $* * *$ \\
\hline DON & 1 & 0.44 & n.s. & & \\
\hline DON $x E$ & 3 & 0.48 & n.s. & & \\
\hline DON x P & 2 & 0.14 & n.s. & & \\
\hline DON $\times$ ExP & 6 & 0.74 & n.s. & & \\
\hline DON x C & 1 & 0.03 & n.s. & & \\
\hline DON $\times$ ExC & 3 & 0.41 & n.s. & & \\
\hline DON $\times \mathrm{P} \times \mathrm{C}$ & 2 & 0.36 & n.s. & & \\
\hline DON $\times E \times P \times C$ & 5 & 0.15 & n.s. & & \\
\hline
\end{tabular}

SV was significantly affected by year and pre-crop (Tab 54, Fig 18). Differences between cultivars were only significant within the interaction of year-pre-crop, yet, not across all samples (cv. Centrum: Ø $84 \mathrm{ml}$, cv. Ritmo: Ø $85 \mathrm{ml}$ ). While SV did not differ significantly between 2007 (Ø 84 $\mathrm{ml})$ and 2008 (Ø $84 \mathrm{ml}$ ), it was significantly higher in 2009 (Ø $86 \mathrm{ml})$. In 2007, SV varied more than in the two following years indicated by wider box plots. In the respective year, SV of both cultivars were lower after pre-crop maize compared than after wheat and sugar beet. In $\mathrm{cv}$. Centrum, the difference was significant. SV of cv. Centrum was reduced on average about 17 and $14 \%$ after maize when compared to wheat and sugar beet, respectively, SV of cv. Ritmo after precrop maize was only reduced about $6 \%$.

ANCOVA revealed a significant effect of DON on SV across all samples, within environment, precrop, as well as in the interaction of environment (year $\mathrm{x}$ location) and pre-crop (Tab 18). 
Tab 18. ANCOVA for effects of environment (E) (year, location), pre-crop (P), wheat cultivar $(C)$, and $D_{O O N_{L O G}}$ on sedimentation value

\begin{tabular}{|c|c|c|c|}
\hline Effect & DF & $\mathbf{F}$ & $\mathbf{p}$ \\
\hline Environment (E) & 3 & 15.50 & $* * *$ \\
\hline Pre-crop (P) & 2 & 17.21 & $* * *$ \\
\hline$E \times P$ & 6 & 8.37 & $* * *$ \\
\hline Cultivar (C) & 1 & 0.42 & n.s. \\
\hline $\mathrm{E} \times \mathrm{C}$ & 3 & 5.42 & $* *$ \\
\hline $\mathrm{P} \times \mathrm{C}$ & 2 & 0.88 & n.s. \\
\hline$E \times P \times C$ & 5 & 0.55 & n.s. \\
\hline DON & 1 & 7.70 & $*$ \\
\hline DON XE & 3 & 24.36 & $* * *$ \\
\hline DON x P & 2 & 4.20 & $*$ \\
\hline DON x ExP & 6 & 8.66 & $* * *$ \\
\hline DON x C & 1 & 1.52 & n.s. \\
\hline DON $x$ Ex C & 3 & 0.90 & n.s. \\
\hline DON x P x C & 2 & 0.87 & n.s. \\
\hline DON $\times E \times P \times C$ & 5 & 2.58 & $(*)$ \\
\hline
\end{tabular}

Even though ANCOVA revealed that there is a significant effect of $\mathrm{DON}_{\mathrm{LOG}}$ on $\mathrm{SV}$ across all samples and within different environments and pre-crops, only one linear regression out of 36 ones with a very small number of observations had an $\mathrm{R}^{2} \geq 0.50$ with $\mathrm{p}<0.05$ (Fig 19). In 2009, across cultivars SV increased significantly with increasing DON $_{\mathrm{LOG}}$ content after pre-crop maize. DON $_{\mathrm{ORG}}$ content in the respective samples ranged from 0.27 to $3.84 \mathrm{mg} \mathrm{kg}^{-1}$. Fig 19 also displays $\mathrm{EU}_{\mathrm{Max}}$ for $\mathrm{DON}$ in cereal flours $\left(\mathrm{EU}_{\mathrm{MaxCF}}\right)$ and unprocessed cereals $\left(\mathrm{EU}_{\mathrm{MaxUP}}\right)$

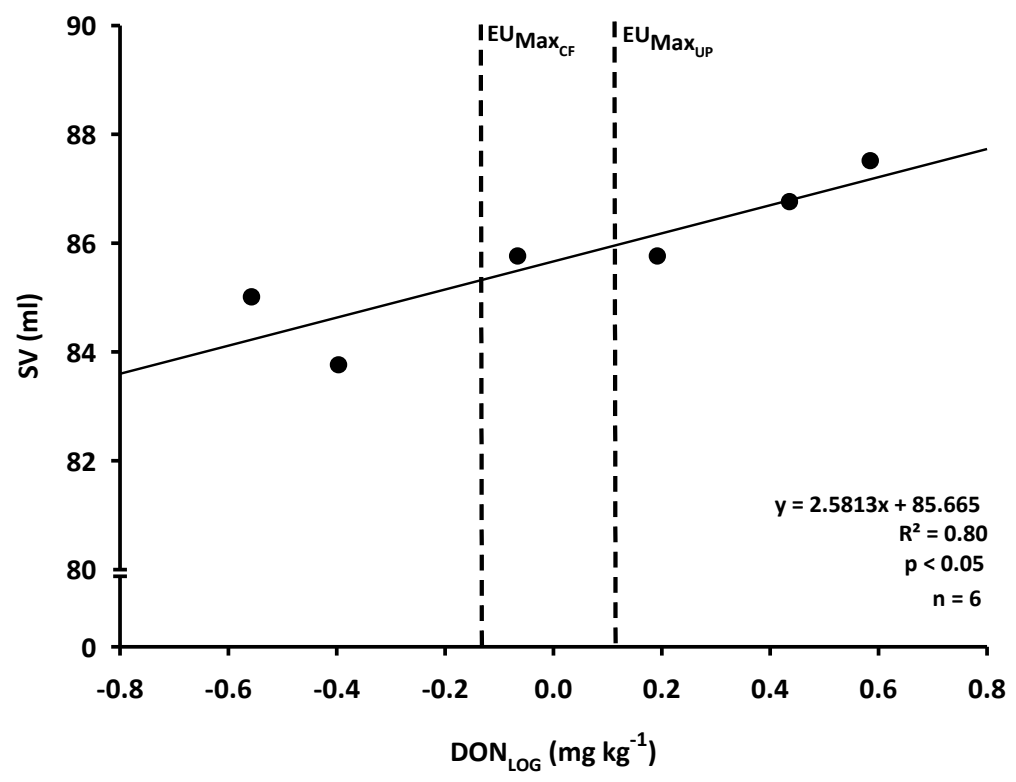

Fig 19. Linear regression of sedimentation value (SV) and $D O N_{\mathrm{LOG}}$ of flour Type $\mathbf{5 5 0}$ across cultivars (Centrum, Ritmo) in 2009 at location Gladebeck after pre-crop maize, $\mathrm{EU}_{\text {MaxcF }}=0.75 \mathrm{mg} \mathrm{kg}^{-1}, \mathrm{EU}_{\text {MaxuP }}=$ $1.25 \mathrm{mg} \mathrm{kg}^{-1}$ 


\subsubsection{Falling number $(\mathrm{FN})$}

FN was significantly affected by environment (year, location), pre-crop, and cultivar (Tab 54, Fig 20). Regarding years, FN was highest in 2009 (Ø 406), followed by 2008 (Ø 315) and lowest in 2007 (Ø 249). Across three years, cv. Ritmo showed significantly higher FN than cv. Centrum. The difference to cv. Centrum was 32, 39, and 21\% in 2007, 2008, and 2009, respectively. Even though not always statistically significant, FN generally dropped stepwise from pre-crop wheat over maize to sugar beet. This was particularly pronounced in 2007. FN of cv. Centrum was on average 18 and $29 \%$ and FN of cv. Ritmo 11 and 23\% lower after pre-crop maize and sugar beet, respectively, when compared to wheat as pre-crop.
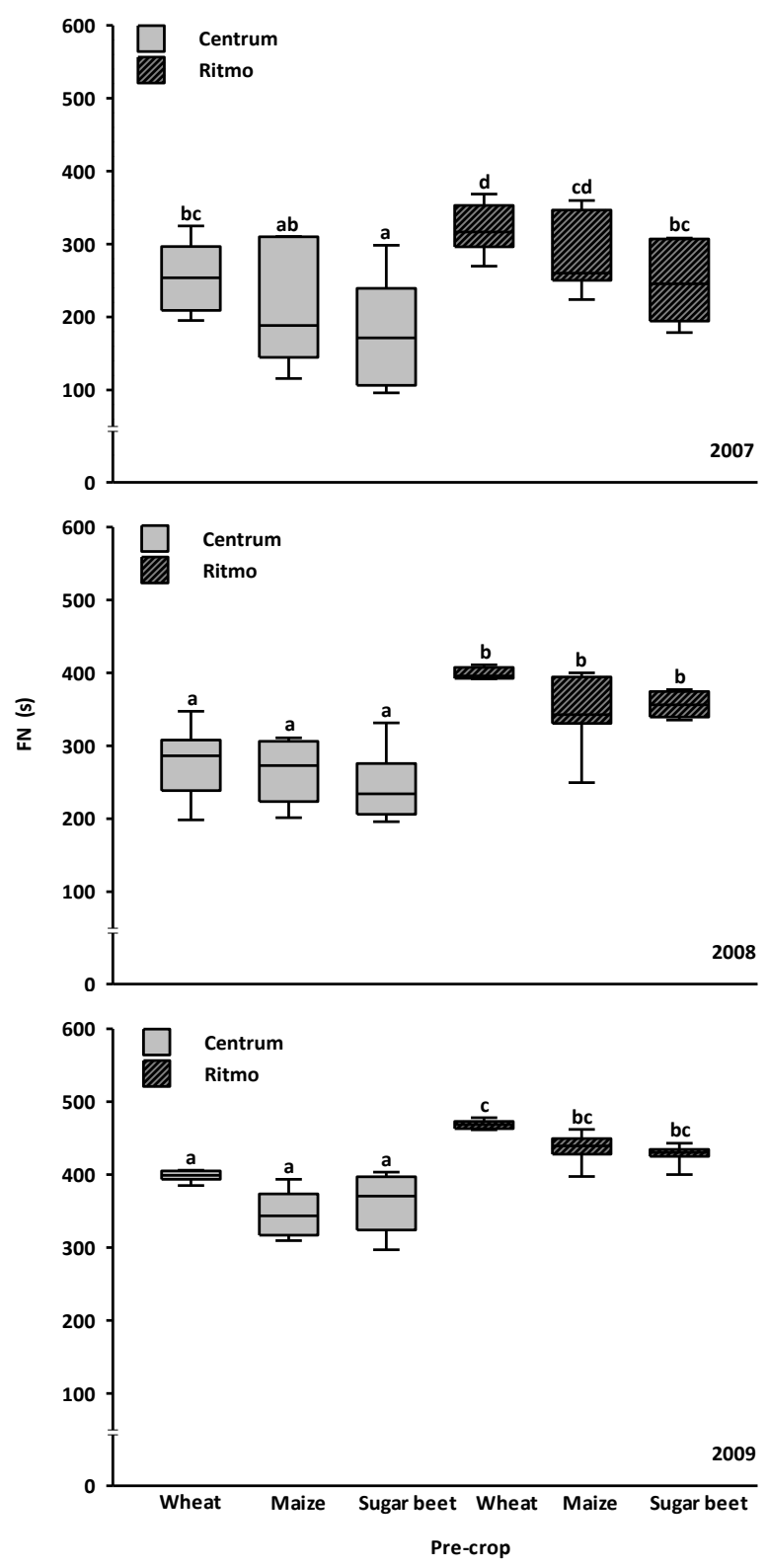

Fig 20. Falling number (FN) of wheat cultivars (Centrum, Ritmo) grown after pre-crop wheat, maize, and sugar beet in 2007, 2008, and 2009. Box plots with median (solid line) and whiskers indicating $5^{\text {th }} / 95^{\text {th }}$ percentiles. Box plots $(n=6)$ with same letters are not significantly different at $p<0.05$ according to Tukey test. 
ANCOVA showed a significant effect of DON within the interaction of environment and pre-crop (Tab 19). Investigation of the effect by means of linear regression showed that FN seemed to increase significantly with increasing DON content across cultivars within pre-crops sugar beet and maize on at least one location each year (Tab 20).

Tab 19. ANCOVA for effects of environment (E) (year, location), pre-crop (P), wheat cultivar (C), and DON ${ }_{L O G}$ on falling number (both measured in whole grain flour)

\begin{tabular}{|c|c|c|c|}
\hline Effect & DF & $\mathbf{F}$ & $\mathbf{p}$ \\
\hline Environment (E) & 3 & 73.90 & $* * *$ \\
\hline Pre-crop (P) & 2 & 16.07 & $* * *$ \\
\hline$E \times P$ & 6 & 6.59 & $* * *$ \\
\hline Cultivar (C) & 1 & 14.99 & $* * *$ \\
\hline $\mathrm{E} \times \mathrm{C}$ & 3 & 7.29 & $* *$ \\
\hline$P \times C$ & 2 & 3.25 & $(*)$ \\
\hline$E \times P \times C$ & 4 & 4.60 & $* *$ \\
\hline DON & 1 & 1.96 & n.s. \\
\hline DON x E & 3 & 2.16 & n.s. \\
\hline DON x P & 2 & 2.00 & n.s. \\
\hline DON x E x P & 6 & 2.65 & $*$ \\
\hline DON x C & 1 & 0.06 & n.s. \\
\hline DON x ExC & 3 & 1.08 & n.s. \\
\hline DON $\times$ P x C & 2 & 0.13 & n.s. \\
\hline DON $x E \times P \times C$ & 4 & 2.68 & $(*)$ \\
\hline
\end{tabular}

Tab 20. Parameters of linear regression of falling number (s) and $D O N_{L O G}\left(\mathrm{mg} \mathrm{kg}^{-1}\right)$ (both measured in whole grain flour) in different environments (E) (years, location) and pre-crops (P) across cultivars, and range of original DON values (DON ${ }_{O R G}$ )

\begin{tabular}{|c|c|c|c|c|c|c|c|c|c|c|}
\hline \multirow[t]{2}{*}{ Effect } & \multicolumn{4}{|c|}{ Effect level } & \multirow[b]{2}{*}{$\mathbf{n}$} & \multirow[b]{2}{*}{$\mathbf{R}^{2}$} & \multirow[b]{2}{*}{$\mathbf{p}$} & \multirow[b]{2}{*}{ b } & \multicolumn{2}{|c|}{$\mathrm{DON}_{\mathrm{ORG}}\left(\mathrm{mg} \mathrm{kg}^{-1}\right)$} \\
\hline & Year & Location & Cultivar & Pre-crop & & & & & a & Min-Max \\
\hline \multirow{6}{*}{$E \times P$} & \multirow{2}{*}{2007} & \multirow{2}{*}{$\mathrm{TL}$} & Centrum & Maize & 6 & 0.88 & $* *$ & 74.66 & 240.62 & $1.38-6.61$ \\
\hline & & & \& Ritmo & Sugar beet & 6 & 0.81 & $*$ & 175.54 & 154.36 & $0.26-1.74$ \\
\hline & \multirow{4}{*}{2009} & TL \& GB & $\begin{array}{l}\text { Centrum } \\
\& \text { Ritmo }\end{array}$ & Sugar beet & 12 & 0.56 & $* *$ & 456.70 & 47.98 & $0.00-1.70$ \\
\hline & & $\mathrm{TL}$ & $\begin{array}{l}\text { Centrum } \\
\& \text { Ritmo }\end{array}$ & Sugar beet & 6 & 0.94 & $* *$ & 451.79 & 28.07 & $0.00-0.37$ \\
\hline & & \multirow{2}{*}{ GB } & Centrum & Maize & 6 & 0.88 & $* *$ & 436.73 & 40.82 & $0.00-1.70$ \\
\hline & & & \& Ritmo & Sugar beet & 6 & 0.82 & $*$ & 463.57 & 68.54 & $0.00-0.30$ \\
\hline
\end{tabular}

n number of observations, $\mathrm{p}$ significance: ${ }^{* *},{ }^{* *}$, and ${ }^{*}=\mathrm{p}<0.001,0.01,0.05, \mathrm{~b}$ constant, a slope, TL Torland, GB Gladebeck

Since cultivar had a significant influence on FN, regardless of Fusarium infection, linear regression was additionally performed within cultivars. Thereafter, only in cv. Ritmo a significant positive correlation between $\mathrm{DON}_{\mathrm{LOG}}$ and FN could be detected after previous crop maize in 2007 and previous crop wheat in 2009, respectively (Fig 21). DON ORG $_{\text {of }}$ WGF from cv. Ritmo ranged from $3.11-10.24 \mathrm{mg} \mathrm{kg}^{-1}$ in 2007 after maize and from 0.13 to $2.05 \mathrm{mg} \mathrm{kg}^{-1}$ in 2009 after pre-crop wheat. 


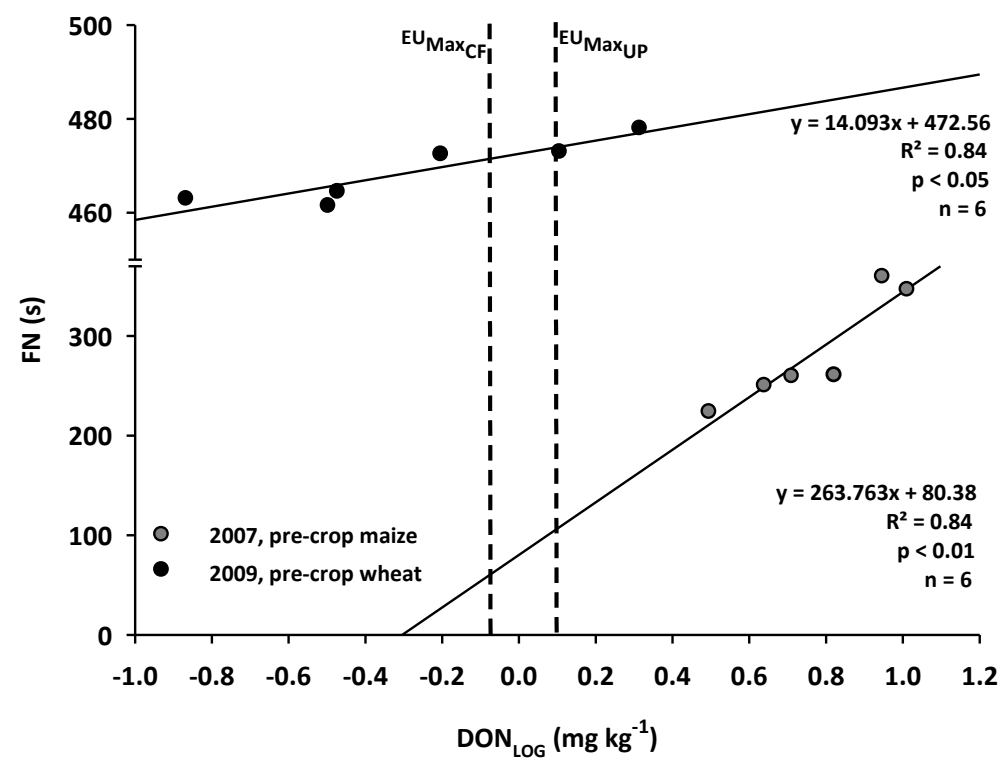

Fig 21. Linear regression between falling number (FN) and $D O N_{L O G}$ (both measured in whole grain flour) from cv. Ritmo in 2007 and 2009 grown after pre-crop maize and wheat across locations (Torland, Gladebeck), $\mathrm{EU}_{\mathrm{MaxCF}}=0.75 \mathrm{mg} \mathrm{kg}^{-1}, \mathrm{EU}_{\text {MaxUP }}=1.25 \mathrm{mg} \mathrm{kg}^{-1}$

\subsubsection{Water absorption (WA) and mixing properties of dough (DDT, DST, DS)}

WA was primarily influenced by year and pre-crop (Tab 21, Tab 55). In 2007, WA was significantly higher than in the two following years. Flour absorbed on average 63.5, 57.2, and $54.9 \%$ water in 2007,2008 , and 2009, respectively. Within 2007, additionally a significant effect of cultivar and pre-crop was observed which could not be detected in the two following years. In 2007, cv. Ritmo exhibited overall higher WA than cv. Centrum, a difference which was significant after pre-crop wheat and sugar beet.

DDT was influenced by year and cultivar (Tab 21, Tab 55). Doughs developed significantly faster in 2007 (Ø $1.4 \mathrm{~min}$ ), than in 2008 (Ø $1.9 \mathrm{~min})$ and 2009 (Ø $2.0 \mathrm{~min})$. Across years, doughs from cv. Centrum (Ø $1.5 \mathrm{~min}$ ) developed significantly faster than the respective doughs of cv. Ritmo ( $1.9 \mathrm{~min}$ ). Within years 2008 and 2009, differences between cultivars were not detectable, only cv. Ritmo after pre-crop maize showed significantly higher DDT than the rest of the doughs. In 2007, an effect of pre-crop was observed in cv. Ritmo. After maize, dough developed within significantly less time than after sugar beet and wheat.

DST highly depended on year (Tab 21, Tab 55). Doughs were significantly more tolerant to mixing in 2009 (Ø $7.8 \mathrm{~min}$ ) than in 2007 (Ø $1.3 \mathrm{~min})$ and 2008 (Ø $2.8 \mathrm{~min})$. Within and across years and cultivars, a significant effect of cultivar and pre-crop was not detectable.

DS was particularly influenced by year (Tab 21, Tab 55). In 2007 (Ø 95 VU) and 2008 (Ø 92 FU) doughs lost significantly more of their consistency after 12 min of mixing than in 2009 (Ø $50 \mathrm{FU}$ ). Effect of cultivar depended on environment. Effect of pre-crop depended on cultivar and year. 
However across all samples, no significant effect of cultivar and pre-crop on DS could be detected. Interestingly, in 2007 DS showed a very high variability within cultivars and pre-crops (indicated by high SD) which was not so pronounced in the other years. Average coefficient of variation in 2007 was $40 \%$ compared to 15 and $32 \%$ in 2008 and 2009, respectively.

Tab 21. Water absorption (WA) and mixing properties of dough (dough development time: DDT, dough stability: DST, dough softening: DS) of wheat cv. (Centrum, Ritmo) grown after different pre-crops in 2007, 2008, and 2009 (MV \pm SD, $n=6$ )

\begin{tabular}{|c|c|c|c|c|c|c|c|c|c|c|c|c|c|c|c|c|c|c|}
\hline \multirow{2}{*}{ Year } & \multirow{4}{*}{$\begin{array}{l}\text { Cultivar } \\
\text { Centrum }\end{array}$} & \multirow{2}{*}{$\begin{array}{l}\text { Pre-crop } \\
\text { Wheat }\end{array}$} & \multicolumn{4}{|c|}{ WA (\%) } & \multicolumn{4}{|c|}{ DDT (min) } & \multicolumn{4}{|c|}{ DST (min) } & \multicolumn{4}{|c|}{ DS (2007: VU, 2008/9: FU) } \\
\hline & & & 62.5 & \pm & 1.1 & $a$ & 1.1 & \pm & 0.2 & $a$ & 1.4 & \pm & 0.6 & $a$ & 67 & \pm & 28 & a \\
\hline \multirow{5}{*}{2007} & & Maize & 62.5 & \pm & 0.5 & a & 1.2 & \pm & 0.2 & $a b$ & 0.8 & \pm & 0.4 & $\mathbf{a}$ & 98 & \pm & 47 & b \\
\hline & & Sugar beet & 62.8 & \pm & 0.9 & a & 1.3 & \pm & 0.2 & $a b$ & 1.0 & \pm & 0.1 & a & 85 & \pm & 44 & $a b$ \\
\hline & & Wheat & 65.2 & \pm & 0.9 & b & 1.9 & \pm & 0.3 & c & 1.8 & \pm & 0.4 & $a$ & 83 & \pm & 24 & $a b$ \\
\hline & Ritmo & Maize & 63.0 & \pm & 1.0 & $a$ & 1.1 & \pm & 0.2 & a & 1.2 & \pm & 0.6 & a & 140 & \pm & 51 & c \\
\hline & & Sugar beet & 65.0 & \pm & 1.5 & b & 1.6 & \pm & 0.4 & bc & 1.6 & \pm & 0.2 & a & 97 & \pm & 33 & b \\
\hline \multirow{4}{*}{2008} & \multirow{2}{*}{ Centrum } & Maize & 57.0 & \pm & 0.8 & a & 1.8 & \pm & 0.1 & a & 2.4 & \pm & 0.8 & a & 97 & \pm & 7 & $a b$ \\
\hline & & Sugar beet & 56.4 & \pm & 0.6 & $a$ & 1.7 & \pm & 0.2 & a & 2.4 & \pm & 1.0 & a & 107 & \pm & 13 & b \\
\hline & \multirow{2}{*}{ Ritmo } & Maize & 57.7 & \pm & 0.7 & $a$ & 2.6 & \pm & 1.0 & b & 3.5 & \pm & 1.5 & $a$ & 76 & \pm & 19 & $a$ \\
\hline & & Sugar beet & 57.8 & \pm & 0.6 & a & 2.0 & \pm & 0.3 & $\mathbf{a}$ & 2.9 & \pm & 1.3 & a & 83 & \pm & 12 & $\mathbf{a}$ \\
\hline \multirow{4}{*}{2009} & \multirow{2}{*}{ Centrum } & Maize & 54.5 & \pm & 0.5 & $a$ & 1.9 & \pm & 0.2 & $a$ & 9.2 & \pm & 7.6 & $a b$ & 33 & \pm & 17 & $a$ \\
\hline & & Sugar beet & 55.0 & \pm & 0.6 & $a$ & 1.9 & \pm & 0.1 & a & 9.4 & \pm & 6.3 & b & 29 & \pm & 12 & $\mathbf{a}$ \\
\hline & \multirow{2}{*}{ Ritmo } & Maize & 55.0 & \pm & 0.2 & a & 2.6 & \pm & 0.9 & b & 5.3 & \pm & 2.4 & $a$ & 59 & \pm & 15 & b \\
\hline & & Sugar beet & 55.1 & \pm & 0.3 & a & 2.0 & \pm & 0.3 & a & 7.4 & \pm & 2.7 & $a b$ & 39 & \pm & 5 & $a b$ \\
\hline
\end{tabular}

Same letters indicate no differences between cultivars and pre-crops within years at a significance level of $p<0.05$ according to Tukey test

ANCOVA showed that Fusarium infection neither explained any of the variance of WA of flour (Tab 22), nor of DDT (Tab 23) or DST (Tab 24) sufficiently. Therefore, ANOVA was adequate for these parameters.

Tab 22. ANCOVA for effects of environment (E) (year. Location), pre-crop (P), wheat cultivar (C), and DON ${ }_{\mathrm{LOG}}(\mathrm{DON})$ and ANOVA for effects of $\mathrm{E}$, P, and $\mathrm{C}$ on water absorption

\begin{tabular}{|c|c|c|c|c|c|}
\hline \multirow[b]{2}{*}{ Effect } & \multicolumn{3}{|c|}{ ANCOVA } & \multicolumn{2}{|c|}{ ANOVA } \\
\hline & DF & $F$ & $p$ & $\mathbf{F}$ & $p$ \\
\hline Environment (E) & 3 & 31.40 & $* * *$ & 464.69 & $* * *$ \\
\hline Pre-crop (P) & 2 & 0.00 & n.s. & 6.81 & $* *$ \\
\hline$E \times P$ & 4 & 2.45 & $(*)$ & 1.68 & n.s. \\
\hline Cultivar (C) & 1 & 0.62 & n.s. & 34.50 & $* * *$ \\
\hline$E \times C$ & 3 & 0.99 & n.s. & 2.61 & $(*)$ \\
\hline$P \times C$ & 2 & 1.20 & n.s. & 4.16 & $*$ \\
\hline$E \times P \times C$ & 4 & 0.53 & n.s. & 1.65 & n.s. \\
\hline DON & 1 & 0.13 & n.s. & & \\
\hline DON XE & 3 & 1.51 & n.s. & & \\
\hline DON X P & 2 & 1.82 & n.s. & & \\
\hline$D O N \times E \times P$ & 4 & 0.49 & n.s. & & \\
\hline DON x C & 1 & 0.92 & n.s. & & \\
\hline DON $\times E \times C$ & 3 & 0.81 & n.s. & & \\
\hline DON x P x C & 2 & 0.13 & n.s. & & \\
\hline DON $\times E \times P \times C$ & 4 & 2.60 & $(*)$ & & \\
\hline
\end{tabular}


Tab 23. ANCOVA for effects of environment (E) (year, location), pre-crop (P), wheat

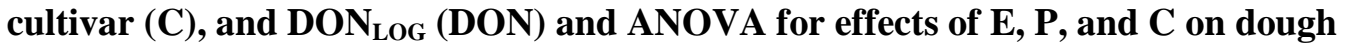
development time

\begin{tabular}{|c|c|c|c|c|c|}
\hline \multirow[b]{2}{*}{ Effect } & \multicolumn{3}{|c|}{ ANCOVA } & \multicolumn{2}{|c|}{ ANOVA } \\
\hline & DF & $\mathbf{F}$ & $p$ & $\mathbf{F}$ & $p$ \\
\hline Environment (E) & 3 & 3.06 & $(*)$ & 55.83 & $* * *$ \\
\hline Pre-crop (P) & 2 & 0.23 & n.s. & 2.53 & $(*)$ \\
\hline$E \times P$ & 4 & 0.35 & n.s. & 6.91 & $* * *$ \\
\hline Cultivar (C) & 1 & 0.26 & n.s. & 48.05 & $* * *$ \\
\hline $\mathrm{E} \times \mathrm{C}$ & 3 & 1.05 & n.s. & 10.82 & $* * *$ \\
\hline$P \times C$ & 2 & 0.03 & n.s. & 7.25 & $* *$ \\
\hline$E \times P \times C$ & 4 & 0.55 & n.s. & 5.17 & $* *$ \\
\hline DON & 1 & 0.8 & n.s. & & \\
\hline DON xE & 3 & 0.57 & n.s. & & \\
\hline DON x P & 2 & 0.56 & n.s. & & \\
\hline DON $x$ ExP & 4 & 1.24 & n.s. & & \\
\hline DON x C & 1 & 0.09 & n.s. & & \\
\hline DON $\times$ ExC & 3 & 0.48 & n.s. & & \\
\hline DON $x$ P x C & 2 & 0.35 & n.s. & & \\
\hline DON $x E \times P \times C$ & 4 & 0.68 & n.s. & & \\
\hline
\end{tabular}

Tab 24. ANCOVA for effects of environment (E) (year, location), pre-crop (P), wheat

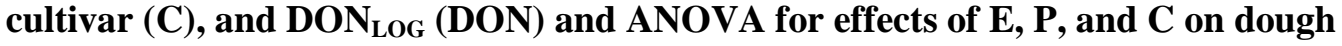
stability

\begin{tabular}{|c|c|c|c|c|c|}
\hline \multirow[b]{2}{*}{ Effect } & \multicolumn{3}{|c|}{ ANCOVA } & \multicolumn{2}{|c|}{ ANOVA } \\
\hline & DF & $\mathbf{F}$ & $p$ & $\mathbf{F}$ & p \\
\hline Environment (E) & 3 & 1.99 & n.s. & 54.57 & $* * *$ \\
\hline Pre-crop (P) & 2 & 0.06 & n.s. & 0.82 & n.s. \\
\hline$E \times P$ & 4 & 0.36 & n.s. & 1.21 & n.s. \\
\hline Cultivar (C) & 1 & 0.02 & n.s. & 3.30 & $(*)$ \\
\hline $\mathrm{E} \times \mathrm{C}$ & 3 & 0.73 & n.s. & 6.96 & $* * *$ \\
\hline $\mathrm{P} \times \mathrm{C}$ & 2 & 0.13 & n.s. & 0.34 & n.s. \\
\hline$E \times P \times C$ & 4 & 0.22 & n.s. & 0.89 & n.s. \\
\hline DON & 1 & 0.01 & n.s. & & \\
\hline DON XE & 3 & 0.54 & n.s. & & \\
\hline DON x P & 2 & 0.04 & n.s. & & \\
\hline DON x ExP & 4 & 0.03 & n.s. & & \\
\hline DON x C & 1 & 0.01 & n.s. & & \\
\hline DON x E x C & 3 & 0.07 & n.s. & & \\
\hline DON $\times$ P x C & 2 & 0.04 & n.s. & & \\
\hline DON $\times E \times P \times C$ & 4 & 0.38 & n.s. & & \\
\hline
\end{tabular}

ANCOVA for DS discovered a significant effect of $\mathrm{DON}_{\mathrm{LOG}}$ within environment and the interaction of environment with pre-crop (Tab 25). Since the slight differences between cultivars (Tab 21) and also environmental effects became insignificant when ${ }^{-} \mathrm{N}_{\text {LOG }}$ was considered, it seemed legitimate to perform linear regression of DS and $\mathrm{DON}_{\mathrm{LOG}}$ within pre-crops across cultivars and locations (Tab 26). In pre-crop maize, $\mathrm{DON}_{\mathrm{LOG}}$ explained 60 and $82 \%$ of the variability in DS 
in 2007 and 2009. $\mathrm{R}^{2}$ increased if linear regression was performed separately for locations and precrop maize. Linear regression across cultivars and pre-crops within years increased the number of observations but gave weaker $\mathrm{R}^{2}$ (Tab 26, Fig 22).

Tab 25. ANCOVA for effects of environment (E), pre-crop (P), wheat cultivar (C), and DON $_{\text {LOG }}(\mathrm{DON})$ on dough softening

\begin{tabular}{|c|c|c|c|}
\hline Effect & DF & $\mathbf{F}$ & $\mathbf{p}$ \\
\hline Environment (E) & 3 & 0.44 & n.s. \\
\hline Pre-crop (P) & 2 & 3.58 & $*$ \\
\hline$E \times P$ & 4 & 2.34 & $(*)$ \\
\hline Cultivar (C) & 1 & 0.00 & n.s. \\
\hline $\mathrm{E} \times \mathrm{C}$ & 3 & 3.33 & $*$ \\
\hline$P \times C$ & 2 & 0.51 & n.s. \\
\hline$E \times P \times C$ & 4 & 2.38 & $(*)$ \\
\hline DON & 1 & 0.44 & n.s. \\
\hline DON x E & 3 & 5.90 & $* *$ \\
\hline DON x P & 2 & 2.34 & n.s. \\
\hline DON $\times E \times P$ & 4 & 3.02 & $*$ \\
\hline DON x C & 1 & 0.83 & n.s. \\
\hline DON $\times E \times C$ & 3 & 0.60 & n.s. \\
\hline DON $\times$ P x C & 2 & 3.40 & $(*)$ \\
\hline DON $x E \times P \times C$ & 4 & 0.84 & n.s. \\
\hline
\end{tabular}

Regardless of the factors levels included into linear regression, DS increased significantly with higher DON content of flour Type 550 (Fig 22) which was particularly observed after previous crop maize (Tab 26).

Tab 26. Parameters of linear regression of dough softening (VU/FU) and $D_{\text {OON }}(\mathrm{mg}$ $\mathrm{kg}^{-1}$ ) within different environments (E) (year, location) and pre-crops (P) across cultivars, and range of original DON values (DON $\left.{ }_{\text {ORG }}\right)$

\begin{tabular}{|c|c|c|c|c|c|c|c|c|c|c|}
\hline \multirow[t]{2}{*}{ Effect } & \multicolumn{4}{|c|}{ Effect level } & \multirow[b]{2}{*}{$\mathbf{n}$} & \multirow[b]{2}{*}{$\mathbf{R}^{2}$} & \multirow[b]{2}{*}{ p } & \multirow[b]{2}{*}{ l } & \multicolumn{2}{|c|}{$\mathrm{DON}_{\mathrm{ORG}}\left(\mathrm{mg} \mathrm{kg}^{-1}\right)$} \\
\hline & Year & Location & Cultivar & Pre-crop & & & & & $\mathbf{a}$ & Min-Max \\
\hline \multirow{3}{*}{$E$} & \multirow[b]{2}{*}{2007} & $\overline{\mathrm{TL}}$ & \multirow{2}{*}{$\begin{array}{l}\text { Centrum } \\
\& \text { Ritmo }\end{array}$} & \multirow{2}{*}{$\begin{array}{c}\text { Wheat \& } \\
\text { Maize \& } \\
\text { Sugar beet }\end{array}$} & 18 & 0.57 & $* * *$ & 112.68 & 55.07 & $0.31-11.84$ \\
\hline & & GB & & & 18 & 0.59 & $* * *$ & 57.67 & 34.77 & $0.33-8.70$ \\
\hline & 2009 & TL & $\begin{array}{l}\text { Centrum } \\
\text { \& Ritmo }\end{array}$ & $\begin{array}{c}\text { Maize \& } \\
\text { Sugar beet }\end{array}$ & 12 & 0.69 & $* * *$ & 44.19 & 24.69 & $0.16-8.42$ \\
\hline \multirow{7}{*}{$E \times P$} & 2007 & \multirow{2}{*}{$\mathrm{TL} \& \mathrm{~GB}$} & Centrum & \multirow{2}{*}{ Maize } & 12 & 0.60 & $* *$ & 61.63 & 98.21 & $0.37-11.84$ \\
\hline & 2009 & & \& Ritmo & & 12 & 0.82 & $* * *$ & 34.13 & 39.78 & $0.39-8.42$ \\
\hline & \multirow{2}{*}{$2007 \& 2009$} & $\overline{T L}$ & Centrum & Sugar beet & 12 & 0.51 & $* *$ & 105.48 & 104.16 & $0.16-1.73$ \\
\hline & & GB & \& Ritmo & Maize & 12 & 0.74 & $* * *$ & 43.04 & 54.76 & $0.27-8.70$ \\
\hline & \multirow{2}{*}{2007} & $\mathrm{TL}$ & \multirow{3}{*}{$\begin{array}{l}\text { Centrum } \\
\text { \& Ritmo }\end{array}$} & \multirow{3}{*}{ Maize } & 6 & 0.88 & $* *$ & 92.31 & 91.73 & $2.52-11.84$ \\
\hline & & GB & & & 6 & 0.80 & $*$ & 56.15 & 48.85 & $0.67-8.70$ \\
\hline & 2009 & GB & & & 6 & 0.81 & $*$ & 32.94 & 37.14 & $0.27-3.84$ \\
\hline
\end{tabular}

$\mathrm{n}$ number of observations, $\mathrm{p}$ significance: ${ }^{* * *},{ }^{* *}$, and ${ }^{*}=\mathrm{p}<0.001,0.01,0.05, \mathrm{~b}$ constant, a slope, TL Torland, GB Gladebeck 


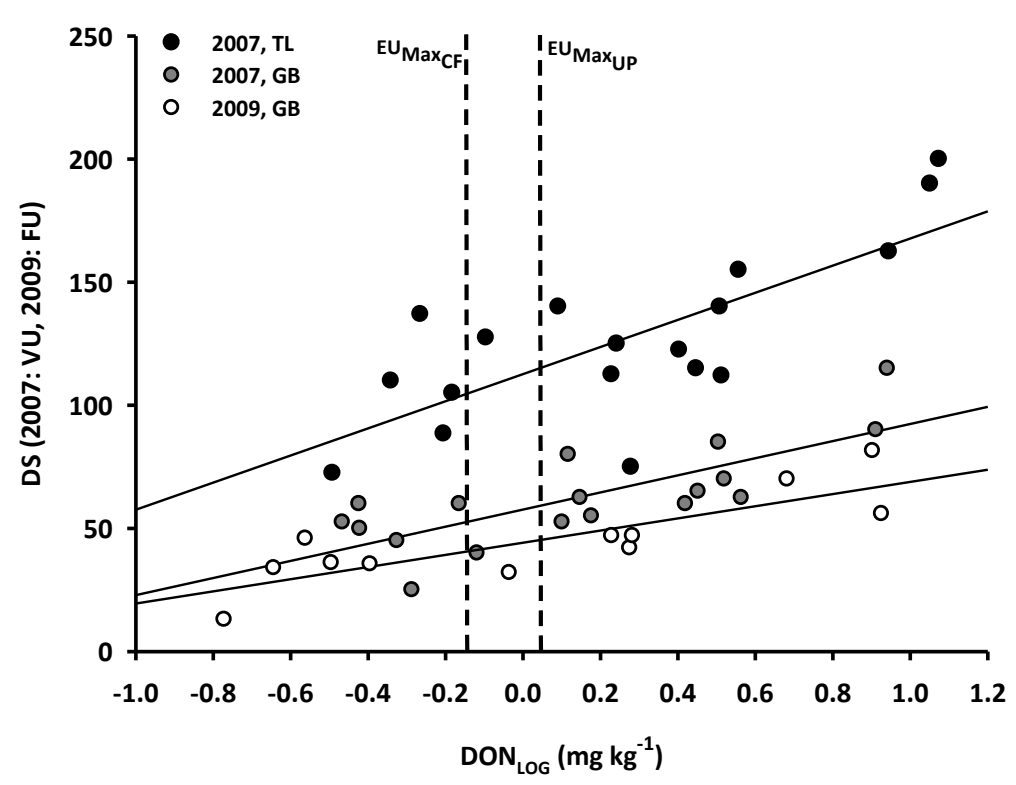

Fig 22. Linear regression of dough softening (DS) and $D O N_{\text {LOG }}$ in 2007 within locations Torland (TL) and Gladebeck (GB) and within location GB in $\mathbf{2 0 0 9}$ across cultivars and pre-crops (for regression parameters see $\mathrm{Tab} 26), \mathrm{EU}_{\text {MaxcF }}=0.75 \mathrm{mg} \mathrm{kg}^{-1}, \mathrm{EU}_{\text {MaxUP }}=1.25 \mathrm{mg} \mathrm{kg}^{-1}$

\subsubsection{Baking properties (BV, LH, LL, LW)}

BV was predominately influenced by year (Fig 23, Tab 28, Tab 56). In 2007 (Ø $408 \mathrm{ml} 100 \mathrm{~g}^{-1}$

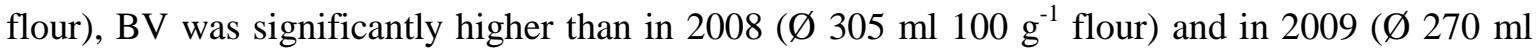
$100 \mathrm{~g}^{-1}$ flour). Only in 2007, baking properties showed significant differences between cultivars. Cv. Ritmo (Ø $428 \mathrm{ml} 100 \mathrm{~g}^{-1}$ flour) showed on average a 10\% higher BV than cv. Centrum (Ø 388 $\mathrm{ml} 100 \mathrm{~g}^{-1}$ flour) while there were no differences between pre-crops within cultivars. Regarding loaf shape, all measures, LH, LL; LW, were also significantly affected by year (Fig 23, Tab 28, Tab 56). Loaves in 2007 were significantly longer, wider, and flatter than in the two following years. While there were no significant differences in LL, LH or LW detectable between cultivars and pre-crops in 2008 and 2009, in 2007 differences of shape could be observed in cv. Ritmo. Loaves produced from wheat grown after maize expressed reduced height when compared to sugar beet, reduced length when compared to pre-crop wheat, and increased width when compared to both (Fig 23, Fig 24). 

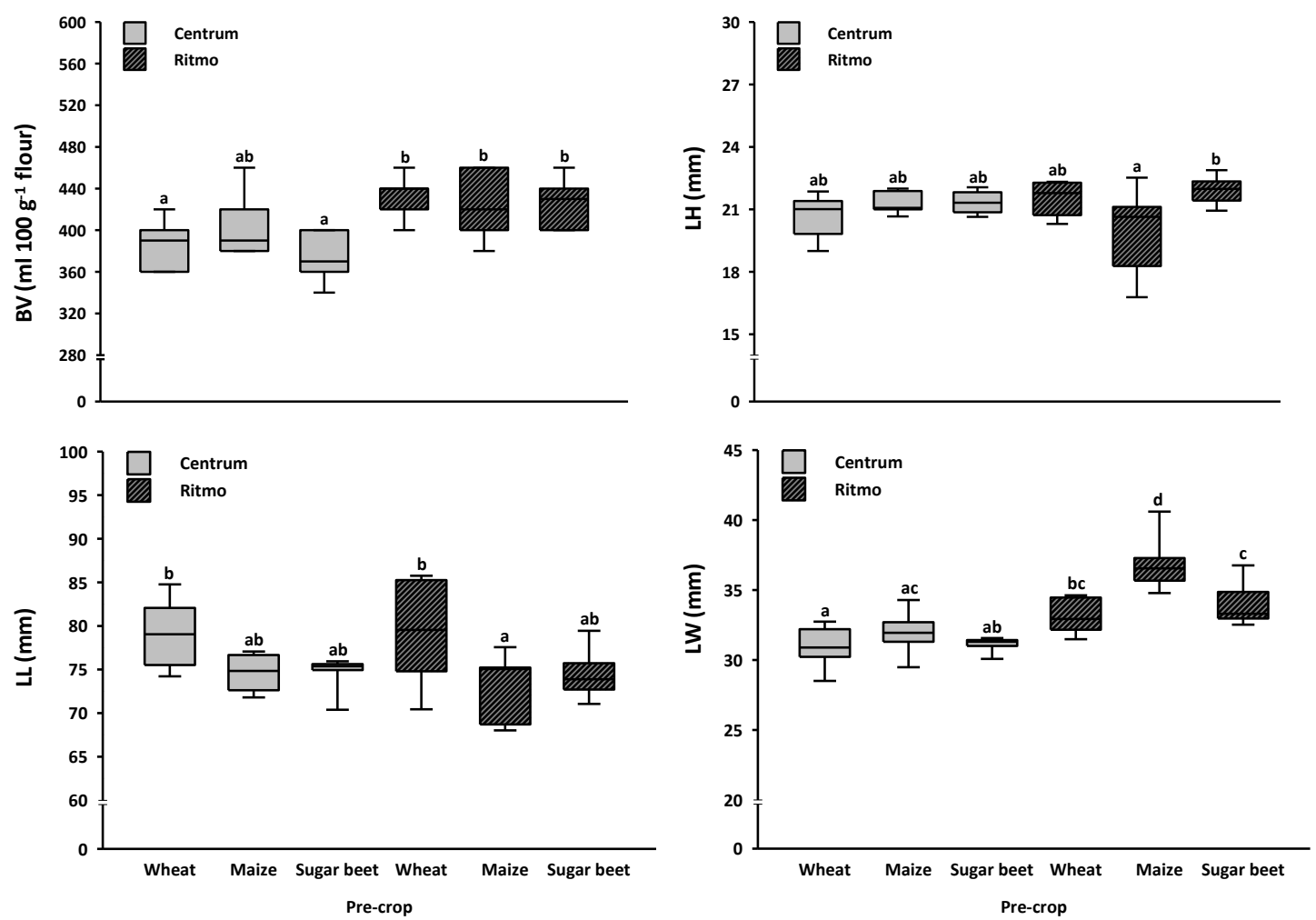

Fig 23. Baking properties (baking volume: BV, loaf heigth: LH, loaf length: LL, loaf width: LW) of two winter wheat cultivars (Centrum, Ritmo) grown after pre-crop wheat, maize, and sugar beet in 2007. Box plots with median (solid line) and whiskers indicating $5^{\text {th }} / 95^{\text {th }}$ percentiles. Box plots $(n=6)$ with same letters are not significantly different at $p<0.05$ according to Tukey test.

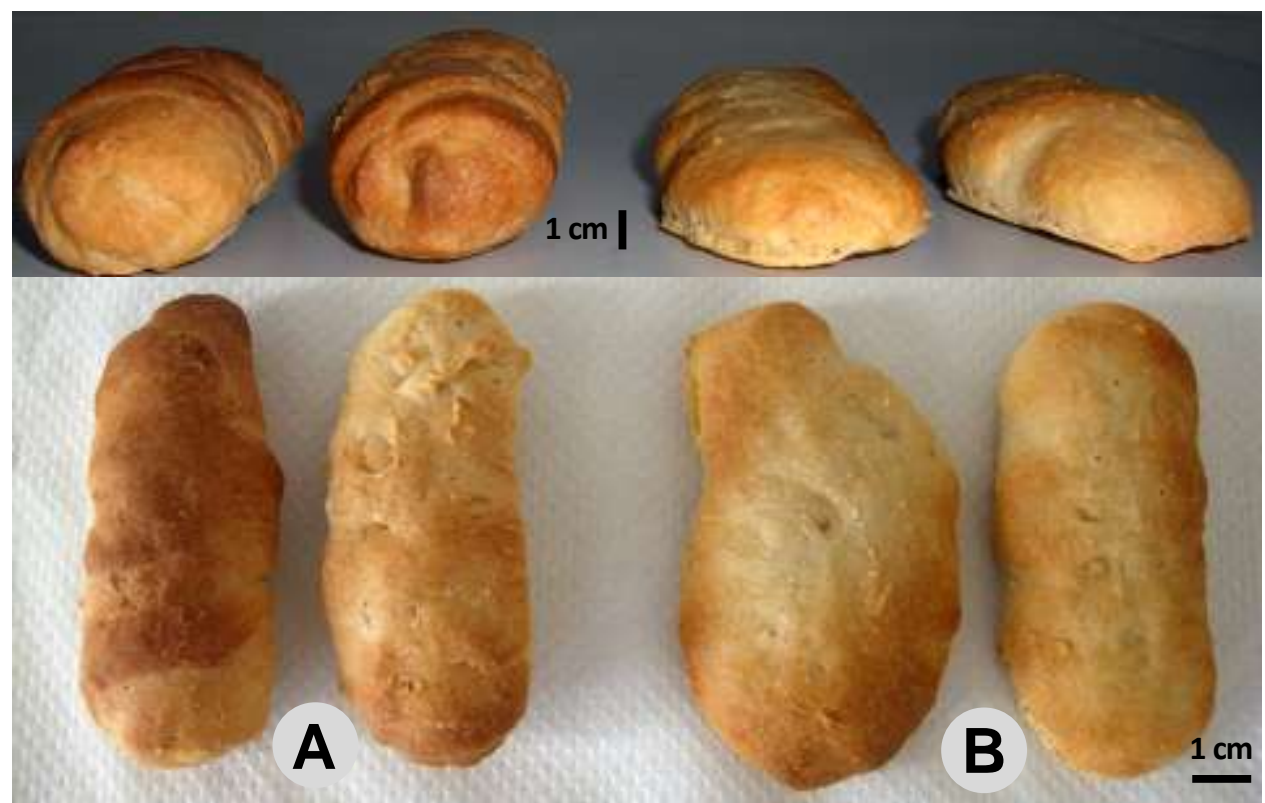

Fig 24. Loaves prepared from flour Type 550 from cv. Ritmo grown after pre-crop sugar beet (A) and precrop maize (B) in 2007, Pictures: KREUZBERGER 2008 
Tab 28. Baking properties(baking volume: BV, loaf length: LL, loaf height: $L H$, loaf width: LW) wheat cv. (Centrum, Ritmo) grown after pre-crop maize and sugar beet in 2008 and 2009 (pre-crop wheat: not analyzed) $(M V \pm S D, n=6)$

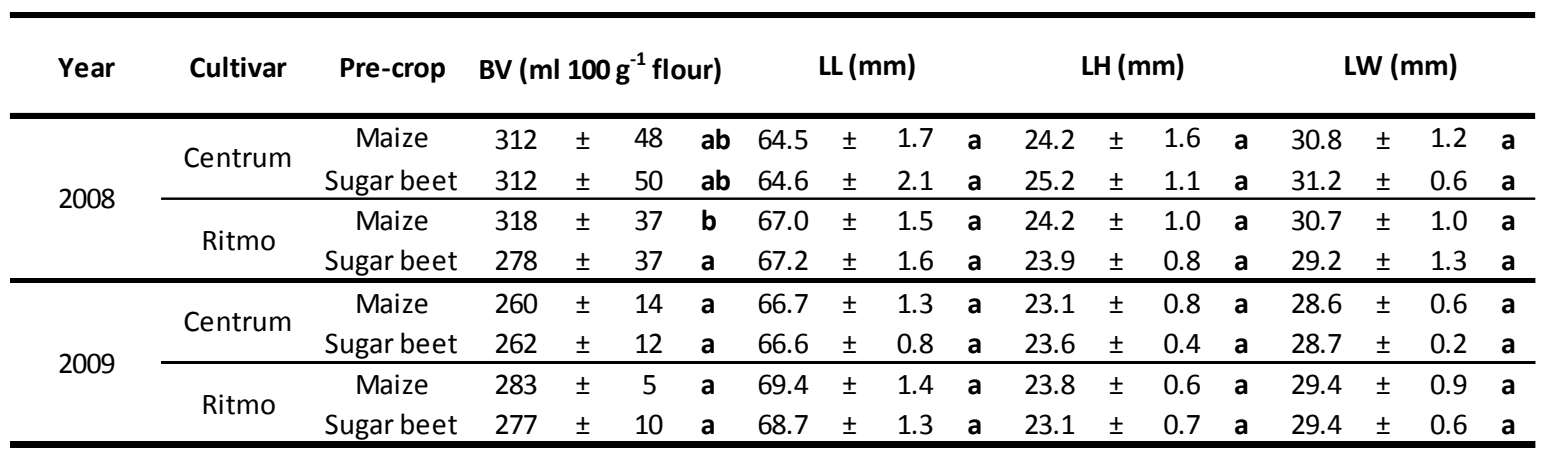

Same letters indicate no differences between cultivars and pre-crops within years at a significance level of $p<0.05$ according to Tukey test

ANCOVA detected an effect of $\mathrm{DON}_{\mathrm{LOG}}$ on $\mathrm{BV}$ and $\mathrm{LH}$ (Tab 29). However, linear regression of $D_{\text {DON }}$ LOG and LH did not reveal a significant relationship between the two parameters $\left(R^{2}=0.05, p\right.$ $>0.05, \mathrm{n}=72$ ). ANCOVA did not reveal a significant impact of DON on LL (Tab 30) and LW (Tab 31). In summary, there seemed to be no impact of Fusarium infection (on the basis of DON) on loaf shape.

Tab 29. ANCOVA for effects of environment (E) (year, location), pre-crop (P), wheat

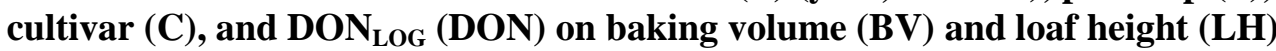

\begin{tabular}{|c|c|c|c|c|c|}
\hline \multirow[b]{2}{*}{ Effect } & \multirow[b]{2}{*}{ DF } & \multicolumn{2}{|c|}{ BV } & \multicolumn{2}{|c|}{ LH } \\
\hline & & $\mathbf{F}$ & $\mathbf{p}$ & $\mathbf{F}$ & $\mathbf{p}$ \\
\hline Environment (E) & 3 & 9.88 & $* * *$ & 4.95 & $* *$ \\
\hline Pre-crop (P) & 2 & 0.39 & n.s. & 2.21 & n.s. \\
\hline$E \times P$ & 4 & 1.34 & n.s. & 2.30 & $(*)$ \\
\hline Cultivar (C) & 1 & 7.89 & $*$ & 2.87 & n.s. \\
\hline$E \times C$ & 3 & 2.71 & $(*)$ & 1.52 & n.s. \\
\hline $\mathrm{P} \times \mathrm{C}$ & 2 & 1.09 & n.s. & 1.21 & n.s. \\
\hline$E \times P \times C$ & 4 & 3.31 & $*$ & 2.16 & n.s. \\
\hline DON & 1 & 0.27 & n.s. & 5.39 & $*$ \\
\hline DON x E & 3 & 2.98 & $(*)$ & 0.58 & n.s. \\
\hline DON x P & 2 & 4.46 & $*$ & 1.93 & n.s. \\
\hline DON $x$ ExP & 4 & 1.40 & n.s. & 1.37 & n.s. \\
\hline DON x C & 1 & 1.80 & n.s. & 0.42 & n.s. \\
\hline DON $x$ ExC & 3 & 4.36 & $*$ & 1.58 & n.s. \\
\hline DON x P x C & 2 & 2.12 & n.s. & 0.24 & n.s. \\
\hline DON $\times E \times P \times C$ & 4 & 5.48 & $* *$ & 2.37 & $(*)$ \\
\hline
\end{tabular}


Tab 30. ANCOVA for effects of environment (E) (year, location), pre-crop (P), wheat cultivar (C), and DON ${ }_{\mathrm{LOG}}(\mathrm{DON})$ and ANOVA for effects of E, P, and C on loaf length

\begin{tabular}{|c|c|c|c|c|c|}
\hline \multirow[b]{2}{*}{ Effect } & \multicolumn{3}{|c|}{ ANCOVA } & \multicolumn{2}{|c|}{ ANOVA } \\
\hline & $\mathrm{DF}$ & $\mathbf{F}$ & $p$ & $\mathbf{F}$ & $p$ \\
\hline Environment (E) & 3 & 3.12 & * & 23.82 & $* * *$ \\
\hline Pre-crop (P) & 2 & 3.36 & $(*)$ & 13.09 & $* * *$ \\
\hline$E \times P$ & 4 & 1.49 & n.s. & 3.30 & $*$ \\
\hline Cultivar (C) & 1 & 0.76 & n.s. & 1.57 & n.s. \\
\hline$E \times C$ & 3 & 1.66 & n.s. & 1.57 & n.s. \\
\hline $\mathrm{P} \times \mathrm{C}$ & 2 & 0.64 & n.s. & 0.13 & n.s. \\
\hline$E \times P \times C$ & 4 & 0.78 & n.s. & 0.94 & n.s. \\
\hline DON & 1 & 1.60 & n.s. & & \\
\hline DON x E & 3 & 1.12 & n.s. & & \\
\hline DON x P & 2 & 0.88 & n.s. & & \\
\hline DON $x$ ExP & 4 & 0.47 & n.s. & & \\
\hline DON x C & 1 & 0.10 & n.s. & & \\
\hline DON $\times E \times C$ & 3 & 0.73 & n.s. & & \\
\hline DON $x$ P x C & 2 & 0.94 & n.s. & & \\
\hline DON $x E \times P \times C$ & 4 & 0.70 & n.s. & & \\
\hline
\end{tabular}

Tab 31. ANCOVA for effects of environment (E), pre-crop (P), wheat cultivar (C), and $D \mathrm{~N}_{\mathrm{LOG}}(\mathrm{DON})$ and ANOVA for effects of $\mathrm{E}, \mathrm{P}$, and $\mathrm{C}$ on loaf width

\begin{tabular}{|c|c|c|c|c|c|}
\hline \multirow[b]{2}{*}{ Effect } & \multicolumn{3}{|c|}{ ANCOVA } & \multicolumn{2}{|c|}{ ANOVA } \\
\hline & DF & $\mathbf{F}$ & p & $\mathbf{F}$ & $\mathbf{p}$ \\
\hline Environment (E) & 3 & 0.06 & n.s. & 63.21 & $* * *$ \\
\hline Pre-crop (P) & 2 & 0.04 & n.s. & 10.28 & $* * *$ \\
\hline$E \times P$ & 4 & 0.69 & n.s. & 2.30 & $(*)$ \\
\hline Cultivar (C) & 1 & 0.83 & n.s. & 41.20 & $* * *$ \\
\hline$E \times C$ & 3 & 0.52 & n.s. & 7.64 & $* * *$ \\
\hline $\mathrm{P} \times \mathrm{C}$ & 2 & 0.96 & n.s. & 3.45 & $*$ \\
\hline$E \times P \times C$ & 4 & 0.08 & n.s. & 1.90 & n.s. \\
\hline DON & 1 & 0.02 & n.s. & & \\
\hline DON x E & 3 & 1.42 & n.s. & & \\
\hline DON x P & 2 & 3.07 & $(*)$ & & \\
\hline DON x ExP & 4 & 0.40 & n.s. & & \\
\hline DON x C & 1 & 1.10 & n.s. & & \\
\hline DON $\times E \times C$ & 3 & 0.86 & n.s. & & \\
\hline DON x P x C & 2 & 0.13 & n.s. & & \\
\hline DON $\times E \times P \times C$ & 4 & 0.71 & n.s. & & \\
\hline
\end{tabular}

Linear regression between DON and BV in significant effects of ANCOVA revealed a significant moderate to strong increase of $\mathrm{BV}$ with increasing $\mathrm{DON}_{\mathrm{LOG}}$ in $\mathrm{cv}$. Centrum across all pre-crops in 2007 at location Torland and within maize across both locations (Tab 32). Correlation of $\mathrm{DON}_{\mathrm{LOG}}$ and BV within pre-crop wheat/sugar beet across years, locations, and cultivars revealed the same trend. 
Tab 32. Parameters of linear regression of baking volume ( $\mathrm{ml} 100 \mathrm{~g}^{-1}$ flour) and DON $_{L O G}$ in different environments (E) (year, location), cultivars (C), and pre-crops $(P)$, and range of original DON values (DON $\left.{ }_{O R G}\right)$

\begin{tabular}{|c|c|c|c|c|c|c|c|c|c|c|}
\hline \multirow[t]{2}{*}{ Effect } & \multicolumn{4}{|c|}{ Effect level } & \multirow[b]{2}{*}{$\mathbf{n}$} & \multirow[b]{2}{*}{$\mathbf{R}^{2}$} & \multirow[b]{2}{*}{ p } & \multirow[b]{2}{*}{ b } & \multicolumn{2}{|c|}{$\mathrm{DON}_{\mathrm{ORG}}\left(\mathrm{mg} \mathrm{kg}^{-1}\right)$} \\
\hline & Year & Location & Cultivar & Pre-crop & & & & & a & Min-Max \\
\hline \multirow{2}{*}{$\mathbf{P}$} & 2007 & \multirow{2}{*}{$\mathrm{TL} \& \mathrm{~GB}$} & Centrum & Wheat & 12 & 0.51 & $* *$ & 407.89 & 55.72 & $0.31-3.65$ \\
\hline & $2007 \& 2009$ & & \& Ritmo & Sugar beet & 24 & 0.53 & $* * *$ & 366.55 & 84.67 & $0.33-2.82$ \\
\hline \multirow{3}{*}{$\mathrm{E} \times \mathrm{C}$} & \multirow{4}{*}{2007} & \multirow{3}{*}{$\mathrm{TL}$} & \multirow{4}{*}{ Centrum } & Wheat \& & & & & & & \\
\hline & & & & Maize \& & 9 & 0.66 & $* *$ & 400.75 & 58.47 & $0.31-3.59$ \\
\hline & & & & Sugar beet & & & & & & \\
\hline$E \times P \times C$ & & $\mathrm{TL} \&$ GB & & Maize & 6 & 0.66 & $*$ & 378.52 & 94.21 & $0.67-3.59$ \\
\hline
\end{tabular}

Gluten properties $\left(\mathbf{R}_{\mathrm{Max}}, \mathrm{EXT}, \mathbf{R}_{\mathrm{Max}} / \mathrm{EXT}\right)$

A micro-extension experiment on wet gluten from flour Type 550 in 2007 showed that both cultivars differed significantly in their gluten properties (Tab 33, Tab 59). While gluten stripes from cv. Centrum ruptured at an average force of $0.64 \mathrm{~N}$ and could be stretched until this point to an average length of $109 \mathrm{~mm}$, gluten stripes of $\mathrm{cv}$. Ritmo stayed intact until technical limitation of stretching $(140 \mathrm{~mm})$. Therefore, the two parameters $-\mathrm{R}_{\mathrm{MAX}}$ and EXT- which typically characterize the micro-extension experiment on dough and gluten, could not be used to compare the two cultivars directly except by a qualitative statement. In order to find a common quantitative measure to compare both cultivars, $\mathrm{R}_{\mathrm{MAX}} / \mathrm{EXT}$ was calculated. It became clear that significantly less force (about 66\%) was necessary to extend gluten of $\mathrm{cv}$. Ritmo $\left(\varnothing 2.1 \mathrm{~N} \mathrm{~m}^{-1}\right)$ to the same length as gluten of cv. Centrum $\left(\varnothing 6.0 \mathrm{~N} \mathrm{~m}^{-1}\right)$.

Tab 33. Gluten properties (resistance to extension: $\mathbf{R}_{\mathrm{MAx}}$, extensibility: EXT) of wheat cv. (Centrum, Ritmo) grown after pre-crop wheat, maize, and sugar beet in 2007 measured with SMS/Kieffer Dough and Gluten Extensibility Rig with Texture Analyzer (MV $\pm \mathrm{SD}, \mathrm{n}=6$ )

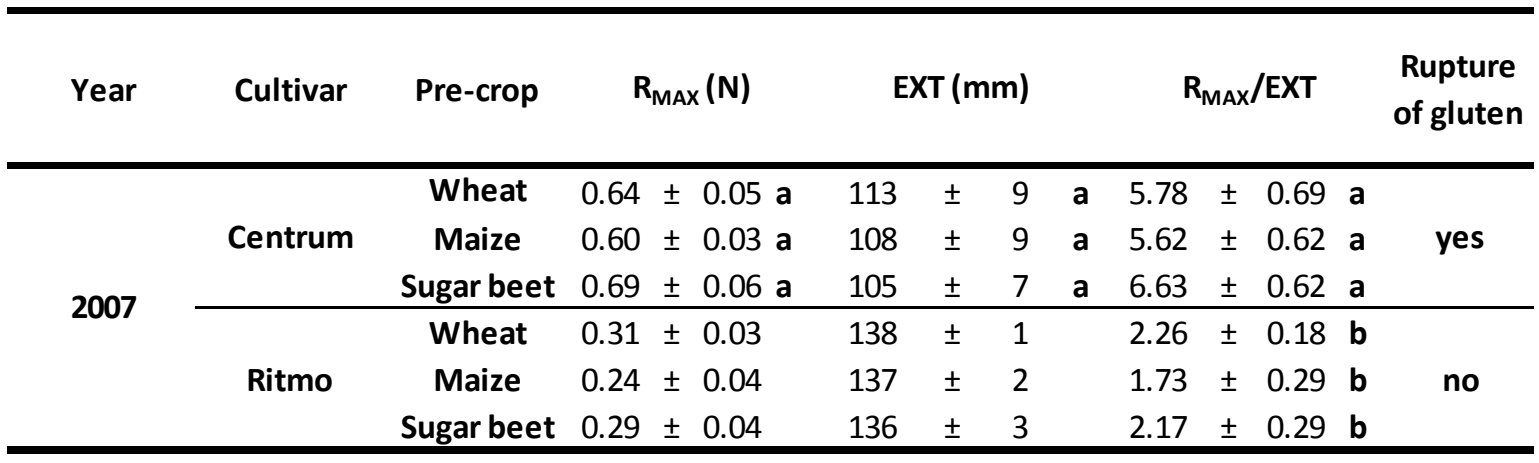

Same letters indicate no differences within cultivar Centrum between pre-crops for resistance to extension and extensibility and between cultivars and pre-crops for ratio of resistance to extension/extensibility at a significance level of $p<0.05$ according to Tukey test

ANCOVA for $\mathrm{R}_{\mathrm{MAX}} / \mathrm{EXT}$ showed no significant effect of $\mathrm{DON}_{\mathrm{LOG}}$ on the same and demonstrated again the highly significant effect of cultivar on the properties of gluten (Tab 34). 
Tab 34. ANCOVA for effects of location ( $L)$, pre-crop (P), wheat cultivar $(C)$, and $D^{D O N}{ }_{L O G}(D O N)$ and ANOVA for effects of $L, P$, and C on $R_{M A X} / E X T$ of wet gluten extracted from flour Type 550 in 2007

\begin{tabular}{|c|c|c|c|c|c|}
\hline \multirow[b]{2}{*}{ Effect } & \multicolumn{3}{|c|}{ ANCOVA } & \multicolumn{2}{|c|}{ ANOVA } \\
\hline & DF & $\mathbf{F}$ & $\mathbf{p}$ & $\mathbf{F}$ & p \\
\hline Location (L) & 1 & 0.55 & n.s. & 0.01 & n.s. \\
\hline Pre-crop (P) & 2 & 0.20 & n.s. & 2.39 & n.s. \\
\hline$L \times P$ & 2 & 0.77 & n.s. & 2.11 & n.s. \\
\hline Cultivar (C) & 1 & 19.48 & $* * *$ & 194.27 & $* * *$ \\
\hline $\mathrm{L} \times \mathrm{C}$ & 1 & 0.16 & n.s. & 0.01 & n.s. \\
\hline$P \times C$ & 2 & 0.22 & n.s. & 0.69 & n.s. \\
\hline $\mathrm{L} \times \mathrm{P} \times \mathrm{C}$ & 2 & 0.50 & n.s. & 1.95 & n.s. \\
\hline DON & 1 & 0.01 & n.s. & & \\
\hline DON x L & 1 & 0.01 & n.s. & & \\
\hline DON x P & 2 & 0.92 & n.s. & & \\
\hline DON x L x P & 2 & 0.20 & n.s. & & \\
\hline DON x C & 1 & 0.12 & n.s. & & \\
\hline DON x L x C & 1 & 1.73 & n.s. & & \\
\hline DON x P x C & 2 & 0.75 & n.s. & & \\
\hline
\end{tabular}

\subsection{Fusarium infection and flour composition}

\subsubsection{Starch}

Starch content in flour Type 550 was primarily influenced by year and pre-crop (Tab 35, Tab 59). Starch content varied significantly between all years. Lowest starch content was measured in 2007 (Ø $73.5 \%$ ), followed by 2008 (Ø 75.7\%) and 2009 (Ø 77.7\%). While differences between cultivars were not significant across all samples, pre-crop had an effect on starch content. In 2008 and 2009, pre-crop maize led to higher starch contents of flours in both cultivars compared to previous crop wheat and sugar beet resulting in a significant effect of pre-crop across all three years. This effect was not present within 2007. 
Tab 35. Starch content of flour Type 550 of wheat cultivars (Centrum, Ritmo) grown after different pre-crops in 2007, 2008, and $2009(M V \pm S D, n=6)$

\begin{tabular}{|c|c|c|c|c|c|c|}
\hline Year & Cultivar & Pre-crop & \multicolumn{4}{|c|}{ Starch (\%) } \\
\hline \multirow{6}{*}{2007} & \multirow{3}{*}{ Centrum } & Wheat & 73.0 & \pm & 0.8 & $\overline{a b}$ \\
\hline & & Maize & 74.0 & \pm & 0.9 & $a b$ \\
\hline & & Sugar beet & 74.1 & \pm & 0.8 & b \\
\hline & \multirow{3}{*}{ Ritmo } & Wheat & 72.6 & \pm & 0.5 & $a$ \\
\hline & & Maize & 73.7 & \pm & 1.4 & $a b$ \\
\hline & & Sugar beet & 73.4 & \pm & 0.7 & $a b$ \\
\hline \multirow{6}{*}{2008} & \multirow{3}{*}{ Centrum } & Wheat & 74.7 & \pm & 0.7 & $\bar{a}$ \\
\hline & & Maize & 78.1 & \pm & 1.6 & b \\
\hline & & Sugar beet & 74.1 & \pm & 1.0 & a \\
\hline & \multirow{3}{*}{ Ritmo } & Wheat & 74.8 & \pm & 1.3 & $a$ \\
\hline & & Maize & 78.5 & \pm & 2.2 & b \\
\hline & & Sugar beet & 74.2 & \pm & 0.8 & a \\
\hline \multirow{6}{*}{2009} & \multirow{3}{*}{ Centrum } & Wheat & 76.5 & \pm & 1.1 & $a$ \\
\hline & & Maize & 79.3 & \pm & 0.8 & b \\
\hline & & Sugar beet & 76.8 & \pm & 0.5 & a \\
\hline & \multirow{3}{*}{ Ritmo } & Wheat & 76.7 & \pm & 0.3 & a \\
\hline & & Maize & 79.8 & \pm & 0.8 & b \\
\hline & & Sugar beet & 77.0 & \pm & 0.7 & a \\
\hline
\end{tabular}

Same letters indicate no differences between cultivars and pre-crops within years at a significance level of $p<0.05$ according to Tukey test

ANCOVA did not reveal a significant effect of $\mathrm{DON}_{\mathrm{LOG}}$ on starch content on flour Type 550 (Tab 36). Therefore, ANOVA described variability in starch content adequately.

Tab 36. ANCOVA for effects of environment (E) (year, location), pre-crop (P), wheat cultivar (C), and DON ${ }_{\mathrm{LOG}}(\mathrm{DON})$ and $A N O V A$ for effects of $E, P$, and $\mathrm{C}$ on starch content $(\%)$ of flour Type 550

\begin{tabular}{|c|c|c|c|c|c|}
\hline \multirow[b]{2}{*}{ Effect } & \multicolumn{3}{|c|}{ ANCOVA } & \multicolumn{2}{|c|}{ ANOVA } \\
\hline & DF & $\mathbf{F}$ & p & $\mathbf{F}$ & $p$ \\
\hline Environment (E) & 3 & 12.66 & $* * *$ & 247.70 & $* * *$ \\
\hline Pre-crop (P) & 2 & 2.77 & $(*)$ & 57.51 & $* * *$ \\
\hline$E \times P$ & 6 & 1.31 & n.s. & 12.62 & $* * *$ \\
\hline Cultivar (C) & 1 & 0.16 & n.s. & 0.38 & n.s. \\
\hline $\mathrm{E} \times \mathrm{C}$ & 3 & 1.11 & n.s. & 2.89 & $*$ \\
\hline$P \times C$ & 2 & 0.71 & n.s. & 0.43 & n.s. \\
\hline$E \times P \times C$ & 5 & 0.80 & n.s. & 0.63 & n.s. \\
\hline DON & 1 & 1.26 & n.s. & & \\
\hline DON xE & 3 & 0.18 & n.s. & & \\
\hline DON x P & 2 & 0.15 & n.s. & & \\
\hline DON xExP & 6 & 0.70 & n.s. & & \\
\hline DON x C & 1 & 1.65 & n.s. & & \\
\hline DON $\times E \times C$ & 3 & 0.47 & n.s. & & \\
\hline DON x P x C & 2 & 0.07 & n.s. & & \\
\hline DON $x E \times P \times C$ & 5 & 0.60 & n.s. & & \\
\hline
\end{tabular}




\subsubsection{Gluten proteins}

\subsubsection{Total gluten}

More than $75 \%$ of $\mathrm{PC}_{\mathrm{Type} 550}$ of $\mathrm{cv}$. Ritmo and $\mathrm{cv}$. Centrum consisted of gluten forming proteins whereas gliadin proteins made up for the major proportion (Fig 25). Total gluten content was primarily influenced by year and pre-crop (Tab 38, Tab 57). Across all samples, total gluten content was highest in 2009 and after pre-crop sugar beet. However, differences between years as well as pre-crops only averaged $2-3 \%$. Within years, differences between pre-crops were in most cases not significant. In general, there were no significant differences between cultivars across or within years.

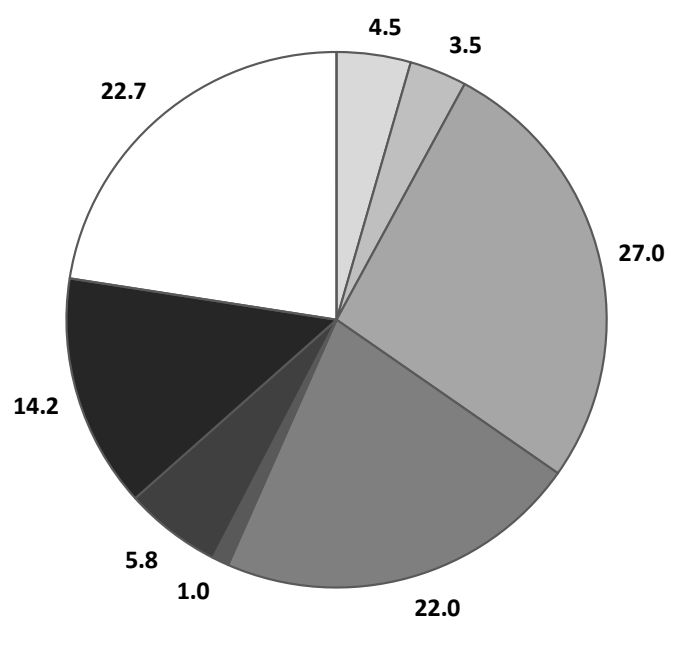

$\square \omega 5 \square \omega 1,2 \square \alpha \square \gamma \square \omega b \square \mathrm{HMW} \square \mathrm{LMW} \square$ Other

Fig 25. Average relative proportion (\%) of gliadins ( $\omega 5, \omega 1,2, \alpha, \gamma)$, glutenins ( $\omega b, \mathrm{HMW}-\mathrm{GS}$, LMW-GS), and residual (other) protein in total protein of flour Type 550 across all investigated samples $(n=108)$ 
Tab 38. Total gluten content (\% Protein) of wheat cultivars (Centrum, Ritmo) grown after pre-crops wheat, maize, and sugar beet in 2007, 2008, and 2009 (MV \pm SD, $n=6)$

\begin{tabular}{|c|c|c|c|c|c|c|}
\hline Year & Cultivar & Pre-crop & Total gl & er & Pro & \\
\hline \multirow{6}{*}{2007} & \multirow{3}{*}{ Centrum } & Wheat & 75.4 & \pm & 2.2 & $a b$ \\
\hline & & Maize & 78.1 & \pm & 5.8 & $a b$ \\
\hline & & Sugar beet & 81.7 & \pm & 5.1 & b \\
\hline & \multirow{3}{*}{ Ritmo } & Wheat & 75.3 & \pm & 3.7 & $a b$ \\
\hline & & Maize & 70.1 & \pm & 4.7 & a \\
\hline & & Sugar beet & 79.7 & \pm & 2.8 & b \\
\hline \multirow{6}{*}{2008} & \multirow{3}{*}{ Centrum } & Wheat & 69.9 & \pm & 3.7 & a \\
\hline & & Maize & 77.3 & \pm & 3.1 & $a b$ \\
\hline & & Sugar beet & 79.0 & \pm & 1.8 & b \\
\hline & \multirow{3}{*}{ Ritmo } & Wheat & 75.7 & \pm & 4.5 & $a b$ \\
\hline & & Maize & 79.3 & \pm & 1.8 & b \\
\hline & & Sugar beet & 80.6 & \pm & 4.8 & b \\
\hline \multirow{6}{*}{2009} & \multirow{3}{*}{ Centrum } & Wheat & 84.4 & \pm & 1.4 & c \\
\hline & & Maize & 73.1 & \pm & 2.7 & $a b$ \\
\hline & & Sugar beet & 80.4 & \pm & 2.0 & bc \\
\hline & \multirow{3}{*}{ Ritmo } & Wheat & 80.4 & \pm & 1.5 & bc \\
\hline & & Maize & 80.8 & \pm & 1.8 & bc \\
\hline & & Sugar beet & 71.0 & \pm & 9.2 & a \\
\hline
\end{tabular}

Same letters indicate no differences between cultivars and pre-crops within years at a significance level of $p<0.05$ according to Tukey test

ANCOVA showed a significant effect of $\mathrm{DON}_{\mathrm{LOG}}$ on total gluten content within the effect of environment and the interaction of environment and pre-crop (Tab 39). Linear regression revealed trends in both directions, either total gluten content increased with increasing $\mathrm{DON}_{\mathrm{LOG}}$ or the opposite effect. Strength and direction of the effect depended on year, pre-crop, location, and the number of observations included (Tab 40).

Tab 39. ANCOVA for effects of environment (E) (year, location), pre-crop (P), wheat cultivar (C), and DON $\mathrm{LOG}_{\mathrm{G}}(\mathrm{DON})$ and $A N O V A$ for effects of $\mathrm{E}, \mathrm{P}$, and $\mathrm{C}$ on total gluten content

\begin{tabular}{|c|c|c|c|}
\hline Effect & DF & $\mathbf{F}$ & $\mathbf{p}$ \\
\hline Environment (E) & 3 & 4.03 & $*$ \\
\hline Pre-crop (P) & 2 & 4.66 & $*$ \\
\hline$E \times P$ & 6 & 4.68 & $* *$ \\
\hline Cultivar (C) & 1 & 0.44 & n.s. \\
\hline$E \times C$ & 3 & 2.70 & $(*)$ \\
\hline $\mathrm{P} \times \mathrm{C}$ & 2 & 0.96 & n.s. \\
\hline$E \times P \times C$ & 5 & 4.19 & $* *$ \\
\hline DON & 1 & 0.76 & n.s. \\
\hline DON x E & 3 & 3.56 & $*$ \\
\hline DON x P & 2 & 1.20 & n.s. \\
\hline DON x ExP & 6 & 4.09 & $* *$ \\
\hline DON x C & 1 & 0.00 & n.s. \\
\hline DON $\times E \times C$ & 3 & 1.81 & n.s. \\
\hline DON x P x C & 2 & 0.09 & n.s. \\
\hline DON $x E \times P \times C$ & 5 & 1.08 & n.s. \\
\hline
\end{tabular}


Tab 40. Parameters of linear regression of total gluten (\% Protein) and $\mathrm{DON}_{\mathrm{LOG}}(\mathrm{mg}$

$\mathrm{kg}^{-1}$ ) within environments (E) (year, location), cultivars (C), and pre-crops (P), and range of original DON values $\left(\mathrm{DON}_{\mathrm{ORG}}\right)$

\begin{tabular}{|c|c|c|c|c|c|c|c|c|c|c|}
\hline \multirow[t]{2}{*}{ Effect } & \multicolumn{4}{|c|}{ Effect level } & \multirow[b]{2}{*}{$\mathbf{n}$} & \multirow[b]{2}{*}{$\mathbf{R}^{\mathbf{2}}$} & \multirow[b]{2}{*}{ p } & \multirow[b]{2}{*}{ b } & \multicolumn{2}{|c|}{$\mathrm{DON}_{\mathrm{ORG}}\left(\mathrm{mg} \mathrm{kg}^{-1}\right)$} \\
\hline & Year & Location & Pre-crop & Cultivar & & & & & $\mathbf{a}$ & Min-Max \\
\hline \multirow{5}{*}{$E \times P$} & 2009 & TL \& GB & Maize & & 12 & 0.68 & $* *$ & 74.57 & 8.18 & $0.39-8.42$ \\
\hline & $2007 \& 2009$ & \multirow{2}{*}{ GB } & Wheat & \& Ritmo & 12 & 0.62 & $* *$ & 75.69 & -4.19 & $0.00-3.99$ \\
\hline & 2007 & & Maize & & 6 & 0.99 & $* * *$ & 79.87 & -14.17 & $0.67-8.70$ \\
\hline & \multirow{2}{*}{2009} & \multirow{2}{*}{ GB } & Wheat & Centrum & 6 & 0.88 & $* *$ & 78.57 & -2.69 & $0.00-0.73$ \\
\hline & & & Maize & \& Ritmo & 6 & 0.74 & $*$ & 75.64 & 10.41 & $0.27-3.84$ \\
\hline
\end{tabular}

$\mathrm{n}$ number of observations, $\mathrm{p}$ significance: ${ }^{* * *},{ }^{* *}$, and ${ }^{*}=\mathrm{p}<0.001,0.01,0.05, \mathrm{~b}$ constant, a slope, TL Torland, GB Gla debeck

\subsubsection{Total gliadin and subfractions}

Across all investigated samples, total gliadin (sum of all gliadin subfractions) made up the major proportion of total protein in flour Type 550 ( $\varnothing 56.9 \%$ Protein) (Fig 25). The total gliadin content was significantly influenced by year and cultivar (Tab 41, Tab 57). Total gliadin content differed significantly between all three years and averaged 57.0, 52.4, and 61.3\% in 2007, 2008, and 2009. While within years not always apparent, across years cv. Ritmo (Ø 57.9\% Protein) contained about $4 \%$ more total gliadin than cv. Centrum ( crop did not influence gliadin content significantly, only within some combinations of year and cultivar.

$\omega 5$ - and $\omega 1$,2-gliadin presented the smallest proportion of total gliadin (Fig 25). Both subfractions made up only for about 4.5 and $3.5 \%$ of total protein in flour, respectively. Both $\omega 5$-gliadin and $\omega 1$,2-gliadin content differed significantly between all the years (Tab 41, Tab 57). In 2007, flours contained significantly more $\omega$-gliadins than in 2009 and 2008. Within the years, neither significant differences between cultivars or pre-crops could be observed for both gliadin fractions in 2008, however, data of 2007 and 2009 showed more variation. While in 2007, cv. Centrum expressed slightly more $\omega 5$-Gliadin ( effect of cultivar was adverse ( $\varnothing \mathrm{cv}$. Centrum: 4.2\% Protein, $\varnothing \mathrm{cv}$. Ritmo: 4.7\% Protein) in 2009. The effect of pre-crop depended on cultivar and year. Across all years cv. Ritmo ( $\varnothing 4.6 \%$ Protein) contained significantly more $\omega 5$-gliadin than cv. Centrum $(\varnothing 4.4 \%$ Protein). For $\omega 1,2$-gliadin content there was not significant difference between cultivars across year, but a significant effect of pre-crop. Across years and cultivars, significantly higher $\omega 1,2$-gliadin content was observed after pre-crop wheat (3.7\% protein) when compared to maize (3.4\% protein), and sugar beet $(3.3 \%$ protein). Effect of pre-crop and cultivar depended on year and on the interaction of pre-crop and cultivar.

$\alpha$-gliadin was quantitatively the biggest fraction of total gliadin (Fig 25). Across all samples $\alpha$ gliadin averaged $27.0 \%$ of total protein. The content varied only slightly between the years 2007 (Ø 
26.4\%) and 2008 (Ø 26.0\%) and was significantly higher in 2009 (Ø: 28.5\%) (Tab 41, Tab 57). Within and across the years no significant differences between cultivars and pre-crops could be observed.

$\gamma$-gliadin presented the second biggest proportion of total gliadin (Fig 25). Across the years it made up for averagely $22.0 \%$ of total protein. Differences between the years were significant (Tab 41, Tab 57). Highest $\gamma$-gliadin content was observed in 2009 (Ø 24.8\% protein), followed by 2007 (Ø $22.1 \%$ protein), and 2008 (Ø 19.0\% protein). Across all years, cv. Ritmo (Ø 22.7\% protein) contained significantly more $\gamma$-gliadin than $\mathrm{cv}$. Centrum ( not so apparent within the single years. Across all years and cultivars, pre-crop showed a significant effect on $\gamma$-gliadin content. Content was on average highest after sugar beet $(23.1 \%)$, followed by maize (22.3\%) and significantly lower in wheat $(20.6 \%)$.

Tab 41. Content of total gliadin and subfractions $(\omega 5, \omega 1,2, \alpha, \gamma)(\%$ Protein) of flour Type 550 from wheat cultivars (Centrum, Ritmo) grown after pre-crop wheat, maize, and sugar beet in 2007, 2008, and $2009(\mathrm{MV} \pm \mathrm{SD}, \mathrm{n}=6)$

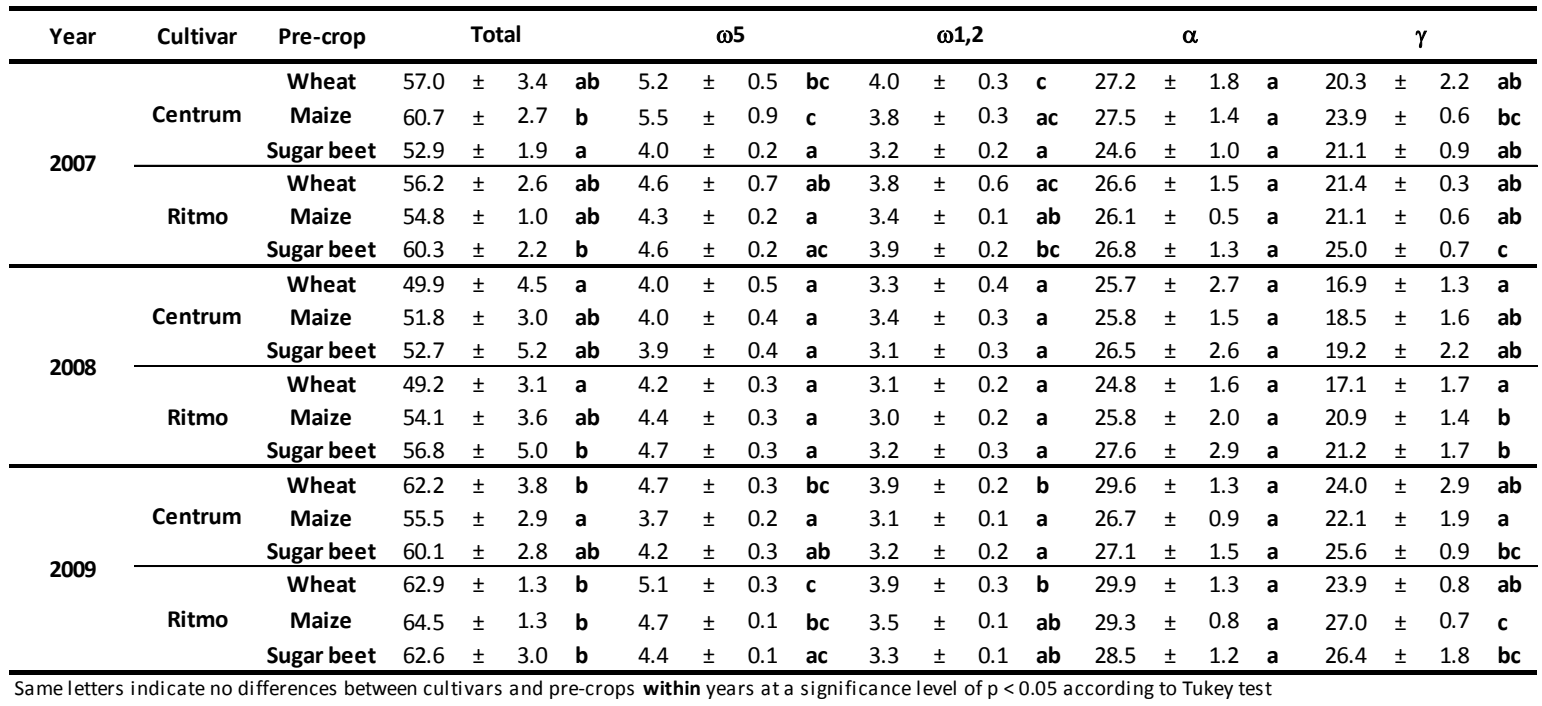


ANCOVA for total gliadin (Tab 42) and $\alpha$-gliadin (Tab 43) showed that there was no significant effect of DON $\mathrm{LOG}_{\mathrm{L}}$ on both. Therefore, ANOVA was sufficient to explain variability of data.

Tab 42. ANCOVA for effects of environment (E) (year, location), pre-crop (P), wheat

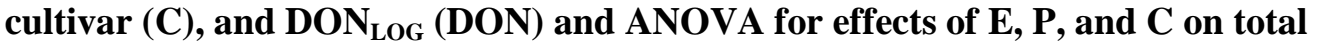
gliadin content

\begin{tabular}{|c|c|c|c|c|c|}
\hline \multirow[b]{2}{*}{ Effect } & \multicolumn{3}{|c|}{ ANCOVA } & \multicolumn{2}{|c|}{ ANOVA } \\
\hline & DF & $\mathbf{F}$ & p & $\mathbf{F}$ & $\mathbf{p}$ \\
\hline Environment (E) & 3 & 3.94 & $*$ & 23.24 & $* * *$ \\
\hline Pre-crop (P) & 2 & 0.22 & n.s. & 0.63 & n.s. \\
\hline$E \times P$ & 6 & 1.47 & n.s. & 1.45 & n.s. \\
\hline Cultivar (C) & 1 & 2.07 & n.s. & 15.68 & $* * *$ \\
\hline $\mathrm{E} \times \mathrm{C}$ & 3 & 0.52 & n.s. & 5.24 & $* *$ \\
\hline $\mathrm{P} \times \mathrm{C}$ & 2 & 1.66 & n.s. & 7.13 & $* *$ \\
\hline$E \times P \times C$ & 5 & 3.82 & $*$ & 11.67 & $* * *$ \\
\hline DON & 1 & 2.90 & n.s. & & \\
\hline DON xE & 3 & 1.64 & n.s. & & \\
\hline DON x P & 2 & 1.01 & n.s. & & \\
\hline DON $x E \times P$ & 6 & 1.76 & n.s. & & \\
\hline DON x C & 1 & 0.36 & n.s. & & \\
\hline DON $\times E \times C$ & 3 & 0.55 & n.s. & & \\
\hline DON $x \mathrm{P} \times \mathrm{C}$ & 2 & 0.45 & n.s. & & \\
\hline DON $x E \times P \times C$ & 5 & 1.31 & n.s. & & \\
\hline
\end{tabular}

Tab 43. ANCOVA for effects of environment (E) (year, location), pre-crop (P), wheat cultivar (C), and DON ${ }_{\text {LOG }}(\mathrm{DON})$ and ANOVA for effects of $E, P$, and $C$ on content of $\alpha$-gliadin

\begin{tabular}{|c|c|c|c|c|c|}
\hline \multirow[b]{2}{*}{ Effect } & \multicolumn{3}{|c|}{ ANCOVA } & \multicolumn{2}{|c|}{ ANOVA } \\
\hline & DF & $\mathbf{F}$ & $p$ & $\mathbf{F}$ & $p$ \\
\hline Environment (E) & 3 & 3.64 & $*$ & 16.99 & $* * *$ \\
\hline Pre-crop (P) & 2 & 0.12 & n.s. & 10.00 & $* * *$ \\
\hline$E \times P$ & 6 & 0.98 & n.s. & 1.09 & n.s. \\
\hline Cultivar (C) & 1 & 1.41 & n.s. & 6.78 & $*$ \\
\hline$E \times C$ & 3 & 0.50 & n.s. & 3.80 & $*$ \\
\hline$P \times C$ & 2 & 2.00 & n.s. & 3.57 & $*$ \\
\hline$E \times P \times C$ & 5 & 2.19 & $(*)$ & 3.11 & $*$ \\
\hline DON & 1 & 3.04 & $(*)$ & & \\
\hline DON x E & 3 & 2.15 & n.s. & & \\
\hline DON x P & 2 & 0.45 & n.s. & & \\
\hline DON $x$ ExP & 6 & 2.03 & $(*)$ & & \\
\hline DON x C & 1 & 0.47 & n.s. & & \\
\hline DON x ExC & 3 & 0.48 & n.s. & & \\
\hline DON x P x C & 2 & 0.45 & n.s. & & \\
\hline DON $\times E \times P \times C$ & 5 & 0.95 & n.s. & & \\
\hline
\end{tabular}

For $\omega 5$ - and $\gamma$-gliadin ANCOVA showed a slight significant effect of $\mathrm{DON}_{\mathrm{LOG}}$ within environment (Tab 44). However, linear regression did not reveal a single significant correlation between these protein fractions and $\mathrm{DON}_{\mathrm{LOG}}$. Out of eight possible linear regressions for each subfraction nearly 
all showed $\mathrm{R}^{2}<0.05$ ( $\left.\mathrm{p}>0.05\right)$. The same applied to $\omega 1,2$-gliadin where ANCOVA calculated a significant effect of $\mathrm{DON}_{\mathrm{LOG}}$ across all samples and within environment (Tab 44). Therefore, it can be summarized that DON concentration did not have linear relationship with the content of any of the three gliadin subfractions and ANOVA with main effects of environment, pre-crop, and cultivar was sufficient to describe variability of data.

Tab 44. ANCOVA for effects of environment (E) (year, location), pre-crop (P), cultivar (C), and DON ${ }_{\text {LOG }}(\mathrm{DON})$ on content of $\omega 5$-gliadin, $\omega 1$,2-gliadin, and $\gamma$-gliadin

\begin{tabular}{|c|c|c|c|c|c|c|c|}
\hline \multirow[b]{2}{*}{ Effect } & \multirow[b]{2}{*}{ DF } & \multicolumn{2}{|c|}{$\omega 5$-Gliadin (\% Protein) } & \multicolumn{2}{|c|}{$\omega 1,2-$-Gliadin (\% Protein) } & \multicolumn{2}{|c|}{$\gamma$-Gliadin (\% Protein) } \\
\hline & & $\mathbf{F}$ & $\bar{p}$ & $\mathbf{F}$ & $\bar{p}$ & $\mathbf{F}$ & $\bar{p}$ \\
\hline Environment (E) & 3 & 1.95 & n.s. & 1.21 & n.s. & 8.02 & $* * *$ \\
\hline Pre-crop (P) & 2 & 1.59 & n.s. & 1.57 & n.s. & 6.34 & $* *$ \\
\hline$E \times P$ & 6 & 1.14 & n.s. & 1.22 & n.s. & 2.81 & $*$ \\
\hline Cultivar (C) & 1 & 0.30 & n.s. & 2.88 & n.s. & 2.62 & n.s. \\
\hline $\mathrm{E} \times \mathrm{C}$ & 3 & 0.86 & n.s. & 0.35 & n.s. & 2.09 & n.s. \\
\hline$P \times C$ & 2 & 1.52 & n.s. & 3.17 & $(*)$ & 0.44 & n.s. \\
\hline$E \times P \times C$ & 5 & 1.17 & n.s. & 0.75 & n.s. & 6.10 & $* * *$ \\
\hline DON & 1 & 3.33 & $(*)$ & 5.09 & $*$ & 0.63 & n.s. \\
\hline DON x E & 3 & 5.01 & $* *$ & 4.14 & $*$ & 3.55 & $*$ \\
\hline DON x P & 2 & 0.88 & n.s. & 2.07 & n.s. & 2.47 & n.s. \\
\hline DON x ExP & 6 & 1.57 & n.s. & 1.75 & n.s. & 2.22 & $(*)$ \\
\hline DON x C & 1 & 0.05 & n.s. & 0.01 & n.s. & 0.38 & n.s. \\
\hline DON $x E \times C$ & 3 & 0.55 & n.s. & 0.85 & n.s. & 2.29 & n.s. \\
\hline DON x P x C & 2 & 0.57 & n.s. & 0.41 & n.s. & 1.81 & n.s. \\
\hline DON $x E \times P \times C$ & 5 & 0.76 & n.s. & 0.89 & n.s. & 1.86 & n.s. \\
\hline
\end{tabular}

\subsubsection{Total glutenin and subfractions}

Compared to total gliadin total glutenin presented a significantly smaller fraction of total protein (Fig 25). Across all samples, total glutenin content averaged $20.9 \%$ of protein. Year had a significant effect on glutenin content (Tab 45, Tab 58). In 2008 (Ø 24.5\% protein), across all samples, flour contained a significantly higher glutenin proportion than in 2007 (Ø 19.8\% protein) and 2009 (Ø $18.5 \%$ protein). Across all years and pre-crops, cv. Ritmo (Ø 20.0\% protein) contained about $8.4 \%$ less glutenin than cv. Centrum ( cultivars were not significant within years. Across years and cultivars, total protein of flours consisted of about $14 \%$ less glutenin when gained from wheat grown after maize ( $\varnothing 19.5 \%$ Protein) compared to pre-crop sugar beet ( Compared to pre-crop wheat the difference was only $5.1 \%$ and not significant. Differences between pre-crops within in years were not significant (except for cv. Centrum after sugar beet in 2007). Interestingly, glutenin contents varied more in 2007 than in the following years, indicated by relatively high $\mathrm{SD}$. 
$\omega \mathrm{b}$ was the smallest proportion of glutenin and made up averagely $1 \%$ of total protein and was therefore the smallest subfraction of all gluten forming proteins (Fig 25). $\omega b$ content was significantly influenced by year ( $\mathrm{Tab} 45$, Tab 58). There were no significant differences between the two cultivars and pre-crops within years In 2009, across all samples protein consisted of significantly less $\omega \mathrm{b}(0.7 \%)$ than in the other two years $(2007: 1.1 \%, 2008,1,2 \%)$. Across years and pre-crops, cv. Ritmo contained significantly less $\omega \mathrm{b}-\mathrm{GS}(\varnothing 0.9 \%$ protein) than $\mathrm{cv}$. Centrum ( $1.1 \%$ protein). The difference was $15 \%$ on average. Pre-crops also did not influence $\omega b$-GS content across years.

On average, protein consisted of 5.8\% HWW-GS across all samples (Fig 25). Across all samples, HMW-GS content was significantly influenced by year and pre-crop, however not by cultivar (Tab 45, Tab 58). In 2008 (Ø 6.6\% protein), flours contained significantly more HMW-GS than in 2007 (Ø 5.5\% protein) and 2009 (Ø 5.6\% protein). After pre-crop maize, HMW-GS content was on average significantly reduced about $12 \%$ when compared to sugar beet and $10 \%$ when compared to wheat. Within years, the effect of pre-crop was not significant (Tab 45, Tab 58). Across and within years, no significant differences between the two cultivars were observed. Protein of cv. Ritmo and cv. Centrum contained averagely 5.7\% and 6.0\% HMW-GS, respectively.

LMW-GS made up the biggest proportion of the glutenin subfractions (Fig 25). On average 14.2\% of protein consisted of LMW-GS (Fig 25). Looking at all samples, year, cultivar, and pre-crop influenced LMW-GS content significantly (Tab 45, Tab 58). As described for HMW-GS, LMWGS content was significantly higher in 2008 ( $\varnothing 16.9 \%$ protein), than in the other two years (2007: 13.2\% protein, 2009: 12.2\% protein). Across all samples, cv. Ritmo (Ø 13.4\% protein) comprised significantly less LMW-GS than cv. Centrum ( $\varnothing 14.8 \%$ protein). Average difference was $9.3 \%$. After pre-crop maize ( $\varnothing 13.2 \%$ Protein) and wheat ( $\varnothing 13.6 \%$ Protein) flours contained significantly less LMW-GS than after pre-crop sugar beet (15.3\%). Within years, neither differences of cultivars nor pre-crops were significant. 
Tab 45. Content of total glutenin and subfractions ( $\omega b$, HMW-GS, LMW-GS) (\%

Protein) of flour Type 550 from wheat cultivars (Centrum, Ritmo) grown after precrop wheat, maize, and sugar beet in 2007, 2008, and 2009 (MV $\pm S D, n=6$ )

\begin{tabular}{|c|c|c|c|c|c|c|c|c|c|c|c|c|c|c|c|c|c|c|}
\hline Year & Cultivar & Pre-crop & & To & & & & $\omega$ & & & & $\mathrm{MV}$ & -GS & & & nu & & \\
\hline \multirow{6}{*}{2007} & & Wheat & 18.4 & \pm & 1.3 & $a$ & 0.8 & \pm & 0.3 & $a$ & 5.4 & \pm & 0.5 & $a b$ & 12.2 & \pm & 1.3 & $a$ \\
\hline & Centrum & Maize & 17.4 & \pm & 8.1 & a & 1.1 & \pm & 0.7 & a & 4.7 & \pm & 2.3 & a & 11.7 & \pm & 5.2 & a \\
\hline & & Sugar beet & 28.8 & \pm & 4.9 & b & 1.8 & \pm & 0.5 & b & 7.1 & \pm & 1.3 & b & 19.9 & \pm & 3.2 & b \\
\hline & & Wheat & 19.1 & \pm & 2.9 & $a$ & 1.1 & \pm & 0.1 & a & 5.6 & \pm & 1.1 & $a b$ & 12.5 & \pm & 1.8 & a \\
\hline & Ritmo & Maize & 15.3 & \pm & 4.6 & a & 0.8 & \pm & 0.2 & a & 4.5 & \pm & 1.7 & a & 10.0 & \pm & 2.8 & a \\
\hline & & Sugar beet & 19.4 & \pm & 2.5 & a & 1.0 & \pm & 0.1 & a & 5.6 & \pm & 1.1 & $a b$ & 12.8 & \pm & 1.4 & a \\
\hline \multirow{6}{*}{2008} & & Wheat & 20.0 & \pm & 1.6 & a & 0.8 & \pm & 0.1 & a & 5.8 & \pm & 0.5 & a & 13.3 & \pm & 1.1 & a \\
\hline & Centrum & Maize & 25.5 & \pm & 2.3 & a & 1.3 & \pm & 0.2 & a & 6.8 & \pm & 0.5 & a & 17.4 & \pm & 1.7 & $a b$ \\
\hline & & Sugar beet & 26.3 & \pm & 3.6 & $a$ & 1.3 & \pm & 0.3 & a & 6.7 & \pm & 0.6 & a & 18.4 & \pm & 2.8 & b \\
\hline & & Wheat & 26.4 & \pm & 4.2 & a & 1.4 & \pm & 0.4 & a & 6.9 & \pm & 0.6 & a & 18.1 & \pm & 3.3 & $a b$ \\
\hline & Ritmo & Maize & 25.2 & \pm & 2.6 & a & 1.3 & \pm & 0.2 & a & 6.4 & \pm & 0.6 & a & 17.5 & \pm & 1.9 & $a b$ \\
\hline & & Sugar beet & 23.8 & \pm & 1.6 & $a$ & 1.1 & \pm & 0.1 & a & 6.3 & \pm & 0.4 & a & 16.5 & \pm & 1.3 & $a b$ \\
\hline \multirow{6}{*}{2009} & & Wheat & 22.2 & \pm & 3.5 & a & 1.0 & \pm & 0.3 & b & 6.6 & \pm & 0.7 & a & 14.6 & \pm & 2.6 & a \\
\hline & Centrum & Maize & 17.6 & \pm & 1.6 & a & 0.7 & \pm & 0.1 & $a b$ & 5.0 & \pm & 0.5 & a & 11.9 & \pm & 1.3 & a \\
\hline & & Sugar beet & 20.3 & \pm & 1.6 & a & 0.9 & \pm & 0.2 & b & 5.8 & \pm & 0.5 & a & 13.6 & \pm & 1.1 & $\mathbf{a}$ \\
\hline & & Wheat & 17.5 & \pm & 1.4 & a & 0.7 & \pm & 0.1 & $a b$ & 5.6 & \pm & 0.5 & a & 11.2 & \pm & 0.9 & a \\
\hline & Ritmo & Maize & 16.3 & \pm & 1.1 & a & 0.6 & \pm & 0.1 & $a b$ & 5.0 & \pm & 0.6 & a & 10.7 & \pm & 0.5 & a \\
\hline & & Sugar beet & 16.9 & \pm & 1.4 & a & 0.3 & \pm & 0.3 & a & 5.2 & \pm & 0.7 & a & 11.2 & \pm & 0.7 & a \\
\hline
\end{tabular}

Same letters indicate no differences between cultivars and pre-crops within years at a significance level of $p<0.05$ according to Tukey test

ANCOVA detected a significant and a highly significant effect of $\mathrm{DON}_{\mathrm{LOG}}$ on total glutenin content and HMW-GS content, respectively, within environment (Tab 46).

Tab 46. ANCOVA for effects of environment (E) (year, location), pre-crop (P), wheat cultivar $(C)$, and $D \mathrm{~N}_{\mathrm{LOG}}(\mathrm{DON})$ on content of total glutenin and HMW-GS

\begin{tabular}{|c|c|c|c|c|c|}
\hline \multirow[b]{2}{*}{ Effect } & \multicolumn{3}{|c|}{ Glutenin (\% Protein) } & \multicolumn{2}{|c|}{ HMW-GS (\% Protein) } \\
\hline & DF & $\mathbf{F}$ & $p$ & $\mathbf{F}$ & p \\
\hline Environment (E) & 3 & 5.40 & $* *$ & 6.15 & $* *$ \\
\hline Pre-crop (P) & 2 & 2.56 & $(*)$ & 4.02 & $*$ \\
\hline$E \times P$ & 6 & 2.14 & $(*)$ & 3.33 & $*$ \\
\hline Cultivar (C) & 1 & 2.80 & n.s. & 2.25 & n.s. \\
\hline $\mathrm{E} \times \mathrm{C}$ & 3 & 0.43 & n.s. & 2.95 & $(*)$ \\
\hline $\mathrm{P} \times \mathrm{C}$ & 2 & 0.49 & n.s. & 0.58 & n.s. \\
\hline$E \times P \times C$ & 4 & 0.29 & n.s. & 0.41 & n.s. \\
\hline DON & 1 & 1.36 & n.s. & 1.80 & n.s. \\
\hline DON x E & 3 & 3.24 & $*$ & 8.30 & $* * *$ \\
\hline DON x P & 2 & 0.33 & n.s. & 1.38 & n.s. \\
\hline DON $\times$ ExP & 6 & 1.92 & n.s. & 2.07 & $(*)$ \\
\hline DON x C & 1 & 0.48 & n.s. & 0.45 & n.s. \\
\hline DON $\times$ ExC & 3 & 0.72 & n.s. & 0.98 & n.s. \\
\hline DON $\times P \times C$ & 2 & 0.03 & n.s. & 0.05 & n.s. \\
\hline DON $\times E \times P \times C$ & 4 & 0.48 & n.s. & 0.67 & n.s. \\
\hline
\end{tabular}

Linear regression between $\mathrm{DON}_{\mathrm{LOG}}$ and total glutenin content revealed that even though all possible correlations within different environments showed without exceptions a negative trend (average $R^{2}$ of 20 linear regression curves was 0.27 ), only two showed a significant $R^{2} \geq 0.5, p<0.05$ 
(Fig 26). In 2007, DON ${ }_{\text {LOG }}$ was very highly negatively related to total glutenin content in cv. Ritmo at location Gladebeck. DON ${ }_{\text {ORG }}$ in these samples ranged from 1.30 to $8.70 \mathrm{mg} \mathrm{kg}^{-1}$. In 2009, across cultivars, $\mathrm{DON}_{\mathrm{LOG}}$ was highly adversely correlated to total glutenin content at the same location. $\mathrm{DON}_{\mathrm{ORG}}$ of the respective samples ranged from $0.00-3.84 \mathrm{mg} \mathrm{kg}^{-1}$. The same significant negative trend of similar strength could be observed between HMW-GS content and DON ${ }_{\text {LOG }}$ for the identical samples (Fig 26). In general, as shown for total glutenin content, a negative relationship between HMW-GS content and $\mathrm{DON}_{\mathrm{LOG}}$ could be observed within more environments, yet, $\mathrm{R}^{2}$ was below 0.50 (average $\mathrm{R}^{2}$ of 20 linear regression curves was 0.24 ).
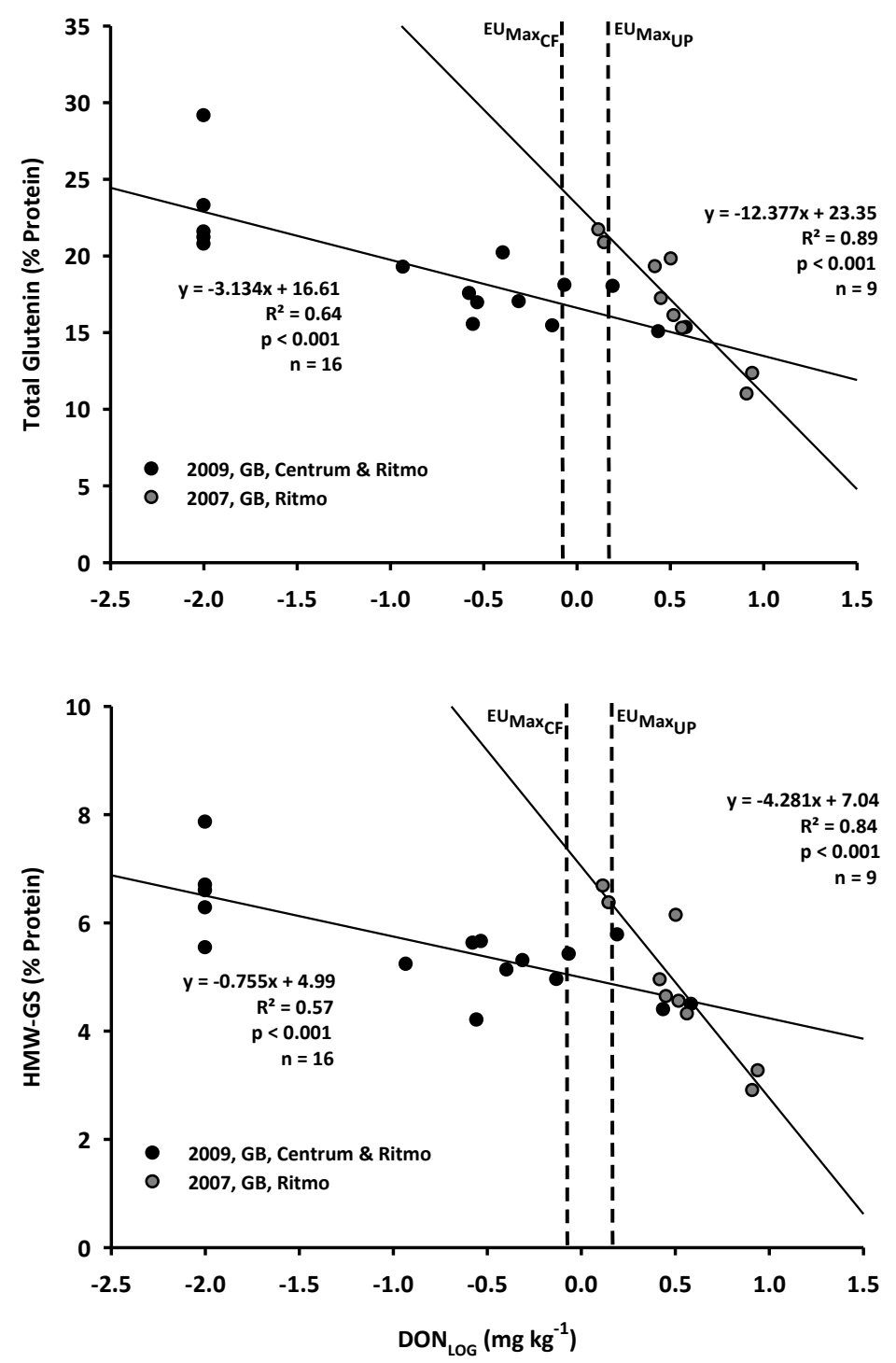

Fig 26. Linear regression of total glutenin content and DON $\mathrm{LOG}_{\text {and }}$ HMW-GS content and DON $\mathrm{LOG}_{\text {of flour }}$ Type 550 within cv. Ritmo in 2007 and across cultivars (Centrum, Ritmo) in 2009 at location Gladebeck (GB), $\mathrm{EU}_{\text {MaxCF }}=0.75 \mathrm{mg} \mathrm{kg}^{-1}, \mathrm{EU}_{\text {MaxUP }}=1.25 \mathrm{mg} \mathrm{kg}^{-1}$ 
ANCOVA did not find a significant effect of $\mathrm{DON}_{\mathrm{LOG}}$ on content of $\omega \mathrm{b}$ (Tab 47) and LMW-GS (Tab 48), therefore ANOVA with effects of environment, cultivar, and pre-crop described variance in these parameters sufficiently.

Tab 47. ANCOVA for effects of environment (E) (year, location), pre-crop (P), cultivar (C), and DON $\mathrm{LOG}_{\mathrm{LON}}(\mathrm{DO})$ and ANOVA for effects of E, P, and C on $\omega b$ content

\begin{tabular}{|c|c|c|c|c|c|}
\hline \multirow[b]{2}{*}{ Effect } & \multicolumn{3}{|c|}{ ANCOVA } & \multicolumn{2}{|c|}{ ANOVA } \\
\hline & DF & $\mathbf{F}$ & $\bar{p}$ & $\mathbf{F}$ & $p$ \\
\hline Environment (E) & 3 & 4.58 & $*$ & 9.94 & $* * *$ \\
\hline Pre-crop (P) & 2 & 1.03 & n.s. & 3.12 & $(*)$ \\
\hline$E \times P$ & 6 & 1.21 & n.s. & 2.83 & $*$ \\
\hline Cultivar (C) & 1 & 0.85 & n.s. & 16.13 & $* * *$ \\
\hline $\mathrm{E} \times \mathrm{C}$ & 3 & 0.52 & n.s. & 0.91 & n.s. \\
\hline$P \times C$ & 2 & 0.26 & n.s. & 7.29 & $* *$ \\
\hline$E \times P \times C$ & 5 & 0.67 & n.s. & 1.44 & n.s. \\
\hline DON & 1 & 1.01 & n.s. & & \\
\hline DON $x E$ & 3 & 1.16 & n.s. & & \\
\hline DON x P & 2 & 0.07 & n.s. & & \\
\hline DON $x$ ExP & 6 & 1.67 & n.s. & & \\
\hline DON x C & 1 & 0.18 & n.s. & & \\
\hline DON $\times E \times C$ & 3 & 0.98 & n.s. & & \\
\hline DON $\times$ P x C & 2 & 0.06 & n.s. & & \\
\hline DON $x E \times P \times C$ & 5 & 0.46 & n.s. & & \\
\hline
\end{tabular}

Tab 48. ANCOVA for effects of environment (E) (year, location), pre-crop (P),

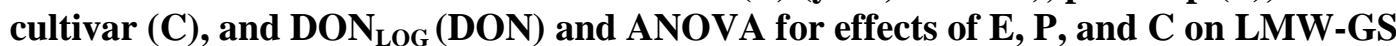
content

\begin{tabular}{|c|c|c|c|c|c|}
\hline \multirow[b]{2}{*}{ Effect } & \multicolumn{3}{|c|}{ ANCOVA } & \multicolumn{2}{|c|}{ ANOVA } \\
\hline & DF & $\mathbf{F}$ & $\bar{p}$ & $\mathbf{F}$ & $p$ \\
\hline Environment (E) & 3 & 5.30 & $* *$ & 1.12 & n.s. \\
\hline Pre-crop (P) & 2 & 2.24 & n.s. & 9.21 & $* * *$ \\
\hline$E \times P$ & 6 & 1.97 & n.s. & 1.89 & n.s. \\
\hline Cultivar (C) & 1 & 3.16 & $(*)$ & 17.63 & $* * *$ \\
\hline $\mathrm{E} \times \mathrm{C}$ & 3 & 0.16 & n.s. & 0.65 & n.s. \\
\hline $\mathrm{P} \times \mathrm{C}$ & 2 & 0.44 & n.s. & 2.89 & $(*)$ \\
\hline $\mathrm{E} \times \mathrm{P} \times \mathrm{C}$ & 4 & 0.34 & n.s. & 1.81 & n.s. \\
\hline DON & 1 & 1.25 & n.s. & & \\
\hline DON xE & 3 & 2.43 & $(*)$ & & \\
\hline DON x P & 2 & 0.15 & n.s. & & \\
\hline DON $\times$ ExP & 6 & 1.92 & n.s. & & \\
\hline DON x C & 1 & 0.49 & n.s. & & \\
\hline DON XEXC & 3 & 0.76 & n.s. & & \\
\hline DON x P x C & 2 & 0.07 & n.s. & & \\
\hline DON $\times E \times P \times C$ & 4 & 0.47 & n.s. & & \\
\hline
\end{tabular}




\subsubsection{Gluten composition}

Across all samples of three years, gliadin/glutenin ratio averaged 2.9. Year and pre-crop showed a significant effect on the ratio (Fig 27, Tab 58). In 2008 (Ø 2.2), ratio was significantly smaller than in the other two years (2007: 3.3, 2009: 3.4). Regarding pre-crop across three years, gliadin/glutenin ratio was significantly higher after pre-crop maize (Ø 3.3$)$ than after pre-crop sugar beet (Ø 2.7). The difference of maize to pre-crop wheat (Ø 2.8) was not significant. Across the years, cultivars did not appear to differ significantly within gliadin/glutenin ratio (cv. Centrum: $\varnothing$ 2.8, cv. Ritmo: Ø 3.1). Within years, effect of pre-crop was not significant in 2008 and 2009. In 2007, however, cv. Centrum showed a significantly higher gliadin/glutenin ratio after pre-crop maize (Ø 4.7) than after pre-crop sugar beet (Ø 1.9).

Samples comprised an average LMW/HMW ratio of 2.4. The ratio was significantly affected by year, cultivar, and pre-crop (Fig 27, Tab 58). Differences between the years were overall significant. Highest ratio was on average present in 2008 (Ø 2.6), followed by 2007 (Ø 2.4), and 2009 (Ø 2.2). Across all samples, cv. Ritmo (Ø 2.4) showed a 4.4\% smaller ratio than cv. Centrum (Ø 2.5), which made up a significant difference. A significantly smaller ratio was detected after pre-crop wheat $(\varnothing 2.3)$ than after the other two pre-crops ( $\varnothing$ maize: 2.5, $\varnothing$ sugar beet: 2.5). Significant effects of cultivar and pre-crops could not be detected within years, except for cv. Centrum in 2007, where pre-crop sugar beet (Ø 2.8) led to a significantly higher LMW/HMW ratio than pre-crop wheat $(\varnothing 2.3)$. 

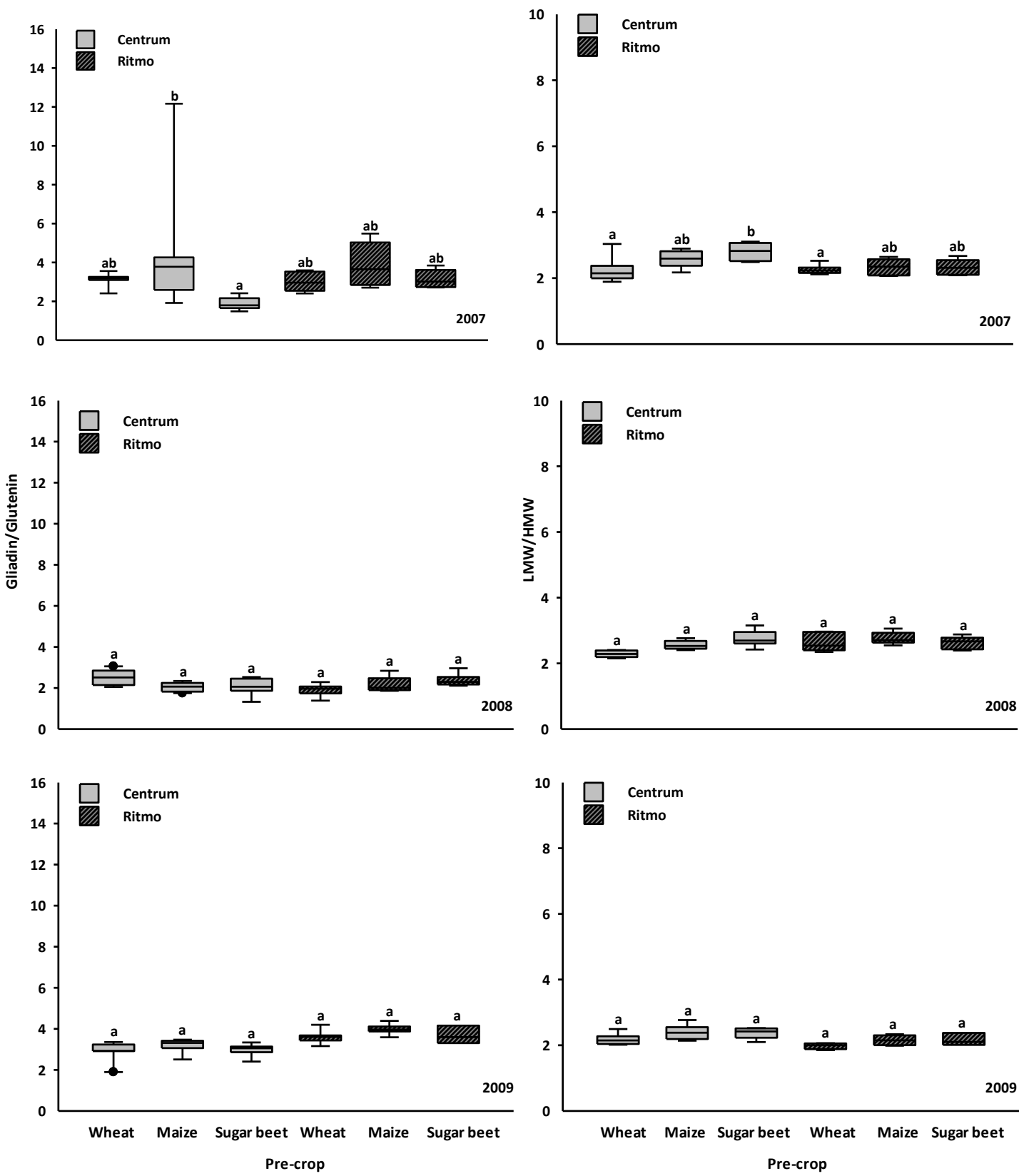

Fig 27. Gliadin/Glutenin ratio and LMW/HMW ratio of wheat cultivars (Centrum, Ritmo) grown after pre-crop wheat, maize, and sugar beet in 2007, 2008, and 2009. Box plots with median (solid line) and whiskers indicating $5^{\text {th }} / 95^{\text {th }}$ percentiles. Box plots ( $n=6$, except 2009 , Ritmo, pre-crop sugar beet: $n=3$ ) with same letters are not significantly different at $p<0.05$ according to Tukey test. Outliers are indicated by a dot.

ANCOVA revealed a significant effect of $\mathrm{DON}_{\mathrm{LOG}}$ on gliadin/glutenin ratio across all samples, within environment, and within environment and pre-crop (Tab 49). For LMW/HMW ratio, a significant influence of $\mathrm{DON}_{\mathrm{LOG}}$ within environment, pre-crop, and the interaction of environment and pre-crop were calculated. 
Tab 49. ANCOVA for effects of environment (E) (year, location), pre-crop (P), wheat cultivar $(C)$, and DON LOG $_{(D O N)}$ on ratio of gliadin/glutenin and LMW/HMW

\begin{tabular}{|c|c|c|c|c|c|}
\hline \multirow[b]{2}{*}{ Effect } & \multicolumn{3}{|c|}{ Gliadin/Glutenin } & \multicolumn{2}{|c|}{ LMW/HMW } \\
\hline & DF & $\mathbf{F}$ & $\bar{p}$ & $\mathbf{F}$ & $p$ \\
\hline Environment (E) & 3 & 10.63 & $* * *$ & 5.40 & $* *$ \\
\hline Pre-crop (P) & 2 & 8.25 & $* *$ & 3.85 & $*$ \\
\hline$E \times P$ & 6 & 7.37 & $* * *$ & 5.56 & $* *$ \\
\hline Cultivar (C) & 1 & 0.27 & n.s. & 0.87 & n.s. \\
\hline$E \times C$ & 3 & 0.58 & n.s. & 11.37 & $* * *$ \\
\hline$P \times C$ & 2 & 0.90 & n.s. & 0.37 & n.s. \\
\hline$E \times P \times C$ & 4 & 0.24 & n.s. & 2.58 & $(*)$ \\
\hline DON & 1 & 4.68 & $*$ & 1.12 & n.s. \\
\hline DON xE & 3 & 9.57 & $* * *$ & 19.30 & $* * *$ \\
\hline DON x P & 2 & 2.62 & $(*)$ & 6.12 & $* *$ \\
\hline DON $x$ ExP & 6 & 6.68 & $* * *$ & 1.84 & n.s. \\
\hline DON $\times$ C & 1 & 1.52 & n.s. & 0.02 & n.s. \\
\hline DON $\times E \times C$ & 3 & 0.80 & n.s. & 3.34 & $*$ \\
\hline DON $\times \mathrm{P} \times \mathrm{C}$ & 2 & 0.71 & n.s. & 2.19 & n.s. \\
\hline DON $\times E \times P \times C$ & 4 & 2.62 & $(*)$ & 2.31 & $(*)$ \\
\hline
\end{tabular}

Linear regression showed a strong and highly significant positive correlation of $\mathrm{DON}_{\mathrm{LOG}}$ with gliadin/glutenin ratio in 2007 and 2009 at location Gladebeck across pre-crops and cultivars (Fig 28). $\mathrm{DON}_{\mathrm{ORG}}$ ranged from $0.33-8.70 \mathrm{mg} \mathrm{kg}^{-1}$ and $0.00-3.84 \mathrm{mg} \mathrm{kg}^{-1}$ in 2007 and 2009 , respectively, in these samples. Further linear regressions where $\mathrm{R}^{2} \geq 0.50$ are presented in Tab 50. All of them showed that gliadin/glutenin ratio increased with increasing DON concentration in flours. This was also the general trend across all 27 possible linear regression curves $\left(\mathrm{R}^{2}\right.$ averaged 0.36 with $\mathrm{r}=$ 0.43). An exception was observed 2007 at location Torland after pre-crop wheat where the effect appeared to be adverse (Tab 50). 


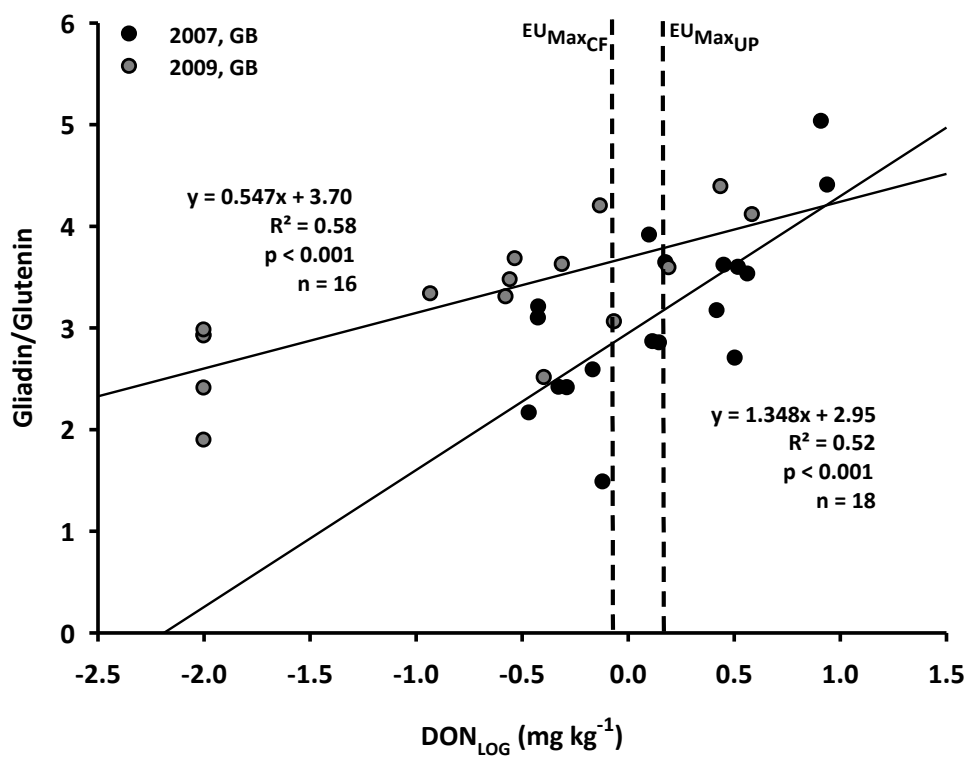

Fig 28. Linear regression of gliadin/glutenin ratio and $D O N_{\mathrm{LOG}}\left(\mathrm{mg} \mathrm{kg}^{-1}\right)$ at location Gladebeck (GB) across cultivars and pre-crops in 2007 and 2009 (for other significant linear regressions see Tab 50), EU $\mathrm{MaxCF}=$ $0.75 \mathrm{mg} \mathrm{kg}^{-1}, \mathrm{EU}_{\text {MaxUP }}=1.25 \mathrm{mg} \mathrm{kg}^{-1}$

Out of 28 linear regression curves for $\mathrm{DON}_{\mathrm{LOG}}$ and LMW/HMW only two were significant (Tab 50). At location Gladebeck, across all pre-crops, within cv. Ritmo with increasing DON content a significant increase of LMW/HMW ratio was observed across 2007 and 2009 as well as within 2009.

Tab 50. Parameters of linear regression of gliadin/glutenin ratio and LMW/HMW ratio and $\mathrm{DON}_{\mathrm{LOG}}\left(\mathrm{mg} \mathrm{kg}^{-1}\right)$ of flour Type 550 within environments $(\mathrm{E})$, cultivars $(C)$, and pre-crops $(P)$, and range of original DON values $\left(\mathrm{DON}_{\mathrm{ORG}}\right)$

\begin{tabular}{|c|c|c|c|c|c|c|c|c|c|c|c|}
\hline \multirow[t]{2}{*}{ Ratio } & \multirow[t]{2}{*}{ Effect } & \multicolumn{4}{|c|}{ Effect level } & \multirow[b]{2}{*}{$\mathrm{n}$} & \multirow[b]{2}{*}{$\mathbf{R}^{2}$} & \multirow[b]{2}{*}{ p } & \multirow[b]{2}{*}{ b } & \multicolumn{2}{|c|}{$\mathrm{DON}_{\mathrm{ORG}}\left(\mathrm{mg} \mathrm{kg}^{-1}\right)$} \\
\hline & & Year & Location & Pre-crop & Cultivar & & & & & a & Min-Max \\
\hline \multirow{4}{*}{ Gliadin/Glutenin } & \multirow{4}{*}{ EXP } & \multirow{2}{*}{2007} & TL \& GB & Sugar beet & Centrum & 12 & 0.51 & $* *$ & 2.53 & 1.79 & $0.33-2.82$ \\
\hline & & & TL & Wheat & \& Ritmo & 6 & 0.66 & * & 3.05 & -0.88 & $0.31-3.24$ \\
\hline & & \multirow{2}{*}{2009} & TL \& GB & \multirow{2}{*}{ Maize } & Centrum & 12 & 0.51 & $* *$ & 3.35 & 0.79 & $0.27-8.42$ \\
\hline & & & TL & & \& Ritmo & 6 & 0.87 & $* *$ & 3.13 & 0.93 & $1.68-8.42$ \\
\hline \multirow[b]{2}{*}{ LMW/HMW } & \multirow[b]{2}{*}{$E \times C$} & $2007 \& 2009$ & & Wheat \& & & 16 & 0.61 & $* * *$ & 2.12 & 0.42 & $0.26-8.70$ \\
\hline & & 2009 & GB & $\begin{array}{c}\text { Maize \& } \\
\text { Sugar beet }\end{array}$ & Ritmo & 7 & 0.69 & * & 2.09 & 0.29 & $0.26-3.84$ \\
\hline
\end{tabular}

\subsection{Protease activity (PA)}

PA (only analyzed in 2007) of flours was significantly influenced by location, pre-crop and Fusarium infection (Tab 51, Tab 59). Extinctions at $440 \mathrm{~nm}$, indicating PA, were on average 26\% higher in cv. Ritmo (Ø 0.61 AU) than in cv. Centrum (Ø 0.45 AU). However, this difference was not significant (except for cv. Centrum after sugar beet compared to cv. Ritmo after pre-crop 
maize). Regardless of location and cultivar PA was highest after maize, followed by wheat and sugar beet. Within cultivars, a significant effect of pre-crop was not observed.

Tab 51. Protease activity (AU $440 \mathrm{~nm}$ ) in flour Type 550 from wheat cultivars (Centrum, Ritmo) grown after pre-crops wheat, maize, and sugar beet in 2007 (MV \pm $\mathrm{SD}, \mathbf{n}=\mathbf{6})$

\begin{tabular}{ccccccc}
\hline Year & Cultivar & Pre-crop & \multicolumn{4}{c}{ Protease activity (AU 440 nm) } \\
\hline \multirow{4}{*}{2007} & Wheat & 0.49 & \pm & 0.17 & ab \\
& \multirow{3}{*}{ Centrum } & Maize & 0.48 & \pm & 0.15 & ab \\
\cline { 3 - 7 } & & Sugar beet & 0.38 & \pm & 0.14 & a \\
\cline { 3 - 7 } & \multirow{2}{*}{ Ritmo } & Wheat & 0.62 & \pm & 0.15 & ab \\
& & Maize & 0.70 & \pm & 0.20 & b \\
& & Sugar beet & 0.51 & \pm & 0.15 & ab
\end{tabular}

Same letters indicate no differences between cultivars and pre-crops at a significance level of $p<0.05$ according to Tukey test

ANCOVA revealed a significant effect of $\mathrm{DON}_{\mathrm{LOG}}$ on PA across all samples and within location and pre-crop (Tab 52). Across all 36 samples, linear regression of both parameters demonstrated a positive but rather moderate correlation $\left(\mathrm{R}^{2}=0.35, \mathrm{p}<0.001\right)$.

Out of six further linear regression curves within the two locations and the three pre-crops, only across cultivars within pre-crop maize at location Torland a strong significant increase of PA with increasing $\mathrm{DON}_{\mathrm{LOG}}$ was observed (Fig 29). Linear regression of protease activity and $\mathrm{DON}_{\mathrm{LOG}}$ curve could be described with $y=0.50 x+0.34, R^{2}=0.69, p<0.05$ across these six observations. $D_{\text {DON }}$ ORG of these samples ranged from 2.52 to $11.84 \mathrm{mg} \mathrm{kg}^{-1}$. However, the trend within all correlations was without exception positive $\left(\mathrm{R}^{2}\right.$ averaged 0.30 with $\left.\mathrm{r}=0.53\right)$.

Tab 52. ANCOVA for effects of location ( $L)$, pre-crop (P), wheat cultivar $(C)$, and $\mathrm{DON}_{\mathrm{LOG}}(\mathrm{DON})$ on protease activity

\begin{tabular}{|c|c|c|c|}
\hline Effect & DF & $\mathbf{F}$ & $p$ \\
\hline Location (L) & 1 & 8.92 & $*$ \\
\hline Pre-crop (P) & 2 & 7.24 & $* *$ \\
\hline$L \times P$ & 2 & 6.96 & $* *$ \\
\hline Cultivar (C) & 1 & 2.86 & n.s. \\
\hline $\mathrm{L} \times \mathrm{C}$ & 1 & 1.14 & n.s. \\
\hline$P \times C$ & 2 & 1.06 & n.s. \\
\hline$L \times P \times C$ & 2 & 12.79 & $* * *$ \\
\hline DON & 1 & 7.30 & $*$ \\
\hline DON x L & 1 & 2.63 & n.s. \\
\hline DON x P & 2 & 0.56 & n.s. \\
\hline DON x L x P & 2 & 18.53 & $* * *$ \\
\hline DON x C & 1 & 0.06 & $(*)$ \\
\hline DON x L x C & 1 & 1.34 & n.s. \\
\hline DON $\times$ P x C & 2 & 2.83 & $(*)$ \\
\hline
\end{tabular}




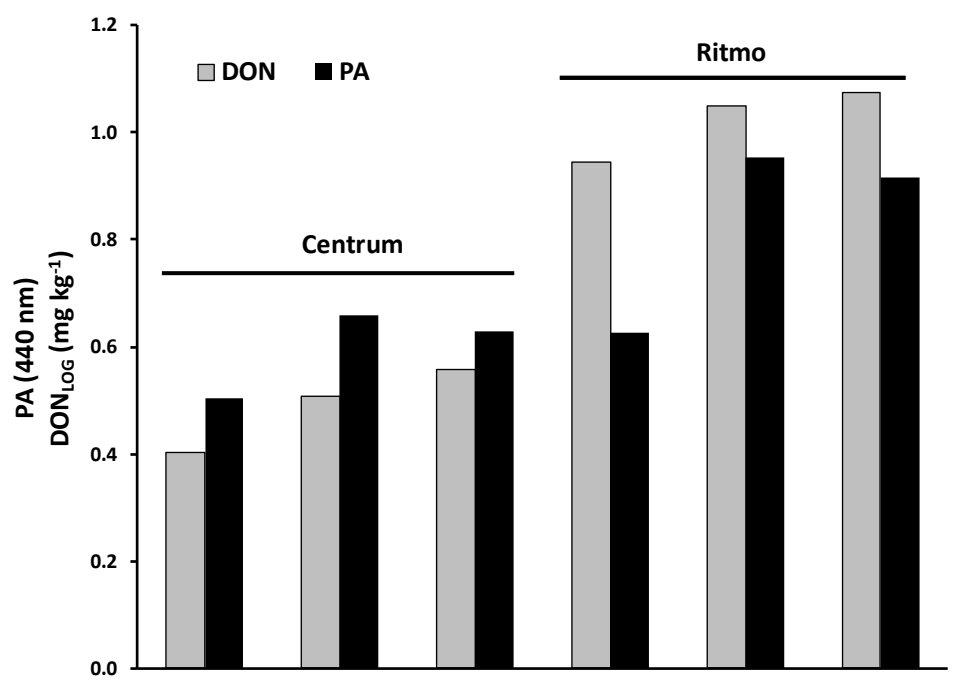

Fig 29. Protease activity (PA) and $D O N_{\mathrm{LOG}}$ of flour Type 550 from wheat (Centrum, Ritmo) grown after pre-crop maize at location Torland in 2007. Each bar represents the MV of the technical measurements of one flour sample

\subsection{Relationship among quality parameters and flour components}

Correlation studies showed that both $\mathrm{PC}_{\mathrm{WGF}}$ and $\mathrm{PC}_{\mathrm{Type550}}$ were highly positively correlated to $\mathrm{WG}$, WA, BV and loaf shape (LL) (Tab 53). Both parameters were strongly positively related among each other. Furthermore, both WG and WA showed a strong positive relationship with BV, while BV was apparently higher if LW increased. LH and LL were inversely related. Gluten property $\left(\mathrm{R}_{\mathrm{MAX}} / \mathrm{EXT}\right)$ was inversely related to $\mathrm{LW}$. Interestingly, none of the measured single flour components was significantly correlated to any of the quality parameters, except for PC and starch content which showed a moderate negative trend with WA. Main gluten fractions, gliadin and glutenin, as well as single subfractions merely showed significant correspondence among each other and with gliadin/glutenin ratio. The complete correlation matrices for all quality parameters and flour components can be viewed in the supplementary material (Tab 62, Tab 63, Tab 64) 
Tab 53. Linear relationships among quality parameters and total gluten subfractions where $R^{2} \geq 0.50$ and $p<0.05$

\begin{tabular}{|c|c|c|c|c|c|}
\hline Dependent variable & $\mathbf{n}$ & Independent variable & Trend & $\mathbf{R}^{2}$ & $\mathbf{p}$ \\
\hline \multirow{6}{*}{$P C_{W G F}$} & 108 & $\mathrm{PC}_{\mathrm{Type550}}$ & + & 0.83 & $* * *$ \\
\hline & 108 & WG & + & 0.63 & $* * *$ \\
\hline & 84 & WA & + & 0.69 & $* * *$ \\
\hline & 84 & BV & + & 0.66 & $* * *$ \\
\hline & 84 & $\mathrm{LH}$ & - & 0.54 & $* * *$ \\
\hline & 84 & $\mathrm{LL}$ & + & 0.59 & $* * *$ \\
\hline \multirow{4}{*}{$\mathrm{PC}_{\text {Type550 }}$} & 108 & WG & + & 0.67 & $* * *$ \\
\hline & 108 & WA & + & 0.73 & $* * *$ \\
\hline & 84 & BV & + & 0.72 & $* * *$ \\
\hline & 84 & LL & + & 0.55 & $* * *$ \\
\hline \multirow{3}{*}{ WG } & 84 & WA & + & 0.83 & $* * *$ \\
\hline & 84 & BV & + & 0.75 & $* * *$ \\
\hline & 84 & $\mathrm{LL}$ & + & 0.53 & $* * *$ \\
\hline \multirow{3}{*}{ WA } & 84 & BV & + & 0.79 & $* * *$ \\
\hline & 84 & LL & + & 0.54 & $* * *$ \\
\hline & 84 & Starch & - & 0.55 & $* * *$ \\
\hline BV & 84 & LW & + & 0.57 & $* * *$ \\
\hline LH & 84 & $\mathrm{LL}$ & - & 0.54 & $* * *$ \\
\hline LW & 36 & $\mathrm{R}_{\text {MAX }} /$ EXT & - & 0.54 & $* * *$ \\
\hline $\mathbf{R}_{\text {MAX }} /$ EXT & 18 & $\mathrm{R}_{\mathrm{MAX}}$ & + & 0.54 & $* * *$ \\
\hline \multirow{2}{*}{ Total Gliadin } & 108 & $\alpha$-Gliadin & + & 0.78 & $* * *$ \\
\hline & 108 & $\gamma$-Gliadin & + & 0.81 & $* * *$ \\
\hline$\omega 5$-Gliadin & 108 & $\omega 1,2$-Gliadin & + & 0.66 & $* * *$ \\
\hline \multirow{4}{*}{ Total Glutenin } & 105 & $\omega b-G S$ & + & 0.78 & $* * *$ \\
\hline & 105 & HMW-GS & + & 0.82 & $* * *$ \\
\hline & 105 & LMW-GS & + & 0.99 & $* * *$ \\
\hline & 105 & Gliadin/Glutenin & - & 0.67 & $* * *$ \\
\hline$\omega b-G S$ & 105 & LMW-GS & + & 0.79 & $* * *$ \\
\hline \multirow{2}{*}{ HMW-GS } & 105 & LMW-GS & + & 0.73 & $* * *$ \\
\hline & 105 & Gliadin/Glutenin & - & 0.66 & $* * *$ \\
\hline LMW-GS & 105 & Gliadin/Glutenin & - & 0.64 & $* * *$ \\
\hline \multicolumn{6}{|c|}{$\begin{array}{l}\mathrm{n} \text { number of observations, } \mathrm{p} \text { significance: }{ }^{* * *}=\mathrm{p}<0.001, \mathrm{PC}_{\mathrm{WFG}} \text { protein content of whole } \\
\text { grain flour, } \mathrm{PC}_{\text {Type550 }} \text { protein content of flour Type } 550, \text { WG wet gluten, WA water }\end{array}$} \\
\hline
\end{tabular}




\section{Discussion}

\subsection{Fusarium biomass and mycotoxins}

\subsubsection{Occurrence of Fusarium DNA and mycotoxins}

The occurrence of the two most prevalent Fusarium spp., F. graminearum and F. culmorum, that are commonly associated with FHB in wheat in the Europe and northern America were investigated in milling products of wheat by qPCR with the objective to determine fungal abundance over a time period of three years. The results showed that both species at the same time could only be detected in 2007 (Tab 7), where humid weather conditions during anthesis enhanced a natural Fusarium infection of wheat spikes. While FgDNA could also be detected in 2008 and 2009 in lower concentrations in a few samples, $F c$ DNA was not found in 2009 in any of the flours and bran (2008: not analyzed). Subsequently, in 2009, FgDNA made up 100\% of total Fusarium DNA (if only $F g$ DNA and $F c$ DNA were considered). In 2007, $F g$ DNA accounted for a significant proportion of over $90 \%$ of total Fusarium DNA (Tab 8) which indicated the predominant existence of F. graminearum on and within the wheat kernels. This finding is supported by GÖDECKE 2010 who isolated Fusarium spp. from the resembling samples and identified at least seven different species, including $F$. culmorum, $F$. tricinctum, $F$. compactum, $F$. poae, $F$. avenaceum, and Microdochium nivale. However, F. graminearum was the most frequently isolated pathogen in 2007 and 2009. In 2008, hardly any Fusarium spp. could be detected, F. graminearum isolates made up < 5\%. In 2007, F. culmorum accounted for up to $10 \%$ of all fungal isolates whereas it could not be isolated at all in 2008 and 2009. This confirms the results of the qPCR. These species were not considered in our investigation, but are also assumed to be part of the FHB pathogen complex in wheat (BOTTALICO \& PERRONE 2002; LIDELL 2003). However, it`s likely that infected samples contained more Fusarium DNA aside from $F$. graminearum and $F$. culmorum DNA since coexistence of different Fusarium spp. at field sites is well known (KLIX ET AL. 2008; XU ET AL. 2008A).

The presence and the predominance of Fusarium pathogens in wheat are first of all assumed to be determined by climatic conditions, primarily temperature and humidity (PARRY ET AL. 1995). While the occurrence of $F$. graminearum was particularly verified in warmer and humid environmental conditions, F. culmorum seems to prefer a cooler and also humid/wet climate (PARRY ET AL. 1995; XU ET AL. 2008A). In Germany, several studies that focused on the pathogen spectrum of Fusarium spp. in wheat demonstrated a differing predominance of single species depending on the geographical region of investigation and its climatic conditions. In southern Germany (Bavaria) $F$. poae was the most prevalent specie followed by $F$. graminearum and $F$. avenaceaum while $F$. culmorum and other species played a minor role (BÜTTNER 2006). In Rhineland, characterized by a cooler climate than Bavaria, $F$. avenaceum was the most frequently isolated pathogen, followed by 
F. culmorum, F. graminearum and F. poae (LIENEMANN ET AL. 2001). During the 1980s, in northern Germany, characterized by cooler and partly maritime climatic conditions, F. culmorum was the dominant specie while $F$. graminearum was hardly detected (SCHLÜTER ET AL. 2006). A more recent study demonstrated that $F$. graminearum was the most frequently detected specie in Schleswig-Holstein followed by $F$. poae, $F$. avenaceum and $F$. culmorum despite wet and cool and maritime conditions that would favor the development of F. culmorum (KLIX ET AL. 2008). The predominance of $F$. graminearum over $F$. culmorum as DON-producing specie in the south of Lower Saxony, geographically placed between the northern and southern part of Germany, as shown with our field trial, is supported by several other investigations that described a shift in FHB incidence caused nowadays rather rarely by $F$. culmorum but more often by $F$. graminearum in European countries with differing climatic conditions (PARRY ET AL. 1995; WAALWIJK ET AL. 2003; XU ET AL. 2005). Three main reasons are discussed for this phenomenon. First, the increasing production area for maize which is apparently an optimal host plant for $F$. graminearum and has been demonstrated to increase FHB incidence and severity in wheat significantly when compared to other pre-crops (BECK \& LEPSCHY 2000; RINTELEN 2000; STACK 2000; LOGRIECO ET AL. 2002). Second, XU ET AL. 2005 assumed that F. graminearum becomes steadily adapted to cooler geographical regions. Third, a possible climate change caused former cooler regions to become warmer (XU ET AL. 2005; BÜTTNER 2006). While the later two arguments can neither be proven nor rejected for the region of south Lower Saxony since they were not in the focus of this investigation, the first argument -intensified maize cultivation- has to be considered. Due to the increasing demand for substrate meant for biogas production, from 1999 to 2007 the maize production area of Lower Saxony increased in average about 5\%, in some areas about 10 to $15 \%$. This led to a change in crop rotation from the typical winter wheat/winter wheat/winter barely/winter rapeseed (sugar beet) or winter wheat/winter wheat/sugar beet to a less wheat dominated maize/winter wheat/winter barely/rapeseed (sugar beet) rotation. Some farmers even reduced their crop spectrum and applied a maize/winter wheat/winter wheat and maize/winter wheat/sugar beet rotation (KARPENSTEINMACHAN \& WEBER 2010). With the objective to investigate FHB in wheat under typical agronomical practices for Lower Saxony, pre-crop maize and minimum tillage was integrated into the 3-year-field experiment. $\mathrm{FgDNA}$ was most abundant in wheat milling products with pre-crop maize (Fig 8). In our investigation, $F g$ DNA levels after maize pre-crop were approx. 7-fold and 3.5-fold higher than after pre-crop sugar beet and winter wheat.

\section{Mycotoxins}

The focus of our qPCR study did not only lay on $F$. graminearum and $F$. culmorum because of their worldwide distribution and connection to FHB, but primarily because they have been associated with the presence of mycotoxins in grain including trichothecenes (DON, ADON, NIV, ANIV, FUS X), ZEA and zearalenol of which all of them present a greater concern to human 
health (BotTALiCO 1998; Lidell 2003). Since at least FgDNA could be detected in a bigger amount of samples, the presence of these mycotoxins could also be expected. Of all mycotoxins, only DON, 3-ADON, and ZEA could be detected (Tab 7) while zearalenol was not investigated.

The absence of NIV and FUS X in all samples and the simultaneous contamination with DON and 3-ADON suggests a predominant infection of the grain with Fusarium genotypes that were only able to produce DON and its acetyl derivate 3-ADON. The ability of $F$. graminearum strains to produce exclusively DON and 3-ADON or NIV and FUS X was verified by ICHINOE ET AL. 1983 and led to the classification of "DON chemotypes" and "NIV chemotypes" whereas 3-ADON and FUS X can be assumed to be precursors within the biosynthesis pathway of the later, respectively. These findings supported the results of in vitro assays conducted from $42 \mathrm{~F}$. culmorum isolates that either synthesized DON or NIV but not both toxins together (GANG ET AL. 1998). The reports are contradicted by SUGIURA ET AL. 1990 who firstly demonstrated a cross-production of both toxins in F. graminearum strains. A further division of the DON chemotype (chemotype I) into subgroups IA (DON, 3-ADON) and IB (DON, 15-ADON) that characterized the formation of only one specific DON acetyl derivate by MILLER ET AL. 1991 and which may explain the particular detection of 3-ADON but not 15-ADON in our samples was rejected by Sugiura et al. 1990. They attributed the prevalence of either 3-ADON or 15-ADON to the environmental temperature that either enhances or inhibits the enzymatic catalysation of 3-ADON into 15-ADON. The exclusive presence of DON and 3-ADON in our samples suggested an infection by $F$. graminearum (and $F$. culmorum in 2007) of chemotype IA or environmental conditions that favored the production of 3ADON rather than 15-ADON. In a recent study, 26 isolates of $F$. graminearum from Hungary were mainly of chemotype IB (Toth ET AL. 2005). Both Toth ET AL. 2005 and PERKOWSKI ET AL. 1997 cited several studies conducted in Europe, including Germany, and worldwide which demonstrated the co-existence of DON, NIV and their derivates in harvested grain. The reasons for the predominance of single chemotypes and therefore their produced toxins in different geographical regions are not clear yet. An influence of host, specie, temperature and soil type are assumed (Tотн ET AL. 2005). After all, only about 15\% (37/252) of all samples analyzed in our study contained 3-ADON, all of them below the $\mathrm{EU}_{\mathrm{MAX}}$ for DON in flours. In our study, only $6 \%$ (16/252) of all samples analyzed were contaminated with ZEA. ZEA was frequently detected together with DON (LOGRIECO ET AL. 2002; XU ET AL. 2008B). Since the occurrence of other Fusarium ssp. was likely (GÖDECKE 2010) and only a small range of the total mycotoxin spectrum that can be produced by Fusarium spp. was analyzed, the presence of other mycotoxins in milling products could not be excluded (BOTTALICO \& PERRONE 2002).

\subsubsection{Factors influencing $F g D N A$ and DON}

As has been described in several previous studies (OBST ET AL. 2000; SCHAAFSMA ET AL. 2001; BEYER ET AL. 2006), all factors (environment, pre-crop, cultivar, fungicide) that were investigated 
in our field experiment had a significant influence on the DON levels in grain and their afterwards produced milling products. Obviously, even though grain had been cleaned to a certain degree, effects of the agricultural practices on DON levels were still clearly visible. This study is the first, that also takes the abundance of the most prevalent DON-producing Fusarium specie, $F$. graminearum, measured as $F g D N A$ into account and therefore allows for conclusion of the influence of agricultural practices on fungal abundance and DON contamination.

\section{Environment}

The tremendous significance of weather conditions during the time period around and during wheat anthesis for successful Fusarium infection has been reported before (LACEY ET AL. 1999). F. graminearum forms perithecia on crop debris that forcibly release ascospores into the air and conidia which are transported by rain splashes up to the wheat spike. Both inoculum sources are critically influenced by temperature and moisture (XU \& NICHOLSON 2009). While different FHB pathogens seem to require different temperature conditions for the process of colonization and infection (XU ET AL. 2008A), generally all of them need wet or moist conditions before and during anthesis as well as during the early grain development stages (DE WOLF ET AL. 2003).

FgDNA and DON levels ranged widely between the six environments (Fig 7). The weather conditions during the years 2007, 2008 and 2009 varied widely between the years, which may explain the significant differences of DON levels and amount of $F g$ DNA in milling products (Fig 30). In 2007, the average daily precipitation in May (153.4 mm) and June (141.6 mm) was at least twice as high as in the same months in 2008 and 2009 while average daily temperatures were comparatively warm in June. A few heavy rain incidences with more than $10 \mathrm{~mm} / \mathrm{h}$ precipitation prior to anthesis and during anthesis led in average to 218- and 358-fold higher FgDNA amounts and to 65 and 95-fold higher DON levels in 2007 at the locations Torland and Gladebeck, respectively, when compared to the same locations in 2008. Samples in 2007 also contained 18and 59-fold more FgDNA and 1.6- and 5.1-fold higher DON amounts when compared to the respective samples in 2009. In 2008, a long dry period during May (average precipitation only 6.1 $\mathrm{mm}$ ) with only 4 rain fall events ( $<2 \mathrm{~mm}$ precipitation) and wheat anthesis may have prevented the development of ascospores within perithecia on crop debris which is favored by high humidity and their dispersal which is often connected to rainfall events (XU \& NICHOLSON 2009). This was reflected by hardly detectable DON concentrations in only a few samples, and rarely detectable $F g$ DNA (Tab 7). In 2009, average precipitation was higher than in 2008 and also were there a few more rainfall events pre-anthesis and also during flowering, but average daily temperature in June $2009\left(14.8{ }^{\circ} \mathrm{C}\right)$ was $1-2{ }^{\circ} \mathrm{C}$ lower than in 2008 and 2007 which was mainly due to daily minimum temperatures down to $5^{\circ} \mathrm{C}$. Development of perithecia and sexual development of $F$. graminearum occurs between $15-29^{\circ} \mathrm{C}$ (PARRY ET AL. 1995). The optimum temperatures for ascospore production are $15-20^{\circ} \mathrm{C}$ (XU \& NICHOLSON 2009). Lower temperatures and precipitation in 2009 prevented an 
epidemic as in 2007 but obviously supported the fungal growth and DON accumulation in grain better than the weather conditions in 2008 since DON levels were 4- and 19-fold higher at location Torland and location Gladebeck, respectively than in the previous year, and wheat contained 12and 6-fold higher $F g$ DNA contents.

In general, the effects of the environment on $F g$ DNA amount corresponded very well to the effects on DON. The more FgDNA was detected the higher the DON levels were found in milling products. The effect of location on both parameters was not clear. While $F g$ DNA was clearly more abundant in wheat from location Torland in 2007, DON levels were not significantly different between the two locations. This is contradictory to the results of GÖDECKE 2010 who reported 3fold higher DON contents in wheat samples from location Torland in 2007 and concluded that there is clear difference between the two locations in potential to accumulate DON in grain even though they are geographically not far apart. The discrepancy of the results might have derived from the pre-harvest cleaning of our grain samples prior to further processing which was not applied for the samples of GÖDECKE 2010. It is known from literature that wheat kernel with very high DON concentrations are usually lower in weight (TKACHUK ET AL. 1991). It is thinkable that the actually heavier DON contaminated but lighter wheat kernels from location Torland might have been removed during cleaning because the sample cleaning machine included an aspiration to remove light grains, chaff and dust by air. Therefore, samples from the two locations apparently contained equal DON levels.

In 2009, DON was 3-fold more abundant at Torland while there was not a significant difference in FgDNA levels between the two locations. The differences in $F g$ DNA and DON between the locations might have resulted from small differences in temperature and water availability (MAGAN ET AL. 2002), soil conditions influencing the presence of crop debris (OLDENBURG ET AL. 2007B), neighboring crops that function as hosts for $F$. graminearum such as maize, differences in mycoflora composition (DOOHAN ET AL. 2003) or oxidative stress that is present at one site and enhances toxin production more than at the other site (PONTS ET AL. 2009; REVERBERI ET AL. 2010). The interactions of factors that lead to DON accumulation are complex and yet not fully understood.

The results demonstrate once more the importance of specific weather conditions during the susceptible stage of wheat flowering for the successful colonization of the wheat heads by $F$. graminearum, the development of FHB, and the subsequent contamination of harvested grain with DON which has been stressed by many other studies before (PARRY ET AL. 1995; MCMULLEN ET AL. 1997; Meier et AL. 2000; ObSt ET AL. 2000; De Wolf ET AL. 2003). De Wolf ET AL. 2003 stated that FHB epidemics are generally associated with the longer periods of temperatures between 15 to $30^{\circ}$ and extended periods of relative high humidity ( $\left.\geq 90 \%\right)$ before or during flowering. In a four year survey conducted by SCHAAFSMA ET AL. 2001, who analyzed the effect of 
different agronomic practices on DON content in wheat, $48 \%$ of the total variation of DON levels was explained by the influence of the year, which represented of all the most important factor. This agrees with our result that the environment and the year in particular showed of all experimental factors the highest effect on DON content in milling products reflected by highest SoE (Tab 10)

Regardless of environmental conditions, which cannot (weather) or hardly be influenced (location), and type of milling product which is in the hands of the miller, for the farmer it's crucial to know which agronomical measures avoid high DON levels in harvested wheat.

\section{Pre-crop}

Pre-crop maize generally led to higher contents of DON and $F g$ DNA in milling products than wheat and sugar beet (Fig 8). The high potential risk that pre-crop maize presents for the accumulation of DON in following wheat especially after minimum tillage (as applied in our study) or non tillage systems has been reported many times before (DILL-MACKY \& JONES 2000; BEYER ET AL. 2006). BECK \& LEPSCHY 2000 gave three main reasons for this. First, maize is a host of $F$. graminearum. Second, maize leaves plenty of colonized debris after harvest where the fungus survives saprophytically. Third, the rot of maize debris proceeds rather slowly due to comparatively wide C/N ratio. While KOCH ET AL. 2006 also reported significantly reduced DON contents (by a factor of 4.3) in wheat after pre-crop sugar beet when compared to pre-crop wheat, which supports our own results, BECK \& LEPSCHY 2000 found higher DON contents in wheat after sugar beet. GODECKE \& VON TIEDEMANN 2011 concluded that the effect of the year/weather conditions influences strongly how the pre-crop affects DON contamination in wheat, which was also reflected in the significant interactions between environment and pre-crop in our study (Tab 9 ). In years with severe natural infection, e.g. 2007, there might not be a difference between wheat and sugar beet, because inoculum might not primarily result from the debris of pre-crop at site but rather from conidia spread by wind from neighboring host plants.

The difference between pre-crop wheat and sugar beet as a potential inoculum source for Fusarium infection might be a qualitative as well as a quantitative one. While the infection of wheat and maize with $F$. graminearum, the most important causal pathogen of FHB, is well studied, the Fusarium spp. composition in sugar beet is not well researched and therefore the possible carryover of single species on the following crop is still a matter of discussion. CHRIST ET AL. 2011A have shown that the infection of wheat with Fusarium spp. isolated from sugar beet is possible under greenhouse conditions. In a further study the authors demonstrated that stored sugar beets (which can be regarded comparable to sugar beet crop debris left on the field) contained Fusarium spp. that are in Europe part of the FHB complex and therefore sugar beet debris in the field cannot be ruled out as primary inoculum source (CHRIST ET AL. 2011B). Furthermore, compared to wheat (3.7 $\mathrm{t} \mathrm{ha}^{-1}$ ) and maize (9.2 $\mathrm{t} \mathrm{ha}^{-1}$ ) (BUYANOVSKY \& WAGNER 1986), sugar beet leaves less crop residues in the soil, only up to $1.8 \mathrm{t} \mathrm{ha}^{-1}$ (ZANDSTRA \& SQUIRE 2007). OLDENBURG ET AL. 2007B showed a 
strong relation between the remaining amount of maize residues on the soil surface and their content of Fusarium biomass, whereas the DON contamination in wheat particularly depended on the susceptibility of cultivar against FHB.

\section{Cultivar}

Since the two winter wheat cultivars were primarily chosen because of their difference in susceptibility against FHB out of all varieties available grouped in quality class B (Tab 2), it was not surprising that the highly susceptible cv. Ritmo (grade 7) comprised significantly higher DON levels in milling products that less susceptible cv. Centrum (grade 2) (Fig 9). Additionally, cv. Ritmo also contained considerably more $\mathrm{FgDNA}$ than $\mathrm{cv}$. Centrum. These results are confirmed by the findings of GOSMAN 2001 (cited in NICHOLSON ET AL. 2003) who also reported higher DON levels and higher Fusarium DNA in the grain of the susceptible cultivar. Since we did not have any information about the types of resistance obtained by the cultivars (see chapter 1.2.4), it can just be concluded that neither cultivar is completely resistant to spread of the fungus $F$. graminearum within the kernels, nor DON/trichothecenes accumulation within the kernels. It can be assumed that cv. Centrum is less susceptible to disease spread (type II resistance according to ScHROEDER \& CHRISTENSEN 1963) and to DON accumulation within kernels (type III resistance according to MILLER \& ARNISON 1986, type V resistance according to MESTERHAZY 2003) than cv. Ritmo. Especially, the reason for the later is not known. One explanation could be that there was less DON in cv. Centrum because there was also less FgDNA. Another could be that there was less DON because cv. Centrum is capable of modifying the trichothecene chemically (type V class 1 resistance) or because cv. Centrum is able to inhibit trichothecene synthesis (type V class 2 resistance) to a certain degree (MESTERHAZY 2003; BOUTIGNY ET AL. 2008). In addition to the active resistance mechanisms summarized by FOROUD \& EUDES 2009, passive mechanisms as described by Schroeder \& CHRISTENSEN 1963 and MESTERHAZY 1995 might contribute to the different reaction of the two cultivars towards FHB or be an indicator for the FHB resistance. E.g. plant height of cv. Ritmo was visibly less than that of cv. Centrum. HILTON ET AL. 1999 found a negative correlation between straw height and the presence of FHB symptoms. This suggested a possible escape of the spikes due to the greater distance to the inoculum on the ground, e.g. conidia which are splash dispersed to wheat heads as suggested by HORBERG 2002. However, the reason for the correlation seems to be rather due to an overlapping of QTLs for FHB resistance and plant height as well as with other plant features (time of anthesis, awnedness) which were assumed to influence disease incidence (MESTERHAZY 1995; GERVAIS ET AL. 2003). Similar to the results of BEYER ET AL. 2006 who demonstrated that the use of a moderately susceptible cultivar (cv. Dekan) reduced DON content about $76 \%$ when compared to cv. Ritmo, in our study DON content of cv. Centrum was only $25 \%$ of that in cv. Ritmo which emphasizes once more the key role of cultivar choice within the management of FHB which has been discussed before (OBST ET AL. 2000; 
SCHAAFSMA ET AL. 2001; BEYER ET AL. 2006). After, environment and pre-crop, cultivar was the most important factor to influence DON content of milling products (Tab 10). A significant interaction between environment and cultivar (susceptibility) for DON and $F g D N A$ as shown in Tab 9 has also been observed by MIEDANER ET AL. 2001 who demonstrated a strong interaction between FHB resistance in wheat, rye, and triticale cultivars and environmental conditions.

\section{Fungicide}

Even though efficacy of tebuconazole in reducing FHB and mycotoxin levels in grain has been demonstrated to vary (PAUL ET AL. 2007) it`s common census that at present triazole fungicides present the most effective available chemical control of FHB and DON contamination (MATTHIES \& Buchenauer 2000; Beyer ET AL. 2006; PAUl ET AL. 2007; XU \& NiCHOlson 2009). Triazole inhibit the $\mathrm{C}_{14}$ demethylase in microsomes that catalyze an intermediate step of the ergosterol biosynthesis, with ergosterol being an essential part of the fungal cell well (HALLMANN ET AL. 2007). While the direction of the effect of triazoles on DON content in grain is clear, the treatment with strobilurins have produced contradictory results (see chapter 1.2.4). Strobilurins are single site inhibitors of the mitochondrial respiratory chain within the fungal cell (HALLMANN ET AL. 2007). Except for their direct effect on the fungal cell, an indirect impact of the fungicides on disease development can also be expected since WU \& VON TIEDEMANN 2001 have shown a significant delay of senescence after application of azoxystrobin and epoxyconazole at GS 31/32 and GS 59/61. To gain more knowledge how fungicide application in the stage of shooting (GS 31-39) might indirectly affect FHB development was the main objective of the study of GöDECKE 2010, one of our cooperation partners within the FAEN joint project, therefore fungicides were not applied at wheat anthesis (GS 61-69) in order to prevent/reduce FHB development and DON accumulation, but at GS 31-39 (stage of shooting). Additionally to strobilurin and triazole, chlorthalonil, a fungicide of which a senescence delaying effect was not known, was applied. Chlorthalonil is a phthalonitrile impairing fungal growth by reacting with glutathione and coenzyme A in fungal metobolism (ANONYMUS 2011). Since the results are discussed in detail by GÖDECKE 2010, at this point will be no further discussion concerning the possible reasons for the effects of the applied fungicides on DON and $F g$ DNA (Fig 10). It should just be concluded, that these fungicides significantly contributed to the variance within FgDNA and DON levels in milling products (Tab 9).

Since also fungicide treatment influenced DON concentration of milling products significantly, yet not as strong as pre-crop and cultivar, it seem reasonable that the combination of the "worst" factor combinations (maize x susceptible cultivar (cv. Ritmo) x strobilurin/chlorthalonil application) of agricultural measures led to the highest DON concentrations in milling products whereas the combination of sugar beet $\mathrm{x}$ cultivar with low susceptibility (cv. Centrum) $\mathrm{x}$ triazole application minimized the risk of DON accumulation (Tab 10). 


\section{Milling product}

As described in chapter 1.1.1 further processing of harvested grain leads to a reduction of DON/trichothecenes to a certain degree. Several studies reviewed by KUSHIRO 2008 have shown that DON contamination of the grain leads to a distribution of DON in all milling fractions, but that there is in general at least a slight reduction of DON in flours milled from endosperm, the more inner part of the kernel (straight-grade flour, extraction flour, break flour), when compared to the milling products containing more of the kernel`s outer layers (bran, shorts). In our study, DON content in bran was in average 1.7-fold higher than in WGF (cleaned grain) (Fig 11). Increased DON levels in a similar range were also observed by HART \& BRASELTON 1983, TANAKA ET AL. 1986, TRigo-StOCKLI ET AL. 1996, and LANCOVA ET AL. 2008 who observed 2.3, 2.7, 1.2, and 2.0 times higher DON content in bran than in the original wheat. Unlike other studies (YOUNG ET AL. 1984; ABBAS ET AL. 1985; SeITZ ET AL. 1985; SEITZ ET AL. 1986; NOWICKI ET AL. 1988; DEXTER ET AL. 1996; TRIGO-STOCKLI ET AL. 1996; LANCOVA ET AL. 2008), we could not observe a reduction of DON in flour Type 550 by milling. Instead, DON concentrations in flour Type 550, which resembles $75 \%$ yield straight-grade flour, were $150 \%$ of the DON content of WGF and not significantly different from DON levels in bran. At the same time, $\mathrm{FgDNA}$ content in flour Type 550 was only $33 \%$ of $\mathrm{FgDNA}$ contained in WGF and $13 \%$ of $\mathrm{FgDNA}$ content in bran, suggesting the dominant prevalence of $F$. graminearum within the outer layers of the kernels and a less dense colonization of the endosperm. The stepwise reduction of Fusarium DNA during wheat cleaning and processing has been reported by TERZI ET AL. 2007. They showed that cleaned grain contained $60 \%$, extraction flour $20 \%$, and bread just $4 \%$ of the original amount of Fusarium DNA measured in uncleaned grain. In our study, the increased DON level and the reduced $\mathrm{FgDNA}$ content in flour Type 550 when compared to WGF and bran, resulted in similar DON:DNA ratios in WGF (0.013) and bran (0.009) and a significantly higher ratio in flour Type 550 (0.061). This result was confirmed by the linear regressions between DON levels and $F g$ DNA of milling products in (Fig 16). Regression curves of WGF and bran had similar slopes ( $\mathrm{a}=0.01$ and 0.007$)$ but for flour Type 550 we estimated about 4 times more DON per $\mu$ g $F g$ DNA (a=0.04) (see also chapter 5.1.3). DON concentration per $\mu \mathrm{g}$ Fusarium DNA in different milling products gives an interesting inside where the fungus is located within the kernels and associated toxins at the same time. The higher DON content in flour Type 550 compared to WGF deserves consideration. HART \& BRASELTON 1983 made the same observation and gave two possible explanations 1) the higher recovery of DON from milled fractions, 2) fungal growth and subsequent DON production during one week of tempering prior to milling. Even though matrices effects interfering with the detection of mycotoxins are known from other studies (ZHOU ET AL. 2007; VENDL ET AL. 2009), this explanation seems unlikely for our data, since DON quantification was done by means of matrix-matched calibration (see chapter 3.2.2) and would certainly not account for the double amount of DON in flour Type 550. The term 'tempering' describes the process of incubating grain with a defined 
amount of water for a particular time in order to reach the same moisture content and physical condition within all kernels with the objective to "toughen the bran and mellow the endosperm" (POSNER \& HIBBS 2005). In our case, fungal growth and associated DON accumulation within $12 \mathrm{~h}$ of tempering cannot be excluded, but does not explain the higher DON:DNA ratio in white flour compared to bran if we assume that the production rate of DON per unit $\mathrm{FgDNA}$ is equal in all kernel parts. Therefore, it's suggested that there had been a translocation of DON from the outer parts of the kernels into the endosperm at some point. DON is well water soluble (EMAN 2011). The translocation might have occurred already in the field while moisture content in grain is still high as described by SNIJDERS \& KRECHTING 1992, and/or during storage as well as during the tempering process itself. DELGADO ET AL. 2010 discussed the possibility of diffusion of DON produced by $F$. graminearum from rotten tissue of potato tubers into surrounding asymptomatic tissue during storage. The authors came to the conclusion that warmer temperatures $\left(\geq 20^{\circ} \mathrm{C}\right)$ during storage might enhance the diffusion of DON into adjacent tissue while cooler storage temperatures $\left(10-12^{\circ} \mathrm{C}\right)$ retard the process. Such a diffusion process could also be thinkable for grain, even though harvested grain contains considerably less water than potato. In the present study, DON obviously diffused more rapidly into the endosperm than it was penetrated by the fungus. This process could have been enhanced by the warm ambient temperatures during storage until milling $\left(>20^{\circ} \mathrm{C}\right)$ or/and during tempering $\left(18-20^{\circ} \mathrm{C}\right)$. XU ET $A L .2007$ demonstrated that mycotoxin production by Fusarium spp. increased with high temperatures $\left(\geq 20^{\circ} \mathrm{C}\right)$ during the initial infection period. Optimal production of type B trichothecenes occurs at warm $\left(25-28^{\circ} \mathrm{C}\right)$ and humid $\left(\mathrm{a}_{\mathrm{w}}=\right.$ 0.97) conditions (DOOHAN ET AL. 2003). HOMDORK ET AL. 2000 found a significant increase of DON levels in low to moderately $F$. culmorum infected wheat when grain was stored for 6-8 weeks under warm and humid conditions $\left(25^{\circ} \mathrm{C}, 90 \% \mathrm{RH}\right)$. Therefore we conclude, that tempering can be seen as short term storage (12-16h) which provides optimal conditions for mycotoxin production and translocation, since water content of grain is raised from 8-10\% storage moisture up to $15-16 \%$ milling moisture under ambient temperature $\left(18-20^{\circ} \mathrm{C}\right)$. This might have caused DON levels of flour Type 550 to exceed DON levels of WGF and to be similar high as DON contents of bran.

\section{DON levels of flour Type 550}

The large number of experimental factors (year, location, pre-crop, cultivar, fungicide) that had been shown to influence DON and $F g$ DNA content in flours and bran significantly, led to a wide spectrum of DON levels in flour Type 550, ranging from below LOD up to extreme values of 11.8 $\mathrm{mg} \mathrm{kg}^{-1}$ (Fig 12). In our study, flour type 550 was primarily investigated because it`s most commonly used for the production of bread and bakery products in Germany. In order to have a more practical approach, flour was produced from grain that was cleaned by a single passage through a sample cleaner (see chapter 3.1.2) where a removal of the most contaminated kernels (light, shrunken) could have been expected. Nevertheless, $31 \%$ of all flours contained more DON 
than the $\mathrm{EU}_{\text {MaxuP. }}$ It's obvious that these flours would not have been suitable for further processing of food and that the corresponding grain would have been very likely discarded before milling. 5\% comprised 0.75 to $1.25 \mathrm{mg} \mathrm{kg}^{-1}$ DON. $64 \%$ of flours contained less than $0.75 \mathrm{mg} \mathrm{kg}^{-1} \mathrm{DON}$ and would have been suitable for further processing into cereal products as well as for direct consumption by adults.

Since no considerable amounts of other toxins were found, DON levels in flours would be from the toxicological and legal point of view the most decisive criterion of all for further use. Therefore, in the chapters 5.2 and 5.3 the impact of DON concentration of flours on quality parameters of wheat flours and flour composition will be discussed.

\subsubsection{Relationship of visual disease, DON, and FgDNA}

\section{Visual disease}

In the field, FHB intensity in wheat may be estimated visually by DI, DS, or FHB index whereas the index is assumed to be the most useful parameter since it is the product of DI and DS. High DI might not always correspond with high DS (WILCOXSON ET AL. 1992). Nevertheless, in 2009, DS was so low that we chose to determine only DI, the easier and often more accurate parameter to obtain (Tab 11) (PAUL ET AL. 2005A). In 2008, both were measured but were so low that the index was in most cases very close to zero or zero, respectively. Therefore, in 2008 and 2009, where Fusarium infection was low to moderate (see chapter 5.1.2) in both cultivars a low DI also corresponded with a low DS, implicating that at the time of visual rating not only the primary infection did rarely occur but also the spread of the FHB causing pathogens within the spikes was exceptional. In 2007, were all three parameters could be easily obtained, high DI corresponded with high DS and therefore high FHB indices in both cultivars. The measurement of the visual disease reflected very well the susceptibility of the cultivars against FHB (see chapter 5.1.2). Independent of Fusarium infection level, DI was always significantly higher in highly susceptible cv. Ritmo than in less susceptible cv. Centrum, indicating that cv. Ritmo is less resistant to infection than cv. Centrum (type I resistance) and also less resistant to spread of the infection within the spikes (type II resistance) which was implied by a significantly higher DS in 2007 (Tab $11)$.

It is agreed that generally there exists a positive relationship of DI and DS, however, the modeling of this relationship is still discussed (GROTH ET AL. 1999; PAUL ET AL. 2005A). The easiest model, the linear regression with untransformed data, as applied in our study and resulting in a moderate correlation coefficient $\left(\mathrm{R}^{2}=0.25\right)$, may not be the best-fitted. PAUL ET AL. 2005A found that DS was more precisely estimated at lower DI values than at higher values in a model based on complementary log-log transformation of both visual estimates. 


\section{Visual disease and DON}

The most interesting question regarding visual FHB usually is whether possible mycotoxin occurrence, especially contamination with DON, can be predicted from it. In our study, in general, DI was highly positively associated with DON levels in milling products gained from cleaned (!) wheat (Fig 14). However, the type of equation for predicting DON levels with a high $\mathrm{R}^{2}$ was dependent on the infection intensity of the years. In 2009, where FHB intensity was moderate (with DI up to $0.17 \%$ in cv. Centrum and up to $3.2 \%$ in cv. Ritmo) linear functions of DI described DON contents in flours and bran sufficiently ( $\left.D O N=a^{*} D I+b\right)$. Interestingly, higher DI in cv. Centrum $(\mathrm{a}=6.3,10.4,12.7)$ corresponded with a higher DON accumulation in milling products than in $\mathrm{cv}$. Ritmo ( $\mathrm{a}=1.4,2.4,2.9)$. In 2007, DI was many-fold higher than in 2009 with DI up to $30 \%$ in $\mathrm{cv}$. Centrum, and up to 55\% in cv. Ritmo. DI values $>13 \%$ were without exception determined in plots with pre-crop maize. DON levels of milling products from these samples would have been highly overestimated if predicted with a linear model. Logarithmic functions of DI described the correlation with DON best $(\mathrm{DON}=\mathrm{a} \ln (\mathrm{DI})+\mathrm{b})$. With higher DI, cv. Centrum responded with less DON $(a=0.5,0.7,0.7)$ accumulation in milling product than cv. Ritmo $(a=1.6,1.8,2.9)$. Yet, it has to be considered that DON levels in WGF $\left(\mathrm{R}^{2}=0.45\right)$ and bran $\left(\mathrm{R}^{2}=0.21\right)$ of $\mathrm{cv}$. Ritmo did not correlated well with DI. Inserting $\mathrm{EU}_{\text {MAXuP }}\left(1.25 \mathrm{mg} \mathrm{kg}^{-1}\right)$ and $\mathrm{EU}_{\mathrm{MaxCF}}\left(0.75 \mathrm{mg} \mathrm{kg}^{-1}\right)$ into these prediction models gave an estimate of maximum DI. For EU $U_{\text {MAXUP, }}$ DI could not have been higher than $0.63 \%$ in 2007 and $0.10 \%$ in 2009 so that all milling products of both cultivars stayed still within the tolerable amounts of DON. Regarding the $\mathrm{EU}_{\mathrm{MaxCF}}$, DI could not have been higher than $0.48 \%$ in 2007 and $0.06 \%$ in 2009 in order that all milling fractions of both cultivars contained no more than $0.75 \mathrm{mg} \mathrm{kg}^{-1}$ DON. These values indicate two things. First, prediction of DON from DI may work well within the years but not between years. Second, in years of epidemic occurrence of FHB it`s unrealistic to stay within the range of $\mathrm{EU}_{\mathrm{Max}}$ for $\mathrm{DON}$ without further prevention management (e.g. triazole application during anthesis) or thorough cleaning of the grain, noting that far less than 1 spike per 100 spikes could show symptoms without considerable subsequent DON contamination. In 2008, the overall low DI indicated very low to zero DON values very precisely.

A meta-analysis performed by PAUL ET AL. 2007 over a total of 163 studies revealed a general positive correlation between DON and visual estimates for FHB, including DI $(r=0.52)$, DS $(r=$ $0.53)$, FHB index $(\mathrm{r}=0.62)$, and Fusarium damaged kernels $(\mathrm{FDK})(\mathrm{r}=0.73)$ which supports our own results regarding relationship between DON:DI and DON:FHB. Other studies did not observe a relation between visual disease in the field and DON levels in grain (LIU ET AL. 1997; EDWARDS ET AL. 2001). Yet, the prevalence and strength of the correlation may depend on cultivars (susceptibility), environment (weather condition, location), pathogen complex, crop production, disease management (fungicides) and other unknown effects (PAUL ET AL. 2007; XU ET AL. 2007). 
Overall, it cannot be recommended to predict DON levels in milling products on the sole parameter of DI, particularly if models contain rather small amount of data $(\mathrm{n}=18)$ as it was the case in our study. The cleaning of the grain and the further processing (tempering, milling) represent further effects which seem to influence relationship between visual disease and DON, which appeared to be positively correlated, but may influence the precision of the prediction $\left(\mathrm{R}^{2}=0.21\right.$ to 0.91 (Fig $14)$.

\section{Visual disease and FgDNA}

For 2007, we found low to strong positive correlations of visual disease assessment and presence of $F$. graminearum depending on the parameter used. DI (Fig 15) and FHB predicted FgDNA concentrations in milling products very well, probably because the two disease estimates (DI and FHB) were also very strongly related to each other, while DS did not provide such a good prediction model. Our results are supported by ZHANG ET AL. 2009 and BURLAKOTI ET AL. 2007 who reported a strong positive association between DS and FgDNA. XU ET AL. 2007 demonstrated a consistent positive relationship between incidence of diseased spikelets and amount of DNA of several Fusarium spp., particularly FgDNA, under controlled environment conditions. Whereas EDWARDS ET AL. $2001 \mathrm{did}$ not find a correlation between visual disease (assessed as DS) and concentration of $F$. graminearum and $F$. culmorum (measured as DNA content) in harvested grain gained from a field trial.

The contradiction might result from the different species composition in the field and specific isolates used in the trials, differing in their capability to produce FHB symptoms by the time of disease assessment and colonizing the grain until harvest. XU ET AL. 2007 demonstrated that inoculation with $F$. graminearum resulted in highest DS but grain infected with $F$. culmorum contained highest fungal DNA amounts, indicating that the same DS value might not result in the same amount of species specific DNA.

\section{FgDNA and DON}

While studies on the relationship between visual disease and Fusarium DNA are rare, the association between fungal biomass and DON contamination has gained more attention in research. Our results revealed a moderate positive linear correlation in flour Type 550 and bran $\left(\mathrm{R}^{2}=0.65\right.$ and $0.77)$ and a strong correlation in WGF $\left(\mathrm{R}^{2}=0.84\right)$ between $F g$ DNA and DON levels (Fig 16). The positive correlation between colonization/fungal biomass (measured as ergosterol or DNA content) and DON levels in grain has been reported by several authors (MILLER ET AL. 1985; EDWARDS ET AL. 2001; Xu et AL. 2007; Zhang et AL. 2009, Gang ET AL. 1998; Miedaner ET AL. 2000; BURLAKOTI ET AL. 2007). We could show that this relationship is not only true for the harvested whole grain but also for milling fractions (flour Type 550 and bran) derived from it. Our results are supported by TERZI ET AL. 2007 who reported a consistent positive linear regression for Fusarium 
DNA and DON levels in (not cleaned) grain $\left(\mathrm{R}^{2}=0.97\right)$, WGF $\left(\mathrm{R}^{2}=0.89\right), 60-63 \%$ yield flour $\left(\mathrm{R}^{2}=0.99\right)$, and bread $\left(\mathrm{R}^{2}=0.87\right)$. Additionally, we could also show that there was a close positive relationship between DON and $F g$ DNA in WGF with DON and $F g$ DNA levels in bran and flour Type 550 (Tab 12) indicating that DON levels and FgDNA amounts of other kernel parts (outer layers, endosperm) could be easily estimated from the WGF which would shorten the detection procedure and reduce costs.

The possible reasons for the 4 times higher DON:DNA ratio of flour Type 550 when compared to WGF and bran, indicated by the slopes of the regression curves, has been discussed before (see chapter 5.1.2). Even though it has not been discussed by TERZI ET AL. 2007, they also reported a higher DON content per amount of Fusarium DNA in extraction flour $(\mathrm{a}=12.6)$ than in corresponding WGF $(\mathrm{a}=7.99$ ) which represented a 1.6-fold higher DON:DNA ratio. The reasons might be the same as discussed in chapter 5.1.2 (tempering, DON translocation), yet, the discrepancy might not have been as distinct as in our study, since they used a flour with a lower extraction rate than ours and also tempering conditions were different. Tempering to a moisture content of $16 \%$ and for $36 \mathrm{~h}$ might have given not only DON translocation but also the trichothecenes-producing fungi ( $F$. graminearum and $F$. culmorum) more time to grow into the inner parts of the kernels than during our grain preparation (15.5\% moisture, $12 \mathrm{~h}$ tempering).

Our results demonstrate that not only cultivar resistance (NICHOLSON ET AL. 2003), environmental conditions, species composition (XU ET AL. 2007), and fungicides (EDWARDS ET AL. 2001) might influence the DON:DNA ratio in wheat but also further processing steps such as tempering pre milling.

The good correlation between DON and $F g D N A$ even across years and cultivars, especially in WGF, compared to the comparatively weaker correlation of visual disease and DON/FgDNA when determined across all samples (data not shown) likely resulted from the differences in tissue and time they were measured. Visual disease was assessed from floral tissue 14-20 days after anthesis (milky stage) while $F g D N A$ and DON were determined in harvested grain which had been roughly cleaned. From the initial location of infection and colonization (glumes) the fungus (and DON) would have to spread through several tissues layers into the kernel (PAUL ET AL. 2005B). Since fungal growth and mycotoxin production highly depends on environmental/weather conditions and also time (LACEY ET AL. 1999; XU ET AL. 2007) discrepancy between visual symptoms and final fungal colonization of grain and toxin accumulation might occur (PAUL ET AL. 2005B). In 2008 and 2009, we could often not measure any FHB symptoms (DI) but still found insignificant levels of DON in WGF, which speaks for a development of the fungus and DON production post time of visual rating. This has also been reported by LACEY ET AL. 1999. 


\subsection{Fusarium infection and quality parameters}

\subsubsection{Protein content $\left(\mathbf{P C}_{\mathrm{WGF}}, \mathbf{P C}_{\mathrm{Type550}}\right)$}

Our results showed the significant effect of year on $\mathrm{PC}_{\mathrm{WGF}}$ and $\mathrm{PC}_{\mathrm{Type} 550}$ (Fig 17, Tab 54). Higher daily average temperatures and higher precipitation during grain filling period in 2007 (Fig 30) obviously favored the accumulation of proteins in kernels more than in the two following years. The importance of environmental conditions on PC e.g. moisture and temperature, has been demonstrated before (WILLIAMS ET AL. 2008., ABEDI ET AL. 2011, DANIEL \& TRIBOI 2000). Higher $\mathrm{PC}_{\mathrm{WGF}}$ resulted in higher $\mathrm{PC}_{\text {Type550 }}$ (Fig 17, Tab 53). The close linkage between PC of grain and flour has also been observed by (BHATT \& DERERA 1975). Slightly reduced PC $_{\text {Type550 }}$ compared to $\mathrm{PC}_{\mathrm{WGF}}$ as demonstrated is the consequence of separating the protein-rich aleuronlayer with bran from the endosperm by milling (POMERANZ 1988). While the potential of both cultivars to accumulate protein was rated to be equal according to BSA (Tab 2), cv. Ritmo showed the potential to accumulate more protein under favorable weather conditions as present in 2007 than $\mathrm{cv}$. Centrum which emphasizes the importance of genotype $\mathrm{x}$ environment interaction which has been reported before (BHATT \& DERERA 1975; GRAUSGRUBER ET AL. 2000, ZECEVIC ET AL. 2009). There was a slight but significant influence of pre-crop on PC across all samples (Tab 54). $\mathrm{PC}_{\mathrm{WGF}}$ and $\mathrm{PC}_{\text {Type550 }}$ after pre-crop wheat was $4-5 \%$ higher when compared to pre-crop maize and sugar beet. Within years, this effect was in general also visible, depending on cultivar and year (Fig 17). This effect might have resulted from a fertilization effect. Next to other factors, $\mathrm{N}$ fertilization plays a key role in the accumulation of grain protein (WILLIAMS ET AL. 2008., ABEDI ET AL. 2011, DANIEL \& TRIBOI 2000). After wheat, soil contained 15 to $24 \mathrm{~kg} \mathrm{~N} \mathrm{ha}^{-1}$ (only analyzed in 2008 and 2009) more than after pre-crop maize and sugar beet (Tab 60). $\mathrm{N}$ fertilization in our trail did not consider the different $\mathrm{N}_{\min }$ contents subsequent to different pre-crops and also not the possible $\mathrm{N}$ mineralization during vegetation coming from the different crop debris, which differed very much in amount and quality (see chapter 5.1.2). Therefore, it is possible that wheat plants grown after wheat had at least up to 15 to $24 \mathrm{~kg} \mathrm{ha}^{-1}$ more $\mathrm{N}$ available than cultivated after maize and sugar beet. Higher $\mathrm{N}$ availability usually does not only promote PC accumulation in grain but also grain yield (GY) (DANIEL \& TRIBOI 2000, ABEDI ET AL. 2011). However, GY and PC are associated adversely with each other (CAMPBELL ET AL. 1977; ClARKE ET AL. 1990; GAUER ET AL. 1992). This trend we could also observe in our study (Tab 62). Across all years, GY was indeed significantly lower after pre-crop wheat $\left(74.5 \mathrm{dt} \mathrm{ha}^{-1}\right)$ than after pre-crop maize $\left(76.6 \mathrm{dt} \mathrm{ha}^{-1}\right)$ and pre-crop sugar beet ( $84 \mathrm{dt} \mathrm{ha}^{-1}$ ) (Tab 59). $\mathrm{N}$ fertilization in our study was conducted in three rates, $1^{\text {st }}$ at middle of tillering (GS 23), $2^{\text {nd }}$ at end of tillering (GS 29), and $3^{\text {rd }}$ at end of stem elongation (GS 39) or at end of booting (GS 49) (Tab 65). While the first dressings (during tillering) rather promotes vegetative growth and yield (ABEDI ET AL. 2011), later applications near anthesis have been demonstrated to promote grain PC more effectively (FINNEY ET AL. 1957; BLY \& WOODARD 2003). Therefore, in 
addition to the different $\mathrm{N}$ levels available for the plants even though $\mathrm{N}$ application was the same for each treatment, also the aspect of time needs to be considered. Different crop residues may have delivered mineralized $\mathrm{N}$ at different time points promoting either GY or PC.

Aside from $\mathrm{N}$ also $\mathrm{S}$ plays an important role in wheat plant metabolism and the accumulation of grain proteins since $S$ is part of cysteine which crosslinks protein polymers (see chapter 1.3). The $S$ nutrition of plants has in the past decade gained more and more attention primarily due to a reduction of atmospheric $\mathrm{S}$ emissions of industrial origin (ZORB ET AL. 2010). Wheat requires 15-20 $\mathrm{kg} \mathrm{ha}^{-1}$ sulfur for optimum growth (ZHAO ET AL. 1999). Since $\mathrm{S}_{\min }$ after the different pre-crops was not analyzed and S fertilization was not applied in our study, we analyzed S content of flours and calculated N/S ratio to rule out $\mathrm{S}$ deficiency in impaired grain protein accumulation. According to RANDALL ET AL. $1981 \mathrm{~S}$ content $<0.12 \%$ and N/S ratio $>17 / 1$ of grain indicates a S-deficient plant status. However, in our study, $\mathrm{S}$ content of flour Type 550 averaged $0.138 \%$ and N/S ratio was 14/1 (Tab 59, Tab 66). Therefore, $S$ deficiency influencing wheat quality could be excluded. Significant differences in $\mathrm{S}$ content between pre-crops within years and across years could not be detected. However, significantly higher S content of flours in 2007 than in 2008 corresponded with higher PC of flours and higher BV in the respective year (Tab 67) which emphasizes the importance of S supply for wheat quality.

Fusarium infection did not have an effect on $\mathrm{PC}_{\mathrm{WGF}}$ (Tab 13), which is supported by the findings of other studies (SEITZ ET AL. 1986; DeXTER ET AL. 1996; PRANGE ET AL. 2005; WANG ET AL. 2005B; TERZI ET AL. 2007). However, there was an effect of Fusarium infection on $\mathrm{PC}_{\text {Type550 }}$ (Tab 14). While in a small amount of samples $\mathrm{PC}_{\text {Type550 }}$ was shown to increase significantly with increasing DON concentration of flour Type 550 in 2007, this effect was adverse in 2009 (Tab 15). Both effects have already been described by other studies e.g. MEYER ET AL. 1986; BOYACIOGLU \& HETTIARACHCHY 1995; PAWELZIK ET AL. 1998; MATTHAUS ET AL. 2004; SiUdA ET AL. 2010 found an increase of PC after severe Fusarium infection. BECHTEL ET AL. 1985; NightingaLE ET AL. 1999; PRANGE ET AL. 2005; GARTNER ET AL. 2008 observed the opposite effect. Yet, one has to be aware that correlations between $\mathrm{PC}_{\text {Type550 }}$ and $\mathrm{DON}_{\mathrm{LOG}}$ in 2007 after pre-crop wheat could have been spurious since they were developed across cultivars. Cv. Ritmo contained significantly more $\mathrm{PC}_{\text {Type550 }}$ than cv. Centrum grown after wheat (average difference $0.6 \%$ protein) (Fig 17). At the same time cv. Ritmo showed about 5.8-fold higher DON content than cv. Centrum in this treatment. Consequently, there might be two possible explanations for the increased $\mathrm{PC}_{\text {Type550 }}$ in $\mathrm{cv}$. Ritmo after wheat. On the one hand, higher intensity of Fusarium infection of cv. Ritmo caused higher $\mathrm{PC}_{\text {Type550 }}$ due to a change of starch to protein ratio in favor of protein as supposed by PAWELZIK ET AL. 1998. For this phenomenon three possible explanations are suggested in literature. The first reason could be the consumption of carbohydrates by the fungus (HAMILTON \& Trenholm 1984; Boyacioglu \& HetTiarachCHY 1995; HeRMann ET AL. 1999; WANG ET AL. 
2005B). The second reason could be temporally earlier accumulation of storage proteins during grain-filling. Thus, proteins might not be influenced by an emergency maturation due to Fusarium infection to the same extend as starch (MEYER ET AL. 1986; MATTHAUS ET AL. 2004). Third, some studies also suggest that fungal protein might contribute additionally to total grain PC (HAMILTON \& Trenholm 1984; Boyacioglu \& HetTIARACHCHY 1995), since Fusarium mycelium comprised about $42 \%$ protein when grown in liquid media. However, the latter explanation was neglected by EGGERT ET AL. 2010 who reported that only 0.3\% of total PC in Fusarium infected wheat was of fungal origin. Aside from the influence of fungal infection, cv. Ritmo might have been able to use higher $\mathrm{N}$ availability after pre-crop wheat more efficiently for the accumulation of storage protein than cv. Centrum leading to significantly higher $\mathrm{PC}_{\mathrm{WGF}} / \mathrm{PC}_{\text {Type550 }}$ in in 2007 . This argument is supported by the observation that the two cultivars, with this one exception, did generally not differ significantly in $\mathrm{PC}_{\text {Type550 }}$ within years. The second argument is supported by the fact, that cv. Ritmo showed significantly lower GY ( $\left.\varnothing 55 \mathrm{dt} \mathrm{ha}^{-1}\right)$ in this treatment than cv. Centrum (69 $\mathrm{dt} \mathrm{ha}^{-1}$ ) (Tab 66) which might have corresponded with the comparatively higher PC. After all, within the other two pre-crops, cultivar differences were not significant even though DON content of cv. Ritmo was 4.2- and 1.6-fold that of cv. Centrum after maize and sugar beet, respectively. The effect of Fusarium infection cannot be cleared doubtlessly with as much as six biological samples per treatment, particularly because both pre-crop and cultivar might influence PC in the same direction as these factors might promote Fusarium infection and as Fusarium infection might influence PC in the same. Nevertheless, a few things became obvious. First, the effect of Fusarium infection on PC depended on flour (WGF/flour Type 550). Second, the direction of effect (increase/decrease/no effect) of Fusarium on PC depended on environment including not only year but also location (which was indicated by an improved $\mathrm{R}^{2}$ if locations were investigated separately), pre-crop, and intensity of Fusarium infection (indicated by varying ranges of DON). Discrepancy between the effect of Fusarium infection on $\mathrm{PC}_{\mathrm{WGF}}$ and $\mathrm{PC}_{\text {Type550 }}$ might have resulted from the different composition of WGF and flour Type 550. Flour Type 550 generally contains a higher starch content and a lower PC than flours with a higher extraction rate (BELITZ ET AL. 2009). In addition, $\mathrm{PC}_{\mathrm{Type} 550}$ mainly consists of gluten proteins which have been shown to be digested by Fusarium spp. in particular (chapter 1.1.2).

Third, year, location, and pre-crop, (and cultivar) might all contribute to different protein levels in flours as well as to different intensity of Fusarium infection so that it is not easy to separate the effects from each other. Other studies also found that the effect of Fusarium infection on PC depended on cultivar (DEXTER ET AL. 1996; Nightingale ET AL. 1999; PRANGE ET AL. 2005 and location (HERMANN ET AL. 1999).

However, a possible change of \% PC in flour from 0.46 to $1.09 \%$ protein in one or the other direction due to Fusarium infection of grain is not crucial for wheat of quality group B since $1 \%$ 
PC more/less only increases/decreases baking volume about $25 \mathrm{ml} 100 \mathrm{~g}^{-1}$ flour (SELING 2010). This would make up only about $4 \%$ of the minimum baking volume required for bread wheat (580 $\mathrm{ml} 100 \mathrm{~g}^{-1}$ flour) (SEIBEL 2005). In this context, also the other significant differences in PC that we observed in our study and that were caused by pre-crop, cultivar, as well as location should be evaluated (Tab 54). Even though significant (because of high $\mathrm{n}$ across years), quantitative differences of $<1 \%$ protein, e.g. between pre-crop maize and wheat, might not be relevant for baking quality. However, only few decimals of PC might decisively influence wheat classification and price (HARTL 2010). Finally, it should be considered that a linear relationship between $\mathrm{PC}_{\text {Type550 }}$ and $\mathrm{DON}_{\mathrm{LOG}}$ was primarily measured within flour samples that contained DON levels in a range from below $\mathrm{EU}_{\mathrm{Max}}$ to highly exceeding these values which would exclude a bigger number of these samples from being processed at all (Tab 13).

\subsubsection{Wet gluten content (WG) and sedimentation value (SV)}

\section{WG}

Our results showed that WG was most influenced by year and cultivar (Fig 18). The strong influence of environment and cultivar on WG has already been demonstrated by others (Grausgruber ET AL. 2000; Mladenov ET AL. 2001; DenCiC ET AL. 2011). These authors also reported a strong positive correlation between WG and PC which confirms our results (Tab 53). WG was highest in 2007 were also PC was highest out of three years. This positive relationship seems reasonable since gluten forming proteins make up the major proportion of total wheat protein (see chapter 1.3). Therefore, the cause for differences in WG between pre-crops might be the same as for PC (see chapter 5.2.1). According to SEIBEL 2005, WG of our flour samples can be evaluated as high to very high in 2007. In both cultivars WG was $>30 \%$. WG was normal (25-30\%) to high $(>30 \%)$ in 2008 and low $(20-24 \%)$ to normal $(>25-30 \%)$ in 2009. From this it could be expected that in samples from 2009, WA of flour, gas retention and tolerance to fermentation might have already been reduced leading to quality losses in baking product (SEIBEL 2005). This is supported by our result that WG was highly positively correlated to WA and BV (Tab 53).

No effect of Fusarium infection on WG could be observed in our study (Tab 17). This result is supported by DEXTER ET AL. 1996 who investigated WG in flour composites of naturally Fusarium infected wheat with DON levels varying from 0.4 to $6.3 \mathrm{mg} \mathrm{kg}^{-1}$. Only in flour milled from handpicked FDK a decline of WG could be observed compared to a clean fraction which accounted culivar-dependent for 3 to $14 \%$ WG. However, DON content in these flours exceeded current legal thresholds drastically, ranging from 35 to $62 \mathrm{mg} \mathrm{kg}^{-1}$. This later finding of DEXTER ET AL. 1996 agrees with the observations of other studies (MEYER ET AL. 1986; BOYACIOGLU \& HETTIARACHCHY 1995; PAWELZIK ET AL. 1998) who found WG reduced in artificially Fusarium 
infected wheat in comparison to a control or less infected samples (determined by DI). In contrast, SIUDA ET AL. 2010 reported an increase of WG in samples with higher kernel DI.

SV

Protein and gluten quality, respectively, are evaluated with the standard procedure of the sedimentation test. The test measures the sedimentation volume of wheat flour that is suspended in an acidified solution which is generally either Zeleny reagent (according to ICC standard 116/1) or an SDS containing solution as we applied in our study (see chapter 3.3.2) (ECKERT ET AL. 1993). Agricultural contractors usually refer to Zeleny sedimentation when setting up the requirement for a specific wheat quality group. Wheat for intervention has to have at least a minimum Zeleny sedimentation volume of $22 \mathrm{ml}$ (Regulation (EC) No 824/2000 of 20 April 2000). SDS-SV has been shown to predict BV more precisely than Zeleny sedimentation by AXFORD ET AL. 1979 which was the reason for the determination in our study. The comparison of the two methods showed that SDS-SV were approximately $20 \mathrm{ml}$ higher than Zeleny volumes (AXFORD ET AL. 1979) which has been later explained by the greater swelling of glutenins in SDS solution by (ECKERT ET AL. 1993). Keeping the quantitative difference between Zeleny and SDS-SV in mind, all flour samples exhibited high to very high protein quality, even in 2007 after pre-crop maize were SV was particularly reduced in cultivar cv. Centrum (Fig 18). The higher SV the higher is gas retention in dough, dough stability, and after all baking volume (ECKERT ET AL. 1993; SEIBEL 2005). The small variation of SV between years within cultivars suggests a stronger influence of genotype on the parameter than environment in our study which has been also reported by WILLIAMS ET AL. 2008. Even though rating of the two cultivars by BSA ( Tab 2$)$ indicated a slightly higher zeleny SV of cv. Centrum compared to cv. Ritmo this difference could not be seen across the years, which emphasizes the importance of environmental conditions in interaction with cultivar as observed by others (e.g. MLADENOV ET AL. 2001; ZECEVIC ET AL. 2009) for SV.

Though literature describes an overall positive relationship between flour sedimentation and PC of grain or flour, the strength of this relationship varies between studies. e.g. PRESTON ET AL. 1982 reported a low to moderate correlation ( $\mathrm{R}^{2} \sim 0.40$ and 0.55$)$ between SDS volume and flour protein. DEXTER \& MATSUO 1977 found a moderate to strong correlation $\left(\mathrm{R}^{2} \sim 0.57\right.$ to 0.88$)$ within durum wheat, whereas MLADENOV ET AL. $2001 \mathrm{did}$ not find a significant relationship ( $\left.\mathrm{R}^{2} \sim 0.08\right)$. In our study no correlation between $\mathrm{SV}$ and $\mathrm{PC}_{\mathrm{WGF}}$ and $\mathrm{PC}_{\text {Type550, }}$, respectively, existed (Tab 62) which was most likely due to the little variation of $\mathrm{PC}$ after all and cultivars belonging to the same quality group.

In 2007, where Fusarium infection was severe and associated with the highest DON levels in grain and flour of all years (see chapter 4.1.2), no linear relationship between SV and $\mathrm{DON}_{\mathrm{LOG}}$ could be detected, even though SV varied more widely in this year than in the others. Nevertheless, SV was lowest in the flours gained from wheat grown after maize which also contained the highest DON 
concentrations. However, when looking at linear regression of SDS sedimentation volume and BV reported by AXFORD ET AL. 1979, the reduction of SV about absolutely 12-15 ml (in cv. Centrum after maize) does not mean a relevant loss in quality if SV is overall very high ( $>50 \mathrm{ml})$. The same applies to the seemingly "improved" SV after severe Fusarium infection in 2009 after pre-crop maize which could be shown in six samples across two cultivars (Fig 19). The demonstrated incline of SV included at least three flour samples that exceeded $\mathrm{EU}_{\mathrm{MaxUP}}$ or $\mathrm{EU}_{\mathrm{MaxCF}}$ by far. However, an absolute difference in $\mathrm{SV}$ of about $4 \mathrm{ml}$ in the respective samples can be considered insignificant. While to our knowledge no study so far has reported an increase of SV with higher Fusarium infection intensity, several authors have reported a decrease of SV with increased intensity of Fusarium infection (MeYer ET AL. 1986; BoyaCiOGLU \& HetTIARACHChy 1995; WANG ET AL. 2005B; TERZI ET AL. 2007; GARTNER ET AL. 2008). It could be possible that a light degradation of proteins by Fusarium proteases might lead to higher swelling of protein in SDS. In contrast, SIUDA ET AL. 2010 did not find an effect of Fusarium infection on SV which supports our own observations for the epidemic year of 2007.

\subsubsection{Falling number $(\mathrm{FN})$}

FN is influenced significantly by climatic conditions (environment) (SMITH \& GoODING 1999, cultivar (GRAUSGRUBER ET AL. 2000; DENCIC ET AL. 2011), nitrogen fertilization (SZENTPETERY ET $A L .2005$ ), and even fungicide treatment in interactions with cultivar and environment (DIMMOCK \& GoODING 2002). The significantly differing FNs between the years in our study are supported by these findings (Fig 20). Significantly higher FNs across years in cv. Ritmo compared to cv. Centrum are not surprising since they have been described by BSA (Tab 2) in this way. The wide range of data (Fig 20), which became especially obvious in 2007, indicated that FNs was also influenced by other factors which were included in box plot data. ANOVA showed that also location had a significant influence on FN (Tab 54, Tab 60). An effect of location on FN has also been reported by WANG ET AL. 2008.

Slight differences of FN within cultivars between pre-crops might be to some degree explained by the slightly different flour composition e.g. $\mathrm{PC}_{\mathrm{Type} 550}$. WANG ET AL. 2008 reported that nitrogen fertilization increased PC and subsequently FN. Indeed, across all samples, FN was significantly higher after pre-crop wheat were also $\mathrm{PC}_{\text {Type550 }}$ was higher than after pre-crop maize and sugar beet (Tab 54). Increased FN with rising PC was also reported by AYOUB ET AL. 1994. Changes of functional properties of proteins (solubility, water absorption) might contribute to the different gelatinization properties of the flour-water suspension. Additionally, also TKW and the content of starch, ash, pentosans, as well as other hemicelluloses (dietary fiber) might correspond to FN (WANG ET AL. 2008). However, no significant correlation between FN and other quality parameters or flour components could be observed in our study (Tab 62, Tab 63). 
From the perspective of indicating quality, FN was below the required 220s (Commission Regulation (EC) No 824/2000 of 20 April 2000, RAIFFEISEN 2011) in cv. Centrum in more than $50 \%$ of the flours in 2007, and in a few samples in 2008. FNs < 200s in flour Type 550 generally indicate grain damage by sprouting and result in soft doughs with small proofing stability and sticky and unelastic crumb (SEIBEL 2005). Most of the samples of cv. Centrum in 2008 and samples of cv. Ritmo in 2007 were in a medium range of 220 to 320s. Loosening of crumb in these samples can be expected to be optimal (SEIBEL 2005). FN > 320 in WGF, as measured in most of the samples of both cultivars in 2009 and cv. Ritmo in 2008, indicated low enzyme activity, low raise, small volume and light crumb color among other negative consequences for baking product (SEIBEL 2005). However, FN only showed a weak negative relationship to BV in our study (Tab $62)$.

Significant positive relationships between $\mathrm{FN}$ and $\mathrm{DON}_{\mathrm{LOG}}$ in various environments as presented in Tab 20 have to be very likely to be interpreted as spurious correlations since the more susceptible cv. Ritmo also displayed generally higher FNs than cv. Centrum independently from the occurrence of Fusarium infection. This became clear when looking at FNs in 2008 (Fig 20) where there was hardly any Fusarium infection. Additionally, ANCOVA results showed a significant effect of cultivar in 2007 and 2009 independently from effect of DON (Tab 19). Therefore, it can be concluded that correlations within pre-crops and environments was rather present due to cultivar effects than to Fusarium infection. When linear regression was performed separately for the two cultivars (Fig 21) only the highly susceptible cv. Ritmo displayed a higher FN with higher DON concentration. Yet, one has to be aware of two things: First, $D_{O N N_{O R G}}$ in 2007 highly exceeded $\mathrm{EU}_{\mathrm{Max}}$, so that grain with an increase of FN about $100 \%$ (as indicated by slope) in the range of 3 to $10 \mathrm{mg} \mathrm{kg}$ would not need to be taken into account for processing quality. The same applies to the detected slight increase of FN about 20s below DON concentrations of $2.0 \mathrm{mg} \mathrm{kg}^{-1}$ (approx. difference between $\mathrm{FN}$ of $\mathrm{DON}_{\mathrm{Max}}$ and $\mathrm{DON}_{\mathrm{Min}}$ ) which would also not be relevant on an overall very high level of FN as present in 2009. Second, due to lack of observations within cultivars, correlations could only be performed across locations which had been demonstrated to have also a significant effect on FN (Tab 54, Tab 60) and which might result in spurious high $\mathrm{R}^{2}$.

However, the effect of increasing FN with increasing intensity of Fusarium infection, as in our samples, has also been reported by others (WANG ET AL. 2005A; WANG ET AL. 2008 and GARTNER ET AL. 2008). PAWELZIK ET AL. 1998 and HERMANN ET AL. 1999 observed the opposite effect. MEYER ET AL. 1986 observed both effects, depending on year of observation. According to the test principle of HAGBERG 1960, which implies a negative correlation of FN and $\alpha$-amylase activity in grain, and according the findings of various authors (DEXTER ET AL. 1996; PAWELZIK ET AL. 1998; NightiNGaLe ET AL. 1999; MATTHAUS ET AL. 2004; WANG ET AL. 2005A; WANG ET AL. 2008) who described an increase of $\alpha$-amylase activity in grain after Fusarium infection, a negative 
relationship between FN and Fusarium infection would seem reasonable. WANG ET AL. 2008 supposed that FN method does not display activity of fungal $\alpha$-amylase activity properly and suggested a longer incubation period of the pasting starch solution. Another reason for increased FN after Fusarium infection could be the earlier maturation of infected kernels (KANG \& BUCHENAUER 2000; RIBICHICH ET AL. 2000; GOSWAMI \& KISTLER 2004). Since weather conditions during grain maturation are essential for the level of HFN of harvested grain -higher temperatures in late-season are associated with higher FN (SMITH \& GOODING 1999)- it might be possible that infected kernels "escape" cooler and moist conditions possibly present during late ripening period of healthy kernels.

\subsubsection{Water absorption (WA) and mixing properties of dough (DDT, DST, DS)}

WA of flour is an indicator for dough yield and therefore bread yield (WEBB \& OWENS 2003). Higher WA of flour leads to higher dough yield. In general flours of Type 550 take up water in a range from 53 to $66 \%$ to reach a dough consistency of $500 \mathrm{FU}$. Optimal WA of flour Type 550 for roll production lays between $>58$ to $61 \%$ (SEIBEL 2005). Regarding these standard values, flours Type 550 of all three years were in this range, however, only flours from 2008 showed an optimum WA for roll production (Tab 21). As for DDT, flours in our study were in the typical range of 1-8 min for flours of Type 550 (SEIBEL 2005). However, optimal DDT between 2-6 min was with a few exceptions not reached by flours, and also a preferable DST exceeding 4 min (according to SEIBEL 2005) was only observed in 2009 (Tab 21). Low WA (<58\%), low DDT ( $<2 \mathrm{~min}$ ), and DST ( $<4$ min) indicated weak gluten properties of the flours investigated in our study (BELITZ ET $A L$. 2009). DS of flour Type 550 generally ranges from 0 to $130 \mathrm{FU}$ with an optimum of $80 \mathrm{FU}$ (according to SEIBEL 2005). Except in 2009 were reduction of dough consistency was <80 FU after 12 min of mixing, doughs generally exceeded this value by far, particularly in 2007 (Tab 21).

All farinograph parameters -WA, DDT, DST, and DS - were significantly influenced by year. DDT was also influenced by cultivar. Most of them showed significant interactions of cultivar with year (WA, DDT, DS) and pre-crop (WA, DDT, DS) (Tab 60). The importance of environment, cultivar, and environment-cultivar interactions for farinograph properties of wheat has been demonstrated before (GRAUSGRUBER ET AL. 2000; MLADENOV ET AL. 2001; DENCIC ET AL. 2011) though the proportion of variance that was explained by these factors differed widely between the studies. The more prominent influence of year observed in all parameters when compared to the effect of cultivar (Tab 55), which has been also observed by GRAUSGRUBER ET AL. 2000, can in our study be explained by the choice of cultivars coming from the same quality group and have been shown to express similar dough properties (Tab 2).

WA was strongly positively correlated with $\mathrm{PC}_{\mathrm{WGF}}, \mathrm{PC}_{\text {Type550, }}$ and $\mathrm{WG}$ (Tab 53), which might explain the overall higher WA after pre-crop wheat when compared to the other two pre-crops (Tab 
55). During dough preparation, primarily gluten proteins take up water and develop a protein network during kneading which results in the typical cohesive, viscous and elastic properties of dough (WIESER 2007; BELITZ ET AL. 2009).

We did not find an effect of Fusarium infection on WA (Tab 22) which is supported by the same observation made by BOCKMANN 1964; GARTNER ET AL. 2008 and DEXTER ET AL. 1996. However, other studies showed at least a slight increase of WA with increasing intensity of Fusarium infection (MEYER ET AL. 1986; PAWELZIK ET AL. 1998; WANG ET AL. 2005B), which might have resulted from a higher proportion of damaged starch granules in Fusarium infected kernels. DEXTER ET AL. 1996 observed a decrease of WA about 1.5 to 3.2\% when they compared flour from exclusively FDK with a control. Since in the cold phase of breadmaking only damaged starch and gluten proteins are able to absorb water, this might have already hinted to a decrease in storage PC or loss of protein functionality due to fungal invasion into the grain. DON contents of flours in the

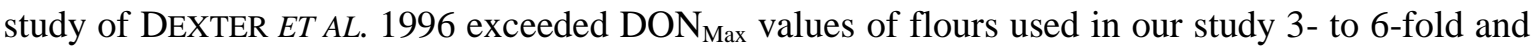
therefore also $\mathrm{EU}_{\mathrm{Max}}$ for DON. The less contaminated flours (1.10-6.30 mg DON kg of DEXTER ET AL. 1996 also neither showed an effect of Fusarium infection on WA, DDT nor DST in comparison to a control (0.40-1.60 $\left.\mathrm{mg} \mathrm{kg}^{-1}\right)$ which confirms our own results (Tab 23, Tab 24). However, other studies reported a decrease of DDT (PAWELZIK ET AL. 1998; NiGHTINGALE ET AL. 1999; WANG ET AL. 2005B), and DST (MEYeR ET AL. 1986; PAWELZIK ET AL. 1998; NightiNGALE ET AL. 1999; WANG ET AL. 2005B) with increasing intensity of Fusarium infection. GARTNER ET AL. 2008 observed cultivar-depended an increase, a decrease as well as no impact of Fusarium infection on DST; also an increase of DS after Fusarium infection was observed. The possible explanation for the contracting results is given in chapter 1.1.3.

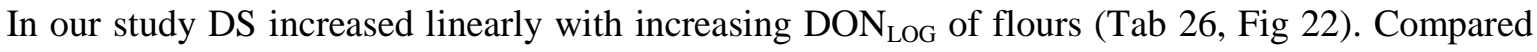
to the contradictory results on the impact of Fusarium infection on other quality traits, e.g. WA, FN, the results of all other studies (BOCKMANN 1964; MEYER ET AL. 1986; PAWELZIK ET AL. 1998; Nightingale $E T$ AL. 1999; WANG $E T$ AL. 2005B; GARTNER ET AL. 2008) agreed with our own observations for DS and Fusarium infection. In a wide range of DON $\mathrm{ORG}_{\text {( }}\left(0.16\right.$ to $\left.11.84 \mathrm{mg} \mathrm{kg}^{-1}\right)$ DS was, depending on factors included in regression, more or less intense as can be seen from the wide range of slopes $(a=24.69-104.16)$ in Tab 26. Especially in 2007, the year with the most severe Fusarium infection out of three cultivation years, at location Torland after pre-crop maize, an increase of DON content led in some samples to a DS exceeding the optimal value of $80 \mathrm{FU}$ for rolls by more than a $100 \%$. The improved $\mathrm{R}^{2}$ of correlations that was gained when separating for locations emphasized the significant influence of location on DS which was observed when performing ANOVA where environment was separated into year and location (Tab 60). Therefore, the relatively high variation of DS data, particularly in 2007, when compared to the other farinogram parameters, can be explained both by impact of Fusarium infection and significant 
differences between locations. A possible interference of $\mathrm{DON}_{\mathrm{LOG}}$ and $\mathrm{DS}$ within linear regression across all pre-crops within years with pre-crop effects that did not result from Fusarium infection cannot be ruled out since ANCOVA also showed a significant fixed effect of pre-crop (Tab 25). The decrease of DDT and DST in other investigations as well as the increase of DS in our study and in other studies due to Fusarium infection might have either resulted from reduced glutenin content in infected grain due to impaired synthesis in later stages of grain development (HUEBNER ET AL. 1990) or was a consequence of enzymatic degradation of proteins and starch by the fungus. A possibly increased protease activity might have led to an earlier destruction of gluten network and therefore to less tolerance during dough mixing in severely Fusarium infected samples (PAWELZIK ET AL. 1998; Nightingale ET AL. 1999).

\subsubsection{Baking properties (BV, LH, LL, LW)}

Baking performance of flours was determined by RMT. The assessment of the actual end-product, which resembled in our study a mini bread loaf or roll $(<10 \mathrm{~g})$, can be regarded as the ultimate evaluation of wheat quality (WILLIAMS ET AL. 2008). We characterized bread loaves by their BV and form (LH, LL, LW). Wheat cultivars meant for baking purposes (B quality and higher) aside

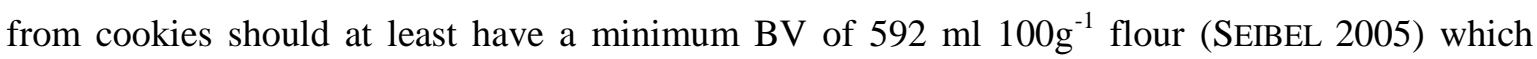
resembles grade 4 according to BSA. Even though both cultivars were rated into quality group B with grade 5 for BV according to BSA (Tab 2), in all cultivation years loaves showed BV below

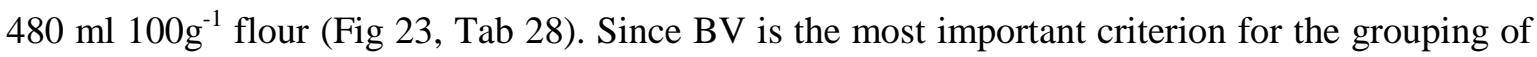
quality classes, this would degrade both cultivars to the status of feed (C) quality or make it suitable the production of cookies $\left(\mathrm{C}_{\mathrm{K}}\right.$ quality).

This result emphasizes the importance of interaction between environmental conditions, cultivation practices and cultivar on BV as demonstrated by others (GRAUSGRUBER ET AL. 2000; MLADENOV ET AL. 2001; DENCIC ET AL. 2011). While in some studies the single effect of cultivar was more decisive for BV than environment and environment-cultivar interaction (MLADENOV ET AL. 2001; DENCIC ET AL. 2011), our results rather revealed the significant effect of year (Tab 56), since both cultivars belonged to the same quality group. Interaction of cultivar and environment became obvious in 2007. Cv. Ritmo showed a significantly higher average BV than cv. Centrum which also corresponded to the significantly higher $\mathrm{PC}_{\mathrm{WGF}}$ and $\mathrm{PC}_{\mathrm{Type550}}$ in the respective year. The dependency of BV on PC is well known (SELING 2010). Already FINNEY \& BARMORE 1948 showed that rising $\mathrm{PC}$ resulted in increased $\mathrm{BV}$, however, this intensity of increase depended on cultivar. This confirms our own observations of a moderate, but highly significant correlation of $\mathrm{PC}_{\mathrm{WGF}}$ and an even higher correlation with $\mathrm{PC}_{\text {Type550 }}$ across the two cultivars and years (Tab 53). With the objective to minimize time and costs at grain trade, BV is generally hoped to be precisely predicted from PC and SV which have been shown to be cultivar-specific and more or less closely related to the baking performance (SEIBEL 2005; LINDHAUER 2009). In our study, BV was not 
significantly related to SV (Tab 62) which might have resulted from the little overall variation of SV throughout the whole investigation (Tab 54).

However, low BV indicated that cv. Ritmo and cv. Centrum did not meet B quality according to the criterion of BV. Obviously weather conditions in the combination with agricultural practices in our field experiment (for details see appendix in GöDECKE 2010) did not meet the demands of the two cultivars to develop their potential as bread wheats. Since $\mathrm{N}$ fertilization is regarded as the most important factor to influence PC and wheat quality directly (ABEDI $E T A L$. 2011), most likely $\mathrm{N}$ regime in our study did rather promote GY than PC. N fertilization management has the objective to optimize yield and grain PC at the same time and is consequently complex, involving the consideration of rate, timing, splitting, as well as source of application (GRANT ET AL. 2001, FuERTES-MENDIZABAL ET AL. 2010 ). Since late N application (close to anthesis) enhances protein concentration in grain, it can be only assumed that either $\mathrm{N}$ rate was to low $\left(60 \mathrm{~kg} \mathrm{~N} \mathrm{ha}^{-1}\right)$ or the timing of the $3^{\text {rd }} \mathrm{N}$ application was not suitable. The $3^{\text {rd }} \mathrm{N}$ donation was applied rather early in our study (during end of stem elongation or booting). Common is a $3^{\text {rd }}$ donation during ear emergence. Additionally, also $\mathrm{S}$ fertilization could have enhanced protein concentration as well as protein quality and therefore BV (ZORB ET AL. 2009). Low FN in 2007 and very high FN in 2008 and 2009 might have also contributed to low BV as well as the fact that all doughs were mixed for $2 \mathrm{~min}$ according to RMT and not according to their optimal DDT. However, the latter procedure could have improved BV as demonstrated by KIEFFER ET AL. 1998

Linear regression showed that BV increased with increasing DON content of flours (Tab 32). However, correlations across years and cultivars were most likely spurious since ANCOVA (Tab 29) showed a fixed significant effect of both environment and cultivar regardless of DON $\mathrm{LOG}_{\text {. }}$ Therefore, only two correlations of $\mathrm{BV}$ and $\mathrm{DON}_{\mathrm{LOG}}$ with a small number of observations in $\mathrm{cv}$. Centrum most likely reflected the impact of Fusarium infection on BV. According to these, an

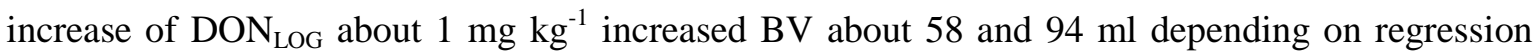
curve within the range of $\mathrm{DON}_{\mathrm{ORG}}$ from $0.31-3.59 \mathrm{mg} \mathrm{kg}^{-1}$. However, the major amount of samples clearly exceeded $\mathrm{EU}_{\text {MaxUP. }}$ An increase of BV after Fusarium infection was also observed by MEYeR ET AL. 1986; DeXTER ET AL. 1996; PRANGE ET AL. 2005; WANG ET AL. 2005B; GARTNER ET AL. 2008 and Lancova ET AL. 2008. MeYer ET AL. 1986 stated that the effect of Fusarium infection on $\mathrm{BV}$ depended on various factors, such as growing season, infection severity, PC and protein quality. Higher BV was observed after low infection degree probably because of low PC and therefore short gluten and resulting in higher dough elasticity which very much resembles the situation of cv. Centrum in 2007 when compared to cv. Ritmo. Also DEXTER ET AL. 1996 explained the increase in BV after Fusarium infection with an improved viscoelastic balance of gluten due to moderate increase of gliadins. In contrast, some of these authors also observed a decrease of BV (FINNEY 1954; MeYer ET AL. 1986; SeITZ ET AL. 1986; DeXTER ET AL. 1996; NightingaLe ET AL. 
1999; GARTNER ET AL. 2008) in some cultivars, and no effect in others (ANTES ET AL. 2001; TERZI ET AL. 2007; GARTNER ET AL. 2008) which highlights once more that the effect of Fusarium infection depends on the complex interaction of cultivar, intensity of Fusarium infection, growing conditions, PC and protein composition. The latter observation supports our own result that Fusarium infection showed no impact on BV of cv. Ritmo but on cv. Centrum even though the latter cultivar was less severely contaminated with DON since it expressed lower susceptibility towards FHB.

Regarding shape of loaves no linear relationship between $\mathrm{DON}_{\mathrm{LOG}}$ and LL, LW, as well as LH could be detected, even though ANCOVA for LH stated otherwise (Tab 29-Tab 31). However, multiple comparisons revealed that in the year 2007 with severe Fusarium infection the highly susceptible cv. Ritmo showed on average a clearly reduced LH, increased LW and decreased LL after pre-crop maize when compared to the other pre-crops (Fig 23, Fig 24). This factor combination had caused the highest DON contamination in wheat samples after all. Such a loss of loaf shape after Fusarium infection was also reported by BOCKMANN 1964 and WANG ET AL. 2005B. These authors also reported on the wet and sticky to gluey dough properties we also observed during dough handling for RMT which made it partly impossible to bring doughs into the "log" shape by noodles machine as required. This observation is supported by the increased DS after Fusarium infection (Fig 22), particularly after maize pre-crop in 2007, which has been discussed before. We suggest that the plastic deformation of dough, which was already visible after the first leavening, was due to enzymatic activity during dough processing, as reported by PAWELZIK ET AL. 1998 and NightiNGALE ET AL. 1999. However, enzymatic activity might not have been linearly correlated to $\mathrm{DON}_{\mathrm{LOG}}$ content.

\subsubsection{Gluten properties $\left(\mathbf{R}_{\mathrm{Max}}, \mathrm{EXT}, \mathbf{R}_{\mathrm{Max}} / \mathrm{EXT}\right)$}

Micro-extension tests clearly showed that there were significant differences in the properties of WG between the two cultivars (Tab 33). Whereas cv. Ritmo comprised very soft gluten indicated by high EXT, gluten of cv. Centrum showed significantly higher $\mathrm{R}_{\mathrm{MAX}}$ and ruptured -adversely to $\mathrm{cv}$. Ritmo- within the technical limitation of our TA settings. The determination of the functionality of gluten by $\mathrm{R}_{\mathrm{MAX}}$, EXT, and $\mathrm{R}_{\mathrm{MAX}} / \mathrm{EXT}$ is a helpful tool for the estimation of baking volume, particularly if CP and WG are considered (KIEFFER ET AL. 1998). Generally, $\mathrm{R}_{\text {MAX }}$ and EXT are inversely correlated while $\mathrm{R}_{\mathrm{MAX}}$ and $\mathrm{R}_{\mathrm{MAX}} / \mathrm{EXT}$ are positively correlated with $\mathrm{BV}$. That there did not exist a significant correlation between BV and gluten properties in our study (Tab 53) might have resulted from the little variation of gluten properties within the two cultivars. However, that gluten properties may differ strongly between cultivars even though their PC only differs about a few decimal as in our study, has been demonstrated by (KIEFFER ET AL. 1998). The reasons for the softer gluten of cv. Ritmo, which could also be a reason for the loss of loaf shape, as discussed before, are not clear. On the one hand cv. Ritmo was the more severely Fusarium affected cultivar; 
on the other hand ANCOVA did not reveal an effect of $\mathrm{DON}_{\mathrm{LOG}}$ on $\mathrm{R}_{\mathrm{MAX}} / \mathrm{EXT}$ (Tab 34). Therefore, it is possible that either gluten properties where cultivar-specific, which might have been demonstrated easily in a year with no or low occurrence of FHB (e.g. 2008) or that gluten of $\mathrm{cv}$. Ritmo softened to a higher degree than gluten of $\mathrm{cv}$. Centrum during $40 \mathrm{~min}$ of incubation due to increased proteolytic activities resulting from higher Fusarium infection level.

A higher EXT of dough as well as a reduced $\mathrm{R}_{\text {Max }}$ after Fusarium infection has been demonstrated by Nightingale et aL. 1999 and PRAnge ET aL. 2005. Since the EXT and $\mathrm{R}_{\text {MaX }}$ of dough generally corresponds very well to the analog parameters of resembling gluten (KIEFFER ET AL. 1998, also the explanation for these observations from the respective authors might apply to gluten samples of cv. Ritmo in our study. NightingaLE ET AL. 1999 supposed that gluten softens due to activity of protein hydrolyzing enzymes. Indeed, the characteristics of Fusarium proteases described by WANG ET AL. 2005B regarding their temperature and $\mathrm{pH}$ optimum, allow the conclusion that the incubation conditions of wet gluten for micro-extension test, which is actually meant for gluten relaxation, might also provide optimal conditions for the degradation of gluten proteins by Fusarium proteases leading in the end to a loss of gluten functionality

\subsection{Fusarium infection and flour composition}

\subsubsection{Starch}

Starch is the most abundant component of wheat flour ( $75 \%$ of dry matter), Fusarium infection does influence its content (Tab 36). This was also reported by WANG ET AL. 2005A while other studies found a decrease of starch content after Fusarium infection (PAWELZIK ET AL. 1998; MATTHAUS ET AL. 2004; SIUDA ET AL. 2010). However, these studies investigated WGF and did not remove small and shriveled kernels (as we did by cleaning) resulting from FHB which might both be reasons for the contradicting results.

Next to storage proteins, starch is other main component of cereal grain whose functional properties are of major importance within the production of bread and bakery products. During baking, starch granules take up approx. 45\% water and gelatinize (BELITZ ET AL. 2009). Yet, not only starch content is important but also starch properties. Even though Fusarium infection must not result in a detectable change of starch content, it might cause a change of starch composition indicated by a change of pasting properties (DEXTER ET AL. 1996; WANG ET AL. 2005A), amylose extractability as a measure of starch damage (DEXTER ET AL. 1996; PAWELZIK ET AL. 1998), amylose content (BOYACIOGLU \& HETTIARACHCHY 1995), and content of free sugars (MEYER ET AL. 1986; BoyaCiOgLU \& HeTtiarachCHY 1995; PAWELZIK ET AL. 1998; WANG ET AL. 2005A). All might result from amolytic activity of the fungus which is generally signified by an increase of amylase activitiy in grain (DEXTER ET AL. 1996; PAWELZIK ET AL. 1998; NiGHTINGALE ET AL. 1999; MATthaus ET AL. 2004; WANG ET AL. 2005A). However, since the focus of this study lay on the 
storage proteins, starch properties in our study were only measured indirectly by falling number which was discussed before and had indicated a change in starch quality by Fusarium infection in some severely infected flours.

Our results showed that starch content is primarily influenced by environmental conditions (year, location) and cultivation practices (pre-crop) as has been demonstrated for other wheat quality traits already (WILLIAMS ET AL. 2008). Correlation studies showed a weak negative trend with $\mathrm{PC}_{\mathrm{WHG}}, \mathrm{PC}_{\mathrm{TYPE} 550}$, and $\mathrm{WG}$, illustrating the competitive relationship between storage proteins and starch in endosperm and also explaining some of the variance in starch content between years and pre-crops (Tab 35). On the other hand, there was a strong positive correlation with WA, emphasizing the importance of starch content for dough yield and therefore also BV (Tab 53).

\subsubsection{Gluten proteins}

$\mathrm{PC}_{\text {Type550 }}$ was composited as described by other studies: about $75 \%$ was made up by gluten proteins (Fig 25), the residual proteins -referred to as "other"- most likely consisted of albumins and globulins (SHEWRY \& HALFORD 2002; GOESAERT ET AL. 2005; WIESER 2007) as well as glutenin macropolymers (GMP) which are insoluble in the used extraction solutions (KOH ET AL. 2010). The major proportion of total gluten was made up by gliadins, whereas $\alpha$-and $\gamma$-gliadins represented the major proportions. This also agreed with an earlier investigation of just gliadin subgroups by WIESER ET AL. 1994. Glutenins made up only half the proportion of gliadins, whereas LMW-GS represented the major proportion. Ratio of gliadin/glutenin and LMW/HMW averaged 2.9 and 2.4, respectively. This composition of gluten is typical for flour Type 550 as demonstrated by WIESER \& KIEFFER 2001.

WIESER \& KIEFFER 2001 demonstrated that gluten content might differ between cultivars either due to genotype or growing conditions. In our study, both cultivars did not differ significantly in total gluten content, but a significant effect of year, pre-crop, which can both be considered as "growing condition", as well as the interaction of year, pre-crop and cultivars on total gluten content were detected (Tab 57, Tab 61). However, quantitative differences were insignificant (2-3\%). Even though across all samples after pre-crop sugar beet significantly more gluten could be extracted (Tab 57) a significant effect of pre-crop within years and across cultivars could not be demonstrated (Tab 38).

An effect of growing season on protein composition and quantity might result to a large extent from differences in nitrogen and water supply, as well as temperature conditions during grain filling (WIESER \& SEILMEIER 1998; DANIEL \& TRIBOI 2000; TRIBOI ET AL. 2003). An effect of precrop as apparent across all investigated samples (Tab 57) might have resulted from different $\mathrm{N}$ availability in the soil (as discussed in 5.2.1). WIESER \& SEILMEIER 1998 showed that higher amounts of $\mathrm{N}$ fertilizer ( $40 \mathrm{~kg} \mathrm{~N}^{-1}$ vs. $200 \mathrm{~kg} \mathrm{~N} \mathrm{ha}^{-1}$ ) increased total PC and gluten about $57 \%$ 
and $67 \%$, respectively. However, total gluten per gram protein was not as severely affected and increased only about $6 \%$ in the treatment with the higher $\mathrm{N}$ rate. Even though $\mathrm{N}_{\min }$ and differing mineralization of crop debris in our study might have led to slightly different $\mathrm{N}$ availability after different pre-crops for subsequent wheat plants, $\mathrm{N}$ supply did in any case not differ about $160 \mathrm{~kg} \mathrm{~N}$ $\mathrm{ha}^{-1}$ as in the study of WIESER \& SEILMEIER 1998 which represents extremely different N regimes. Therefore, it is reasonable that differences between pre-crops in our study were small and rather due to natural variation. This emphasizes that the proportion of gluten in total protein is rather determined by the genetic background than by growing conditions (TRIBOI ET AL. 2003).

The gliadins and glutenins as well as the subfractions ( $\omega 5, \omega 1,2, \alpha, \gamma ; \omega 5$, HMW-GS, LMW-GS) were significantly influenced by year (Tab 57, Tab 58). SoE indicated that year affected gluten subfractions more than all other experimental factors. While for total gluten the effect of year (SoE 1.02) was relatively small, the effect of year within single gluten subfractions, particularly in glutenin (SoE 1.33) and LMW-GS (SoE 1.39), was more apparent (SoE 1.10-1.39). This indicated that gluten compositions seemed to be more variable due to environmental conditions than total gluten proportion. The biosynthesis of gluten fractions is strongly influenced by $\mathrm{N}$ availability, temperatures and water supply during grain filling (TRIBOI ET AL. 2003). Since weather conditions during grain-filling period varied greatly between the three years (Fig 30) this might explain the strong influence of the year. While TRIBOI ET AL. 2000 observed no influence of the year on gliadins, glutenins were found to be affected which supports our own observations of a stronger influence of the year on glutenins and subfractions than on gliadins and subfractions. Since both total gliadin and total glutenin were changed by growing season, year also had a significant effect on gluten composition. Gliadin/glutenin ratio was significantly higher in 2007 and 2009 than in 2008 and therefore reflected the adverse presence of gliadins and glutenins in the single years. LMW/HMW ratio was analog to the single subfractions significantly higher in 2008 than in 2007 and in 2009. In contrast, TRIBOI ET AL. 2000 could not observe an effect of year on gliadin/glutenin ratio and LMW/HMW ratio. The contradiction in our results in comparison to the findings of TRIBOI ET AL. 2000 demonstrated the importance of interaction between growing conditions and cultivars.

Furthermore, a significant effect of cultivar across years could be observed on gluten fractions and some of the subfractions which were less apparent than the effect of year (Tab 57, Tab 58). Cv. Ritmo contained significantly more total gliadin, $\omega 5$-gliadin, and $\gamma$-gliadin and significantly less total glutenin, $\omega b$, and LMW-GS than cv. Centrum. Also the ratio of LMW/HMW was significantly lower in cv. Ritmo than in cv. Centrum. Differences in gliadin and glutenin content and subfractions as well as gluten composition between cultivars were reported before (WIESER ET AL. 1994; TRIBOI ET AL. 2000; WIESER \& KIEFFER 2001). 
Even though significant differences between pre-crops could be detected across all samples for $\omega 5$ gliadin, $\omega 1,2-, \gamma$-gliadin, total glutenin, HMW-GS, LMW-GS and subsequently for ratio of gliadin/glutenin and LMW/HMW (Tab 57, Tab 58), these differences depended on year and cultivar. Slight differences between pre-crops might, as already discussed for total gluten, have resulted from differing $\mathrm{N}$ availability after different pre-crops. WIESER \& SEILMEIER 1998 found that gliadins were more severely affected by $\mathrm{N}$ fertilization than glutenins and that main gluten fractions ( $\gamma$-gliadins, LMW-GS) were more severely affected than minor fractions (HMW-GS, $\omega$ gliadins). However, we could not observe such clear differences between pre-crops concluding that effect of $\mathrm{N}$ on gluten composition was insignificant. This is further supported by the fact that we did not find any moderate to strong relationships between proportions of gluten fractions and subfractions with $\mathrm{PC}_{\mathrm{WGF}}$ or $\mathrm{PC}_{\mathrm{Typ} 550}$ indicating that the effect of $\mathrm{N}$ on gluten fractions was rather quantitative than qualitative (Tab 63). This agrees with the findings of TRIBOI ET AL. 2003 who reported that differences in protein fraction composition mainly depends on total $\mathrm{N}$ quantity of mature grain. High correlations between content of gluten proteins and subfractions have been demonstrated by WIESER \& KIEFFER 2001, however gluten proteins in their study were calculated on DM basis and did not consider total PC.

In three out of five significant correlations between content of total gluten and $\mathrm{DON}_{\mathrm{LOG}}$ the trend was negative (Tab 40), which is in agreement with other studies that reported a reduction of total gluten protein after Fusarium infection (NIGHTINGALE ET AL. 1999; ANTES ET AL. 2001; EGGERT ET $A L$. 2010). However, the correlation across 2007 and 2009 might have been spurious since ANCOVA also revealed a significant relationship of environment regardless of Fusarium infection. Nevertheless, the effect was present in samples where DON levels either highly exceeded $\mathrm{EU}_{\mathrm{Max}}$ e.g. after pre-crop maize in 2007 or where DON levels were below $<0.75 \mathrm{mg} \mathrm{kg}^{-1}$ e.g. after wheat in 2009. In contrast to these observations, we also found an increase of total gluten protein after pre-crop maize in 2009 across locations and even more pronounced for location Gladebeck separately. DON levels of these samples mostly exceeded $\mathrm{EU}_{\mathrm{Max}}$. This effect has not been reported in other studies before. A possible explanation might be a higher extraction rate of gliadins and glutenins due to higher solubility of these gluten fractions in their respective extraction solution. Enzymatic degradation of GMPs by Fusarium proteases might have led to this phenomenon. GMPs are generally not soluble with the common extraction solutions for gliadins and glutenins (KOH ET AL. 2010), however, protease activity might change this. Summarizing, the effect of Fusarium infection on total gluten protein did not become clear in our study and further investigations with a higher number of observations and differing DON levels are needed to elucidate the impact of the fungus in more detail.

Our results showed that Fusarium infection did not influence total gliadin or gliadin subfractions, neither in 2007 where DON contents of glour Type 550 ranged from 0.31 to $11.84 \mathrm{mg} \mathrm{kg}^{-1}$, or in 
2009 where both DI and DON contamination were less severe (Tab 42-Tab 44). This finding is supported by results of BOYACIOGLU \& HETTIARACHCHY 1995 who investigated three categories of artificially infected FDK, by DEXTER ET AL. 1996 whose flours composed DON levels in the range of our samples and significantly more (> $35 \mathrm{mg} \mathrm{kg}^{-1}$ ), and more recently by PRANGE ET AL. 2005 where DON concentration of samples were $0.06-12.30 \mathrm{mg} \mathrm{kg}^{-1}$. On the contrary, WANG $E T$ $A L$. 2005B observed a slight increase in gliadin content of severely infected kernels of one wheat cultivar, and also EGGERT ET AL. 2010 observed a slight increase of total gliadin content and all gliadin subfractions in one spring wheat cultivar when naturally infected samples (DON content: 0.0-0.3 mg kg${ }^{-1}$ ) were compared to artificially infected ones (DON content: 2.1-3.6 mg kg-1). The intensity of increase of gliadin content in the latter study strongly depended on location and subfraction (3-57\%). The increase of gliadin content was explained by the degradation of glutenin subfractions by Fusarium proteases. It was assumed that the solubility of digested glutenin fractions increased and extraction occurred with the gliadins. In our study, either digestion of glutenins did not lead to detectable increase in gliadin concentration or digested glutenin fractions were already extracted with the albumin-globulin fraction. The possibility of this has been demonstrated by EGGERT ET AL. 2011 in an in vitro experiment were Fusarium proteases digested gliadin and glutenin fractions separately.

In our study, an increase of total gliadin content and single subfractions did neither occur in flours with lower nor higher DON levels than $\mathrm{EU}_{\mathrm{Max}}$. Therefore, a resulting loss of flour quality due to increased gliadin content was insignificant. WIESER ET AL. 1994 demonstrated that if e.g. content of $\omega 1,2$-gliadin increased it is correlated with decreased SDS sedimentation value, reduced dough resistance and EXT, as well as decreased BV. This is further supported by our observation that total gliadin as well as gliadin subfractions showed no to very weak correlation with quality parameters (Tab 63). The insignificant influence of just gliadins on gluten, dough and baking properties was confirmed by WIESER \& KIEFFER 2001. However, gliadins played a significant role together with glutenins.

Regarding total glutenin and subfractions, for total glutenin and HMW-GS an effect of Fusarium infection could be detected (Tab 46) while there was no effect on $\omega$ b-GS (Tab 47) and LMW-GS content (Tab 48). In 2007, total glutenin content of cv. Ritmo decreased from $21.7 \%$ Protein to $12.3 \%$ from lowest to highest DON level which resembled a reduction of over 50\% (Fig 26). Since ANCOVA showed no significant effect of pre-crop, a spurious correlation due to effects of precrops was unlikely. Therefore, we can conclude that much of the variation in glutenin content as particularly apparent in 2007 can be explained by Fusarium infection. However, there was a significant effect of environment regardless of Fusarium infection which cannot be just explained by the effect of year. Obviously location had an effect since significant regression curves could only be calculated for the location Gladebeck. In 2009, where Fusarium infection was less severe 
than in 2007, the reduction of glutenin with increasing DON content was less intense. However, linear regression could be performed across cultivars without likely interference of pre-crops and cultivars since ANCOVA did not show a significant effect for these factors. Again, only at location Gladebeck this trend could be observed. In 2007 and 2009, the identical samples showed as similar

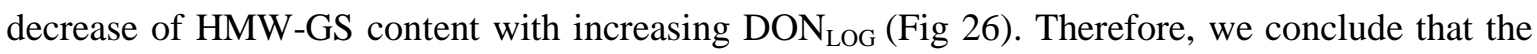
decrease of total glutenin content was mainly due to the decrease of HMW-GS content.

A decrease of total glutenin and HMW-GS content (measured by RP-HPLC) after Fusarium infection of wheat was also detected by WANG ET AL. 2005B and EGGERT ET AL. 2010, however, they also observed an increase of LMW-GS content which we could not see. BOYACIOGLU \& HETTIARACHCHY 1995 and DEXTER ET AL. 1996 also observed a reduction of total glutenin content after Fusarium infection but did not investigate the impact on single glutenin subgroups, whereas PRANGE ET AL. 2005 did not find an effect in flours that contained similar high DON levels as our investigated flours. A decrease of high molecular weight gluten proteins (BECHTEL ET AL. 1985; MEYER ET AL. 1986; Nightingale ET AL. 1999) and a slight increase of low molecular weight gluten proteins (MEYER ET AL. 1986; NIGHTINGALE ET AL. 1999) after Fusarium infection has also been demonstrated by others, however they used other separation methods for gluten proteins (SDS-PAGE, SE-HPLC) and therefore protein fractions investigated by these methods cannot be without exceptions compared to fractions separated by RP-HPLC.

Total glutenin content and HMW-GS content in particular were demonstrated to be moderately to strongly positively correlated to DDT, $\mathrm{R}_{\mathrm{MAX}}$ of gluten and dough, as well as to BV (WIESER \& KIEFFER 2001). Though the observed reduction of total glutenin and HMW-GS content due to Fusarium infection was not insignificant when looking at the possible consequences for baking quality one has to consider two things. First, the major number of flours where an effect of Fusarium infection could be demonstrated would not have been suitable for processing since $\mathrm{EU}_{\mathrm{Max}}$ for DON levels were exceeded in most cases. Second, neither glutenin content nor subfractions showed any considerable correlation with quality parameters in our study (Tab 63). From this we can conclude that neither Fusarium infection nor any other experimental factors caused such variation in gluten composition that quality parameters such as BV were significantly influenced.

Further analysis of impact of Fusarium infections showed, that presence of the fungus did not only cause quantitative changes, as demonstrated for total glutenin and HMW-GS, but also influenced ratios of gliadin/glutenin and LMW/HMW (Tab 49). Several significant correlations across cultivars, across/within environments, and across/within pre-crops showed that in general gliadin/glutenin ratio increased significantly with increasing DON content of flours (Fig 28, Tab 50). However, intensity of increase differed, particularly between years. Some of the correlations, especially those across locations and pre-crops, were possibly spurious since ANCOVA (Tab 49) also showed a significant effect of the respective factors on gliadin/glutenin ratio regardless of 
DON. Again, the effect of location was important since $\mathrm{R}^{2}$ improved when correlations were performed for locations separately. Since total gliadin content was not affected by Fusarium infection in our study, it can be concluded that the increase of gliadin/glutenin ratio resulted from the decrease of total glutenin and subsequently from the reduction of HMW-GS with higher DON content of flour.

Furthermore, in flours of the highly susceptible cv. Ritmo an increase of LMW/HMW ratio with increasing DON content could be observed in the year 2009, where infection level was moderate (Tab 50). A significant correlation could just be detected for the location Gladebeck. The linear relationship between LMW/HMW and $\mathrm{DON}_{\mathrm{LOG}}$ across years showed a similar slope as the correlation for just 2009, however, it can most likely be interpreted as spurious correlation since ANCOVA revealed a significant effect of environment on LMW/HMW ratio regardless of Fusarium infection. Since LMW-GS was not affected by Fusarium infection, it can be concluded that the increase of LMW/HMW ratio resulted from the decrease in HMW-GS content.

Our results, that gluten composition can be changed significantly after Fusarium infection, are supported by DEXTER ET AL. 1996; WANG ET AL. 2005B and EGGERT ET AL. 2010 who also reported an increase of gliadin/glutenin ratio in infected samples. However, no study has so far explicitly described also a change in glutenin composition as indicated by raising LMW/HMW ratio after Fusarium infection as shown in our results. Nevertheless, MEYER ET AL. 1986 and NIGHTINGALE ET $A L .1999$ indicated a change of gluten protein composition when they observed an increase of HMW-gluten proteins and a decrease LMW-gluten proteins. Yet, whether increase and decrease happened to the same extent was not reported since SDS-PAGE only provided semi-quantitative information.

WIESER \& KIEFFER 2001 showed that a wider ratio of gliadin/glutenin and LMW/HMW led to reduced dough, gluten, and baking properties. Therefore, the increase of gliadin/glutenin and LMW/HMW ratio after Fusarium infection cannot be considered insignificant when looking at quality. However, a strong detectable increase could only be detected in flours where DON levels already exceeded $\mathrm{EU}_{\mathrm{Max}}$. Additionally, neither gliadin/glutenin ratio nor LMW/HMW ratio showed a moderate or strong relationship with any of the quality parameters measured (Tab 63).

\subsection{Protease activity (PA)}

In order to determine if differences in gluten quantity and composition resulted from proteolytic activity, we measured PA in flours Type 550 in the year 2007 where FHB was most severe of all three years (Tab 51). Since cereal PA is low at harvest (SHI \& XU 2009), we assume that measured PA mainly resulted from endoproteases secreted into the kernel by Fusarium spp. as reported by PEKKARINEN ET AL. 2000 and PEKKARINEN \& JONES 2002. Nevertheless, enzyme assay was not 
specific to Fusarium proteases; therefore it was possible that both, cereal and fungal proteases were detected together.

Even though average DON ${ }_{\text {ORG }}$ content in flour Type 550 of susceptible cv. Ritmo (4.42 $\mathrm{mg} \mathrm{kg}^{-1}$ ) was about 4-fold higher than of cv. Centrum ( $\left.1.05 \mathrm{mg} \mathrm{kg}^{-1}\right)$, PA in cv. Ritmo was not significantly higher than in cv. Centrum (Tab 51) which one would expect since it is known from other studies that PA in wheat kernels increases with increasing Fusarium infection level (e.g.MEYER ET AL. 1986; PAwelzik ET AL. 1998; Matthaus ET AL. 2004; WANG ET AL. 2005B). However, these authors only measured PA in one cultivar each, except for MEYER ET AL. 1986 who investigated 20 cultivars, but did not report on differences in PA between cultivars. Differences in PA between cultivars could be expected if cultivars obtained different potential to withstand proteolytic activity of fungus, e.g. by production of protease inhibitors (CHILOSI ET AL. 2000; ROBERTS \& HEJGAARD 2008). However, that was obviously not the case since cultivar effect was insignificant in ANCOVA (Tab 52). Therefore slight differences between cultivars were exclusively due to the levels of Fusarium infection. Yet, there was a significant effect of location and pre-crop which could not be explained by DON ${ }_{\text {LOG. }}$ Obviously, physiological status of wheat plant differed between locations and pre-crops making the plants more or less "susceptible" to fungal proteolytic activity. The difference between locations is also the reason why no significant differences between precrops within cultivars could be detected even though there were differences across cultivars. As expected, PA was highest after pre-crop maize where also Fusarium infection was highest in both cultivars followed by wheat and sugar beet, the latter pre-crop causing the least infection levels and DON contaminations in grain. A strong significant positive correlation between $\mathrm{DON}_{\mathrm{LOG}}$ and PA was detected within few flours (Fig 29), however, these exceeded $\mathrm{EU}_{\mathrm{Max}}$ many-fold. Nevertheless, the slight increase of PA with increasing DON content which was observed across all samples agreed with the findings of other studies (MEYER ET AL. 1986; PAWELZIK ET AL. 1998; MATTHAUS ET AL. 2004; WANG ET AL. 2005B).

Degradation of wheat proteins by fungal proteases could be the reason for quantitative and qualitative changes of gluten (e.g. total glutenin and HMW-GS) and related quality traits (e.g. SV, DS) as discussed before and suggested by others (e.g. NIGHTINGALE ET AL. 1999; WANG ET AL. 2005B). Nonetheless, correlation of PA with content of gluten fractions as well as quality parameters was, if at all present, very weak (Tab 63, Tab 64). There could be more than one explanation for this. First of all, it could be argued that variation within PA was so insignificant that it could not cause any significant measurable changes in the quality traits or gluten proteins. Second, assay conditions for the determination of PA did not reflect the conditions (substrate, ph, temperature, incubation time) present in the field, during storage, or processing of wheat where fungal proteases might be active (JONES 2005). Third, PA and $\mathrm{DON}_{\mathrm{LOG}}$ were not correlated linearly. The first argument neglects the significant effect of Fusarium proteases on wheat quality 
in our study, the latter two arguments do not rule out significant changes by proteases. Consequently, further experiments with assay conditions more adapted to field and processing conditions should be carried out in future to investigate the influence of Fusarium protease on gluten proteins during grain-filling and dough processing. For example, a substrate which is closer to the composition of wheat storage proteins than azogelatin would be more suitable.

\subsection{How does Fusarium infection influence wheat quality?}

Two major reasons might be the cause for biochemical changes in grain composition and therefore subsequent changes in wheat quality traits: fungal enzymes and impaired synthesis of grain components (growth impaired, DON).

Fungal enzymes, especially carbohydrases and proteases, are assumed to cause the major changes in flour composition and processing quality (DEXTER \& NOWICKI 2003). An increased activity of amylase, xylanase, cellulase, and glucanase in flours from Fusarium infected grain could partly explain weaker and stickier dough properties, lower water uptake and poorer baking quality of these flours in comparison to less severely infected flours (DEXTER ET AL. 1996; PAWELZIK ET AL. 1998; Nightingale ET AL. 1999; MATtHAUS ET AL. 2004; WANG ET AL. 2005A). It is assumed that the fungus secretes these enzymes during the invasion of the kernel thus degrading starch as well as cell wall components. WANG ET AL. 2005A characterized $\alpha$-amylase of $F$. culmorum and demonstrated that it was active in a wide $\mathrm{pH}$ range from 5.0 to 8.5 and at temperatures from 10 to $100{ }^{\circ} \mathrm{C}$, enabling the enzymes to have an adverse effect on dough and baking properties, particularly in baking procedures involving longer proofing times. Even more important might be the activity of fungal proteases. According to DEXTER \& NOWICKI 2003, proteases of fungal origin are the most reasonable explanation for poorer dough and baking qualities of Fusarium infected wheat in comparison to healthy wheat. PEKKARINEN ET AL. 2000 showed that $F$. graminearum, $F$. culmorum and $F$. poea were able to produce acid, neutral or alkaline proteases when grown on gluten media. Several studies showed that PA in severely Fusarium infected wheat samples was higher than in a control or less infected samples (PAWELZIK ET AL. 1998; MATTHAUS ET AL. 2004; WANG ET AL. 2005B). The authors suggested that the digestion of storage proteins during processing could lead to change in dough properties e.g. such as reduced $\mathrm{R}_{\mathrm{MAX}}$ and loss of loaf shape during baking as we have also observed in our study. Also the weak and soft consistence of WG, as described by DEXTER ET AL. 1996, could be explained by proteolytic activity. With means of SE-HPLC Nightingale ET AL. 1999 showed a time dependent degradation of high molecular weight proteins concomitant with an increase in low molecular weight proteins resulting from proteolysis. A recent in vitro experiment conducted by EGGERT ET AL. 2011 with $F$. graminearum proteases on wheat gluten and isolated gluten subfractions demonstrated that fungal proteases were able to degrade both gliadins and glutenins, but degraded HMW-GS in particular. The authors 
suggested that the high affinity of Fusarium proteases for the HMW-GS was supposed to result from higher lysin content of the respective subfraction which is, next to arginin, one of the important intersections of trypsin-like serine proteases produced by Fusarium spp. (PEKKARINEN \& JONES 2002; PEKKARINEN ET AL. 2007). This is especially crucial for baking purposes since HMWGS contribute highly to the elastic properties of dough and correspond to a high BV (ANJUM ET AL. 2007). A higher content of free amino acids in flour (MEYER ET AL. 1986; WANG ET AL. 2005B) and an increase of low molecular weight gluten proteins (MEYER ET AL. 1986; NiGHTINGALE ET AL. 1999) supports the assumption of protein digestion through fungal proteases. WANG ET AL. 2005B characterized conditions for the PA of $F$. culmorum and showed that fungal protease was, similar to fungal amylase, active in a wide range of $\mathrm{pH}$ (from 4.5 to 8.5 ) and as well very thermostable. Fungal protease stayed active, even though impaired, up to $100{ }^{\circ} \mathrm{C}$. These findings and the observations of other authors suggests a possible degradation of wheat proteins, particularly storage proteins such as HMW-GS, and starch subsequent to Fusarium infection in the field, during dough processing as well as during the first phases of baking.

Besides enzymatic degradation of starch, storage proteins and other flour components another reason for changed flour, dough and baking properties after Fusarium infection might be the incomplete accumulation of kernel constituents. One reason for this could be the mechanical blocking of vascular bundles by fungal mycelium, another reason could be the impaired synthesis of grain components due to the presence of mycotoxins.

As already described in chapter 1.2.3 fungal mycelium growth within xylem and phloem may inhibit the nutrient supply for developing spikelets and leading to their premature death (KANG \& BUCHENAUER 2000; RIBICHICH ET AL. 2000; GOSWAMI \& KISTLER 2004). The interruption of assimilate transport within the spike impairs the normal development of kernels and leads to the typically shrunken and shriveled kernels of Fusarium damaged grain (MEYER ET AL. 1986) and the reduction of TKW and therefore also test weight (see chapter 1.2.2). Since biosynthesis of storage proteins sets in earlier during grain-filling than starch synthesis, it might be that starch content and composition might be affected more severely than PC and protein composition. Depending upon initial infection time, seed development can be already stopped by fungal infection process at early milk stage (SIMMONDS 1968) which is congruent with the observations of BECHTEL ET AL. 1985 who observed the most severe Fusarium damage in wheat kernels between the second and third week after anthesis. This might also be the reason why glutenins were often found to be more affected by Fusarium infection than gliadins. Based on the findings of HUEBNER ET AL. 1990 who observed that glutenins compared to gliadins are more rapidly synthesized in the later stages of kernel development, WANG ET AL. 2005B concluded that gliadins possibly "escape" the attack of Fusarium spp. while accumulation of glutenins stays incomplete due to emergency maturation. 
Furthermore, the incomplete or halted synthesis of grain components could be the result of the presence of trichothecenes such as DON. In experiments with leaf tissue of maize and wheat CASALE \& HART 1988 demonstrated that DON effectively inhibited the incorporation of the amino acid ${ }^{3} \mathrm{H}$-leucine and therefore concluded that DON might be a potent inhibitor of protein synthesis in plant cells as well as in other eukaryotic cell. The mode of action is the binding of DON to the peptidyl transferase as a part of the 60S ribosomal subunit (ERIKSEN \& PETTERSSON 2004). 


\section{Conclusions and outlook}

Due to various interactions between experimental factors, wheat quality parameters, and Fusarium infection, evaluation of bread wheat quality was complex. In general all experimental factors environment (year, location), cultivar, pre-crop, and fungicide - had an impact on the intensity of Fusarium spp. infection in harvested grain and therefore in the respective milling products (chapter 4.1.2 and 5.1.2). At the same time, generally at least one or more of these factors (fungicide not considered) had an effect on the investigated quality parameters and the composition of flour, if not alone, than at least in interaction with other factors. This made the identification of the effect of Fusarium infection on wheat flour composition and wheat quality traits particularly complex. In order to identify this effect, we used ANCOVA were DON content of flour was introduced as covariate. It can be summarized that DON as covariate was in no case able to explain the complete variability in data alone, nevertheless, for a few parameters, $\mathrm{PC}_{\mathrm{Type550}}, \mathrm{SV}, \mathrm{FN}, \mathrm{DS}, \mathrm{BV}$, total gluten, total glutenin, HMW-GS and gluten composition (gliadin/glutenin, LMW/HMW), and PA, a significant effect of Fusarium infection in interaction with other experimental factors and could be detected. However, the application of ANCOVA strategy requires that the covariate is in the "best case" completely independent from all other factors included in the model (LITTEL ET AL. 2006). This requirement was not fulfilled which may therefore have led to interpretation bias of the output. This might be the explanation why in some cases e.g. $\mathrm{PC}_{\text {Type550, }} \mathrm{FN}$, investigation of relationship between target variable and $\mathrm{DON}_{\mathrm{LOG}}$ might have revealed significant linear regressions where correlations were most likely spurious. In these cases the model failed to separate the effects of experimental factors and Fusarium infection on target variable clearly. In an experiment that suited ANCOVA requirements in a better way, DON should vary within the experiment independently from all other experimental factors and not because of the included experimental factors. Such a situation is generally not given in a field experiment as ours which was based on the variation of natural Fusarium infection due to the experimental factors. It would rather be present in an artificial inoculation experiment under completely controlled conditions where inoculum concentration determines the intensity of Fusarium infection and subsequent mycotoxin contamination alone.

With regard to our interest in mycotoxin occurrence in wheat milling products, $\mathrm{EU}_{\mathrm{Max}}$ for DON, and lack of other mycotoxin data, we decided on DON as a covariate. Nevertheless, the question arises whether DON is a suitable parameter to correlate with quality parameters, content of flour components as well as PA, respectively. DON concentration of flours might not be the best way to quantify the impact of Fusarium infection on wheat flour. First, other mycotoxins might be present as well and therefore "total mycotoxin content" might be more suitable. Second, and probably even more important, DON is generally positively correlated to fungal biomass (see chapter 5.1.3), however DON to fungal biomass ratio might differ. Yet, biochemical changes in flour properties 
and subsequent changes in quality traits after Fusarium spp. infection might rather correspond to intensity of fungal growth and therefore Fusarium biomass in grain and subsequent excretion of fungal enzymes. Thus, fungal biomass quantified as Fusarium DNA as in our study or Fusarium soluble proteins as used by WANG ET AL. 2005B and WANG ET AL. 2005A might be better fitting covariates. However, this requires a high sensitivity of these methods. In our study, we did not decide for $\mathrm{FgDNA}$ as covariate because particularly in $2009 \mathrm{Fg}$ DNA content of most flours was below LOQ and did not represent an appropriate measure for the quantification of Fusarium infection; however DON content was in most cases above LOQ.

Furthermore, it has to be considered that ANCOVA only investigates the linear relationship between target variable and covariate. Thus, other possible correlations e.g. exponential or log functional are not taken into account. Consequently, other relationships between quality parameters, flour components, and $\mathrm{DON}_{\mathrm{LOG}}$ aside from linear ones possibly existed. Further considerations refer to $\mathrm{EU}_{\mathrm{Max}}$ and practical relevance of measured significant changes caused by Fusarium spp. infection in wheat quality. If a linear relationship between $\mathrm{DON}_{\mathrm{LOG}}$ and target variable could be detected in our study, it generally included to a major proportion flour samples that exceeded $\mathrm{EU}_{\mathrm{Max}}$ by far and would therefore be neither suitable for direct human consumption nor for further processing into cereal products. Additionally, in most cases linear regression curves with at least moderate $R^{2}$ could only be calculated within very low number of observations $(n \leq 12)$. Functions gained from these curves are not suitable for predicting a trend safely or making a solid forecast of expected quality changes in flours from DON content alone, but rather fulfill the purpose of illustration.

After all, many significant differences in wheat quality parameters and flour composition between various treatment levels were observed. Nevertheless, if enough observations are made, all detected differences become significant at some point, whether of practical relevance or not (ANONYMUS 2001). Consequently, it is necessary that these differences are evaluated critically with respect to a relevant practical meaning. This proposes a big challenge, considering the broad range of end-uses for wheat (cookies, noodles, bread kinds, cakes) and the possible and nowadays common use of bakery improvers which might balance these flaws in raw material (BELITZ ET AL. 2009). Our own observations suggest a rather insignificant impact of Fusarium infection on quality parameters determined in samples that are within the admissible range of $\mathrm{EU}_{\mathrm{Max}}$. However, further investigations with samples from various environments and cultivars differing in baking quality and DON levels below $\mathrm{EU}_{\mathrm{Max}}$ should be performed to support our results.

Even though we could detect a few effects of Fusarium spp. infection on gluten subgroups, e.g. reduction of total glutenin and HMW-GS, we did not observe any moderate to strong significant linear relationships between quality parameters and gluten protein and subfractions (Tab 63). This leads to the conclusion that in our study neither environmental conditions, or agricultural practices, 
or Fusarium infection caused such a variation in gluten content and composition that it led to a significant effect on wheat quality. Significant differences within quality parameters were primarily caused by year which was demonstrated by higher SoE when compared to other effects as pre-crop, cultivar, and location (Tab 54-Tab 59).

For future research, which has the objective to elucidate more of the complex interaction between flour composition, quality parameters, and Fusarium infection, we would suggest a less complex field experiment with a 2-factorial design (cultivar $\mathrm{x}$ inoculation) including at least two cultivars from each quality group according to BSA (E, A, B), differing in their PC as well as in their BV. These should be grown after just one pre-crop where the Fusarium inoculum potential coming from the soil is considered to be low e.g. sugar beet or rapeseed. Cultivars should than be treated with Fusarium macroconidia suspension with differing in density of spores during wheat anthesis. As control one could use untreated plots (natural Fusarium infection) as well as plots where triazole fungicide is applied directly after artificial inoculation. Under favorable weather conditions for Fusarium spp. infection this treatment should lead to varying degrees of fungal growth and subsequent mycotoxin production within grain of the different cultivars. Variation within grain components is than mainly due to genotype and intensity of Fusarium infection and relationships can then be easily calculated without interference of other factors. Especially interesting would be the "production" and investigation of infected grain were DON levels are below $\leq 1.25 \mathrm{mg} \mathrm{kg}^{-1}$.

Further research should also focus on the direct causes for changes in wheat quality after Fusarium infection. In chapter 5.5 three possible reasons (premature death of spikelet, fungal enzymes, mycotoxin) were discussed how Fusarium infection might have an impact on flour composition and subsequently on quality parameters. At least one of them or all three at the same time most likely led to observed changes in $\mathrm{PC}_{\text {Type550, }}, \mathrm{SV}, \mathrm{FN}, \mathrm{DS}, \mathrm{BV}$, total gluten, total glutenin, HMW-GS gliadin/glutenin and LMW/HMW. It would be interesting, to clear the separate effect of the possible causes. E.g. over the period of grain-filling, the first-time occurrence of Fusarium DNA, mycotoxins, and fungal enzymes could be investigated and observed together with the development of important grain components such as starch and gluten protein (and subfractions). At the same time the moment where grain stops developing should be observed and compared to non-infected wheat spikes. This could provide further inside to whether e.g. gluten proteins are already affected in the field by fungal infection or whether changes in gluten composition are primarily due to enzymatic degradation during processing. In addition, the impact of Fusarium spp. that do not produce DON (e.g. F. avenaceum, F. equiseti, or "knock-out mutants" of $F$. graminearum) on grain quality could be interesting and would elucidate the significance of DON in impairing biosynthesis of kernel constituents more. 


\section{Summary}

Fusarium spp. infection of wheat, also known as Fusarium head blight (FHB), is a worldwide occurring disease with a disastrous impact on both grain yield and wheat quality in years of severe epidemics. Wheat quality is primarily degraded because several Fusarium spp. associated to FHB are capable to produce mycotoxins which occur in the harvested grain and pose a threat to human as well as animal health. Aside from the toxicological risk coming from mycotoxin contamination of grain, Fusarium infection changes grain composition affecting proteins, starch, and other grain constituents. Numerous studies on FHB have rather focused on the pathogen complex, epidemiology, Fusarium mycotoxins, and control strategies than on impact on technological quality of wheat. Studies that have been published in this field demonstrated the severe impact of FHB in rather less practical samples, either in just severely Fusarium damaged kernels (FDK) or composite samples that exceeded legal thresholds for mycotoxin content of wheat e.g. deoxynivalenol (DON) many-fold. Therefore, it was the key objective of this study to investigate the impact of Fusarium infection on bread wheat that was cultivated under agricultural measures (pre-crop, cultivar, fungicide) that are known to have an influence on the intensity of natural Fusarium infection. Therefore, a field experiment was conducted over the time period of 20072009 where two bread wheat cultivars that differed widely in their susceptibility against FHB but hardly in their quality attributes were grown after pre-crop winter wheat, (forage) maize, and sugar beet using minimum tillage. Strobilurin, chlorthalonil, and triazole application during growth stage 31-39 was expected to add to natural variation within FHB disease parameters and subsequent mycotoxin levels in grain. Different milling products (whole grain flour (WGF), flour Type 550, bran) were gained from composite samples of cleaned wheat and investigated for Fusarium biomass, measured as Fusarium DNA of the most prevalent Fusarium spp. in Europe, F. graminearum ( FgDNA) and F. culmorum ( FcDNA). Furthermore, mycotoxin contents (DON, 3ADON, 15-ADON, NIV, FUSX, ZEA) of milling products were analyzed. FgDNA made up the major proportion of total Fusarium DNA in all milling product; DON was the most frequently detected and quantitatively most important mycotoxin. 3-ADON and ZEA were detected sporadically. The occurrence and quantity of $F g D N A$ and DON in wheat milling products highly depended on environment (year, location), pre-crop, susceptibility of cultivar, fungicide application, and milling product. FHB occurred only in two out of three cultivations years, demonstrating the significance of weather condition during anthesis. Cultivation of the less susceptible cultivar after pre-crop sugar beet and application of triazole fungicide during shooting represented the most effective measure to avoid high DON levels in milling products. FgDNA content was highest in bran, followed by WGF and flour Type 550. On the contrary, DON content was equally high in bran and flour Type 550 and lowest in WGF. Even though, grain was cleaned, DON levels in flour Type 550 ranged from < LOQ to $11.84 \mathrm{mg} \mathrm{kg}^{-1}$. Possible reasons e.g. 
tempering for this contradiction are discussed. The correlation of $\mathrm{FgDNA}$, DON, and visual disease parameters was investigated. $F g D N A$ and DON content of all milling products generally correlated strongly with visual disease as well as with/among each other.

In the second part of this study, the influence of environment (year, location), pre-crop, cultivar, and Fusarium infection on wheat quality was investigated in flour Type 550 (and partly WGF) by the determination of commonly used parameters that evaluate bread wheat quality. Several quality traits were supposed to assess the properties of flour ( $\mathrm{SV}, \mathrm{WG}, \mathrm{FN}, \mathrm{WA})$, gluten $\left(\mathrm{R}_{\text {Max }}, \mathrm{EXT}\right)$, dough (DDT, DST, DS), and bread (BV, shape). Furthermore, the impact of the respective factors on selected flour components (PC, starch, total gluten, gliadin $[\omega 5, \omega 1,2, \alpha, \gamma]$, glutenin $[\omega b$, HMW-GS, LMW-GS]) as well as protease activity (PA) in flour was determined. Since Fusarium infection had been demonstrated to be influenced by all experimental factors and wheat quality and flours composition was expected to be as well influenced by environment and agricultural measures, ANCOVA was used to investigate the effect of Fusarium infection on the latter. DON was chosen as covariate that quantified Fusarium infection in flours since $\mathrm{EU}_{\mathrm{Max}}$ for DON represent the most important criterion for further use of wheat. In general, all investigated parameters were particularly influenced by year, independently of Fusarium infection. Slight quantitative differences e.g. in PC, WG, FN, SV due to pre-crop could generally only be detected across samples of all years and interacted with cultivar and year. Even though quality traits of both cultivars were classified to be similar according to BSA, in interaction with environment, differences between cultivars e.g. in PC, FN became visible. However, most differences appeared to be insignificant from the perspective of processing. Investigation of the relationship between DON and quality parameters as well as flour components by ANCOVA and subsequent linear regression demonstrated a significant effect of Fusarium infection on $\mathrm{PC}_{\text {Type550 }}, \mathrm{SV}, \mathrm{FN}, \mathrm{DS}, \mathrm{BV}$, total gluten, total glutenin, HMW-GS and gluten composition (gliadin/glutenin, LMW/HMW) as well as on PA. The direction and strength of effects is discussed as well as the possibility of spurious correlation due to interference with other experimental factors. In general, a clear effect of Fusarium infection on wheat quality could only be demonstrated within few flour samples highly exceeding $\mathrm{EU}_{\mathrm{Max}}$. Consequently, these flours were not relevant for further processing and human consumption. In addition, the quantitative changes in wheat quality caused by fungal infection were overall insignificant. This was emphasized by the lack of correlation between flour components, particularly gluten proteins, as well as PA with quality parameters. Based on our observations, the impact of Fusarium infection on technological wheat quality and flour composition seems insignificant in samples that contain less DON than demanded by EU. However, further investigations with more cultivars differing in their susceptibility against FHB and differing in baking performance should be carried out. The key objective should be the investigation of wheat samples that contain less than $1.25 \mathrm{mg} \mathrm{kg}^{-1} \mathrm{DON}$ which represents $\mathrm{EU}_{\mathrm{MAX}}$ for unprocessed cereals. 


\section{Supplementary material}

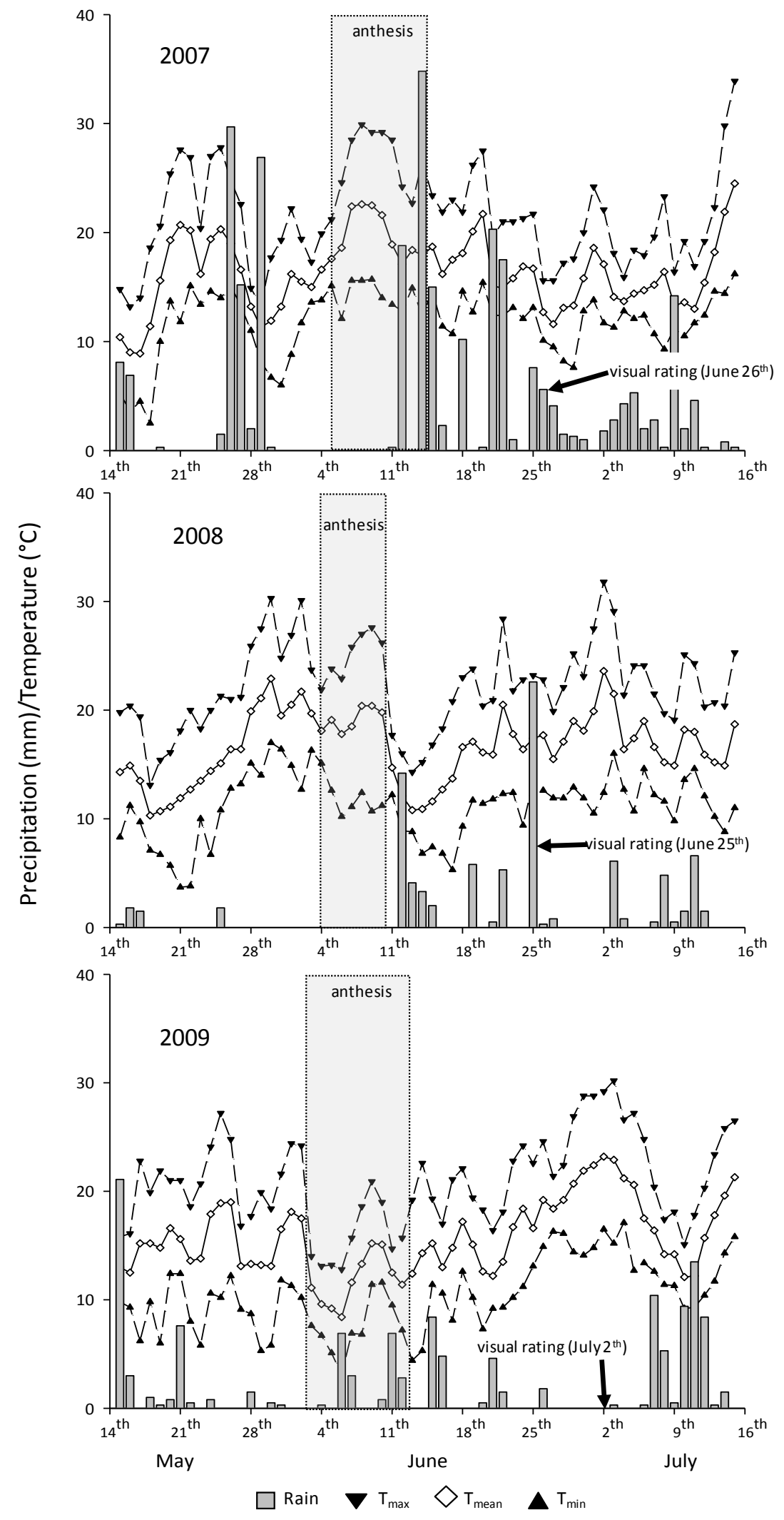

Fig 30. Weather conditions from May $14^{\text {th }}$ to July $16^{\text {th }}$ in 2007,2008 , and 2009: rain incidences with precipitation $(\mathrm{mm})$ and maximum/average/minimum daily temperatures $\left(T_{\max } / \mathrm{T}_{\text {mean }} / \mathrm{T}_{\min }\right)\left({ }^{\circ} \mathrm{C}\right)(\mathrm{WSG}$ 2010) 
Tab 54. Descriptive statistic, multiple comparison of treatment mean value (MV) for effect of year, location, pre-crop, cultivar, and fungicide as well as severity of effect (SoE) for $\mathrm{PC}_{\mathrm{WGF}}, \mathrm{PC}_{\mathrm{Type550}}$, WG, SV, and $\mathrm{FN}$

\begin{tabular}{|c|c|c|c|c|c|c|c|c|c|c|c|c|c|c|c|c|}
\hline & & \multicolumn{3}{|c|}{$P C_{W G F}$} & \multicolumn{3}{|c|}{$\mathrm{PC}_{\text {Type } 550}$} & \multicolumn{3}{|c|}{ WG } & \multicolumn{3}{|c|}{ SV } & \multicolumn{3}{|c|}{ FN } \\
\hline \multicolumn{2}{|l|}{ Dimension } & \multicolumn{3}{|c|}{$\%$} & \multicolumn{3}{|c|}{$\%$} & \multicolumn{3}{|c|}{$\%$} & \multicolumn{3}{|c|}{$\mathrm{ml}$} & \multicolumn{3}{|c|}{$\mathbf{s}$} \\
\hline $\mathbf{n}$ & & \multicolumn{3}{|c|}{108} & \multicolumn{3}{|c|}{108} & \multicolumn{3}{|c|}{108} & \multicolumn{3}{|c|}{108} & \multicolumn{3}{|c|}{108} \\
\hline MV & & \multicolumn{3}{|c|}{12.5} & \multicolumn{3}{|c|}{10.8} & \multicolumn{3}{|c|}{31.2} & \multicolumn{3}{|c|}{84.6} & \multicolumn{3}{|c|}{323.3} \\
\hline SD & & \multicolumn{3}{|c|}{1.3} & \multicolumn{3}{|c|}{0.8} & \multicolumn{3}{|c|}{6.2} & \multicolumn{3}{|c|}{4.9} & \multicolumn{3}{|c|}{91.7} \\
\hline CV (\%) & & \multicolumn{3}{|c|}{10.1} & \multicolumn{3}{|c|}{7.7} & \multicolumn{3}{|c|}{19.8} & \multicolumn{3}{|c|}{5.7} & \multicolumn{3}{|c|}{28.4} \\
\hline Effect & Factor level & MV & & SoE & MV & & SoE & MV & & SoE & MV & & SoE & MV & & SoE \\
\hline Year & 2007 & 14.0 & $\mathrm{C}$ & 1.23 & 11.7 & C & 1.14 & 38.02 & c & 1.44 & 83.67 & a & 1.03 & 249 & $\mathrm{a}$ & 1.63 \\
\hline & 2008 & 11.3 & $a$ & & 10.2 & a & & 29.07 & b & & 84.03 & a & & 315 & $b$ & \\
\hline & 2009 & 12.3 & $b$ & & 10.4 & $b$ & & 26.39 & $a$ & & 86.17 & b & & 406 & $\mathrm{C}$ & \\
\hline Location & Gladebeck & 12.4 & $a$ & 1.02 & 10.7 & a & 1.02 & 31.12 & $a$ & 1.00 & 84.34 & a & 1.01 & 334 & $b$ & 1.07 \\
\hline & Torland & 12.7 & $b$ & & 10.9 & b & & 31.20 & $a$ & & 84.91 & a & & 312 & $a$ & \\
\hline Pre-crop & Maize & 12.3 & a & 1.05 & 10.6 & a & 1.05 & 30.19 & $a$ & 1.09 & 82.40 & a & 1.05 & 314 & $a$ & 1.17 \\
\hline & Sugar beet & 12.4 & a & & 10.6 & a & & 30.25 & $a$ & & 85.28 & b & & 303 & $a$ & \\
\hline & Wheat & 12.9 & $b$ & & 11.2 & b & & 33.04 & b & & 86.19 & b & & 353 & $b$ & \\
\hline Cultivar & Centrum & 12.4 & a & 1.03 & 10.8 & a & 1.00 & 28.97 & $a$ & 1.15 & 84.38 & $a$ & 1.01 & 282 & $\mathrm{a}$ & 1.29 \\
\hline & Ritmo & 12.7 & b & & 10.8 & a & & 33.35 & b & & 84.87 & $a$ & & 365 & $b$ & \\
\hline Fungicide & Chlorthalonil & 12.6 & $b$ & 1.01 & 10.8 & b & 1.01 & 31.22 & $a$ & 1.01 & 84.17 & a & 1.01 & 333 & $b$ & 1.05 \\
\hline & Strobilurin & 12.6 & $b$ & & 10.8 & $b$ & & 31.26 & $a$ & & 84.94 & a & & 321 & $a b$ & \\
\hline & Triazole & 12.4 & a & & 10.7 & a & & 31.00 & $a$ & & 84.76 & a & & 316 & $\mathrm{a}$ & \\
\hline
\end{tabular}

$\mathrm{n}$ number of observations, MV mean value, SD standard diviation, CV coefficient of variation, SoE severity of effect, $P C_{\text {WGF }}$ Protein content of whole grain flour, $\mathrm{PC}_{\text {Type5} 50}$ protein content of flour Type 550, WG wet gluten, SV sedimentation value, FN falling number, same letters indicate no differences between treatment levels at a significance level of $p<0.05$ according to Tukey test

Tab 55. Descriptive statistic, multiple comparison of treatment mean value (MV) for effect of year, location, pre-crop, cultivar, and fungicide as well as severity of effect (SoE) for WA and dough properties (DDT, DST, DS)

\begin{tabular}{|c|c|c|c|c|c|c|c|c|c|c|}
\hline \multirow{3}{*}{$\begin{array}{c}\text { Dimension } \\
n\end{array}$} & & \multicolumn{2}{|c|}{ WA } & \multicolumn{3}{|c|}{ DDT } & \multicolumn{2}{|c|}{ DST } & \multicolumn{2}{|c|}{ DS } \\
\hline & & \multicolumn{2}{|c|}{$\%$} & \multicolumn{3}{|c|}{$\min$} & \multicolumn{2}{|c|}{$\min$} & \multicolumn{2}{|c|}{ FU/VU } \\
\hline & & \multicolumn{2}{|c|}{84} & \multicolumn{3}{|c|}{84} & \multicolumn{2}{|c|}{84} & \multicolumn{2}{|c|}{84} \\
\hline MV & & \multicolumn{2}{|c|}{59.2} & \multicolumn{3}{|c|}{1.7} & \multicolumn{2}{|c|}{3.6} & \multicolumn{2}{|c|}{78.1} \\
\hline SD & & \multicolumn{2}{|c|}{4.0} & \multicolumn{3}{|c|}{0.6} & \multicolumn{2}{|c|}{3.9} & \multicolumn{2}{|c|}{39.1} \\
\hline CV (\%) & & \multicolumn{2}{|c|}{6.7} & \multicolumn{3}{|c|}{35.1} & \multicolumn{2}{|c|}{109.5} & \multicolumn{2}{|c|}{50.1} \\
\hline Effect & Factor level & MV & SoE & MV & & SoE & MV & SoE & MV & SoE \\
\hline \multirow[t]{3}{*}{ Year } & 2007 & 63.5 & C 1.16 & 1.4 & a & 1.53 & 1.3 & a 5.99 & 95.0 & b 2.38 \\
\hline & 2008 & 57.2 & b & 2.0 & b & & 2.8 & a & 90.7 & b \\
\hline & 2009 & 54.9 & $\mathrm{a}$ & 2.1 & $b$ & & 7.8 & $b$ & 40.0 & a \\
\hline \multirow[t]{2}{*}{ Location } & Gladebeck & 59.0 & a 1.01 & 1.8 & a & 1.05 & 4.4 & a 1.55 & 65.4 & a 1.39 \\
\hline & Torland & 59.5 & $a$ & 1.7 & a & & 2.8 & a & 90.7 & b \\
\hline \multirow[t]{3}{*}{ Pre-crop } & Maize & 58.3 & a 1.10 & 1.9 & a & 1.25 & 3.7 & a 2.66 & 83.8 & a 1.18 \\
\hline & Sugar beet & 58.9 & a & 1.7 & a & & 4.3 & $a$ & 70.7 & a \\
\hline & Wheat & 63.8 & b & 1.5 & a & & 1.6 & a & 74.8 & a \\
\hline \multirow[t]{2}{*}{ Cultivar } & Centrum & 58.6 & a 1.02 & 1.5 & a & 1.27 & 3.8 & a 1.19 & 73.4 & a 1.14 \\
\hline & Ritmo & 59.9 & a & 1.9 & $b$ & & 3.2 & $\mathrm{a}$ & 83.5 & a \\
\hline \multirow[t]{3}{*}{ Fungicide } & Chlorthalonil & 59.3 & a 1.01 & 1.8 & a & 1.07 & 3.5 & a 1.10 & 81.2 & a 1.06 \\
\hline & Strobilurin & 58.8 & $\mathrm{a}$ & 1.8 & a & & 3.8 & a & 76.5 & a \\
\hline & Triazole & 59.4 & $\mathrm{a}$ & 1.7 & $\mathrm{a}$ & & 3.5 & a & 77.6 & a \\
\hline
\end{tabular}


Tab 56. Descriptive statistic, multiple comparison of treatment mean value (MV) for effect of year, location, pre-crop, cultivar, and fungicide as well as severity of effect (SoE) for baking properties (BV, LH, LL, LW)

\begin{tabular}{|c|c|c|c|c|c|c|c|c|c|c|}
\hline & & \multicolumn{2}{|c|}{ BV } & \multicolumn{2}{|c|}{ LH } & \multicolumn{2}{|c|}{ LL } & \multicolumn{3}{|c|}{ LW } \\
\hline \multicolumn{2}{|l|}{ Dimension } & \multicolumn{2}{|c|}{$\overline{\mathrm{ml}} 100 \mathrm{~g}^{-1}$ flour } & \multicolumn{2}{|c|}{$\mathrm{mm}$} & \multicolumn{2}{|c|}{$\mathrm{mm}$} & \multicolumn{3}{|c|}{$\mathrm{mm}$} \\
\hline $\mathbf{n}$ & & \multicolumn{2}{|c|}{84} & \multicolumn{2}{|c|}{84} & \multicolumn{2}{|c|}{84} & \multicolumn{3}{|c|}{84} \\
\hline MV & & \multicolumn{2}{|c|}{339.2} & \multicolumn{2}{|c|}{22.7} & \multicolumn{2}{|c|}{70.7} & \multicolumn{3}{|c|}{31.1} \\
\hline SD & & \multicolumn{2}{|c|}{69.3} & \multicolumn{2}{|c|}{1.8} & \multicolumn{2}{|c|}{5.5} & \multicolumn{3}{|c|}{2.5} \\
\hline CV (\%) & & \multicolumn{2}{|c|}{20.4} & \multicolumn{2}{|c|}{7.8} & \multicolumn{2}{|c|}{7.8} & \multicolumn{3}{|c|}{7.9} \\
\hline Effect & Factor level & MV & SoE & MV & SoE & MV & SoE & MV & & SoE \\
\hline \multirow[t]{3}{*}{ Year } & 2007 & 408 & C 1.51 & 21 & a 1.15 & 76 & b 1.15 & 33 & c & 1.14 \\
\hline & 2008 & 305 & $b$ & 24 & $\mathrm{C}$ & 66 & $\mathrm{a}$ & 30 & $b$ & \\
\hline & 2009 & 270 & $\mathrm{a}$ & 23 & $b$ & 68 & $\mathrm{a}$ & 29 & a & \\
\hline \multirow[t]{2}{*}{ Location } & Gladebeck & 328 & a 1.07 & 23 & a 1.02 & 71 & a 1.02 & 31 & a & 1.02 \\
\hline & Torland & 350 & $\mathrm{a}$ & 22 & $\mathrm{a}$ & 70 & $\mathrm{a}$ & 31 & $\mathrm{a}$ & \\
\hline \multirow[t]{3}{*}{ Pre-crop } & Maize & 345 & a 1.28 & 23 & b 1.10 & 69 & a 1.14 & 32 & a & 1.05 \\
\hline & Sugar beet & 321 & $a$ & 23 & $\mathrm{~b}$ & 69 & a & 31 & a & \\
\hline & Wheat & 410 & $b$ & 21 & $a$ & 79 & $b$ & 32 & a & \\
\hline \multirow[t]{2}{*}{ Cultivar } & Centrum & 330 & a 1.06 & 23 & a 1.01 & 70 & a 1.02 & 30 & a & 1.04 \\
\hline & Ritmo & 349 & $a$ & 23 & $a$ & 71 & a & 32 & $b$ & \\
\hline \multirow[t]{3}{*}{ Fungicide } & Chlorthalonil & 339 & a 1.01 & 23 & a 1.02 & 31 & a 1.01 & 71 & $a$ & 1.01 \\
\hline & Strobilurin & 341 & $a$ & 22 & $a$ & 31 & $a$ & 71 & a & \\
\hline & Triazole & 337 & $a$ & 23 & $a$ & 31 & $a$ & 70 & $\mathrm{a}$ & \\
\hline
\end{tabular}

Tab 57. Descriptive statistic, multiple comparison of treatment mean value (MV) for effect of year, location, pre-crop, cultivar, and fungicide as well as severity of effect (SoE) for total gluten, total gliadin, and gliadin subfractions $(\omega 5, \omega 1,2, \alpha, \gamma)$

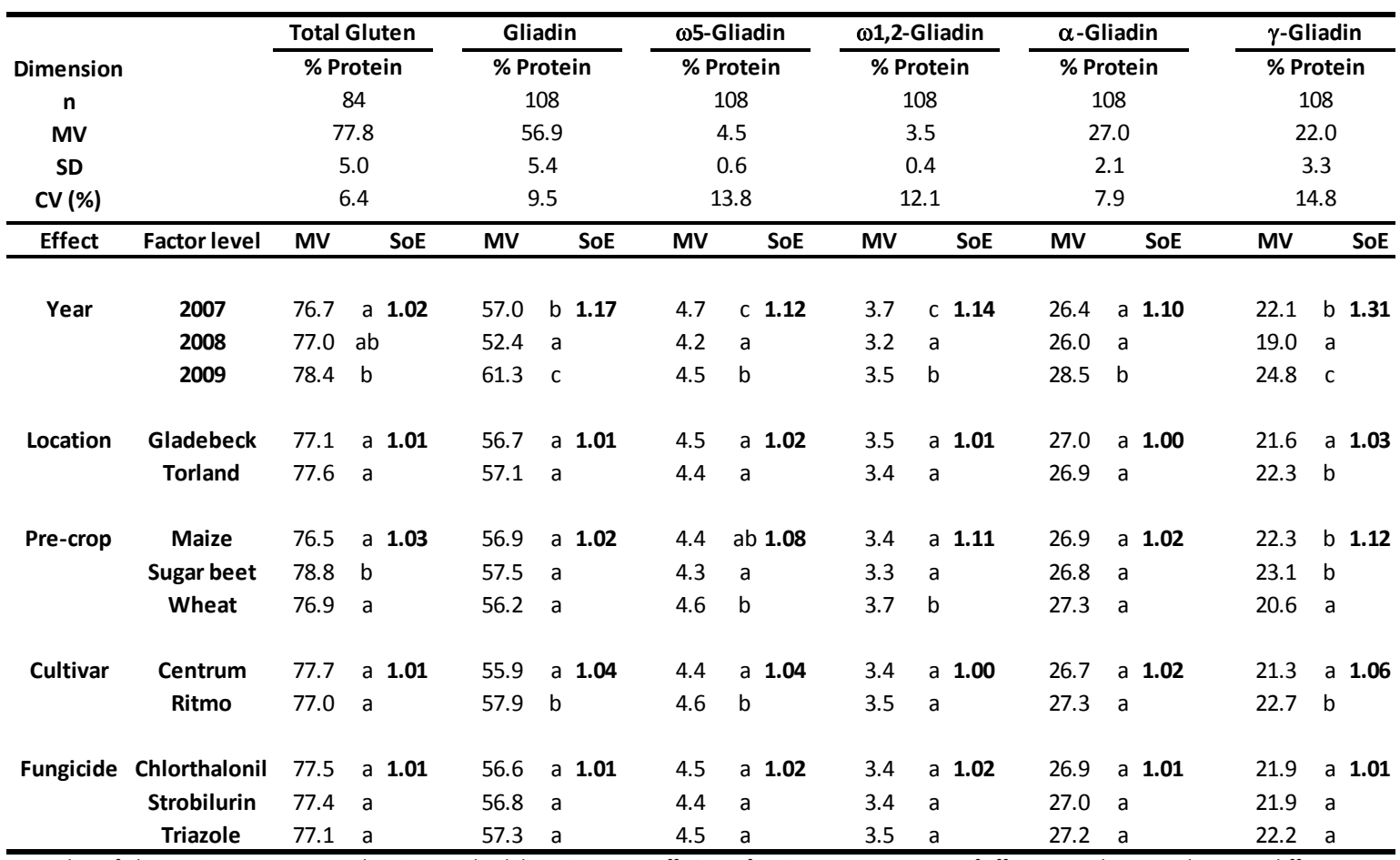

n number of observations, MV mean value, SD standard diviation, CV coefficient of variation, SoE severity of effect, same letters indicate no differences between treatment levels at a significance level of $p<0.05$ according to Tukey test 
Tab 58. Descriptive statistic, multiple comparison of treatment mean value (MV) for effect of year, location, pre-crop, cultivar, and fungicide as well as severity of effect (SoE) for total glutenin, glutenin subfractions ( $\omega b$, HMW-GS, LMW-GS), gliadin/glutenin ratio, and LMW/HMW ratio

\begin{tabular}{|c|c|c|c|c|c|c|c|c|c|c|c|c|c|c|c|c|c|c|c|}
\hline \multirow{3}{*}{ Dimension } & & \multicolumn{3}{|c|}{ Glutenin } & \multicolumn{3}{|c|}{$\omega b$} & \multicolumn{3}{|c|}{ HMW-GS } & \multicolumn{3}{|c|}{ LMW-GS } & \multicolumn{3}{|c|}{ Gliadin/Glutenin } & \multicolumn{3}{|c|}{ LMW/HMW } \\
\hline & & \multicolumn{3}{|c|}{$\%$ Protein } & \multicolumn{3}{|c|}{$\%$ Protein } & \multicolumn{3}{|c|}{ \% Protein } & \multicolumn{3}{|c|}{ \% Protein } & & & & & & \\
\hline & & \multicolumn{3}{|c|}{105} & \multicolumn{3}{|c|}{105} & \multicolumn{3}{|c|}{105} & \multicolumn{3}{|c|}{105} & \multicolumn{3}{|c|}{105} & \multicolumn{3}{|c|}{105} \\
\hline SD & & \multicolumn{3}{|c|}{5.1} & \multicolumn{3}{|c|}{0.4} & \multicolumn{3}{|c|}{1.2} & \multicolumn{3}{|c|}{3.7} & \multicolumn{3}{|c|}{1.2} & \multicolumn{3}{|c|}{0.3} \\
\hline CV (\%) & & & 7.1 & & & .1 & & & .1 & & & 9 & & & 1.5 & & & .1 & \\
\hline Year & 2007 & 19.8 & $\mathrm{a}$ & 1.33 & 1.1 & $b$ & 1.73 & 5.5 & $\mathrm{a}$ & 1.18 & 13.2 & a & 1.39 & 3.30 & $b$ & 1.56 & 2.4 & $b$ & 1.19 \\
\hline & 2008 & 24.5 & $b$ & & 1.2 & $b$ & & 6.5 & $b$ & & 16.9 & $b$ & & 2.18 & a & & 2.6 & c & \\
\hline & 2009 & 18.4 & $\mathrm{a}$ & & 0.7 & a & & 5.6 & $a$ & & 12.1 & a & & 3.41 & $b$ & & 2.2 & a & \\
\hline Location & Gladebeck & 21.1 & $a$ & 1.02 & 1.0 & $\mathrm{a}$ & 1.09 & 5.7 & $\mathrm{a}$ & 1.03 & 14.3 & $\mathrm{a}$ & 1.04 & 2.88 & a & 1.06 & 2.5 & $b$ & 1.06 \\
\hline & Sugar beet & 22.6 & $b$ & & 1.1 & $a$ & & 6.1 & $b$ & & 15.3 & $b$ & & 2.72 & a & & 2.5 & $b$ & \\
\hline & Wheat & 20.6 & $a b$ & & 1.0 & $\mathrm{a}$ & & 6.0 & $b$ & & 13.6 & $\mathrm{a}$ & & 2.84 & $a b$ & & 2.3 & $a$ & \\
\hline Cultivar & Centrum & 21.8 & $b$ & 1.09 & 1.1 & $b$ & 1.17 & 6.0 & $\mathrm{~b}$ & 1.06 & 14.8 & $\mathrm{~b}$ & 1.11 & 2.82 & a & 1.10 & 2.5 & $b$ & 1.05 \\
\hline & Ritmo & 20.0 & $\mathrm{a}$ & & 0.9 & $a$ & & 5.7 & $a$ & & 13.3 & $a$ & & 3.11 & a & & 2.3 & $a$ & \\
\hline Fungicide & Chlorthalonil & 21.2 & $\mathrm{a}$ & 1.04 & 1.0 & $\mathrm{a}$ & 1.10 & 5.9 & $a$ & 1.03 & 14.3 & a & 1.04 & 2.85 & a & 1.11 & 2.4 & $a$ & 1.00 \\
\hline & Strobilurin & 21.1 & a & & 1.0 & a & & 5.9 & $\mathrm{a}$ & & 14.2 & $\mathrm{a}$ & & 2.87 & a & & 2.4 & $a$ & \\
\hline & Triazole & 20.4 & a & & 0.9 & $a$ & & 5.7 & $a$ & & 13.7 & $\mathrm{a}$ & & 3.17 & a & & 2.4 & $\mathrm{a}$ & \\
\hline
\end{tabular}

n number of observations, MV mean value, SD standard diviation, CV coefficient of variation, SoE severity of effect, same letters indicate no differences between treatment levels at a significance level of $p<0.05$ according to Tukey test 
Tab 59. Descriptive statistic, multiple comparison of treatment mean value (MV) for effect of year, location, pre-crop, cultivar, and fungicide as well as severity of effect (SoE) for gluten properties $\left(\mathbf{R}_{\mathrm{MAX}}, \mathrm{EXT}, \mathbf{R}_{\mathrm{MAX}} / \mathrm{EXT}\right)$, starch content, PA, yield parameters (TKW, GY), S content, and N/S ratio of flour Type 550

\begin{tabular}{|c|c|c|c|c|c|c|c|c|c|c|c|c|c|c|c|c|c|c|c|c|c|c|c|c|}
\hline & & \multicolumn{2}{|c|}{$\mathrm{R}_{\mathrm{MAx}}{ }^{*}$} & \multicolumn{2}{|c|}{ EXT* } & \multicolumn{3}{|c|}{$\mathbf{R}_{\text {MAX }} /$ EXT } & \multicolumn{2}{|c|}{ Starch } & \multicolumn{3}{|c|}{ PA } & \multicolumn{3}{|c|}{ TKW } & \multicolumn{2}{|c|}{ GY } & \multicolumn{3}{|c|}{$S$} & \multicolumn{3}{|c|}{$N / S$} \\
\hline & \multicolumn{2}{|c|}{$\mathbf{N}$} & \multicolumn{2}{|c|}{$\mathrm{mm}$} & \multicolumn{3}{|c|}{$\mathrm{N} / \mathrm{m}$} & \multicolumn{2}{|c|}{$\%$} & \multicolumn{3}{|c|}{ AU $440 \mathrm{~nm}$} & \multicolumn{3}{|c|}{ g } & \multicolumn{2}{|c|}{ dt ha ${ }^{-1}$} & \multicolumn{3}{|c|}{$\%$} & \\
\hline$n$ & & \multicolumn{2}{|c|}{18} & \multicolumn{2}{|c|}{18} & \multicolumn{3}{|c|}{36} & \multicolumn{2}{|c|}{108} & \multicolumn{3}{|c|}{36} & \multicolumn{3}{|c|}{108} & \multicolumn{2}{|c|}{108} & \multicolumn{3}{|c|}{72} & & 2 & \\
\hline MV & & & .64 & & 09 & & 0 & & & & & .53 & & & .7 & & & 3.4 & 0.1 & 38 & & & 1.0 & \\
\hline SD & & & .06 & & 8 & & 1 & & & & & 18 & & & 8 & & & 0.3 & 0.0 & 10 & & & .7 & \\
\hline CV (\%) & & & .95 & & .1 & & 8 & & & & & 4.4 & & & .0 & & & 5.9 & 7 & 1 & & & .1 & \\
\hline Effect & Factor level & $\mathrm{MV}$ & SoE & $\mathrm{MV}$ & SoE & MV & & SoE & MV & SoE & $\mathrm{MV}$ & & SoE & $\mathrm{MV}$ & & SoE & $\mathrm{MV}$ & SoE & MV & & SoE & MV & & SoE \\
\hline Year & 2007 & & - & & - & & & & 73.5 & a 1.06 & & - & & 42.7 & b 1 & 1.33 & 64.8 & a 1.60 & 0.145 & b 1 & 1.11 & 14.1 & $b$ & 1.03 \\
\hline & 2008 & & - & & - & & & & 75.7 & $b$ & & - & & 53.8 & c & & 103.5 & $\mathrm{C}$ & 0.131 & a & & 13.8 & $\mathrm{a}$ & \\
\hline & 2009 & & - & & - & & & & 77.7 & c & & - & & 40.5 & $a$ & & 67.0 & $b$ & - & & & - & & \\
\hline Location & Gladebeck & 0.66 & a 1.05 & 109 & a 1.00 & 4.1 & a 1 & 1.04 & 75.6 & a 1.00 & 0.51 & $\mathrm{a}$ & 1.08 & 45.0 & a 1 & 1.03 & 81.4 & b 1.08 & 0.137 & a 1 & 1.02 & 13.7 & $\mathrm{a}$ & 1.04 \\
\hline & Torland & 0.63 & $a$ & 109 & $a$ & 4.0 & $a$ & & 75.7 & a & 0.55 & $\mathrm{~b}$ & & 46.3 & $b$ & & 75.4 & $a$ & 0.139 & a & & 14.2 & $b$ & \\
\hline Pre-crop & Maize & 0.60 & a 1.15 & 108 & a 1.08 & 3.7 & a 1 & 1.20 & 77.2 & b 1.03 & 0.59 & $\mathrm{~b}$ & 1.33 & 45.5 & b 1 & 1.09 & 76.6 & b 1.13 & 0.137 & a 1 & 1.01 & 13.7 & a & 1.05 \\
\hline & Sugar beet & 0.69 & b & 105 & $\mathrm{a}$ & 4.4 & $a$ & & 74.9 & a & 0.44 & $\mathrm{a}$ & & 47.7 & c & & 84.2 & c & 0.139 & a & & 13.7 & $\mathrm{a}$ & \\
\hline & Wheat & 0.64 & $a b$ & 113 & $a$ & 4.0 & $\mathrm{a}$ & & 74.7 & a & 0.55 & $\mathrm{~b}$ & & 43.8 & $\mathrm{a}$ & & 74.5 & $\mathrm{a}$ & 0.138 & a & & 14.4 & $b$ & \\
\hline Cultivar & Centrum & & - & & - & 6.0 & b 2 & 2.92 & 75.6 & a 1.00 & 0.45 & a & 1.35 & 48.1 & b 1 & 1.11 & 83.1 & b 1.13 & 0.139 & a 1 & 1.01 & 13.8 & a & 1.02 \\
\hline & Ritmo & & - & & - & 2.1 & $a$ & & 75.6 & a & 0.61 & $\mathrm{~b}$ & & 43.2 & $\mathrm{a}$ & & 73.8 & $\mathrm{a}$ & 0.138 & a & & 14.1 & $\mathrm{a}$ & \\
\hline Fungicide & Chlorthalonil & 0.66 & a 1.05 & 112 & a 1.05 & 4.0 & a 1 & 1.04 & 75.5 & a 1.00 & 0.54 & $\mathrm{~b}$ & 1.15 & 44.8 & a 1 & 1.04 & 76.9 & a 1.05 & 0.138 & a 1 & 1.01 & 14.0 & $\mathrm{a}$ & 1.00 \\
\hline & Strobilurin & 0.63 & $a$ & 108 & $a$ & 3.9 & $\mathrm{a}$ & & 75.6 & a & 0.56 & $\mathrm{~b}$ & & 45.6 & $b$ & & 77.4 & $\mathrm{a}$ & 0.139 & a & & 13.9 & $\mathrm{a}$ & \\
\hline & Triazole & 0.64 & $a$ & 107 & $\mathrm{a}$ & 4.1 & $a$ & & 75.8 & $a$ & 0.49 & $a$ & & 46.7 & c & & 81.0 & $\mathrm{~b}$ & 0.137 & a & & 14.0 & $a$ & \\
\hline
\end{tabular}

activity, TKW thousand kernel weight, GY grain yeld, S sulfur, N/S ratio of nitrogen (N) and sulfur, same letters indicate no differences between treatment levels at a significance level of $p<0$.05 according to Tukey te 
Tab 60. Significance of effects from ANOVA for indirect quality parameters $\left(\mathrm{PC}_{\mathrm{WGF}}, \mathrm{PC}_{\mathrm{Type550}}\right.$, WG, $\mathrm{SV}$, FN, WA), dough properties (DDT, DST, DS), baking properties (BV, LH, LL, LW), gluten properties $\left(\mathbf{R}_{\text {MAX }}, E X T, R_{\text {MAX }} / E X T\right)$, and starch content including all analyzed samples

\begin{tabular}{|c|c|c|c|c|c|c|c|c|c|c|c|c|c|c|c|c|c|}
\hline Effect & $\mathrm{PC}_{\mathrm{WGF}}$ & $\mathrm{PC}_{\text {Type } 550}$ & WG & sv & $\mathrm{FN}$ & WA & DDT & DST & DS & BV & LH & LL & LW & $\mathbf{R}_{\text {MAX }}$ & EXT & $\mathbf{R}_{\text {MAX }} /$ EXT & Starch \\
\hline Year (Y) & $* * *$ & $* * *$ & $* * *$ & $* *$ & $* * *$ & $* * *$ & $* * *$ & $* * *$ & $* * *$ & $* * *$ & $* * *$ & $* * *$ & $* * *$ & & & & $* * *$ \\
\hline Location (L) & $* * *$ & $* * *$ & n.s. & n.s. & $* * *$ & $*$ & n.s. & $* *$ & $* * *$ & $* *$ & n.s. & $*$ & $(*)$ & n.s. & n.s. & n.s. & n.s. \\
\hline$Y \times L$ & $* * *$ & $* * *$ & $* *$ & n.s. & $* * *$ & $*$ & $* * *$ & $* * *$ & $* * *$ & $* *$ & n.s. & n.s. & n.s. & & & & $* *$ \\
\hline Pre-crop (P) & $* * *$ & n.s. & $* * *$ & n.s. & $* * *$ & $(*)$ & $* *$ & n.s. & $* * *$ & $(*)$ & $(*)$ & $*$ & $*$ & n.s. & n.s. & $(*)$ & $* * *$ \\
\hline$Y \times P$ & $* * *$ & $* * *$ & $* * *$ & $*$ & $*$ & $(*)$ & $* *$ & n.s. & $* *$ & n.s. & $(*)$ & n.s. & $(*)$ & & & & $* * *$ \\
\hline$L \times P$ & $* * *$ & n.s. & n.s. & n.s. & $(*)$ & n.s. & n.s. & n.s. & $* *$ & $(*)$ & $*$ & $*$ & n.s. & n.s. & n.s. & n.s. & $(*)$ \\
\hline$Y X \operatorname{LXP}$ & $* * *$ & $* *$ & $* *$ & n.s. & $*$ & n.s. & $* *$ & $(*)$ & $*$ & n.s. & n.s. & n.s. & n.s. & & & & $* * *$ \\
\hline Cultivar (C) & $* * *$ & $* * *$ & $* * *$ & $* * *$ & $* * *$ & $* *$ & $* * *$ & n.s. & $* *$ & $*$ & n.s. & $*$ & $*$ & & & $* * *$ & n.s. \\
\hline$Y \times C$ & $* * *$ & $* * *$ & $* * *$ & $* * *$ & $(*)$ & $(*)$ & $*$ & $* *$ & $* * *$ & $*$ & n.s. & $(*)$ & $*$ & & & & n.s. \\
\hline $\mathrm{LxC}$ & $* *$ & $* * *$ & $* * *$ & n.s. & $*$ & n.s. & n.s. & $*$ & $*$ & n.s. & n.s. & n.s. & n.s. & & & n.s. & n.s. \\
\hline$Y \times L x C$ & $* * *$ & $(*)$ & $* * *$ & n.s. & $*$ & n.s. & $* * *$ & $*$ & n.s. & $(*)$ & $*$ & n.s. & n.s. & & & & n.s. \\
\hline$P \times C$ & $* * *$ & $*$ & $*$ & $*$ & n.s. & $(*)$ & $* *$ & n.s. & $* *$ & n.s. & $\left({ }^{*}\right)$ & n.s. & $(*)$ & & & n.s. & n.s. \\
\hline$Y \times P \times C$ & $*$ & $*$ & $* *$ & $(*)$ & n.s. & n.s. & $* *$ & n.s. & $*$ & $*$ & $*$ & n.s. & n.s. & & & & n.s. \\
\hline $\operatorname{LxP} \times C$ & n.s. & n.s. & $*$ & n.s. & $* *$ & n.s. & n.s. & n.s. & n.s. & n.s. & n.s. & n.s. & n.s. & & & n.s. & n.s. \\
\hline$Y \times L \times P \times C$ & $* *$ & $*$ & $*$ & n.s. & $(*)$ & n.s. & $* *$ & $(*)$ & $(*)$ & n.s. & $(*)$ & n.s. & n.s. & & & & n.s. \\
\hline Fungicide (F) & $* * *$ & $*$ & n.s. & n.s. & * & n.s. & n.s. & n.s. & n.s. & n.s. & * & n.s. & n.s. & n.s. & n.s. & n.s. & n.s. \\
\hline$Y \times F$ & n.s. & $(*)$ & n.s. & n.s. & $*$ & n.s. & n.s. & n.s. & n.s. & n.s. & n.s. & n.s. & n.s. & & & & n.s. \\
\hline LxF & $*$ & n.s. & n.s. & $* *$ & n.s. & n.s. & $*$ & $*$ & $*$ & n.s. & n.s. & $(*)$ & n.s. & n.s. & n.s. & n.s. & n.s. \\
\hline$Y \times L x F$ & $*$ & $*$ & n.s. & $* * *$ & n.s. & n.s. & n.s. & $*$ & n.s. & n.s. & n.s. & n.s. & n.s. & & & & n.s. \\
\hline$P \times F$ & n.s. & n.s. & n.s. & n.s. & n.s. & n.s. & $*$ & n.s. & $*$ & n.s. & n.s. & n.s. & n.s. & n.s. & n.s. & n.s. & n.s. \\
\hline$Y \times P \times F$ & n.s. & $*$ & n.s. & n.s. & n.s. & n.s. & n.s. & n.s. & $*$ & n.s. & n.s. & n.s. & n.s. & & & & n.s. \\
\hline$L \times P \times F$ & $(*)$ & n.s. & n.s. & $(*)$ & n.s. & n.s. & $(*)$ & n.s. & $(*)$ & n.s. & $(*)$ & n.s. & n.s. & & & n.s. & n.s. \\
\hline$Y \times L \times P \times C$ & n.s. & n.s. & $*$ & n.s. & n.s. & n.s. & n.s. & $*$ & $(*)$ & n.s. & n.s. & n.s. & n.s. & & & & n.s. \\
\hline$C \times F$ & $*$ & n.s. & n.s. & n.s. & n.s. & n.s. & $(*)$ & n.s. & $*$ & n.s. & n.s. & n.s. & n.s. & & & n.s. & n.s. \\
\hline$Y \times C \times F$ & $(*)$ & $(*)$ & n.s. & n.s. & $(*)$ & n.s. & $(*)$ & n.s. & n.s. & n.s. & n.s. & n.s. & n.s. & & & & n.s. \\
\hline $\operatorname{LxCxF}$ & $*$ & $*$ & n.s. & $*$ & n.s. & n.s. & $(*)$ & n.s. & n.s. & n.s. & n.s. & n.s. & n.s. & & & n.s. & n.s. \\
\hline$Y \times L x C \times F$ & n.s. & n.s. & n.s. & $*$ & n.s. & n.s. & n.s. & $(*)$ & n.s. & n.s. & n.s. & n.s. & n.s. & & & & n.s. \\
\hline$P \times C \times F$ & n.s. & n.s. & n.s. & n.s. & n.s. & n.s. & n.s. & n.s. & n.s. & n.s. & n.s. & n.s. & n.s. & & & n.s. & n.s. \\
\hline$Y \times P \times C \times F$ & $(*)$ & n.s. & n.s. & n.s. & n.s. & n.s. & n.s. & n.s. & n.s. & n.s. & n.s. & n.s. & n.s. & & & & n.s. \\
\hline$L \times P \times C \times F$ & $*$ & n.s. & n.s. & n.s. & n.s. & n.s. & n.s. & n.s. & n.s. & n.s. & n.s. & $(*)$ & n.s. & & & & n.s. \\
\hline
\end{tabular}

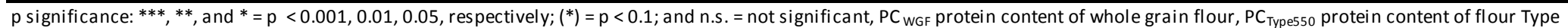
550, WG wet gluten, SV sedimentation value, FN falling number, WA water absorption, DDT dough development time, DST dough stability, DS dough softening, BV baking volume, LH loaf height, LL loaf length, LW loaf width, $\mathrm{R}_{\mathrm{MAx}}$ resistance to extension, EXT extensibility 
Tab 61. Significance of effects from ANOVA for total gluten, total gliadin, gliadin subfractions $(\omega 5, \omega 1,2, \alpha, \gamma)$, total glutenin, glutenin subfractions ( $\omega b$, HMW-GS, LMW-GS, gliadin/glutenin ratio, LMW/HMW ratio, protease activity, TKW, grain yield, S content and N/S ratio including all analyzed samples

\begin{tabular}{|c|c|c|c|c|c|c|c|c|c|c|c|c|c|c|c|c|c|}
\hline Effect & Total Gluten & Gliadin & $\omega 5$-Gliadin & $\omega 1,2-$ Gliadin & $\alpha$-Gliadin & $\gamma$-Gliadin & Glutenin & $\omega \mathbf{b}$ & HMW-GS & LMW-GS & Gliadin/Glutenin & LMW/HMW & PA & TKW & GY & $\mathbf{s}$ & $N / S$ \\
\hline Year (Y) & * & $* * *$ & ** & $* * *$ & $* *$ & *** & *** & $* * *$ & $* * *$ & *** & ** & $* * *$ & & $* * *$ & $* * *$ & $* * *$ & * \\
\hline Location (L) & n.s. & n.s. & n.s. & n.s. & n.s. & $*$ & n.s. & n.s. & n.s. & n.s. & n.s. & $* * *$ & $*$ & $* * *$ & $* * *$ & n.s. & $* *$ \\
\hline$Y \times L$ & $*$ & n.s. & n.s. & n.s. & n.s. & $(*)$ & n.s. & n.s. & n.s. & n.s. & n.s. & n.s. & & $* * *$ & $* * *$ & n.s. & $(*)$ \\
\hline Pre-crop (P) & $* *$ & n.s. & * & $* * *$ & n.s. & $* * *$ & $* *$ & n.s. & $* *$ & $* *$ & * & $* * *$ & $* * *$ & $* * *$ & $* * *$ & n.s. & $* *$ \\
\hline$Y \times P$ & $* * *$ & $(*)$ & $* *$ & * & $(*)$ & n.s. & $* *$ & * & $* *$ & $*$ & $(*)$ & n.s. & & $* * *$ & $* * *$ & $(*)$ & n.s. \\
\hline LXP & n.s. & n.s. & n.s. & n.s. & n.s. & n.s. & n.s. & n.s. & n.s. & n.s. & n.s. & n.s. & $* * *$ & $* * *$ & $* * *$ & $(*)$ & n.s. \\
\hline$Y x L X P$ & n.s. & n.s. & n.s. & n.s. & n.s. & n.s. & n.s. & n.s. & n.s. & n.s. & n.s. & n.s. & & $*$ & $* * *$ & $(*)$ & $*$ \\
\hline Cultivar (C) & n.s. & $*$ & $*$ & n.s. & n.s. & $* *$ & $*$ & $*$ & $(*)$ & $*$ & n.s. & $* *$ & $* * *$ & $* * *$ & $* * *$ & n.s. & n.s. \\
\hline$Y \times C$ & $* *$ & n.s. & $* * *$ & $(*)$ & n.s. & n.s. & * & $*$ & n.s. & $*$ & n.s. & $* * *$ & & $* * *$ & $* * *$ & $(*)$ & n.s. \\
\hline $\mathrm{LxC}$ & n.s. & n.s. & n.s. & n.s. & n.s. & n.s. & n.s. & n.s. & n.s. & n.s. & n.s. & n.s. & n.s. & $* * *$ & $* * *$ & n.s. & n.s. \\
\hline$Y X L X C$ & n.s. & n.s. & n.s. & n.s. & n.s. & n.s. & n.s. & n.s. & n.s. & n.s. & n.s. & $(*)$ & & n.s. & n.s. & n.s. & n.s. \\
\hline $\mathrm{P} \times \mathrm{C}$ & $*$ & $(*)$ & $*$ & $* *$ & n.s. & $(*)$ & $*$ & $* *$ & n.s. & $*$ & n.s. & $* *$ & $*$ & n.s. & $* *$ & n.s. & $(*)$ \\
\hline$Y \times P \times C$ & $* * *$ & $*$ & $* *$ & * & n.s. & $* *$ & $*$ & n.s. & $*$ & * & n.s. & $(*)$ & & n.s. & $* *$ & n.s. & n.s. \\
\hline$L \times P \times C$ & n.s. & n.s. & n.s. & n.s. & n.s. & n.s. & n.s. & n.s. & n.s. & n.s. & n.s. & n.s. & n.s. & n.s. & n.s. & n.s. & n.s. \\
\hline$Y \times L \times P \times C$ & $* *$ & n.s. & n.s. & n.s. & n.s. & $(*)$ & n.s. & n.s. & n.s. & n.s. & n.s. & $(*)$ & & n.s. & $*$ & n.s. & n.s. \\
\hline Fungicide (F) & n.s. & n.s. & n.s. & n.s. & n.s. & n.s. & n.s. & n.s. & n.s. & n.s. & n.s. & n.s. & $* *$ & $* * *$ & $* * *$ & n.s. & n.s. \\
\hline$Y \times F$ & n.s. & n.s. & n.s. & n.s. & n.s. & n.s. & n.s. & n.s. & n.s. & n.s. & n.s. & n.s. & & $* *$ & $* *$ & n.s. & n.s. \\
\hline $\operatorname{LxF}$ & n.s. & n.s. & $* *$ & $* *$ & n.s. & $*$ & $*$ & n.s. & $* * *$ & n.s. & $(*)$ & $* * *$ & $* *$ & $(*)$ & $*$ & n.s. & n.s. \\
\hline$Y X L X F$ & $* *$ & n.s. & n.s. & n.s. & n.s. & n.s. & * & n.s. & $* *$ & * & $(*)$ & $*$ & & n.s. & $*$ & n.s. & n.s. \\
\hline$P \times F$ & n.s. & n.s. & n.s. & n.s. & n.s. & n.s. & n.s. & n.s. & n.s. & n.s. & n.s. & n.s. & $*$ & n.s. & $(*)$ & n.s. & n.s. \\
\hline$Y \times P \times F$ & n.s. & n.s. & n.s. & n.s. & n.s. & n.s. & n.s. & n.s. & n.s. & n.s. & n.s. & n.s. & & n.s. & n.s. & n.s. & n.s. \\
\hline$L \times P \times F$ & $*$ & n.s. & n.s. & n.s. & n.s. & n.s. & n.s. & n.s. & $(*)$ & n.s. & n.s. & n.s. & $* * *$ & n.s. & n.s. & n.s. & n.s. \\
\hline$Y \times L \times P \times C$ & $(*)$ & n.s. & n.s. & n.s. & n.s. & n.s. & n.s. & n.s. & $(*)$ & n.s. & n.s. & n.s. & & $(*)$ & n.s. & n.s. & n.s. \\
\hline $\mathrm{CXF}$ & n.s. & n.s. & n.s. & n.s. & n.s. & n.s. & n.s. & n.s. & n.s. & n.s. & n.s. & n.s. & n.s. & n.s. & $* *$ & n.s. & n.s. \\
\hline$Y \times C X F$ & $(*)$ & n.s. & n.s. & n.s. & n.s. & n.s. & n.s. & n.s. & n.s. & n.s. & n.s. & n.s. & & n.s. & n.s. & n.s. & n.s. \\
\hline$L \times C \times F$ & $*$ & n.s. & n.s. & n.s. & n.s. & n.s. & n.s. & n.s. & n.s. & n.s. & n.s. & n.s. & n.s. & n.s. & $(*)$ & n.s. & n.s. \\
\hline$Y \times L \times C \times F$ & n.s. & n.s. & n.s. & n.s. & n.s. & n.s. & n.s. & n.s. & n.s. & n.s. & n.s. & n.s. & & n.s. & n.s. & n.s. & n.s. \\
\hline$P \times C \times F$ & n.s. & n.s. & n.s. & n.s. & n.s. & n.s. & n.s. & n.s. & n.s. & n.s. & n.s. & n.s. & n.s. & n.s. & n.s. & n.s. & n.s. \\
\hline$Y \times P \times C \times F$ & n.s. & n.s. & n.s. & n.s. & n.s. & n.s. & n.s. & n.s. & n.s. & n.s. & n.s. & n.s. & & n.s. & n.s. & n.s. & n.s. \\
\hline$L \times P \times C \times F$ & $(*)$ & n.s. & n.s. & n.s. & n.s. & n.s. & n.s. & n.s. & n.s. & n.s. & n.s. & n.s. & & n.s. & n.s. & n.s. & n.s. \\
\hline
\end{tabular}


Tab 62. Correlation matrix for yield components and quality parameters of flour (+/- direction of trend, $\mathbf{R}^{2}$, significance) for all analyzed samples

\begin{tabular}{|c|c|c|c|c|c|c|c|c|c|c|c|c|c|c|c|c|c|c|c|c|c|c|c|c|c|c|c|c|c|c|c|c|c|c|c|c|c|c|}
\hline & GY & & TKW & & $\mathbf{P C}_{\mathrm{WG}}$ & & $\mathbf{P C}_{\text {Type } 55}$ & & sv & & WG & & $\mathrm{FN}$ & & WA & & DDT & & DST & & DS & & B & $3 \mathrm{v}$ & & LH & & LL &.$L$ & & LW & & $\mathbf{R}_{\text {MAX }} / \mathbf{E X}$ & & $\mathbf{R}_{\operatorname{MAX}}$ & & EXT & \\
\hline $\mathrm{PC}_{\text {WGF }}$ & 0.54 & $* *$ & \begin{tabular}{|l|} 
\\
\end{tabular} & $* * *$ & & & & & & & & & & & & & & & & & & & & & & & & & & & & & & & & & & \\
\hline $\mathrm{PC}_{\text {Types } 50}$ & 0.33 & $* * *$ & 0.10 & $* * *$ & 0.83 & $* * *$ & & & & & & & & & & & & & & & & & & & & & & & & & & & & & & & & \\
\hline sv & -0.02 & n.s. - & 0.01 & n.s. + & 0.00 & n.s. + & +0.00 & n.s. & & & & & & & & & & & & & & & & & & & & & & & & & & & & & & \\
\hline WG & 0.18 & $* *$ & \begin{tabular}{|l|} 
\\
\end{tabular} & $* *$ & 0.63 & $* * *+$ & +0.67 & $* * *$ & 0.00 & n.s. & & & & & & & & & & & & & & & & & & & & & & & & & & & & \\
\hline $\mathrm{FN}$ & 0.03 & n.s. & 0.14 & $* * *$ & 0.07 & $* *$ & 0.14 & $* * *+$ & 0.01 & n.s. & 0.10 & $* *$ & & & & & & & & & & & & & & & & & & & & & & & & & & \\
\hline WA & $=0.21$ & $* *$ & 0.06 & $* *$ & 0.69 & $* * *+$ & +0.73 & $* * *$ & 0.00 & n.s. + & \begin{tabular}{|l|} 
\\
\end{tabular} & $* * *$ & 0.33 & $* * *$ & & & & & & & & & & & & & & & & & & & & & & & & \\
\hline DDT & +0.01 & n.s. + & 0.01 & n.s. - & 0.07 & $*$ & 0.06 & $*+$ & 0.02 & n.s. & 0.04 & n.s. + & 0.34 & $* * *$ & 0.19 & $* * *$ & & & & & & & & & & & & & & & & & & & & & & \\
\hline DST & +0.01 & n.s. - & 0.00 & n.s. & 0.05 & $*$ & 0.10 & $* *+$ & 0.01 & n.s. & \begin{tabular}{|l|} 
\\
\end{tabular} & $* * *$ & 0.23 & $* * *$ & 0.31 & $* * *+$ & 0.15 & $* * *$ & & & & & & & & & & & & & & & & & & & & \\
\hline DS & +0.00 & n.s. + & 0.03 & n.s. + & 0.05 & $*+$ & 0.06 & $*$ & 0.00 & n.s. + & 0.15 & $* * *$ & 0.41 & $* * *$ & 0.23 & $* * *$ & 0.19 & $* *$ & $0.36 *$ & $* * *$ & & & & & & & & & & & & & & & & & & \\
\hline BV & $=0.26$ & $* * *$ & 0.06 & $* *+$ & 0.66 & $* * *+$ & +0.72 & $* * *$ & 0.00 & n.s. + & 0.75 & $* * *$ & 0.24 & $* * *$ & 0.79 & $* * *$ & \begin{tabular}{|l|}
0.13 \\
\end{tabular} & $* * *$ & $0.26{ }^{*}$ & $* *++$ & 0.21 & $* * *$ & & & & & & & & & & & & & & & & \\
\hline$\angle \mathrm{H}$ & +0.40 & $* *+$ & 0.27 & $* *$ & 0.54 & $* * *$ & 0.44 & $* * *+$ & 0.00 & n.s. & 0.31 & $* * *$ & 0.14 & $* * *$ & 0.45 & $* * *+$ & 0.21 & $* *+$ & +0.09 & $* *$ & \begin{tabular}{|l|} 
\\
\end{tabular} & $* *$ & 0.36 & $6 \longdiv { 6 * * }$ & $*$ & & & & & & & & & & & & & \\
\hline LL & $=0.39$ & $* * *$ & \begin{tabular}{|l|} 
\\
\end{tabular} & $* *+$ & 0.59 & $* * *+$ & +0.55 & $* * *+$ & 0.00 & n.s. + & 0.53 & $* * *$ & 0.08 & $* *$ & 0.54 & $* * *$ & \begin{tabular}{|l|}
0.13 \\
\end{tabular} & $* *$ & 0.12 & $* *+$ & 0.02 & n.s. & 0.4 & $14{ }^{* * *}$ & $*$ & 0.54 & $* * *$ & & & & & & & & & & & \\
\hline$L W$ & 0.11 & $* *$ & 0.03 & n.s. + & 0.34 & $* * *+$ & 0.30 & $* *$ & 0.00 & n.s. & 0.46 & $* * *$ & 0.17 & $* * *$ & 0.50 & $* * *$ & 0.13 & $* *$ & $0.20 *$ & $* * *+$ & 0.43 & $* * *$ & 0.5 & $7{ }^{* * *}$ & $*-0$ & 0.17 & $* * *$ & +0.11 & ** & & & & & & & & & \\
\hline$R_{\text {MAX }} / E X T$ & +0.36 & $* *+$ & 0.30 & $* * *+$ & 0.24 & $* *$ & 0.04 & n.s. & 0.00 & n.s. & \begin{tabular}{|c|} 
\\
\end{tabular} & $* * *$ & 0.19 & $* *$ & 0.31 & $* * *$ & 0.14 & $*$ & 0.17 & $*$ & 0.11 & ${ }^{*}$ & 0.38 & $8^{* * *}$ & +0 & $0.00 \mathrm{r}$ & n.s. + & $\begin{array}{r}+0.01 \\
\end{array}$ & n.s. & & $0.54 *$ & *** & & & & & & \\
\hline$R_{\operatorname{mAX}}$ & +0.09 & $* * *+$ & 0.02 & $* *$ & 0.15 & $* *$ & $0.01 \mathrm{r}$ & n.s. - & 0.09 & n.s. & 0.06 & $* * *$ & 0.02 & $*$ & 0.05 & $* * *$ & 0.16 & $*$ & 0.03 & $*$ & 0.07 & $*$ & 0.08 & $8^{* * *}$ & $*+0$ & $0.00 \mathrm{r}$ & n.s. + & $\begin{array}{r}+0.09 \\
\end{array}$ & n.s. & & \begin{tabular}{l|l}
0.09 & $*$ \\
\end{tabular} & $* * *$ & 0.54 & $* * *$ & & & & \\
\hline EXT & 0.06 & $* * *$ & \begin{tabular}{|l|}
0.27 \\
\end{tabular} & $* * *+$ & $\begin{array}{ll} \\
\end{array}$ & $* *+$ & 0.03 & n.s. + & 0.00 & n.s. + & \begin{tabular}{|l|}
0.01 \\
\end{tabular} & $* * *+$ & 0.06 & $* *$ & 0.04 & $* *+$ & \begin{tabular}{|l|}
0.11 \\
\end{tabular} & $*+$ & +0.06 & $* *+$ & 0.00 & n.s. & +0.03 & $33^{* * * *}$ & $*+0$ & $0.01 \mathrm{r}$ & n.s. - & -0.01 & n.s. & +0. & \begin{tabular}{l|l}
0.12 & $*$ \\
\end{tabular} & $* * *$ & 0.47 & $* * *$ & 0.00 & $* *$ & & \\
\hline
\end{tabular}

s significance: ***, **, and $*=p<0.001,0.01,0.05$, and $\mathrm{n} . \mathrm{s}$. = not significant, $\mathrm{GY}$ grain yield, TKW thousand-kernel weight, $\mathrm{PC}$ WGF protein content of whole grain flour, $\mathrm{PC}$ Types5o protein content of flour Type $550, \mathrm{SV}$ sedimentation value, $\mathrm{WG}$ wet gluten, $\mathrm{FN}$ falling number, $\mathrm{WA}$

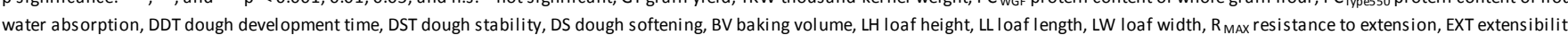


Tab 63. Correlation matrix for yield components, quality parameters of flour, flour components, and PA (+/- direction of trend, $\mathbf{R}^{2}$, significance) for all analyzed samples

\begin{tabular}{|c|c|c|c|c|c|c|c|c|c|c|c|c|c|c|c|c|c|c|c|c|c|c|c|c|c|c|c|c|c|c|c|c|c|c|c|c|}
\hline & GY & & TKW & & $\mathrm{PC}_{\mathrm{wg}}$ & & $\mathbf{P C}_{\text {Types }}$ & & SV & & WG & & $\mathrm{FN}$ & & WA & & DDT & & DST & & DS & & BV & & LH & & LL & & LW & & $R_{\operatorname{MAX}} / E X$ & & $\mathbf{R}_{\max }$ & & EXI & \\
\hline Starch & 0.00 & n.s. & 0.00 & n.s. & 0.28 & Tan & 0.33 & $* * *+$ & 0.02 & n.s. & 0.43 & ${ }^{* * *}+$ & 0.17 & $* * *$ & 0.55 & $* * *+$ & 0.15 & *** & 0.17 & **** & 0.09 & ** & 0.47 & *** & 0.20 & 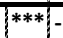 & 0.32 & *** & 0.22 & $*^{* * *}+$ & $+0.06 n$ & n.s. + & 0.00 & & 0.01 & n.s. \\
\hline Total Gluten & 0.01 & n.s. & 0.02 & n.s. & 0.01 & n.s. & 0.02 & n.s. + & 0.08 & $* *$ & 0.02 & n.s. + & 0.02 & n.s & 0.04 & n.s. + & 0.01 & n.s. & $0.00 \mathrm{r}$ & n.s & 0.00 & n.s. & 0.06 & $*$ & 0.09 & $* *$ & 0.02 & n.s. & 0.11 & ** & 0.13 & $*$ & 0.03 & ${ }^{*}$ & 0.01 & n.s. \\
\hline Total Gliadin & 0.26 & $* * *$ & 0.38 & $* * *$ & 0.02 & n.s. & 0.00 & n.s. & 0.00 & n.s. & 0.01 & n.s. + & 0.11 & $* * *$ & 0.02 & n.s. + & 0.01 & n.s. & $0.02 \mathrm{r}$ & n.s. & 0.05 & $*$ & 0.01 & n.s. & 0.00 & n.s. + & 0.01 & n.s. & 0.02 & n.s. & $0.01 \mathrm{n}$ & n.s. & 0.00 & n.s. + & 0.07 & n.s. \\
\hline$\omega 5$ & 0.01 & ** & 0.17 & $* * *$ & 0.07 & $* *$ & 0.04 & $*$ & 0.19 & $* * *+$ & 0.07 & $* *$ & 0.01 & n.s. & 0.11 & ** & 0.03 & n.s. & 0.06 & $*+$ & 0.00 & n.s. & 0.08 & $*$ & 0.05 & $*+$ & \begin{tabular}{|l|}
+0.13 \\
\end{tabular} & $* *$ & 0.02 & n.s. + & $0.03 \mathrm{n}$ & n.s. + & 0.19 & n.s. - & 0.09 & $\begin{array}{l}\text { in.s. } \\
\end{array}$ \\
\hline$\omega 1,2$ & 0.20 & $* * *$ & 0.20 & $* * *$ & 0.17 & $* * *+$ & 0.16 & $* * *$ & 0.01 & n.s. + & 0.11 & $* * *$ & 0.00 & n.s. + & 0.24 & $* * *$ & 0.09 & ** & 0.08 & $* *+$ & 0.01 & n.s. & 0.22 & $* * *$ & 0.12 & $* *$ & \begin{tabular}{|l|} 
\\
+0.23 \\
\end{tabular} & $* * *$ & 0.10 & $* *$ & $0.01 n$ & n.s. & 0.20 & n.s. + & 0.19 & n.s. \\
\hline$\alpha$ & 0.09 & $* *$ & 0.19 & *** & 0.03 & n.s. & 0.02 & n.s. & 0.00 & n.s. & 0.03 & n.s. + & 0.13 & $* * *$ & 0.06 & ${ }^{*}+$ & 0.00 & n.s. & $0.02 \mathrm{r}$ & n.s. & 0.02 & n.s. & 0.04 & n.s. + & 0.02 & n.s. & 0.00 & n.s. & 0.02 & n.s. & $0.01 n$ & n.s. & 0.19 & n.s. + & 0.13 & n.s. \\
\hline$\gamma$ & 0.30 & $* * *$ & 0.37 & $* * *$ & 0.28 & * & 0.00 & n.s. + & 0.00 & n.s. & 0.01 & n.s. + & 0.09 & ** & 0.04 & n.s. + & 0.03 & n.s. & 0.06 & $*$ & 0.08 & $* *$ & 0.02 & n.s. + & 0.00 & n.s. + & 0.00 & n.s. & 0.03 & n.s. & $0.04 n$ & n.s. & 0.12 & n.s. + & 0.00 & n.s. \\
\hline Total Glutenin & +0.22 & $* * *+$ & 0.26 & $* * *$ & 0.08 & $* *$ & 0.02 & n.s. + & 0.11 & $* *$ & 0.01 & n.s. & 0.04 & $*$ & 0.01 & n.s. + & 0.00 & n.s. & $0.02 r$ & n.s. + & 0.01 & n.s. & 0.03 & n.s. & 0.08 & * & 0.04 & n.s. & 0.04 & n.s. + & 0.16 & ${ }^{*}+$ & 0.07 & * & 0.05 & $*$ \\
\hline$\omega \mathrm{b}-\mathrm{GS}$ & +0.07 & $* *+$ & 0.14 & $* * *$ & 0.00 & n.s. & 0.03 & n.s. + & 0.01 & n.s. + & 0.05 & $*$ & 0.14 & $* *$ & 0.08 & $* *$ & 0.02 & n.s. & 0.09 & $* *+$ & 0.06 & * & 0.03 & n.s. & 0.00 & n.s. & 0.00 & n.s. + & 0.00 & n.s. + & +0.13 & $*$ & 0.08 & $*$ & 0.07 & $*$ \\
\hline HMW-GS & +0.11 & $* * *+$ & 0.15 & $* *$ & 0.05 & $*$ & 0.01 & n.s. + & 0.28 & $* *$ & 0.01 & n.s. & 0.01 & n.s. & 0.01 & n.s. + & 0.00 & n.s. & $0.02 \mathrm{r}$ & n.s. + & 0.02 & n.s. & 0.02 & n.s. + & 0.05 & $*$ & 0.02 & n.s. & 0.03 & n.s. + & $0.07 n$ & n.s. & 0.03 & n.s. & 0.02 & n.s. \\
\hline LMW-GS & +0.26 & $* * *+$ & 0.30 & $* * *$ & 0.10 & $* * *$ & 0.04 & n.s. + & 0.08 & $* *$ & 0.01 & n.s. & 0.04 & $*$ & 0.01 & n.s. + & 0.00 & n.s. & $0.02 \mathrm{r}$ & n.s. + & 0.01 & n.s. & 0.04 & n.s. + & 0.10 & $* *$ & 0.06 & $*$ & 0.05 & \begin{tabular}{|l|}
$*$ \\
\end{tabular} & 0.19 & $* *$ & 0.03 & n.s. & 0.06 & $*$ \\
\hline Gliadin/Glutenin & 0.15 & $* * *$ & 0.20 & $* *+$ & 0.07 & $* *$ & 0.02 & n.s. & 0.29 & $* *$ & 0.01 & n.s. + & 0.00 & n.s. & 0.01 & n.s. & 0.01 & n.s. & $0.00 \mathrm{r}$ & n.s. + & 0.00 & n.s. & 0.03 & n.s. & 0.06 & $*$ & 0.02 & n.s. + & 0.03 & n.s. & $0.02 n$ & n.s. & 0.10 & n.s. & 0.01 & n.s. \\
\hline LMW/HMW & +0.20 & $* * *+$ & 0.20 & $* *$ & 0.05 & $*$ & 0.02 & n.s. & 0.15 & $* *$ & 0.00 & n.s. & 0.08 & $* *$ & 0.00 & n.s. + & 0.00 & n.s. & 0.00 & n.s. & 0.00 & n.s. & 0.02 & n.s. & 0.04 & n.s. & 0.07 & * & 0.01 & n.s. + & 0.16 & $*$ & 0.09 & $*$ & 0.09 & $* *$ \\
\hline PA & 0.08 & n.s. & 0.41 & $* * *$ & 0.05 & n.s. + & 0.00 & n.s. + & 0.00 & n.s. + & 0.04 & n.s. + & 0.07 & n.s. + & 0.05 & n.s. + & 0.04 & n.s. & $0.01 \mathrm{r}$ & n.s. + & 0.07 & n.s. + & 0.00 & n.s. & 0.24 & $* *$ & 0.00 & n.s. & 0.13 & $*$ & 0.28 & ** & 0.10 & \begin{tabular}{|c|}
$* *$ \\
\end{tabular} & 0.06 & $* *$ \\
\hline$s$ & 0.56 & $* * *$ & 0.37 & $* * *$ & 0.62 & ${ }^{* * *+}+$ & 0.62 & $* * *+$ & 0.01 & n.s. + & 0.49 & $* * *$ & 0.17 & $* *$ & 0.57 & $* *$ & 0.17 & $* *$ & 0.22 & $* * *+$ & 0.03 & n.s. & 0.50 & $* * *$ & 0.39 & $* * *$ & +0.41 & $* *+$ & 0.27 & $* * *$ & $0.02 r$ & n.s. & 0.09 & n.s. + & 0.10 & n.s. \\
\hline $\mathrm{N} / \mathrm{s}$ & 0.14 & $* *$ & 0.07 & $*$ & 0.21 & $* * *+$ & 0.30 & $* * *+$ & 0.00 & n.s. + & 0.16 & $* * *+$ & 0.02 & n.s. + & 0.23 & $* * *+$ & 0.04 & n.s. & 0.01 & n.s. & 0.06 & n.s. + & 0.25 & $* * *$ & 0.07 & $*$ & \begin{tabular}{|l|}
+0.12 \\
\end{tabular} & $* *+$ & 0.00 & n.s. & $0.00 \mathrm{r}$ & n.s. + & $\begin{array}{l}0.02 \\
\end{array}$ & n.s. + & 0.09 & n.s. \\
\hline
\end{tabular}


Tab 64. Correlation matrix for flour components, and PA (+/- direction of trend, $\mathbf{R}^{2}$, significance) for all analyzed samples

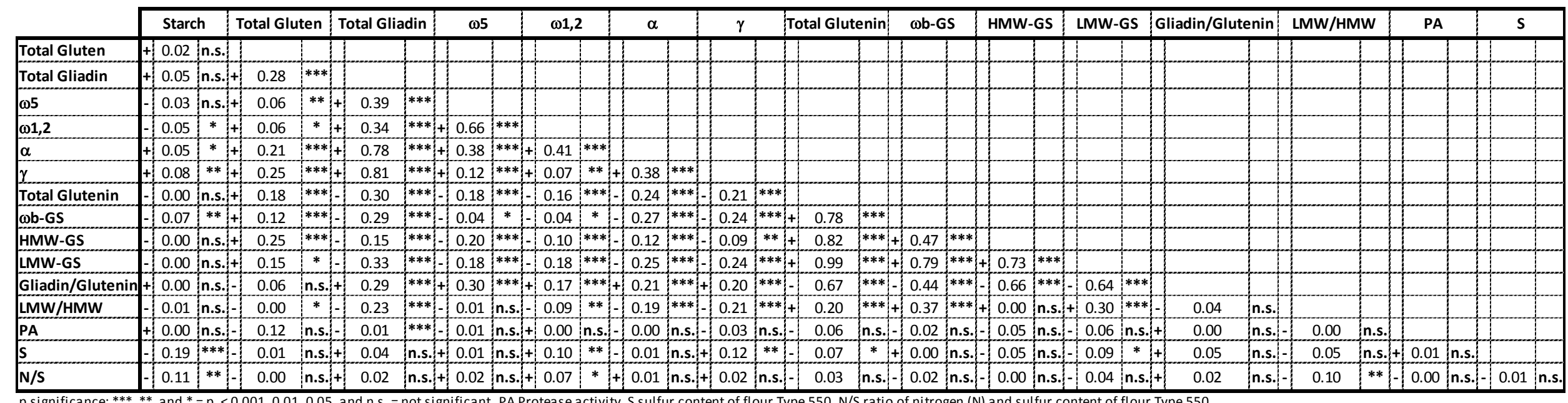

p significance: *****, and * $=\mathrm{p}<0.001,0.01,0.05$, and $\mathrm{n} s$ = not significant, PA Protease activity, $\mathrm{S}$ sulfur content of flour Type $550 \mathrm{~N} / \mathrm{S}$ ratio of nitrogen (N) and sulfur content of flour Type 550 
Tab 65. Mineral $N\left(N_{\min }\right)$ content of soil $(90 \mathrm{~cm}$ depth) after different pre-crops (MV of two locations) and fertilization regime with urea-ammonium nitrate (UAN) at different growth stages (GS) according to BBCH

\begin{tabular}{ccccc}
\hline N partition & Pre-crop & 2007 & 2008 & 2009 \\
\hline \multirow{3}{*}{$\mathrm{N}_{\min }\left(\mathrm{kg} \mathrm{ha}^{-1}\right)$} & Wheat & - & 71 & 84 \\
& Maize & - & 51 & 69 \\
& Sugar beet & - & 55 & 60 \\
\hline \multirow{2}{*}{$1^{\text {st }} \mathrm{N}$ donation } & $\mathrm{GS}$ & 29 & 23 & 21 \\
& $\mathrm{UAN}\left(\mathrm{kg} \mathrm{ha}^{-1}\right)$ & 60 & 60 & 60 \\
\hline \multirow{2}{*}{$2^{\text {nd }} \mathrm{N}$ donation } & $\mathrm{GS}$ & $31 / 32$ & 29 & 27 \\
& $\mathrm{UAN}\left(\mathrm{kg} \mathrm{ha}^{-1}\right)$ & 60 & 60 & 70 \\
\multirow{2}{*}{$3^{\text {rd }} \mathrm{N}$ donation } & $\mathrm{GS}$ & 39 & 39 & 49 \\
\hline \multirow{2}{*}{ Total N $\left(\mathrm{kg} \mathrm{ha}^{-1}\right)$} & $\mathrm{UAN}\left(\mathrm{kg} \mathrm{ha}^{-1}\right)$ & 65 & 60 & 60 \\
without $\mathrm{N}_{\text {min }}$ & & 185 & 180 & 190 \\
\hline
\end{tabular}

Tab 66. Grain yield (GY), thousand-kernel weight (TKW), sulfur content (S), and ratio of nitrogen:sulfur content (N/S) of flour Type $550(\mathrm{MV} \pm \mathrm{SD}, \mathrm{n}=6)$ from cv. Centrum and cv. Ritmo grown after different pre-crops in 2007, 2008, and 2009

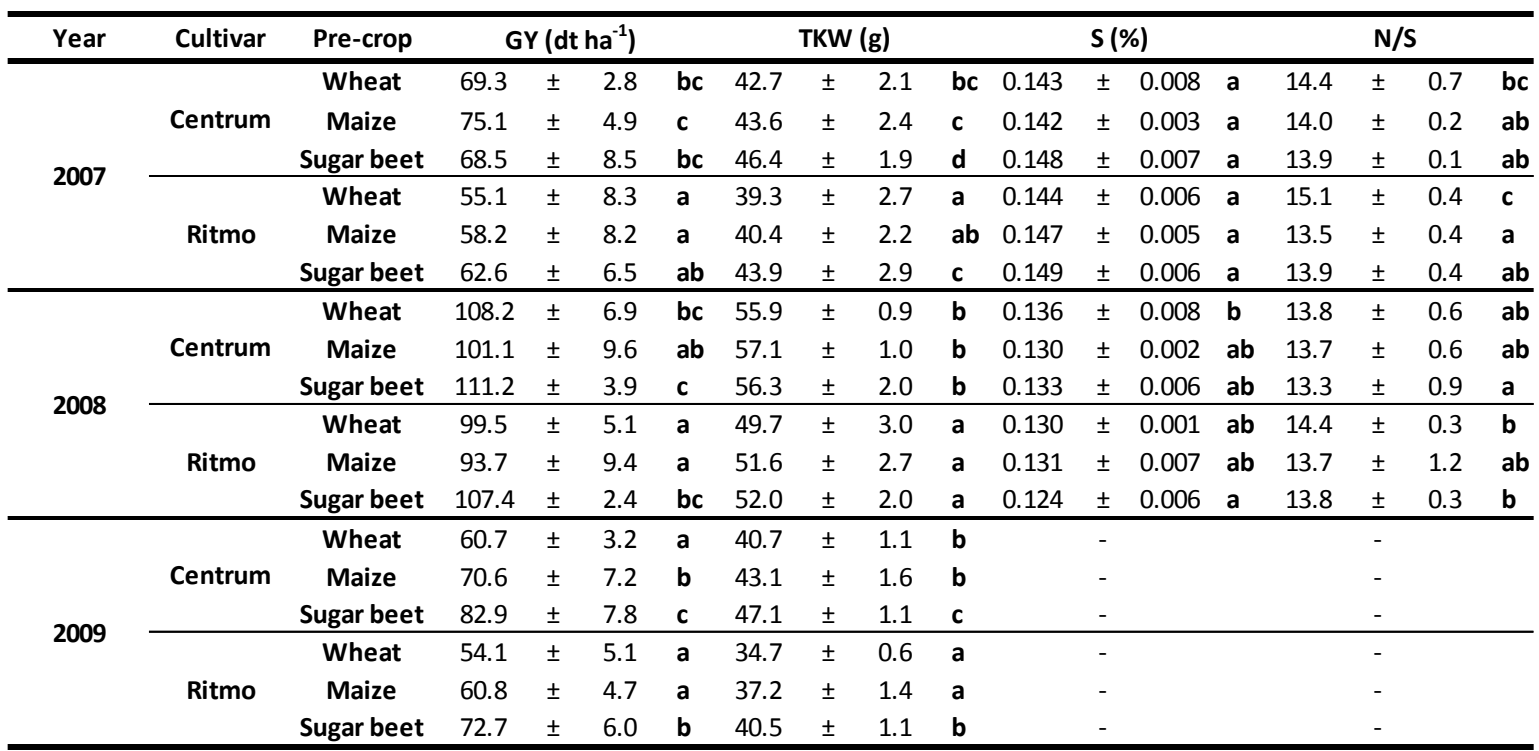

GY grain yield, TKW thousand-kernel weight, S sulfur content of flour Type 550, N/S ratio of nitrogen (N) and sulfur (S) content of flour Type 550 , same letters indicate no differences between cultivars and pre-crops within years at a significance level of $p<0.05$ according to Tukey test

Tab 67. Linear relationship between quality parameters and sulfur content (S) of flour Type 550 and grain yield (GY)

\begin{tabular}{lclccc}
\hline Dependent variable & $\mathbf{n}$ & Independent variable & Trend & $\mathbf{R}^{2}$ & $\mathbf{p}$ \\
\hline PC $_{\text {WGF }}$ & 72 & & + & 0.62 & $* * *$ \\
PC $_{\text {Type550 }}$ & 72 & & + & 0.62 & $* * *$ \\
WA & 60 & & + & 0.57 & $* * *$ \\
BV & 60 & & + & 0.50 & $* * *$ \\
\hline & 108 & TKW & + & 0.75 & $* * *$ \\
GY & 108 & $\mathrm{PC}_{\text {WGF }}$ & - & 0.54 & $* * *$ \\
& 72 & $\mathrm{~S}$ & - & 0.56 & $* * *$ \\
\hline
\end{tabular}

$n$ number of observations, $p$ significance: ${ }^{* * *}=p<0.001, P_{\text {WFG }}$ protein content of whole grain flour, $\mathrm{PC}_{\text {Types50 }}$ protein content of flour Type 550, WA water absorption, BV baking volume, $\mathrm{S}$ sulfur, GY grain yield 


\section{References}

Anonymus (2001) Primer on statistical significance and P values Effective clinical practice 4: 183184.

Anonymus (2011) Gladio® Bravo @ Pack (Syngenta) Retrieved 03/03/2011 from http://www.syngenta.de/syngenta_infos/pdf_dateien/prd_ga/ga_gladio_bravo_pack_de.pdf

Abbas, H. K., C. J. Mirocha, R. J. Pawlosky and D. J. Pusch (1985) Effect of cleaning, milling, and baking on deoxynivalenol in wheat Applied and Environmental Microbiology 50: 482-486.

Abedi, T., A. Alemzadeh and S. A. Kazemeyni (2011) Wheat yield and grain protein response to nitrogen amount and timing Australian Journal of Crop Science 5: 327-333.

Adejumo, T. O., U. Hettwer and P. Karlovsky (2007) Survey of maize from south-western Nigeria for zearalenone, alpha- and beta-zearalenols, fumonisin B-1 and enniatins produced by Fusarium species Food Additives and Contaminants 24: 993-1000.

Anjum, F. M., M. R. Khan, A. Din, M. Saeed, I. Pasha and M. U. Arshad (2007) Wheat gluten: high molecular weight glutenin subunits-structure, genetics, and relation to dough elasticity Journal of Food Science 72: R56-R63.

Antes, S., B. Birzele, A. Prange, J. Krämer, A. Meier, H.-W. Dehne and P. Köhler (2001) Rheological and breadmaking properties of wheat samples infected with Fusarium spp. Mycotoxin Research 17: 76-80.

Argyris, J., D. Van Sanford and D. TeKrony (2003) Fusarium graminearum infection during wheat seed development and its effect on seed quality Crop Science 43: 1782-1788.

Aufhammer, W., E. Kübler, H.-P. Kaul, W. Hermann, D. Höhn and C. Yi (2000) Ährenbefall mit Fusarien ( $F$. graminearum, $F$. culmorum) in Deoxynivalenolgehalt in Korngut von Winterweizen in Abhängigkeit von der N-Düngung Pflanzenbauwissenschaften 4: 72-78.

Axford, D. W. E., E. E. McDermott and D. G. Redman (1979) Sodium dodecyl sulfate test of breadmaking quality - comparison with Pelshenke and Zeleny tests Cereal Chemistry 56: 582-584.

Ayoub, M., S. Guertin, J. Fregeaureid and D. L. Smith (1994) Nitrogen fertilizer effect on breadmaking quality of hard red spring wheat in eastern Canada Crop Science 34: 1346-1352.

Bai, G. H., R. Plattner, A. Desjardins and F. Kolb (2001) Resistance to Fusarium head blight and deoxynivalenol accumulation in wheat Plant Breeding 120: 1-6.

Bai, G. H. and G. Shaner (1994) Scab of Wheat - Prospects for Control Plant Disease 78: 760766. 
Bai, G. H. and G. Shaner (2004) Management and resistance in wheat and barley to Fusarium head blight Annual Review of Phytopathology 42: 135-161.

Barrier-Guillot, B., M. Delambre, A. Morel, C. Maumere, H. Gouet, F. Grosjean and M. Leuillet (2004). Occurrence of deoxynivalenol in wheat (Triticum aestivum) grown in France and identification of factors involved in content variations. In: An Overview on Toxigenic Fungi and Mycotoxins in Europe. (Ed.) A. Logrieco and A. Visconti. Dordrecht, The Netherlands, Kluwer Academic Publishers: 101-108.

Bechtel, D. B., L. A. Kaleikau, R. L. Gaines and L. M. Seitz (1985) The Effects of Fusarium graminearum Infection on Wheat Kernels Cereal Chemistry 62: 191-197.

Beck, R. and J. Lepschy (2000). Ergebnisse aus dem Fusarium-Monitoring 1989-1999-Einfluss der produktionstechnischen Faktoren Fruchtfolge und Bodenbearbeitung. In: Schriftenreihe der Bayerischen Landesanstalt für Bodenkultur und Pflanzenbau. (Ed.) Bayerische Landesanstalt für Bodenkultur und Pflanzenbau. Freising und München: 39-47.

Belitz, H.-D., W. Grosch and P. Schieberle (Ed.) (2009). Food Chemistry. Berlin Heidelberg, Springer-Verlag: 670-745

Berova, S. and M. Mladenov (1974) Influence of wheat ear and grain Fusariosis (Fusarium graminearum Schwabe) on the chemical, technological and baking qualities (in Bulgarian) Rastenievudni Nauki 11: 125-133.

Beyer, M., M. B. Klix, H. Klink and J. A. Verreet (2006) Quantifying the effects of previous crop, tillage, cultivar and triazole fungicides on the deoxynivalenol content of wheat grain - a review Journal of Plant Diseases and Protection 113: 241-246.

Bhatt, G. M. and N. F. Derera (1975) Genotype x environment interactions for, heritabilities of, and correlations among quality traits in wheat Euphytica 24: 597-604.

Bly, A. G. and H. J. Woodard (2003) Foliar nitrogen application timing influence on grain yield and protein concentration of hard red winter and spring wheat Agronomy Journal 95: 335-338.

BMELV (2009). Statistisches Jahrbuch über Ernährung, Landwirtschaft und Forsten 2009 Bremerhaven, Wirtschaftverlag NW GmbH.

Bockmann, H. (1964) Qualität und Backfähigkeit von Weizen bei Befall von Septoria nodorum Berk. und Fusarium culmorum Link (in German) Nachrichtenblatt des Deutschen Pflanzenschutzdienstes 16: 5-10.

Bottalico, A. (1998) Fusarium diseases of cereals: Species complex and related mycotoxin profiles, in Europe Journal of Plant Pathology 80: 85-103. 
Bottalico, A. and G. Perrone (2002) Toxigenic Fusarium species and mycotoxins associated with head blight in small-grain cereals in Europe European Journal of Plant Pathology 108: 611-624.

Boutigny, A. L., F. Richard-Forget and C. Barreau (2008) Natural mechanisms for cereal resistance to the accumulation of Fusarium trichothecenes European Journal of Plant Pathology 121: 411-423.

Boyacioglu, D. and N. S. Hettiarachchy (1995) Changes in some Biochemical Components of Wheat Grain that was infected with Fusarium graminearum Journal of Cereal Science 21: 57-62.

Boyacioglu, D., N. S. Hettiarachchy and B. L. Dappolonia (1993) Additives affect deoxynivalenol (vomitoxin) flour during breadbaking Journal of Food Science 58: 416-418.

Brandfass, C. and P. Karlovsky (2006) Simultaneous detection of Fusarium culmorum and Fgraminearum in plant material by duplex PCR with melting curve analysis Bmc Microbiology 6.

Brandfass, C. and P. Karlovsky (2008) Upscaled CTAB-Based DNA Extraction and Real-Time PCR Assays for Fusarium culmorum and F. graminearum DNA in Plant Material with Reduced Sampling Error International Journal of Molecular Sciences 9: 2306-2321.

Brooker, B. E. (1996) The Role of Fat in the Stabilisation of Gas Cells in Bread Dough Journal of Cereal Science 24: 187-198.

BSA (2007). Beschreibende Sortenliste Getreide, Mais, Ölfrüchte, Leguminosen (grobkörnig), Hackfrüchte (außer Kartoffeln). Hannover, Deutscher Landwirtschaftsverlag.

Buerstmayr, H., T. Ban and J. A. Anderson (2009) QTL mapping and marker-assisted selection for Fusarium head blight resistance in wheat: a review Plant Breeding 128: 1-26.

Burlakoti, R. R., R. Estrada, V. V. Rivera, A. Boddeda, G. A. Secor and T. B. Adhikari (2007) Real-time PCR quantification and mycotoxin production of Fusarium graminearum in wheat inoculated with isolates collected from potato, sugar beet, and wheat Phytopathology 97: 835-841.

Büttner, P. (2006) Das Artenspektrum der Gattung Fusarium an Weizen und Roggen in Bayern in den Jahren 2003 und 2004 Gesunde Pflanzen 58: 28-33.

Buyanovsky, G. and G. Wagner (1986) Post-harvest residue input to cropland Plant and Soil 93: $57-65$.

Campbell, C. A., D. R. Cameron, W. Nicholaichuk and H. R. Davidson (1977) Effects of fertilizer $\mathrm{N}$ and soil moisture on growth, $\mathrm{N}$ content, and moisture use by spring wheat Canadian Journal of Soil Science 57: 289-310.

Casale, W. L. and L. P. Hart (1988) Inhibition of 3H-leucine incorporation by trichothecene mycotoxins in maize and wheat tissue Phytopathology 78: 1673-1677. 
Chilosi, G., C. Caruso, C. Caporale, L. Leonardi, L. Bertini, A. Buzi, M. Nobile, P. Magro and V. Buonocore (2000) Antifungal activity of Bowman-Birk-type trypsin inhibitor from wheat kernel Journal of Phytopathology 148: 477-481.

Christ, D. S., R. Goedeck, A. von Tiedemann and M. Varrelmann (2011a) Pathogenicity, symptom development, and mycotoxin formation in wheat by Fusarium species frequently isolated from sugar beet Phytopathology in press.

Christ, D. S., B. Maerlaender and M. Varrelmann (2011b) Characterization and mycotoxigenic potential of Fusarium species in freshly-harvested and stored sugar beet in Europe Phytopathology in press.

Clarke, J. M., C. A. Campbell, H. W. Cutforth, R. M. Depauw and G. E. Winkleman (1990) Nitrogen and phosphorus uptake, translocation, and utilizatiob efficiency of wheat in relation to environment and cultivar yield and protein levels Canadian Journal of Plant Science 70: 965-977.

Daniel, C. and E. Triboi (2000) Effects of temperature and nitrogen nutrition on the grain composition of winter wheat: Effects on gliadin content and composition Journal of Cereal Science 32: $45-56$.

De Wolf, E. D., L. V. Madden and P. E. Lipps (2003) Risk assessment models for wheat Fusarium head blight epidemics based on within-season weather data Phytopathology 93: 428-435.

Delgado, J. A., P. B. Schwarz, J. Gillespie, V. V. Rivera-Varas and G. A. Secor (2010) Trichothecene Mycotoxins Associated with Potato Dry Rot Caused by Fusarium graminearum Phytopathology 100: 290-296.

Dencic, S., N. Mladenov and B. Kobiljski (2011) Effects of genotype and environment on breadmaking quality in wheat International Journal of Plant Production 5: 71-81.

Dexter, J. E., R. M. Clear and K. R. Preston (1996) Fusarium head blight: Effect on the milling and baking of some Canadian wheats Cereal Chemistry 73: 695-701.

Dexter, J. E. and R. R. Matsuo (1977) Influence of protein content on some durum wheat quality parameters Canadian Journal of Plant Science 57: 717-727.

Dexter, J. E. and T. W. Nowicki (2003). Safety Assurance and Quality Assurance Issues Associated with Fusarium Head Blight in Wheat.In: Fusarium Head Blight of Wheat and Barley. (Ed.) K. J. Leonard and W. R. Bushnell. St. Paul, APS Press: 420-460.

Dill-Macky, R. and R. K. Jones (2000) The effect of previous crop residues and tillage on Fusarium head blight of wheat Plant Disease 84: 71-76. 
Dimmock, J. and M. J. Gooding (2002) The effects of fungicides on Hagberg falling number and blackpoint in winter wheat Crop Protection 21: 475-487.

Doohan, F. M., J. Brennan and B. M. Cooke (2003) Influence of climatic factors on Fusarium species pathogenic to cereals European Journal of Plant Pathology 109: 755-768.

Eckert, B., T. Amend and H. D. Belitz (1993) The course of the SDS and Zeleny sedimentation tests for gluten quality and related phenomena studies using the light microscope Zeitschrift für Lebensmittel-Untersuchung und -Forschung 196: 122-125.

Edwards, S. G. (2004) Influence of agricultural practices on Fusarium infection of cereals and subsequent contamination of grain by trichothecene mycotoxins Toxicology Letters 153: 29-35.

Edwards, S. G. and N. P. Godley (2010) Reduction of Fusarium head blight and deoxynivalenol in wheat with early fungicide applications of prothioconazole Food Additives and Contaminants Part a-Chemistry Analysis Control Exposure \& Risk Assessment 27: 629-635.

Edwards, S. G., S. R. Pirgozliev, M. C. Hare and P. Jenkinson (2001) Quantification of trichothecene-producing Fusarium species in harvested grain by competitive PCR to determine efficacies of fungicides against Fusarium head blight of winter wheat Applied and Environmental Microbiology 67: 1575-1580.

Eggert, K., H. M. Rawel and E. Pawelzik (2011) In vitro degradation of wheat gluten fractions by Fusarium graminearum proteases European Food Research and Technology in press.

Eggert, K., H. Wieser and E. Pawelzik (2010) The influence of Fusarium infection and growing location on the quantitative protein composition of (part I) emmer (Triticum dicoccum) European Food Research and Technology 230: 837-847.

Elbanna, A. A., P. Y. Lau and P. M. Scott (1983) Fate of mycotoxins during processing of foodstuffs 2. Deoxynivalenol (vomitoxin) during making of Egyptian bread Journal of Food Protection 46: 484-486.

EMAN (2011) Deoxynivalenol. Basic Factsheet. Naturally Occurring Deoxynivalenol and Related Compounds. Retrieved 03/07/2011, from http://services.leatherheadfood.com/mycotoxins/display.asp?factsheetid=9\&noback=yes\&strFiltera =deoxynivalenol.

Eriksen, G. S. and H. Pettersson (2004) Toxicological evaluation of trichothecenes in animal feed Animal Feed Science and Technology 114: 205-239.

FAO (2011) Dimesions of need - An atlas for food and agriculture. Staple foods: What do people eat? Retrieved 01/03/2011, from http://www.fao.org/docrep/u8480e/u8480e07.htm. 
Finney, K. F. (1954) Physical, chemical, and baking properties of flours milled from scabby wheat In: 17th Ann. Rep. Hard Winter Wheat Quality Lab. USDA/ARS 1953. crop. Kansas Agric. Exp. Stn., Manhattan.

Finney, K. F. and M. A. Barmore (1948) Loaf volume and protein content of hard winter and spring wheats Cereal Chemistry 25: 291-312.

Finney, K. F., J. W. Meyer, F. M. Smith and H. C. Fryer (1957) Effects of foliar spraying of Pawnee wheat with urea solutions on yield, protein content, and protein quality Agronomy Journal 49: 341-347.

Foroud, N. A. and F. Eudes (2009) Trichothecenes in Cereal Grains International Journal of Molecular Sciences 10: 147-173.

Fuertes-Mendizabal, T., A. Aizpurua, M. B. Gonzalez-Moro and J. M. Estavillo (2010) Improving wheat breadmaking quality by splitting the $\mathrm{N}$ fertilizer rate European Journal of Agronomy 33: 52-61.

Gang, G., T. Miedaner, U. Schuhmacher, M. Schollenberger and H. H. Geiger (1998) Deoxynivalenol and nivalenol production by Fusarium culmorum isolates differing in aggressiveness toward winter rye Phytopathology 88: 879-884.

Gartner, B. H., M. Munich, G. Kleijer and F. Mascher (2008) Characterisation of kernel resistance against Fusarium infection in spring wheat by baking quality and mycotoxin assessments European Journal of Plant Pathology 120: 61-68.

Gauer, L. E., C. A. Grant, D. T. Gehl and L. D. Bailey (1992) Effects of nitrogen fertilization on grain protein content, nitrogen uptake, and nitrogen use efficiency of six spring wheat (Triticum aestivum L.) cultivars, in relation to estimated moisture supply Canadian Journal of Plant Science 72: $235-241$.

Gervais, L., F. Dedryver, J. Y. Morlais, V. Bodusseau, S. Negre, M. Bilous, C. Groos and M. Trottet (2003) Mapping of quantitative trait loci for field resistance to Fusarium head blight in an European winter wheat Theoretical and Applied Genetics 106: 961-970.

Gilbert, J. and A. Tekauz (2000) Review: Recent developments in research on Fusarium head blight of wheat in Canada Canadian Journal of Plant Pathology-Revue Canadienne De Phytopathologie 22: 1-8.

GMF (2004) Brotvielfalt: Kleiner Führer durch die deutschen Brot- und Brötchenlande. Retrieved 02/03/2011, from http://www.gmf-info.de/frames.htm.

Gödecke, R. (2010). Einflussfaktoren der Mykotoxinbildung durch Ährenbefall mit Fusarium spp. in verschiedenen Winterweizenfruchtfolgen (in German). $\mathrm{PhD}$ thesis. Göttingen. 
Gödecke, R. and A. von Tiedemann (2011) Effect of the previous crop on Fusarium spectrum and mycotoxin contamination in grains of winter wheat Zuckerindustrie 136: 172-178.

Goesaert, H., K. Brijs, W. S. Veraverbeke, C. M. Courtin, K. Gebruers and J. A. Delcour (2005) Wheat flour constituents: How they impact bread quality, and how to impact their functionality Trends in Food Science \& Technology 16: 16-30.

Gosman, N. E. (2001). Analysis of the genetic basis of resistance to Fusarium culmorum in wheat. $\mathrm{PhD}$ thesis. University of East Anglia, UK.

Goswami, R. and H. Kistler (2004) Heading for disaster: Fusarium graminearum on cereal crops Molecular plant pathology 5: 515-525.

Grant, C. A., K. R. Brown, G. J. Racz and L. D. Bailey (2001) Influence of source, timing and placement of nitrogen on grain yield and nitrogen removal of durum wheat under reduced-and conventional-tillage management Canadian Journal of Plant Science 81: 17-27.

Grausgruber, H., M. Oberforster, M. Werteker, P. Ruckenbauer and J. Vollmann (2000) Stability of quality traits in Austrian-grown winter wheats Field Crops Research 66: 257-267.

Groth, J. V., E. A. Ozmon and R. H. Busch (1999) Repeatability and relationship of incidence and severity measures of scab of wheat caused by Fusarium graminearum in inoculated nurseries Plant Disease 83(11): 1033-1038.

Hagberg, S. (1960) A rapid method for determining alpha-amylase activity Cereal Chemistry 37: 218-222.

Hallmann, J., A. Quadt-Hallmann and A. Von Tiedemann (2007). Phytomedizin. Grundwissen Bachelor. Stuttgart, GE.

Hamilton, R. M. G. and H. L. Trenholm (1984) Observations on the Chemical and Nutritive Content of White Winter and Spring Wheats Contaminated with Deoxynivalenol (Vomitoxin) Animal Feed Science and Technology 11: 293-300.

Hart, L. P. and W. E. Braselton (1983) Distribution of vomitoxin in dry milled fractions of wheat infected with Gibberella zeae Journal of Agricultural and Food Chemistry 31: 657-659.

Hartl, L. (2010) Die Bedeutung des Proteingehaltes von Backweizen aus Sicht der Landwirtschaft Getreidetechnologie 64: 111-114.

Hermann, W., W. Aufhammer, E. Kübler and H.-P. Kaul (1999) Auswirkungen von Ährenbefall mit Fusarium graminearum auf die Kornqualität von Winterweizen, Wintertriticale und Winterroggen Pflanzenbauwissenschaften 3: 82-87. 
Hilton, A. J., P. Jenkinson, T. W. Hollins and D. W. Parry (1999) Relationship between cultivar height and severity of Fusarium ear blight in wheat Plant Pathology 48: 202-208.

Homdork, S., H. Fehrmann and R. Beck (2000) Influence of Different Storage Conditions on the Mycotoxin Production and Quality of Fusarium-Infected Wheat Grain Journal of Phytopathology 148: 7-15.

Horberg, H. M. (2002) Patterns of splash dispersed conidia of Fusarium poae and Fusarium culmorum European Journal of Plant Pathology 108: 73-80.

Huebner, F. R., J. Kaczkowski and J. A. Bietz (1990) Quantitative variation of wheat proteins from grain at different stages of maturity and from different spike locations Cereal Chemistry 67: 464-470.

Huff, W. E. and W. M. Hagler (1985) Density segregation of corn and wheat naturally contaminated with aflatoxin, deoxynivalenol and zearalenone Journal of Food Protection 48: 416420.

ICC (Ed.) (1999). Standard Methods of the International Association for Cereal Science and Technology (ICC). Vienna, ICC.

Ichinoe, M., H. Kurata, Y. Sugiura and Y. Ueno (1983) Chemotaxonomy of Gibberella zeae with special reference to production of trichothecenes and zearalenone Applied and Environmental Microbiology 46: 1364-1369.

Jones, B. L. (2005) Endoproteases of barley and malt Journal of Cereal Science 42: 139-156.

Jones, B. L., D. Fontanini, M. Jarvinen and A. Pekkarinen (1998) Simplified endoproteinase assays using gelatin or azogelatin Analytical Biochemistry 263: 214-220.

Jones, R. K. and C. J. Mirocha (1999) Quality parameters in small grains from Minnesota affected by Fusarium head blight Plant Disease 83: 506-511.

Jovicevic, B. (1972) Influence of Fusarium graminearum chw. on biological and technological characteristics of wheat grain (in Croatian) Zastita Bilja 23: 305-309.

Kang, Z. and H. Buchenauer (2000b) Ultrastructural and cytochemical studies on cellulose, xylan and pectin degradation in wheat spikes infected by Fusarium culmorum Journal of Phytopathology-Phytopathologische Zeitschrift 148: 263-275.

Kang, Z. S. and H. Buchenauer (2000) Cytology and ultrastructure of the infection of wheat spikes by Fusarium culmorum Mycological Research 104: 1083-1093.

Karpenstein-Machan, M. and C. Weber (2010) Energiepflanzenanbau für Biogasanlagen Naturschutz und Landschaftsplanung 42: 312-320. 
Kieffer, R., H. D. Belitz, M. Zweier, R. Ipfelkofer and G. Fischbeck (1993) A 10-g Microversion of the Rapid-Mix-Test Zeitschrift Fur Lebensmittel-Untersuchung Und-Forschung 197: 134-136.

Kieffer, R., J.-J. Kim and H. D. Belitz (1981) Zugversuche mit Weizenkleber im Mikromaßstab Zeitschrift Fur Lebensmittel-Untersuchung Und-Forschung 172: 190-192.

Kieffer, R., H. Wieser, M. H. Henderson and A. Graveland (1998) Correlations of the breadmaking performance of wheat flour with rheological measurements on a micro-scale Journal of Cereal Science 27: 53-60.

Klix, M. B., M. Beyer and J.-A. Verreet (2008) Effects of cultivar, agronomic practices, geographic location, and meteorological conditions on the composition of selected Fusarium species on wheat heads Canadian Journal of Plant Pathology 30: 46-57.

Klotzel, M., U. Lauber and H. U. Humpf (2006) A new solid phase extraction clean-up method for the determination of 12 type A and B trichothecenes in cereals and cereal-based food by LCMS/MS Molecular Nutrition \& Food Research 50: 261-269.

Koch, H. J., C. Pringas and B. Maerlaender (2006) Evaluation of environmental and management effects on Fusarium head blight infection and deoxynivalenol concentration in the grain of winter wheat European Journal of Agronomy 24: 357-366.

Koh, A., K. Nishimura and R. Urade (2010) Relationship between endogenous protein disulfide isomerase family proteins and glutenin macropolymer Journal of Agricultural and Food Chemistry 58: 12970-12975.

Kolb, F. L., G. H. Bai, G. J. Muehlbauer, J. A. Anderson, K. P. Smith and G. Fedak (2001) Host plant resistance genes for Fusarium head blight: Mapping and manipulation with molecular markers Crop Science 41: 611-619.

Kushiro, M. (2008) Effects of Milling and Cooking Processes on the Deoxynivalenol Content in Wheat International Journal of Molecular Sciences 9: 2127-2145.

Lacey, J., G. L. Bateman and C. J. Mirocha (1999) Effects of infection time and moisture on development of ear blight and deoxynivalenol production by Fusarium spp. in wheat Annals of Applied Biology 134: 277-283.

Lancova, K., J. Hajslova, M. Kostelanska, J. Kohoutkova, J. Nedelnik, H. Moravcova and M. Vanova (2008) Fate of trichothecene mycotoxins during the processing: Milling and baking Food Additives and Contaminants 25: 650-659. 
Lemmens, M., K. Haim, H. Lew and P. Ruckenbauer (2004) The effect of nitrogen fertilization on Fusarium head blight development and deoxynivalenol contamination in wheat Journal of Phytopathology 152: 1-8.

Lidell, C. M. (2003) Systematics of Fusarium species and allies associated with Fusarium head blight. In: Fusarium head blight of wheat and barley (Ed.) K. J. Leonard and W. R. Bushnell. St. Paul, Minnesota, USA, APS Press: 35-43.

Lienemann, K., E. C. Oerke and H. W. Dehne (2001) Variation in the spectrum of Fusarium species on winter wheat Mycotoxin Research 17: 5-9.

Lindhauer, M. (2009) Brotweizenqualität: Aktueller Status und Perspektiven. In: Schriftenreihe des Instituts für Pflanzenbau und -züchtung der CAU Kiel: Norddeutsches Weizenforum 2009 (Ed.) H. Kage and F. Hollmann. Kiel, Germany, Instituts für Pflanzenbau und -züchtung der CAU Kiel: 139-145.

Littel, R. C., G. A. Milliken, W. W. Stroup, R. D. Wolfinger and O. Schabenberger (2006) SAS for Mixed Models. Cary, NC, USA, SAS Institue Inc.

Liu, W. Z., W. Langseth, H. Skinnes, O. N. Elen and L. Sundheim (1997) Comparison of visual head blight ratings, seed infection levels, and deoxynivalenol production for assessment of resistance in cereals inoculated with Fusarium culmorum European Journal of Plant Pathology 103: 589-595.

Logrieco, A., G. Mulè, A. Moretti and A. Bottalico (2002) Toxigenic Fusarium species and mycotoxins associated with maize ear rot in Europe European Journal of Plant Pathology 108: 597-609.

Magan, N., R. Hope, A. Colleate and E. S. Baxter (2002) Relationship between growth and mycotoxin production by Fusarium species, biocides and environment European Journal of Plant Pathology 108: 685-690.

Martin, R. A., J. A. Macleod and C. Caldwell (1991) Influence of productions inputs on incidence of infection by Fusarium species on cereal seed Plant Disease 75: 784-788.

Matthaus, K., S. Danicke, W. Vahjen, O. Simon, J. Wang, H. Valenta, K. Meyer, A. Strumpf, H. Ziesenib and G. Flachowsky (2004) Progression of mycotoxin and nutrient concentrations in wheat after inoculation with Fusarium culmorum Archives of Animal Nutrition 58: 19-35.

Matthies, A. and H. Buchenauer (2000) Effect of tebuconazole (Folicur (R)) and prochloraz (Sportak (R)) treatments on Fusarium head scab development, yield and deoxynivalenol (DON) content in grains of wheat following artificial inoculation with Fusarium culmorum Zeitschrift Fur Pflanzenkrankheiten Und Pflanzenschutz-Journal of Plant Diseases and Protection 107: 33-52. 
McMullen, M., R. Jones and D. Gallenberg (1997) Scab of wheat and barley: A re-emerging disease of devastating impact Plant Disease 81: 1340-1348.

Meier, A., B. Birzele, E. C. Oerke and H. W. Dehne (2000) Impact of growth conditions on the occurrence of Fusarium spp. and the mycotoxin content of wheat Mycotoxin Research 16: 12-15.

Mesterhazy, A. (1995) Types and components of resistance to Fusarium head blight of wheat Plant Breeding 114: 377-386.

Mesterhazy, A. (2003). Breeding for for Fusarium head blight resistance in Europe. In: Fusarium head blight of wheat and barely. (Ed.) K. J. Leonard and W. R. Bushnell. St. Paul, Minnesota, USA, APS Press: 363-381

Meyer, D., D. Weipert and H. Mielke (1986) Beeinflussung der Qualität von Weizen durch den Befall mit Fusarium culmorum (in German) Getreide Mehl Brot 40: 35-39.

Miedaner, T. (1997) Breeding wheat and rye for resistance to Fusarium diseases Plant Breeding 116: $201-220$.

Miedaner, T., C. Reinbrecht, U. Lauber, M. Schollenberger and H. H. Geiger (2001) Effects of genotype and genotype-enviromment interaction on deoxynivalenol accumulation and resistance to Fusarium head blight in rye, triticale, and wheat Plant Breeding 120: 97-105.

Miedaner, T., C. Reinbrecht and A. G. Schilling (2000) Association among aggressiveness, fungal colonization, and mycotoxin production of 26 isolates of Fusarium graminearum in winter rye head blight Zeitschrift Fur Pflanzenkrankheiten Und Pflanzenschutz-Journal of Plant Diseases and Protection 107: 124-134.

Miller, J. D. and P. G. Arnison (1986) Degradation of deoxynivalenol by suspension cultures of the resistant wheat cultivar Frontana Canadian Journal of Plant Pathology-Revue Canadienne De Phytopathologie 8: 147-150.

Miller, J. D., R. Greenhalgh, Y. Z. Wang and M. Lu (1991) Trichothecene chemotypes of 3 Fusarium species Mycologia 83: 121-130.

Miller, J. D., J. C. Young and D. R. Sampson (1985) Deoxynivalenol and Fusarium head blight resistance in spring cereals Phytopathologische Zeitschrift-Journal of Phytopathology 113: 359367.

Mladenov, N., N. Przulj, N. Hristov, V. Djuric and M. Milovanovic (2001) Cultivar-byenvironment interactions for wheat quality traits in semiarid conditions Cereal Chemistry 78: 363367. 
Murphy, P. A., S. Hendrich, C. Landgren and C. M. Bryant (2006) Food mycotoxins: An update Journal of Food Science 71: R51-R65.

Nganje, W. E., D. A. Bangsund, F. L. Leistritz, W. W. Wilson and N. M. Tiapo (2004) Regional economic impacts of Fusarium Head Blight in wheat and barley Review of Agricultural Economics 26: 332-347.

Nicholson, P., E. Chandler, R. C. Draeger, N. E. Gosman, D. R. Simpson, M. Thomsett and A. H. Wilson (2003) Molecular tools to study epidemiology and toxicology of Fusarium head blight of cereals European Journal of Plant Pathology 109: 691-703.

Nightingale, M. J., B. A. Marchylo, R. M. Clear, J. E. Dexter and K. R. Preston (1999) Fusarium head blight: Effect of fungal proteases on wheat storage proteins Cereal Chemistry 76: $150-158$

Nowicki, T. W., D. G. Gaba, J. E. Dexter, R. R. Matsuo and R. M. Clear (1988) Retention of Fusarium mycotoxin deoxynivalenol in wheat during processing and cooking of spaghetti and noodles Journal of Cereal Science 8: 189-202.

Obst, A., J. Lepschy, R. Beck, G. Bauer and A. Bechtel (2000) The risk of toxins by Fusarium graminearum in wheat - interactions between weather and agronomic factors Mycotoxin Research 16: $16-20$.

Oldenburg, E., A. Bramm and H. Valenta (2007a) Influence of nitrogen fertilization on deoxynivalenol contamination of winter wheat - Experimental field trails and evaluation of analytical methods Mycotoxin Research 23: 7-12.

Oldenburg, E., J. Brunotte and J. Weinert (2007b) Strategies to reduce DON contamination of wheat with different soil tillage and variety systems Mycotoxin Research 23: 73-77.

Osborne, L. E. and J. M. Stein (2007) Epidemiology of Fusarium head blight on small-grain cereals International Journal of Food Microbiology 119: 103-108.

Osborne, T. B. (1924). The vegetable proteins. London, UK, Longsman, Breen \& Co.

Parry, D. W., P. Jenkinson and L. McLeod (1995) Fusarium ear blight (scab) in small grain cereals - a review Plant Pathology 44: 207-238.

Parry, D. W., T. R. Pettitt, P. Jenkinson and A. K. Lees (1994). The cereal Fusarium complex In: Ecology of Plant Pathogens (Ed.) J. P. Blakeman and B. Williamson. Wallingford, UK, CAB International: $301-320$. 
Paul, P. A., S. M. El-Allaf, P. E. Lipps and L. V. Madden (2005a) Relationships between incidence and severity of Fusarium head blight on winter wheat in Ohio Phytopathology 95: 10491060 .

Paul, P. A., P. E. Lipps, D. E. Hershman, M. P. McMullen, M. A. Draper and L. V. Madden (2007) A quantitative review of tebuconazole effect on Fusarium head blight and deoxynivalenol content in wheat Phytopathology 97: 211-220.

Paul, P. A., P. E. Lipps and L. V. Madden (2005b) Relationship between visual estimates of Fusarium head blight intensity and deoxynivalenol accumulation in harvested wheat grain: A metaanalysis Phytopathology 95: 1225-1236.

Pawelzik, E., H. H. Permady, J. Weinert and G. A. Wolf (1998) Untersuchungen zum Einfluß einer Fusarien-Kontamination auf ausgewählte Qualitätsmerkmale von Weizen Getreide Mehl Brot 52: $264-266$

Pekkarinen, A., L. Mannonen, B. L. Jones and M. L. Niku-Paavola (2000) Production of proteases by Fusarium species grown on barley grains and in media containing cereal proteins Journal of Cereal Science 31: 253-261.

Pekkarinen, A. I., C. Longstaff and B. L. Jones (2007) Kinetics of the inhibition of Fusarium serine proteinases by barley (Hordeum vulgare L.) inhibitors Journal of Agricultural and Food Chemistry 55: 2736-2742.

Pekkarinen, A. L. and B. L. Jones (2002) Trypsin-like proteinase proteases produced by Fusarium culmorum grown on grain proteins Journal of Agricultural and Food Chemistry 50: 3849-3855.

Perkowski, J., I. Kiecana, U. Schumacher, H. M. Muller, J. Chelkowski and P. Golinski (1997) Head infection and accumulation of Fusarium toxins in kernels of 12 barley genotypes inoculated with Fusarium graminearum isolates of two chemotypes European Journal of Plant Pathology 103: 85-90.

Pestka, J. J. (2010) Deoxynivalenol: mechanisms of action, human exposure, and toxicological relevance Archives of Toxicology 84: 663-679.

Pirgozliev, S. R., S. G. Edwards, M. C. Hare and P. Jenkinson (2002) Effect of dose rate of azoxystrobin and metconazole on the development of Fusarium head blight and the accumulation of deoxynivalenol (DON) in wheat grain European Journal of Plant Pathology 108: 469-478.

Pomeranz, Y. (1988). Chemical composition of kernel structures In: Wheat - Chemistry and Technology. (Ed.) Y. Pomeranz. St. Paul, Minnesota, USA, AACC: 97-158. 
Ponts, N., L. Couedelo, L. Pinson-Gadais, M.-N. Verdal-Bonnin, C. Barreau and F. RichardForget (2009) Fusarium response to oxidative stress by $\mathrm{H}_{2} \mathrm{O}_{2}$ is trichothecene chemotypedependent FEMS Microbiology Letters 293: 255-262.

Posner, E. S. and A. N. Hibbs (Ed.) (2005) Wheat Flour Milling. St. Paul, Minnesota, U.S.A, American Association of Cereal Chemists: 163-171

Prange, A., B. Birzele, J. Kramer, A. Meier, H. Modrow and P. Kohler (2005) Fusariuminoculated wheat: deoxynivalenol contents and baking quality in relation to infection time Food Control 16: 739-745.

Preston, K. R., P. R. March and K. H. Tipples (1982) An assessment of the SDS-sedimentation test for the prediction of Canadian bread wheat quality Canadian Journal of Plant Science 62: 545553.

Raiffeisen (2011) Qualitätskriterien von Weizen Retrieved 08/08/2011, from http://www.raiffeisen.com/pflanzen/ackermanager/weizen_html\#Qualitätskriterien von Weizen

Randall, P. J., K. Spencer and J. R. Freney (1981) Sulfur and nitrogen fertilizer effects on wheat. I. Concentrations of sulfur and nitrogen and the nitrogen to sulfur ratio in grain, in relation to the yield response Australian Journal of Agricultural Research 32: 203-212.

Reverberi, M., A. Ricelli, S. Zjalic, A. A. Fabbri and C. Fanelli (2010) Natural functions of mycotoxins and control of their biosynthesis in fungi Applied Microbiology and Biotechnology 87: 899-911.

Ribichich, K. F., S. E. Lopez and A. C. Vegetti (2000) Histopathological spikelet changes produced by Fusarium graminearum in susceptible and resistant wheat cultivars Plant Disease 84: 794-802.

Rintelen, J. (2000) Ist das starke Auftreten von Giberella zeae (Fusarium graminearum) an Getreideähren auf die Zunahme des Maisanbau zurückzuführen? In: Schriftenreihe der Bayerischen Landesanstalt für Bodenkultur und Pflanzenanbau, Risiken durch den Ährenparasiten Fusarium graminearum - Ergebnisse eines LBP-Forschungsverbundes (Ed.) Bayerische Landesanstalt für Bodenkultur und Pflanzenbau. Freising und München: 11-14.

Roberts, T. H. and J. Hejgaard (2008) Serpins in plants and green algae Functional Integrative Genomics 8: 1-27.

Samar, M. M., M. S. Neira, S. L. Resnik and A. Pacin (2001) Effect of fermentation on naturally occurring deoxynivalenol (DON) in Argentinean bread processing technology Food Additives and Contaminants 18: 1004-1010. 
Saric, M., R. Sekulic and D. Petric (1980) Influence of Fusarium attack on wheat quality (in Croatian) Zito Hieb 7: 3-14.

SBA and BMELV (2010) Anbau, Ertrag und Ernte der Feldfrüchte Retrieved 01/03/2011, from http://berichte.bmelv-statistik.de/SJT-3072200-0000.pdf.

SBA and BMELV (div.) Statistisches Jahrbuch über Ernährung. Landwirtschaft und Forsten verschiedener Jahrgänge Retrieved 01/03/ 2011, from http://www.bmelvstatistik.de/index.php?id=139.

Schaafsma, A. W., L. Tamburic-Ilinic, J. D. Miller and D. C. Hooker (2001) Agronomic considerations for reducing deoxynivalenol in wheat grain Canadian Journal of Plant PathologyRevue Canadienne De Phytopathologie 23: 279-285.

Schade-Schütze, A., J. Muthomi, E. C. Oerke and H. W. Dehne (2000) Yield reduction and mycotoxin contamination of wheat due to Fusarium culmorum Mycotoxin Research 16: 34-37.

Schelle, J. (2010). Einfluss von Fusarium-Befall auf Gluteneigenschaften im Weizenmehl (in German). Bachelor thesis. Göttingen, Germany.

Schlüter, K., U. Kropf and P. Karlovsky (2006) Untersuchungen zur systemischen Infektion von Fusarium culmorum an Winterweizen in Schleswig-Holstein Gesunde Pflanzen 58: 107-116.

Schroeder, H. W. and J. J. Christensen (1963) Factors affecting resistance of wheat to scab caused by Giberella zea Phytopathology 53: 831-838.

Scott, P. M., S. R. Kanhere, P. Y. Lau, J. E. Dexter and R. Greenhalgh (1983) Effects of experimental flour milling and breadbaking on retention of deoxynivalenol (vomitoxin) in hard red spring wheat Cereal Chemistry 60: 421-424.

Seibel, W. (Ed.) (2005). Warenkunde Getreide - Inhaltsstoffe, Analytik, Reinigung, Trocknung, Lagerung, Vermarktung, Verarbeitung. Bergen/Dumme, Deutschland, Agrimedia GmbH: 61-173

Seibel, W. P., K.; Schrader, B. (1985) Analytische, teigrheologische und backtechnische Studien zur Optimierung des Weizen-Backversuches, Rapid-Mix-Test. I. Entwicklung des optimierten Rapid-Mix-Testes (RMT) Getreide, Mehl und Brot 39: 174-178.

Seitz, L. M. and D. B. Bechtel (1985) Chemical, physical, and microscopical studies of scab infected hard red winter wheat Journal of Agricultural and Food Chemistry 33: 373-377.

Seitz, L. M., W. D. Eustace, H. E. Mohr, M. D. Shogren and W. T. Yamazaki (1986) Cleaning, Milling, and Baking Tests with Hard Red Winter Wheat Containing Deoxynivalenol Cereal Chemistry 63: 146-150. 
Seitz, L. M., W. T. Yamazaki, R. L. Clements, H. E. Mohr and L. Andrews (1985) Distribution of deoxynivalenol in soft mill streams Cereal Chemistry 62: 467-469.

Seling, S. (2010) Die Bedeutung des Proteingehaltes von Backweizen aus Sicht der Wissenschaft Getreidetechnologie 64: 103-110.

Shewry, P. R. (2009) Wheat Journal of Experimental Botany 60: 1537-1553.

Shewry, P. R. and N. G. Halford (2002) Cereal seed storage proteins: structures, properties and role in grain utilization Journal of Experimental Botany 53: 947-958.

Shewry, P. R., N. G. Halford, P. S. Belton and A. S. Tatham (2002) The structure and properties of gluten: an elastic protein from wheat grain Philosophical Transactions of the Royal Society of London Series B-Biological Sciences 357: 133-142.

Shi, C. and L.-L. Xu (2009) Characters of cysteine endopeptidases in wheat endosperm during seed germination and subsequent seedling growth Journal of Integrative Plant Biology 51: 52-57.

Shotwell, O. L., G. A. Bennett, R. D. Stubblefield, G. M. Shannon, W. F. Kwolek and R. D. Plattner (1985) Deoxynivalenol in hard red winter wheat - Relationship between toxin levels and factors that could be used in grading Journal of the Association of Official Analytical Chemists 68: 954-957.

Simmonds, P. M. (1968). Wheat seed discolorations and blemishes. In: Technical Bulletin No. 1. (Ed.) Research Branch, Agriculture Canada, Saskatoon, Saskatchewan,Canada: 94.

Simpson, D. R., G. E. Weston, J. A. Turner, P. Jennings and P. Nicholson (2001) Differential control of head blight pathogens of wheat by fungicides and consequences for mycotoxin contamination of grain European Journal of Plant Pathology 107: 421-431.

Siuda, R., A. Grabowski, L. Lenc, M. Ralcewicz and E. Spychaj-Fabisiak (2010) Influence of the degree of fusariosis on technological traits of wheat grain International Journal of Food Science and Technology 45: 2596-2604.

Smewing, J. (1995). The measurement of dough and gluten extensibility using the SMS/Kieffer rig and the TA.XT2 Texture Analyser. Surrey, UK, Stable Micro Systems Ltd.

Smith, G. P. and M. J. Gooding (1999) Models of wheat grain quality considering climate, cultivar and nitrogen effects Agricultural and Forest Meteorology 94: 159-170.

Snijders, C. H. A. (1990) Genetic variation for resistance to Fusarium head blight in bread wheat Euphytica 50: 171-179.

Snijders, C. H. A. (2004) Resistance in wheat to Fusarium infection and trichothecene formation Toxicology Letters 153: 37-46. 
Snijders, C. H. A. and C. F. Krechting (1992) Inhibition of deoxynivalenol translocation and fungal colonization in Fusarium head blight resistant wheat Canadian Journal of Botany-Revue Canadienne De Botanique 70: 1570-1576.

Stack, R. W. (2000) Return of an old problem: Fusarium head blight of small grains Retrieved 05/03/ 2011, from http://www.plantmanagementnetwork.org/pub/php/review/fhb/.

Stack, R. W. (2003). History of Fusarium head blight with emphasis on North America. In: Fusarium head blight of wheat and barley (Ed.) K. J. Leonard and W. R. Bushnell. St. Paul, MI, USA, APS Press: 1-34.

Sugita-Konishi, Y., B. J. Park, K. Kobayashi-Hattori, T. Tanaka, T. Chonan, K. Yoshikawa and S. Kumagai (2006) Effect of cooking process on the deoxynivalenol content and its subsequent cytotoxicity in wheat products Bioscience Biotechnology and Biochemistry 70: 17641768.

Sugiura, Y., Y. Watanabe, T. Tanaka, S. Yamamoto and Y. Ueno (1990) Occurrence of Gibberella zeae strains that produce both nivalenol and deoxynivalenol Applied and Environmental Microbiology 56: 3047-3051.

Sweeney, M. and A. Dobson (1998) Mycotoxin production by Aspergillus, Fusarium and Penicillium species International Journal of Food Microbiology 43: 141-158.

Szentpetery, Z., C. Kleinheincz, G. Szollosi and M. Jolankai (2005) Effect of nitrogen topdressing on winter wheat yield, quantity and quality Acta Alimentaria 34: 177-185.

Tanaka, T., A. Hasegawa, S. Yamamoto, Y. Matsuki and Y. Ueno (1986) Residues of Fusarium mycotoxins, nivalenol, deoxynivalenol and zearalenone, in wheat and processed food after milling and baking Journal of the Food Hygienic Society of Japan 27: 653-655.

Teich, A. H. (1987) Less wheat scab with urea than with ammonium nitrate fertilizers Cereal Research Communications 15: 35-38.

Terzi, V., C. Morcia, P. Faccioli, N. Faccini, V. Rossi, M. Cigolini, M. Corbellini, D. Scudellari and G. Delogu (2007) Fusarium DNA traceability along the bread production chain International Journal of Food Science and Technology 42: 1390-1396.

Tkachuk, R., J. E. Dexter, K. H. Tipples and T. W. Nowicki (1991) Removal by specific gravity table of tombstone kernels and associated trichothecenes from wheat infected with Fusarium head blight Cereal Chemistry 68(4): 428-431.

Toth, B., A. Mesterhazy, Z. Horvath, T. Bartok, M. Varga and J. Varga (2005) Genetic variability of central European isolates of the Fusarium graminearum species complex European Journal of Plant Pathology 113: 35-45. 
Triboi, E., A. Abad, A. Michelena, J. Lloveras, J. L. Ollier and C. Daniel (2000) Environmental effects on the quality of two wheat genotypes: 1. quantitative and qualitative variation of storage proteins European Journal of Agronomy 13: 47-64.

Triboi, E., P. Martre and A. M. Triboi-Blondel (2003) Environmentally-induced changes in protein composition in developing grains of wheat are related to changes in total protein content Journal of Experimental Botany 54: 1731-1742.

Trigo-Stockli, D. M., C. W. Deyoe, R. F. Satumbaga and J. R. Pedersen (1996) Distribution of deoxynivalenol and zearalenone in milled fractions of wheat Cereal Chemistry 73: 388-391.

Tuite, J., G. Shaner and R. J. Everson (1990) Wheat scab in soft red winter wheat in Indiana in 1986 and its relation to some quality measurements Plant Disease 74: 959-962.

Ueno, Y. (1983). Trichothecenes-Chemical, biological and toxicological aspects In: General toxicology I (Ed.) Elsevier Science Publishing Company. New York, NY, USA: 135-146.

Vendl, O., F. Berthiller, C. Crews and R. Krska (2009) Simultaneous determination of deoxynivalenol, zearalenone, and their major masked metabolites in cereal-based food by LC-MSMS Analytical and Bioanalytical Chemistry 395: 1347-1354.

Waalwijk, C., P. Kastelein, I. de Vries, Z. Kerényi, T. van der Lee, T. Hesselink, J. Köhl and G. Kema (2003) Major Changes in Fusarium spp. in Wheat in the Netherlands European Journal of Plant Pathology 109: 743-754.

Wang, J. (2004). Effect of Fusarium-infection and fungicide treatment on quality parameters of winter wheat. $\mathrm{PhD}$ thesis. Göttingen, Cullivier Verlag.

Wang, J. H., E. Pawelzik, J. Weinert and G. A. Wolf (2005a) Impact of Fusarium culmorum on the polysaccharides of wheat flour Journal of Agricultural and Food Chemistry 53: 5818-5823.

Wang, J. H., E. Pawelzik, J. Weinert, Q. Zhao and G. A. Wolf (2008) Factors influencing falling number in winter wheat European Food Research and Technology 226: 1365-1371.

Wang, J. H., H. Wieser, E. Pawelzik, J. Weinert, A. J. Keutgen and G. A. Wolf (2005b) Impact of the fungal protease produced by Fusarium culmorum on the protein quality and breadmaking properties of winter wheat European Food Research and Technology 220(5-6): 552-559.

Wanjiru, W. M., Z. S. Kang and H. Buchenauer (2002) Importance of cell wall degrading enzymes produced by Fusarium graminearum during infection of wheat heads European Journal of Plant Pathology 108: 803-810.

Webb, C. and G. W. Owens (2003) Milling and flour quality In: Bread making: Improving quality S. P. Cauvain. Cambridge, UK, Woodhead Publishing Limited: 200-218. 
Weegels, P. L., R. J. Hamer and J. D. Schofield (1996) Critical review: functional properties of wheat glutenin Journal of Cereal Science 23: 1-18.

Wieser, H. (2000) Simple determination of gluten protein types in wheat flour by turbidimetry Cereal Chemistry 77: 48-52.

Wieser, H. (2007) Chemistry of gluten proteins Food Microbiology 24: 115-119.

Wieser, H., S. Antes and W. Seilmeier (1998) Quantitative determination of gluten protein types in wheat flour by reversed-phase high-performance liquid chromatography Cereal Chemistry 75: 644-650.

Wieser, H. and R. Kieffer (2001) Correlations of the amount of gluten protein types to the technological properties of wheat flours determined on a micro-scale Journal of Cereal Science 34: $19-27$

Wieser, H. and W. Seilmeier (1998) The influence of nitrogen fertilisation on quantities and proportions of different protein types in wheat flour Journal of the Science of Food and Agriculture 76: 49-55.

Wieser, H., W. Seilmeier and H. D. Belitz (1994) Quantitative determination of gliadin subgroups from different wheat cultivars Journal of Cereal Science 19: 149-155.

Wieser, H. and G. Zimmermann (2000) Importance of amounts and proportions of high molecular weight subunits of glutenin for wheat quality European Food Research and Technology 210: $324-330$.

Wilcoxson, R. D., R. H. Busch and E. A. Ozmon (1992) Fusarium head blight resistance in spring wheat cultivars Plant Disease 76: 658-661.

Williams, R. M., L. O'Brien, H. A. Eagles, V. A. Solah and V. Jayasena (2008) The influences of genotype, environment, and genotype $\mathrm{x}$ environment interaction on wheat quality Australian Journal of Agricultural Research 59: 95-111.

Windels, C. E. (2000) Economic and social impacts of Fusarium head blight: Changing farms and rural communities in the Northern Great Plains Phytopathology 90: 17-21.

WSG (2003) Klimabericht für Göttingen Retrieved 10/03/2011, from http://www.wetterstationgoettingen.de/klimabericht.htm.

WSG (2010) Wetter, Klima, Datenarchiv Retrieved 09/03/2011, from www.wetterstationgoettingen.de 
Wu, Y. X. and A. von Tiedemann (2001) Physiological effects of azoxystrobin and epoxiconazole on senescence and the oxidative status of wheat Pesticide Biochemistry and Physiology 71: 1-10.

Xu, X. M. (2003) Effects of environmental conditions on the development of Fusarium ear blight European Journal of Plant Pathology 109: 683-689.

Xu, X. M., W. Monger, A. Ritieni and P. Nicholson (2007) Effect of temperature and duration of wetness during initial infection periods on disease development, fungal biomass and mycotoxin concentrations on wheat inoculated with single, or combinations of, Fusarium species Plant Pathology 56: 943-956.

Xu, X. M. and P. Nicholson (2009) Community Ecology of Fungal Pathogens Causing Wheat Head Blight Annual Review of Phytopathology 47: 83-103.

Xu, X. M., P. Nicholson, M. A. Thomsett, D. Simpson, B. M. Cooke, F. M. Doohan, J. Brennan, S. Monaghan, A. Moretti, G. Mule, L. Homok, E. Beki, J. Tatnell, A. Ritieni and S. G. Edwards (2008a) Relationship between the fungal complex causing Fusarium head blight of wheat and environmental conditions Phytopathology 98: 69-78.

Xu, X. M., D. Parry, P. Nicholson, M. Thomsett, D. Simpson, S. Edwards, B. Cooke, F. Doohan, S. Monaghan, A. Moretti, G. Tocco, G. Mule, L. Hornok, E. Béki, J. Tatnell and A. Ritieni (2008b) Within-field variability of Fusarium head blight pathogens and their associated mycotoxins European Journal of Plant Pathology 120: 21-34.

Xu, X. M., D. W. Parry, P. Nicholson, M. A. Thomsett, D. Simpson, S. G. Edwards, B. M. Cooke, F. M. Doohan, J. M. Brennan, A. Moretti, G. Tocco, G. Mule, L. Hornok, G. Giczey and J. Tatnell (2005) Predominance and association of pathogenic fungi causing Fusarium ear blight in wheat in four European countries European Journal of Plant Pathology 112: 143-154.

Yi, C. L., H. P. Kaul, E. Kubler and W. Aufhammer (2002) Populations of Fusarium graminearum on crop residues as affected by incorporation depth, nitrogen and fungicide application Zeitschrift Fur Pflanzenkrankheiten Und Pflanzenschutz-Journal of Plant Diseases and Protection 109: 252-263.

Young, J. C., R. G. Fulcher, J. H. Hayhoe, P. M. Scott and J. E. Dexter (1984) Effect of milling and baking on deoxynivalenol (vomitoxin) content of Eastern Canadian wheats Journal of Agricultural and Food Chemistry 32: 659-664.

Zandstra, J. and R. Squire (2007). Assessing harvest losses; evaluating potential damage to sugarbees caused by harvesting and piling equipment using and impact recording device In: Final 
Project Report, CORD IV Project Ontario Sugarbeet Growers Association. University of Guelph. Ridgetown, ON, USA.

Zecevic, V., D. Knezevic, J. Boskovic and M. Madic (2009) Effect of genotype and environment on wheat quality Genetika-Belgrade 41: 247-253.

Zhang, Y. J., P. S. Fan, X. Zhang, C. J. Chen and M. G. Zhou (2009) Quantification of Fusarium graminearum in Harvested Grain by Real-Time Polymerase Chain Reaction to Assess Efficacies of Fungicides on Fusarium Head Blight, Deoxynivalenol Contamination, and Yield of Winter Wheat Phytopathology 99: 95-100.

Zhao, F. J., M. J. Hawkesford and S. P. McGrath (1999) Sulphur assimilation and effects on yield and quality of wheat Journal of Cereal Science 30(1): 1-17.

Zhou, B., Y. Li, J. Gillespie, G. Q. He, R. Horsley and P. Schwarz (2007) Doehlert matrix design for optimization of the determination of bound deoxynivalenol in barley grain with trifluoroacetic acid (TFA) Journal of Agricultural and Food Chemistry 55: 10141-10149.

Zinedine, A., J. M. Soriano, J. C. Molto and J. Manes (2007) Review on the toxicity, occurrence, metabolism, detoxification, regulations and intake of zearalenone: An oestrogenic mycotoxin Food and Chemical Toxicology 45: 1-18.

Zorb, C., C. Grover, D. Steinfurth and K. H. Muhling (2010) Quantitative proteome analysis of wheat gluten as influenced by N and S nutrition Plant and Soil 327: 225-234.

Zorb, C., D. Steinfurth, S. Seling, G. Langenkamper, P. Koehler, H. Wieser, M. G. Lindhauer and K. H. Muhling (2009) Quantitative Protein Composition and Baking Quality of Winter Wheat as Affected by Late Sulfur Fertilization Journal of Agricultural and Food Chemistry 57: 38773885 .

Zwatz, B. (1975) Ährenfusariosen des Weizens - Ertrags- und Qualitätsminderung Pflanzenarzt 28: $48-50$. 


\section{Acknowledgements}

At the end of about three years work in the field of Fusarium spp. infection and wheat quality, I would like to express my gratitude to a number of people who have supported my work at the Department of Crop Sciences and contributed to the development of this thesis tremendously.

I would like to thank my supervisor Prof. Dr. Elke Pawelzik for her kind support of my work with thorough scientific guidance, financial support as well as with a friendly working atmosphere. I very much appreciate her trust in me to successfully finishing project 2 of the FAEN joint project as well as all other responsible and interesting tasks during my employment in her section.

Prof. Dr. Bernward Märländer I would like to thank for taking over the co-supervision of this thesis and the valuable hint of looking at correlations critically, which I hope to have taken into account within this work sufficiently.

I express my heartfelt thanks to "my" technical assistance, Ulrike Hill. Without her support it would not have been possible to perform the preparation of the large amount of samples and numerous analytical investigations.

I express my special thanks to Dr. Kai Eggert who has supported my work with valuable ideas and discussion from the very first day on and who helped me to a great deal by introducing me into protein analysis with RP-HPLC as well as with sharing his biochemical knowledge with me.

I would like to thank Dr. Christian Kluth, Applied Biostatistics and Consulting, Göttingen, Germany, in particular for working out a strategy for statistical analyses with me and for his great patience. It finally enabled me to deal with the multifactorial design and the large number of data in an efficient way.

Dr. Ruben Gödecke I would like to thank for the practical knowledge I happened to gain from him during our common field work and for always cheering up the mood. Furthermore, within FAEN joint project, I would like to thank in particular Dr. Silke Stracke for discussion and her friendship, Sasithorn Limsuwan and Patricia Bartochek for the performance of mycotoxin and Fusarium DNA analysis as well as all other cooperation partners for valuable exchange of ideas, experiences, and literature.

Furthermore, I would like to thank all colleagues from the section Quality of Plant Products for technical support as well as discussion of results during $\mathrm{PhD}$ meetings.

Last but not in any way at least, I would like thank my parents Achim and Bärbel Kreuzberger for long years of support during my education in all aspects of life. Heartfelt thanks goes to Stefan, Nina, Kathrin, Chris, Martina, Christina, and Martin for their friendship and interest in my work. 


\section{Curriculum Vitae}

Marie Kreuzberger

born on Sept. 22, 1982 in Potsdam, Germany

\section{Professional experience}

May 2008-Aug. 2010

Dec. 2007-Dec. 2008

Oct. 2007-Nov. 2007

Aug. 2005-Dec. 2006

\section{Study}

May 2008-present

Oct. 2002-July 2007

\section{School education}

2000-2002

1999-2000

1993-1999

1989-1993
Scientific Research Assistant, Georg-August-University of Göttingen, Faculty of Agricultural Sciences, Department of Crop Sciences, Section Quality of Plant Products

Georg-August-Universität Göttingen, Fakultät für Agrarwissenschaften, Department für Nutzpflanzenwissenschaften, Abteilung Qualität Pflanzlicher Erzeugnisse

Administrative project coordination, Forschungsverbund Agrar- und Ernährungswissenschaften Niedersachsen (FAEN), Georg-August-University of Göttingen, Faculty of Agricultural Sciences, Department of Crop Sciences, Section Quality of Plant Products

Research assistant, Georg-August-University of Göttingen, Faculty of Agricultural Sciences, Department of Agronomy and Rural Development, Section Marketing of Food and Agricultural Products

Research assistant, Georg-August-University of Göttingen, Faculty of Agricultural Sciences, Department of Agronomy and Rural Development, Section Marketing of Food and Agricultural Products

$\mathrm{PhD}$ study, Georg-August-University of Göttingen, Faculty of Agricultural Sciences, Department of Crop Sciences, Section Quality of Plant Products

Agricultural Sciences, Georg-August-University of Göttingen, Faculty of Agricultural Sciences, Focus: Agribusiness, Master of Science

High School, Lutherstadt Wittenberg, Germany, High school diploma

High School, RI, USA

High School, Lutherstadt Wittenberg, Germany

Elementary School, Potsdam, Germany 